\title{
NATO, Climate Change, and International Security A Risk Governance Approach
}

Tyler H. Lippert

This document was submitted as a dissertation in October 2016 in partial fulfillment of the requirements of the doctoral degree in public policy analysis at the Pardee RAND Graduate School. The faculty committee that supervised and approved the dissertation consisted of Steven Popper (Chair), Ortwin Renn, and Chad Briggs. 
For more information on this publication, visit http://www.rand.org/pubs/rgs_dissertations/RGSD387.html

Published 2016 by the RAND Corporation, Santa Monica, Calif.

RAND $^{\circledR}$ is a registered trademark

\section{Limited Print and Electronic Distribution Rights}

This document and trademark(s) contained herein are protected by law. This representation of RAND intellectual property is provided for noncommercial use only. Unauthorized posting of this publication online is prohibited. Permission is given to duplicate this document for personal use only, as long as it is unaltered and complete. Permission is required from RAND to reproduce, or reuse in another form, any of its research documents for commercial use. For information on reprint and linking permissions, please visit www.rand.org/pubs/permissions.html.

The RAND Corporation is a research organization that develops solutions to public policy challenges to help make communities throughout the world safer and more secure, healthier and more prosperous. RAND is nonprofit, nonpartisan, and committed to the public interest.

RAND's publications do not necessarily reflect the opinions of its research clients and sponsors.

\section{Support RAND}

Make a tax-deductible charitable contribution at www.rand.org/giving/contribute

www.rand.org 


\section{TABLE OF CONTENTS}

I. Abstract ............................................................................................................................. v

II. Chapter 1: Introduction ......................................................................................................... 1

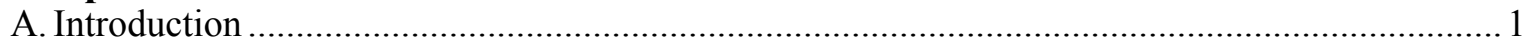

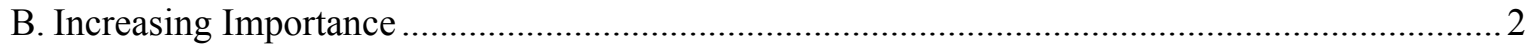

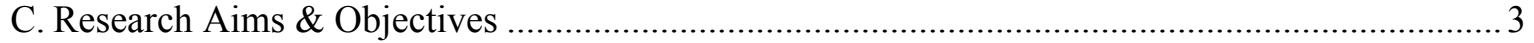

D. Abbreviations …………………………………………………………………………

E. Scope of the Analysis ...................................................................................................... 6

F. Overview of the Dissertation....................................................................................... 8

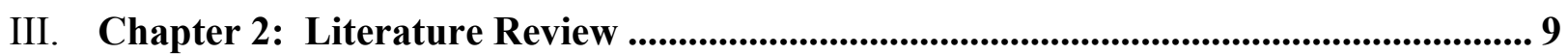

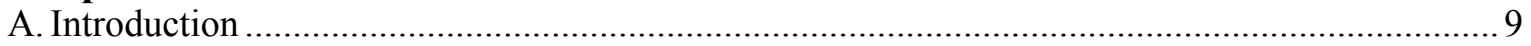

B. Climate Change and Security Consequences ........................................................................ 10

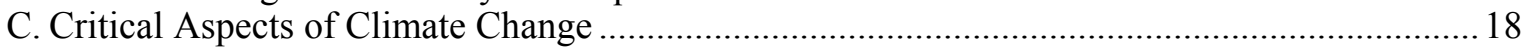

D. Empirical Models of Climate Security ……………………………………………………. 24

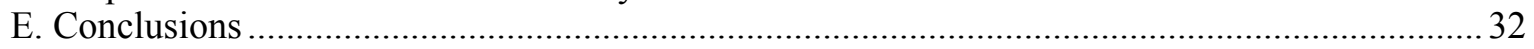

IV. Chapter 3: Taking Stock of the Situation: NATO............................................................... 34

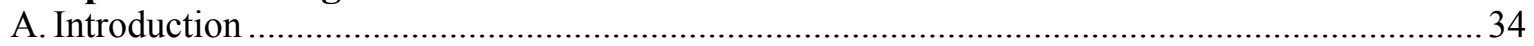

B. NATO's Big Picture — What Future? …………………………………………………........ 34

C. Historical development and transformation of NATO ………………………………………...35

D. NATO, Climate, and the Environment....................................................................................

1. NATO and Middle East/North Africa............................................................................ 40

2. NATO and the Arctic .............................................................................................. 40

3. Creation of NATO's Emerging Security Challenges Division .............................................4 42

E. NATO Foresight Efforts: The Future Security Environment.....................................................4

1. NATO ACT Strategic Foresight Analysis ……………………………………………. 46

2. NATO ACT - Framework for Future Alliance Operations .................................................. 50

3. Instability Situations - (Hazards) ...…………………………………………………. 54

a) Access and Use of Global Commons Challenged …………………………………....5

b) Disruptive Impact of Migration ……………………………………………………....56

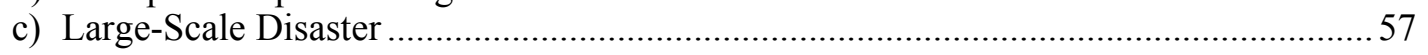

4. Review \& Critique of the Instability Situations ..................................................................58

5. To What Extent do the NATO ACT Instability Situations Represent NATO Perspective? .. 59

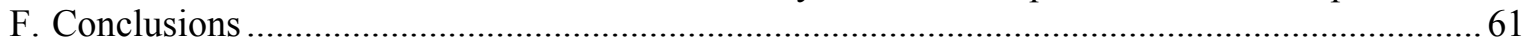

V. Chapter 4: Methodology \& Context .......................................................................................6 63

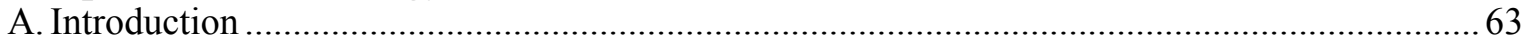

B. Why Risk Governance? NATO \& Climate Security Risk ...........................................................63

C. The IRGC Risk Governance Framework …………………………………………………....6 65

1. Summary of Characteristics: NATO, Climate Security, and Risk Governance........................67

2. Previous Application of the IRGC Risk Governance Framework ...........................................68

D. Risk Governance: Institutions \& Context ……………………………………………...... 72

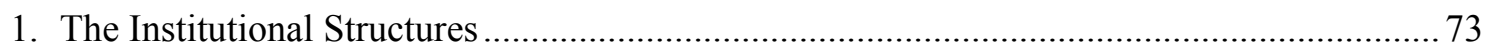

2. Climate Policies \& Plans: NATO Militaries \& Defense Ministries............................................. 74

3. The Context of NATO Decision Making: Consensus and the Silence Procedure …………... 77

4. NATO in the context of a new environment ................................................................ 79

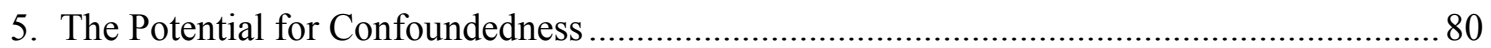

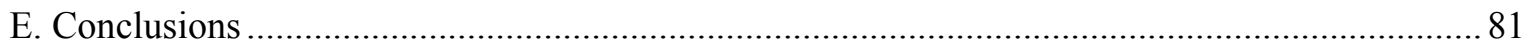

VI. Chapter 5: A Risk Governance Case Study …..................................................................... 83

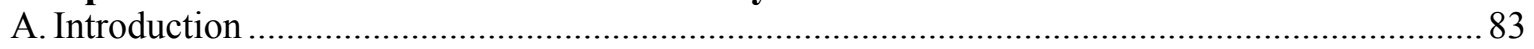

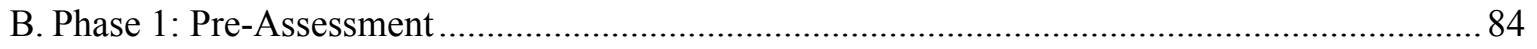




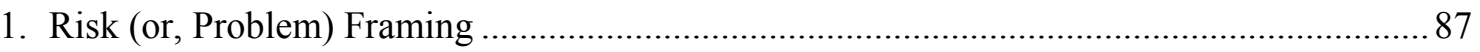

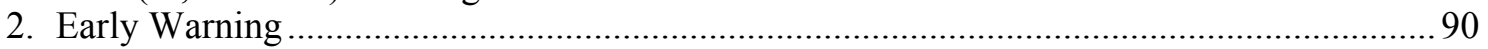

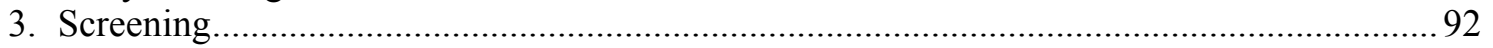

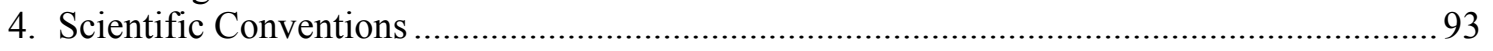

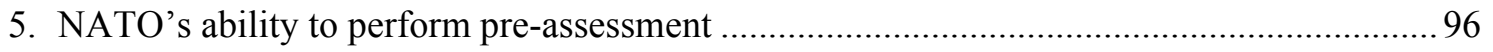

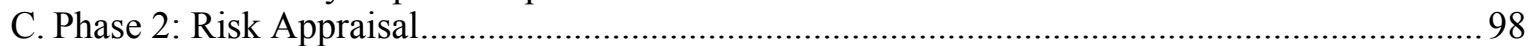

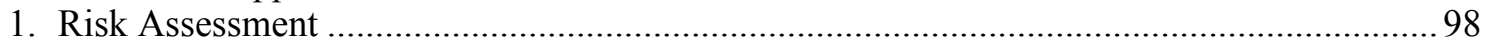

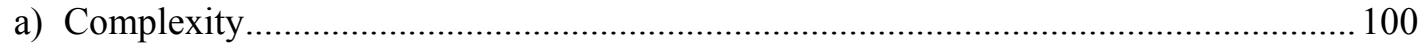

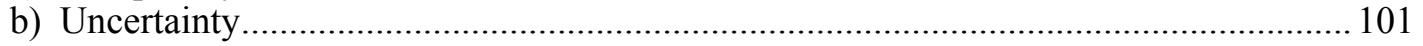

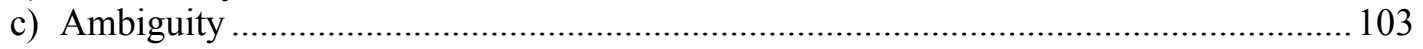

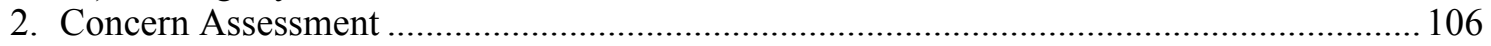

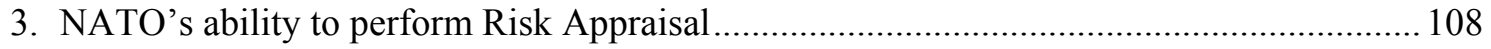

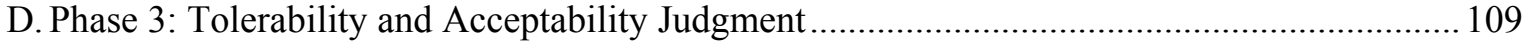

1. Risk Characterization \& Evaluation: Climate \& Security for NATO .................................. 109

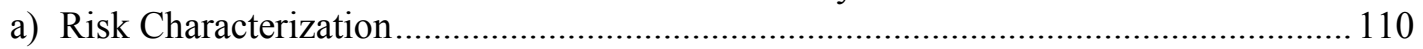

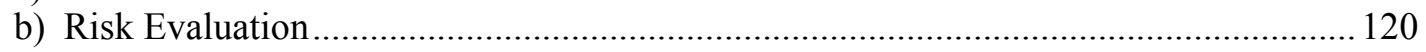

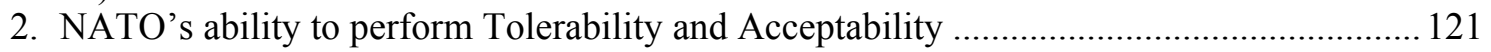

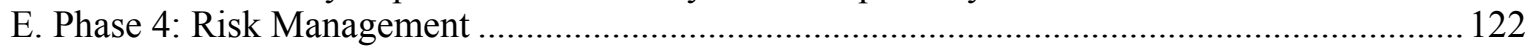

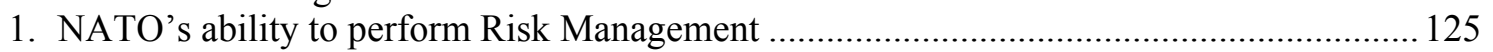

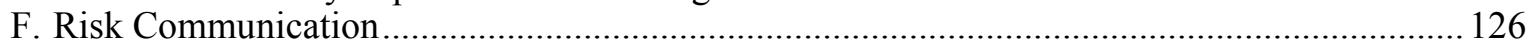

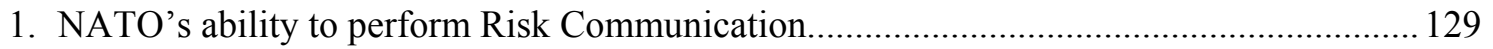

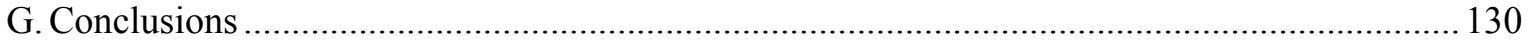

VII. Chapter 6: Major Findings .......................................................................................... 132

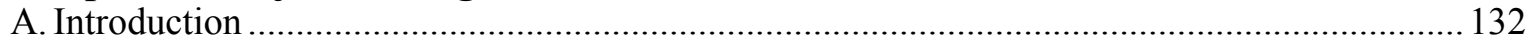

B. Findings: Climate Change and International Security: NATO’s Risk Governance .................. 133

C. Recommendations: A Basis for Prospective Risk Management Options................................. 141

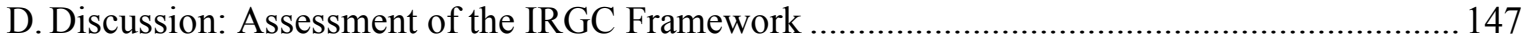

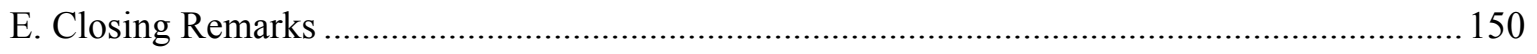

VIII. Bibliography ................................................................................................................... 153

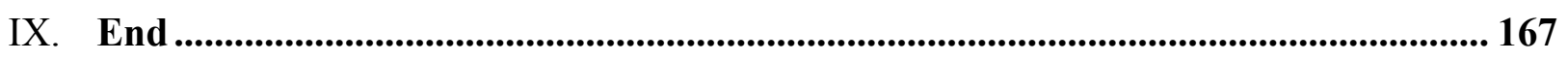

X. 


\section{Abstract}

This dissertation offers a prospective analysis of the North Atlantic Treaty Organization (NATO) and the anticipated security consequences of climate change. Using climate and security literature to complement recent foresight and scenario analysis developed by NATO, I apply the International Risk Governance Council's (IRGC) Risk Governance Framework to identify the considerations and actions that could assist NATO in a context where climate and environmental factors more intensively shape security.

Climate-driven environmental change is anticipated to influence some, if not all, of the factors that threaten security; undermining livelihoods, increasing migration, creating political instability or other forms of insecurity, and weakening the resilience and capabilities of states to respond appropriately. ${ }^{1}$ Climate change has the potential to increase the need for humanitarian assistance and disaster response, to create tension over shared resources, to renew and enhance geo-political interest in the Arctic, and to deepen concern with respect to the Middle East and North Africa (MENA).

While the implications of climate change are not yet fully known, it is widely feared that the environment of the twenty-first century will see greater instability and increased demand for organizations such as NATO. Within this new political and environmental reality, NATO must consider how to adapt to meet new demands, prepare for new security challenges, as well as manage unforeseen consequences. ${ }^{2}$ Unless NATO can develop options to augment standing procedures and grapple with climate security risk, future crises could be met with ad hoc responses. ${ }^{3}$

Although NATO's standing policies and capabilities are impressive, a posture of 'no further action is needed' is not appropriate for a risk anticipated to pose unprecedented challenges. Eventually, NATO will need to enhance its policies. However, that it was difficult to identify precise actions related to climate change reflects NATO's ability to maintain a structure capable of addressing a vast range of security issues. Nevertheless, NATO lacks the means to perform some aspects of risk governance as required by the IRGC Risk Governance Framework, because the characteristics of the climate security risk problem (an insufficient evidentiary and methodological basis), as well as institutional constraints, encumber so doing.

Offering a corrective, this dissertation identifies near-term actions for NATO to improve its risk governance posture, providing a basis upon which longer-range policy considerations can be developed. In mapping the risk governance dimensions to the security and climate nexus from the perspective of NATO, this dissertation provides the foundation for risk-based policy planning for NATO. This analysis is, however, only the opening salvo of what is likely to be a complicated process that spans many years, if not

decades.

\footnotetext{
${ }^{1}$ Karen O'Brien, Mark Pelling, and Anand Patwardhan, "Toward a Sustainable and Resilient Future," in Managing the Risks of Extreme Events and Disasters to Advance Climate Change Adaptation. A Special Report of Working Groups I and II of the Intergovernmental Panel on Climate Change, 2012, 458; W. N. Adger et al., "Human Security," in Climate Change 2014: Impacts, Adaptation, and Vulnerability. Part A: Global and Sectoral Aspects. Contribution of Working Group II to the Fifth Assessment Report of the Intergovernmental Panel on Climate Change, ed. C. B. Field et al. (Cambridge, United Kingdom and New York, NY, USA: Cambridge University Press, 2014), 24.

${ }^{2}$ Michael Rühle, "NATO and Emerging Security Challenges: Beyond the Deterrence Paradigm," American Foreign Policy Interests 33, no. 6 (2011): 278-79.

${ }^{3}$ Climate security risk is the potential for climate change to result in a worsening of security.
} 



\section{Chapter 1: Introduction}

\section{Introduction}

This dissertation examines the anticipated security consequences of climate change using a risk governance framework from the perspective of the North Atlantic Treaty Organization (NATO). Throughout the past decade, a great deal of effort has been devoted to examining the anticipated consequences of climate change, in particular how it will affect security. Yet, little attention has been devoted to understanding how the role or posture of NATO may need to evolve in response.

While NATO isn't a primary actor with respect to global climate policy, a ripple of consequences is anticipated to wash upon its shores as a result of climate change. More attention to climate is a potentially useful element in anticipating the next crises, many of which could present security challenges not fully addressed by current planning and response options. NATO recognizes its responsibility to help reduce the security consequences that could arise as a result of climate change. The challenge is how to elevate and prioritize policy and processes to address the new environment.

The climate-security problem requires consideration of issues often perceived to be near the edge or beyond traditional interpretations of NATO's domain, ${ }^{4}$ and it illustrates the evolving and context-specific nature of security issues. This study seeks to address future challenges that, at present, are not adequately linked to existing policy planning processes, and for which there is neither protocol nor a ready solution. ${ }^{5}$ Accordingly, it starts from the assumption that NATO must adapt and respond to changes in the environment. ${ }^{6}$

Using NATO as the object of analysis for security risk governance in the context of climate change provides an entry point for application of the International Risk Governance Council (IRGC) Risk Governance Framework. To date, the IRGC framework has been applied (mostly) retrospectively to (relatively) well-defined problems that fall within the purview of a single or small number of government ministries. It has not been applied prospectively to a larger risk issue that has a significant number of global dimensions and cascading impacts. The fundamental objective of this dissertation is to address the following question: Can the IRGC Risk Governance Framework add policy-relevant insight for NATO if applied in real-time to a phenomenon as broad, uncertain, and complex as climate change-induced security risk (and, if so, how)?

\footnotetext{
${ }^{4}$ NATO Research and Technology Organisation, "Joint Operations 2030-Final Report (Opérations Interarmées 2030-Rapport Final)” (Brussels, 2011).

${ }^{5}$ Ibid.

${ }^{6}$ Like a similar effort conducted by NATO's Research and Technology Organization, this analysis assumes that if it needed or wanted to, NATO could or would adapt - including in its membership - to organizational change in how the Alliance is structured, managed, and administered, and to various doctrinal debates. Ibid.
} 


\section{Increasing Importance}

With the signing of the Paris Decision in $2015,^{7}$ the 2014 release of the Intergovernmental Panel on Climate Change (IPCC) Fifth Assessment Report, and a wide range of other publications throughout the past decade, the idea that a changing climate will have far-reaching impact — and fundamental influence on the international security environment - has gathered momentum. The international security community is becoming more aware of the necessity to account for and anticipate probable climate issues and to understand the demands climate change will place on international organizations. Climate change related security risk is gaining relevance and provides a substantive, policy-relevant reason to examine how NATO can engage with this issue.

NATO will face a new security environment that will call for new ideas, concepts, and response types. Recognizing that climate change will have security implications, national governments and international and non-governmental organizations (NGOs) have struggled to identify a way forward. ${ }^{8}$ However, as noted by a UK Commission, "[d]espite the magnitude of this challenge and the powerful evidence now available, there is still a lack of understanding about what a changed climate really means for society, or what institutions should be doing to prepare for it."9

In October 2014, NATO welcomed a new Secretary General, Jens Stoltenberg, the former Prime Minister of Norway, who is also a former UN Special Envoy for Climate. Stoltenberg is the second successive NATO Secretary General to be well acquainted with climate change. The previous Secretary General, Anders Fogh Rasmussen, served as Prime Minister of Denmark before his tenure with NATO. While Prime Minister of Denmark, Rasmussen initiated hosting (in Copenhagen) the 15th Conference of the Parties (COP 15) to the United Nations Framework Convention on Climate Change (UNFCCC) and the 5th Meeting of the Parties (MOP 5) to the Kyoto Protocol.

However, the political environment for NATO has changed. In the spring of 2014, Russia annexed the Crimean Peninsula, and the consequent geo-strategic implications reach beyond traditional security considerations in the region. This annexation and the pursuant fallout strongly suggest that NATO will no longer consider Russia as a strategic partner, but rather as an adversary. More than the Russian actions in Georgia (2008), the annexation of Crimea provides a stark demonstration for most North Atlantic nations that Russia feels little obligation to be bound by international law. Thus, NATO may seek to reconsider its policy regarding Arctic security issues. $^{10}$

\footnotetext{
${ }^{7}$ United Nations, The Paris Decision, 2015.

${ }^{8}$ A variation of this point was also included in the following source: Robert J. Lempert, Steven W. Popper, and Steven C. Bankes, Shaping the next One Hundred Years: New Methods for Quantitative, Long-Term Policy Analysis (RAND Corporation, 2003), 1571-73.

${ }^{9}$ UK Royal Commission on Environmental Pollution, “Adapting Institutions to Climate Change,” 2010.

${ }^{10}$ Canada previously opposed a NATO role in the Arctic, insisting that Arctic issues be handled in the Arctic Council.
} 


\section{Research Aims \& Objectives}

The overarching aim of this dissertation is threefold: (1) to determine whether the IRGC Risk Governance Framework can contribute to improved risk governance outcomes for NATO (in the context of climate change); (2) to ascertain how the risk could be better handled if the framework is applied; and (3) to identify areas to improve NATO's risk governance posture. To achieve these aims, this research pursues two fundamental research questions: 1) How can the IRGC framework assist NATO to identify and prepare for the security risk associated with climate change? and 2) How does prospective analysis highlight options for doing so?

Using climate and security literature to complement recent foresight and scenario analyses developed by NATO Allied Command Transformation (ACT) to understand the major (climate relevant) themes of the future security environment, I apply the International Risk Governance Council's (IRGC) Risk Governance Framework to examine the security consequences of climate change from the perspective of NATO. This study seeks to identify possible contours (e.g. actions, ideas, attributes) to create a basis from which NATO can move forward with anticipatory adaptation.

As a further aim, this analysis seeks to test the IRGC framework by applying it to a problem wherein the risks are complex and highly uncertain. In doing this, I assess how well the IRGC framework supports an understanding of the risks and how well it facilitates the development of policy options. ${ }^{1}$ This analysis advances the underlying goal of the IRGC framework, which is to provide guidance for the development of comprehensive assessment and management strategies to cope with risks, in particular at the global level. ${ }^{12}$

There are five distinct objectives for this analysis:

1. Evaluate the literature pertaining to climate and environmental security and the anticipated security consequences of climate change (Chapter 2).

2. Review NATO's history of institutional transformation to understand the context in which previous institutional changes were achieved (Chapter 3).

a. Understand the trajectory of previous institutional transformation.

b. Understand the actions NATO has taken regarding climate and environmental security.

c. Identify the climate-relevant aspects of the NATO Allied Command Transformation (ACT) Strategic Foresight Analysis (SFA) and Framework for Future Alliance Operations (FFAO) workshops.

\footnotetext{
${ }^{11}$ Thus, the analysis is potentially just as useful for the future development and refinement of the framework as it is in helping NATO understand the dimensions of risk governance related to climate and security. As a result, this project will also contribute to the assessment of the framework's "practicability," an effort that followed the 2013 release of the white paper describing the prototype framework.

12 Ortwin Renn, "White Paper No. 1: Risk Governance-Towards and Integrative Approach" (Geneva: International Risk Governance Council, 2005).
} 
3. Conduct an analysis of what is known about the anticipated security consequences of climate change (from the perspective of NATO), using the IRGC's Risk Governance Framework (Chapters 4, 5).

a. Discuss the IRGC Risk Governance Framework in the context of the analysis and why it was selected over other analytic approaches (Chapter 4).

b. Understand the dimensions of risk posed by climate change for NATO (Chapter $5)$.

c. Assess the risk governance challenges (for NATO) in light of the risks posed by climate change (Chapter 5).

4. Assess the strengths and weaknesses of the IRGC framework for the purpose of analyzing the risk posed by climate change for NATO (Chapter 6).

a. Ascertain whether the IRGC Risk Governance Framework can contribute to improved risk governance outcomes for NATO. And, if it can, determine how the IRGC Risk Governance Framework can contribute to improved risk governance outcomes for NATO. ${ }^{13}$

b. Identify where the IRGC Risk Governance Framework is insufficient or inadequate.

5. Draw conclusions with policy relevance for NATO (Chapter 6).

a. Frame what actions may assist NATO to improve its risk governance posture for a security environment in which the impact of climate change is increasingly salient.

${ }^{13}$ The IRGC framework provides guidance "intended to promote thinking about whether an organization has the right procedures in place to deal with risks as they are recognized, even risks that are only vaguely known or the full ramifications of which are not yet understood." International Risk Governance Council, "Risk Governance Deficits: An Analysis and Illustration of the Most Common Deficits in Risk Governance" (Lausanne, 2009), 10. 


\section{Abbreviations}

ACT

FFAO

IPCC

IRGC

MENA

NAC

NATO

OSCE

RTO

SFA

SREX

STO
NATO Allied Command Transformation

Framework for Future Alliance Operations

Inter-governmental Panel on Climate Change

International Risk Governance Council

Middle East and North Africa

North Atlantic Council

North Atlantic Treaty Organization

Organization for Security and Cooperation in Europe

NATO Research and Technology Organization

Strategic Foresight Analysis

Special Report on Managing the Risks of Extreme Events and Disasters to Advance Climate Change Adaptation

NATO Science and Technology Organization 


\section{Scope of the Analysis}

Let us now turn to the parameters of this study. This research seeks to contribute to the body of knowledge regarding NATO and its role in international affairs, particularly with respect to climate security. This dissertation surveys how climate security risk affects NATO's risk governance posture, and how the complexity and uncertainty of climate security risk may encumber its further advancement. Presenting a risk-informed understanding of NATO's environment, this dissertation ascertains whether the IRGC framework can contribute to improved risk governance outcomes for NATO. Accordingly, this dissertation helps to identify the scope and limitations of NATO in climate security.

While some ongoing efforts within NATO have attempted to incorporate climate aspects to support organizational transformation, the author has been unable to locate any analysis done from the perspective of risk governance and has also been unable to locate any research that targeted policy-relevant conclusions for NATO in this context at the level of its political headquarters.

A fundamental assumption of this study is that external drivers (i.e. the strategic environment) shape what choices NATO will make in a given context. However, this study also assumes that NATO's institutional constraints are equally important, if not the deciding factor, with respect to how and when NATO will address new challenges in the security environment. While NATO's current policies illuminate this research, they do not constrain it. Certainly, this dissertation recognizes that its analysis should recognize the constraints on NATO if it were to investigate potential climate security options. For example, any policy could only be pursued on a basis agreed by all 28 NATO member states.

This dissertation also builds upon baseline scenarios and security hazards crafted through NATO ACT's SFA and FFAO efforts. These scenarios and hazards emerged from a variety of workshops throughout the past few years. This dissertation picks up on the climate and environmental change theme, specifically where SFA and FFAO left off, and it pursues the analysis along that dimension.

While my work complements the SFA and FFAO efforts, I also identify conclusions that arise from a deeper focus on climate. I discuss the influences of climate change, where climate change refers to any long-term trend in climate, regardless of whether it results from natural variation or human behaviors. When using the term 'climate security risk' in this dissertation, I refer to the array of climate-related security risks as outlined by NATO ACT in the SFA/FFAO documents. This generalization is specifically applied (in this case) to the Arctic, natural disasters, and potential instability due to migration (NATO ACT identified these three broad areas - termed 'Instability Situations' - for their concern). When it is appropriate to refer to each one separately, I do so. Otherwise, I refer to these as an overarching group and the characteristics they have in common.

It is important to note from the outset that NATO Headquarters is not bound to endorse the NATO ACT Instability Situations, or to include the corresponding insights in their policy planning considerations. At the same time, however, the Instability Situations are fairly generic, and similar scenarios (and associated concerns) are routinely expressed throughout the literature on climate change and security; moreover, NATO ACT created them with input from a broad 
range of experts, including participants from NATO Headquarters (the object of this dissertation).

Noting the potential concern regarding the extent to which the Instability Situations reflect the perspective of NATO Headquarters, I examined the characteristics of each Instability Situation in light of the core conclusions of the Summary for Policymakers of the IPCC Fifth Assessment Report. The IPCC creates the Summary for Policymakers through a consensus process (similar to the decision-making process of NATO), and all NATO member states are also IPCC members. The extent to which the core features of the Summary for Policymakers are reflected in the Instability Situations allows for additional insight into the ability of the Instability Situations to serve as a proxy for the NATO perspective on climate change and its security impact. The core features of climate change upon which NATO ACT created the Instability Situations are supported by the consensus conclusions of the IPCC.

Further, the SFA/FFAO documents were selected because NATO Headquarters has not released anything similar in the public domain, and they were the most recent NATO ACT scenario documents available at the time the research began. Rather than look to a non-NATO source, or design scenarios independently (both of which would have been inconsistent with the IRGC Risk Governance Framework), I sought to preserve a linkage to NATO's institutional perspective of climate-related risks by sourcing NATO documents to the greatest extent possible.

Indeed, this is a particular problem of researching a security organization like NATO: analysis can go only as far as publicly available information allows. For that reason, this dissertation incorporates various literature and conclusions of the IPCC when further richness or insight is necessary. ${ }^{14}$ Despite their shortcomings, IPCC reports serve as a useful platform from which NATO can begin consideration of these issues. ${ }^{15}$

This research focuses principally on the first three phases of the IRGC Risk Governance Framework: pre-assessment, risk appraisal, and tolerability and acceptability. Publicly available information from NATO is not sufficient to address all aspects of each phase, and it is particularly lacking with respect to the fourth and final phase: risk management.

Because this research seeks to provide policy-relevant conclusions for NATO at the level of its political headquarters, I do not discuss the military capabilities needed to respond to the security consequences of climate change. In 2011, NATO's Research and Technology Organization (RTO) tried but failed to produce an assessment regarding the military capabilities required for this circumstance. ${ }^{16}$

${ }^{14}$ Documents such as those released by the IPCC are often criticized as conservative and modest in their estimation of climate forecasts. However, when viewed through the prism of NATO, they possess the "benefit" of having been produced by the IPCC rules on consensus among scientists (and brokering by political actors) in a way that roughly approximates the consensus rule employed by NATO. Therefore, while IPCC reports may be scientifically insufficient, they are nevertheless politically palatable, which is a critical feature in finding agreement within NATO.

${ }^{15}$ The Summary for Policymakers (which accompanies each chapter of their reports) undergoes government review and is agreed upon through a consensus process similar to NATO. All 28 NATO member states are members of the IPCC.

${ }^{16}$ NATO Research and Technology Organisation, "Joint Operations 2030-Final Report (Opérations Interarmées 2030-Rapport Final).” 
However, this dissertation is not advocacy. I do not make a normative judgment as to whether NATO should adopt or pursue a distinct policy regarding the security consequences of climate change. It is an analysis of three risk scenarios using the IRGC Risk Governance Framework. It illuminates baseline considerations and draws conclusions about what they imply for NATO's risk governance at the political level.

Neither does this research perform a comparative analysis of international institutions regarding appropriateness for climate-relevant roles. This is beyond the scope of the analysis, and it would be difficult to achieve as the determination of whether a particular role should fall to NATO, another organization, or a member state is largely a subjective consideration.

What is clear, however, is that organizations need to avoid duplication of roles already undertaken by other organizations. And, for this reason alone, NATO needs to recognize the eventuality that climate-induced social stress will serve as an impetus for worsened security, and to prepare for the corresponding situations that may require NATO involvement.

I use 2030 as the timeline horizon for analysis to be consistent with similar research conducted by NATO's Research and Technology Organization (RTO) and the NATO SFA. ${ }^{17}$ This study will use the risk terminology consistent with the International Risk Governance Council. Terminology concerning NATO is taken from NATO. ${ }^{18}$

\section{Overview of the Dissertation}

The following chapter (Chapter 2) reviews the literature on climate and security. Chapter 3 discusses NATO's historical development and transformation, as well as the workshops conducted by NATO ACT (SFA \& FFAO). Chapter 4 discusses risk governance and the framework employed in this dissertation. It also provides an overview of the institutional context of climate security risk as well as a description of NATO's decision-making procedures. Chapter 5 applies the IRGC Risk Governance Framework to the problem of climate security risk, utilizing primary source information from the NATO ACT (SFA \& FFAO) workshops, as well as from various literature. Chapter 6 summarizes and assesses NATO's posture vis-à-vis the IRGC Risk Governance Framework, offers a variety of recommendations, and evaluates the IRGC framework.

\footnotetext{
${ }^{17}$ The NATO Research and Technology Organization (RTO) is now known as the NATO Science and Technology Organization (STO). When I refer to the Research and Technology Organization, it is in a context where RTO conducted the work in question or was still in existence (prior to 30 June 2012).

${ }^{18}$ In general, when I refer to NATO I am speaking with respect to NATO Headquarters in Brussels. However, I use the expression 'NATO Headquarters' when I feel further clarity and precision is needed.
} 


\section{Chapter 2: Literature Review}

\section{Introduction}

This chapter first examines the literature on the potential security consequences of climate change. While the consequences for NATO are uncertain, it is clear they will vary by region, the type of climate event, and the nature of the impact. Moreover, the consequences of climate change go beyond damage to the physical environment, because they also include the (more concerning) possibility that climate-induced social stress will serve as an impetus for worsened security. The literature has also examined the implications for sovereign states, arguing that some states will be resilient, some will be weakened, and some could face dramatic crises. ${ }^{19}$ These are serious concerns for NATO.

Literature from governments, think tanks, international organizations, and non-profit groups routinely - and often very strongly - suggests a worsening of international security dynamics as a result of climate change, using a wide variety of concepts and perspectives of security. These publications are frequently among the most alarming on the topic. Given their stature and accessibility to a wide audience, they are also often among the most frequently cited-and therefore influential - throughout the policy community. However, these reports lack academic rigor, forebode dangerous conclusions, and face concerns of agency.

This chapter next outlines two critical aspects of climate security: the role of the Arctic and the trans-boundary and international nature of climate change (and associated impacts). Understanding these aspects is critical to any evaluation of empirical and model-based research. First, they inform the debate regarding the usefulness of the econometric models employed (to analyze the climate/security relationship), and the question of whether an (often linear) representation of the relationship may be more appropriately conceived of as a system or network that captures the non-linearity and feedback loops of the climate system. Second, they must be considered when judging the extent to which any model can genuinely account for the potential for abrupt changes and discontinuities in the climate system, how the inter-linked social and political systems will respond, and the globally cascading impact of consequences. Both aspects fundamentally undermine the value of such models from a policy perspective.

Finally, this chapter considers the extensive literature that has attempted to model the linkage between climate change and security through empirical approaches. These empirical studies are described, but they are not privileged in this dissertation. As this chapter shows, empiricism presents problems for the analysis of the climate change-security relationship. This research offers support concerning the linkage between climate and security (using an empirical definition of conflict), although it is important to note that this linkage is not universally accepted and considerable debate surrounding the precise nature and strength of the relationship is ongoing. ${ }^{20}$

${ }^{19}$ John D. Steinbruner, "World Affairs Council Keynote Address: The International Security Implications of Climate Change," 2013.

${ }^{20}$ Topics under environmental security include the following: natural resource scarcity and violence linkages; natural resource abundance and violence; resource scarcity and cooperation; environmental degradation resulting from war or conflict; and issues relating to human security. Mark R. Read, "Embracing Uncertainty: Scenario Planning for Climate Change Security Challenges and Opportunities" (Pennsylvania State University, 2014), 48. 
It is also important to emphasize that the pathways through which the explanatory variables, including some that represent climate, affect the outcome variable (security) are unclear.

\section{Climate Change and Security Consequences}

The Intergovernmental Panel on Climate Change (IPCC) anticipates that climate change will have a dramatic impact. The IPCC's Fourth Assessment Report projected that extreme weather events and associated natural disasters, including droughts, heat waves, wildfires, flash floods, and tropical and mid-latitude storms, will occur more frequently and more intensely in many areas of the globe as a consequence of climate change. ${ }^{21}$ The IPCC also drew attention to the effect that the melting of the polar icecaps will have on the larger climate system, in addition to the opportunity such a melt would create for increased maritime activity in the Arctic. ${ }^{22}$

The IPCC's Fifth Assessment Report (released in 2014) offered greater fidelity, less uncertainty, and more clarity on many aspects of climate science and related issues. It affirmed the IPCC's previous assessments by concluding that climate change will present new challenges and will increasingly shape security and national security policies. ${ }^{23}$

Climate security risk captured the interests of many researchers over the past few decades, and it generated a great deal of attention from policy-oriented organizations. In particular, since the 2007 release of the IPCC's Fourth Assessment Report, research dedicated to the security aspects of climate change increased significantly. ${ }^{24}$ Publications often include narratives to raise concern regarding potential security consequences. For example, "The Brundtland Report" (formally known as "Our Common Future") is typically cited as the genesis of environmental security concepts. This report was sponsored by the United Nations in 1987 to unite countries to pursue sustainable development. ${ }^{25}$ However, a variety of sources, including governments, international organizations, NGOs, research institutes, think tanks, ad hoc task forces and commissions, and official testimony provide a diverse range of insights on the impact of climate change on global security.

These publications often presume a linkage between a changing climate and specific security consequences, and (implicitly) suggest that security actors must consider the magnitude of impact of the worst-case scenario when planning. They serve to create an understanding of the

21 Intergovernmental Panel on Climate Change, "Climate Change 2007: Impacts, Adaptation and Vulnerability," Generic (Cambridge University Press Cambridge, 2007).

${ }^{22}$ Ibid., 12. In Climate and Social Stress, the US National Research Council noted that "the types of economic factors associated with increased susceptibility to harm from climate events generally include low levels of per capita income, a lack of livelihood assets and opportunities, poor functioning of local markets, and a high degree of dependency on agricultural food imports to meet basic needs." Note, also, that many researchers believe the projections of the IPCC to be modest, and actual change could be more severe.

${ }^{23}$ Adger et al., "Human Security," 3. On the point of national security policies, this has already happened in several instances. In particular, the United States released its Climate Change Adaptation Roadmap in October 2014, which followed various other policies related to climate.

24 Intergovernmental Panel on Climate Change, "Climate Change 2007: Impacts, Adaptation and Vulnerability."

${ }^{25}$ World Commission on Environment and Development, "Report of the World Commission on Environment and Development: Our Common Future (The Brundtland Report)," vol. 4, 1987. 
characteristics, highlighting their concerning nature, and state the forecasted consequences. This perspective (based on the precautionary principle) illustrates reasons for concern and can be useful in terms of policy implications. Many imply, suggest, or advocate that various aspects of climate security - causes, consequences, or measures to mitigate and adapt - should receive more attention from governments or other relevant institutions.

A report published by the Center for Naval Analysis (CNA) in 2007 is often credited with bringing climate change into the mainstream of international security awareness, particularly within the United States. ${ }^{26}$ A collective of twelve (12) retired American Generals and Admirals endorsed the report, their judgment bringing new character and credibility to concerns about the impact of climate on security. They judged that climate change will be a concern for military forces as it acts as a 'threat multiplier' for instability in volatile parts of the world. ${ }^{27}$ While they do not use a specific climate projection as the basis for their judgments, they harness their collective wisdom and experience on a range of security implications and potential mitigating steps to reach preliminary thoughts on how to include these factors in defense planning. ${ }^{28}$

In terms of the North Atlantic region, the CNA 2007 report notes the potential for mass migration into Europe, the possibility of natural disasters and their resultant emergencies, as well as new challenges in the Arctic, as potential concerns. The report recommends that the United States commit "to a stronger national and international role to help stabilize climate change at levels that will avoid significant disruption to global security and stability.",29

Climate change is widely anticipated to affect the frequency of extreme events over the coming decades, but it will do so in ways scientists have difficulty predicting with confidence. ${ }^{30}$ Climatedriven environmental change is, nevertheless, anticipated to influence some, if not all, of the

${ }^{26}$ The Center for Naval Analysis, "National Security and the Threat of Climate Change," 2007. This effort potentially served as a counterweight to the position of the Bush Administration with regard to the reality and consequences of climate change, according to Charles Mead and Annie Snider, "Why the CIA Is Spying on a Changing Climate," McClatchy DC, 2011.

${ }^{27}$ The Center for Naval Analysis, "National Security and the Threat of Climate Change." The EU also recognized that climate change is a "threat multiplier which exacerbates existing trends, tensions and instability" in developing countries.

${ }^{28}$ Their perspective is one of assessing and managing risk: their judgments are informed by the concerning environmental and social factors presumed to result from a changing climate. They supply estimations (via experiential judgment and with the consult of advisors) about how these factors could produce worst-case scenarios, and draw conclusions about how this may affect security (particularly in a manner that would require US military resources). They recognize the range of factors required for a security situation to arise but don't question the causal chain (its strength, nature, etc.) that leads between climate and the resulting security consequences.

${ }^{29}$ Ibid.

${ }^{30}$ Christopher B. Field et al., "Managing the Risks of Extreme Events and Disasters to Advance Climate Change Adaptation. A Special Report of Working Groups I and II of the Intergovernmental Panel on Climate Change" (Cambridge University Press, 2012). Cilliers, Hughes, and Moyer note that "Climate change will affect Africa more significantly than most other regions due to its already warm climate, inconsistent rains, generally poor soil, extensive floodplains, predominantly rain-fed agriculture and poor governance with limited coping capacity. Warming will occur across the continent (and the extent of warming in Africa is expected to exceed global averages substantially)." Jakkie Cilliers, Barry B. Hughes, and Jonathan Moyer, "African Futures 2050 The Next Forty Years" (Pretoria / Denver: Institute for Security Studies and the Frederick S. Pardee Center for International Futures, 2011), 40. 
factors that threaten security. It can undermine livelihoods, increase migration, create political instability or other forms of insecurity, and weaken the resilience and ability of states to respond appropriately. ${ }^{31}$ Climate change has the potential to increase the need for humanitarian assistance and disaster response, to create tension over shared resources, to deepen concern with respect to the MENA, and to renew and enhance geo-political interest in the Arctic.

Two of the most commonly identified aspects of climate change are the potential for higher temperatures and greater variability of precipitation; taken independently, or together, these factors can have significant (negative) consequences for food production and availability; and more intense rainfall suggests a corresponding increase in storms and natural disasters. ${ }^{32}$ These dynamics alone, or combined with sea level rise, could lead to migration and create circumstances that could test the resilience and adaptive capacity of governments.

This is consistent with the 2012 study coordinated by Harvard University, which concluded that climate change will "impact water security, energy security, food security, and critical infrastructure," and will "bring into focus the need to consider the accelerating nature of climate stress, in concert with the more traditional political, economic, and social indicators." ${ }^{3} 3$ They concluded that " $[\mathrm{t}]$ he risk of major societal disruption from weather and climate extremes such as droughts, floods, heat waves, wildfires, and destructive storms is expected to increase," and that these changes "already threaten water availability, food security, energy decisions, and critical civil and defense infrastructure." 34

The IPCC found high agreement and robust evidence that climate change will threaten human security because "factors such as poverty and economic shocks that are associated with a higher risk of violent conflict are themselves sensitive to climate change." ${ }^{35}$ The IPCC further concluded (with medium agreement and medium evidence) that climate change will have a significant impact on forms of migration that compromise human security. ${ }^{36}$

${ }^{31}$ O’Brien, Pelling, and Patwardhan, "Toward a Sustainable and Resilient Future," 458; Adger et al., "Human Security."

${ }^{32}$ Ulrich Cubasch et al., "Introduction," in The Physical Science Basis. Contribution of Working Group I to the Fifth Assessment Report of the Intergovernmental Panel on Climate Change, ed. T. F. Stocker et al. (Cambridge, MA: Cambridge University Press, 2013), 119-58.

${ }^{33}$ Michael McElroy and D. James Baker, "Climate Extremes: Recent Trends with Implications for National Security" (Boston: Harvard University, 2012).

${ }^{34}$ Ibid., 4.

${ }^{35}$ Michael Oppenheimer, Maximiliano Campos, and Rachel Warren, "Emergent Risks and Key Vulnerabilities," in Climate Change 2014: Impacts, Adaptation, and Vulnerability. Part A: Global and Sectoral Aspects. Contribution of Working Group II to the Fifth Assessment Report of the Intergovernmental Panel on Climate Change, ed. C. B. Field et al. (Cambridge, United Kingdom and New York, NY, USA: Cambridge University Press, 2014), 23.

${ }^{36}$ Adger et al., "Human Security," 2. Chapter 12 focused on human security and threats to political stability, among other aspects. Also, as illustrated in here, in addition to quantified measures of uncertainty, the IPCC communicates the degree of certainty in their judgments using 1) confidence in the validity of a finding, and 2 ) the degree of agreement. The details of this protocol are explained in the 2010 IPCC publication of 'Guidance Note for Lead Authors of the IPCC Fifth Assessment Report on Consistent Treatment of Uncertainties.' 


\section{Weakened States}

In 2014, the same year that the IPCC released its 5th Assessment Report, CNA revisited the report on climate change and national security. In this report, they note " $[\mathrm{t}]$ he national security risks of projected climate change are as serious as any challenge we have faced." 37 Beyond validating their original conclusions, they note the risks are advancing more rapidly than anticipated ${ }^{38}$ and that "without action to build resilience in the most vulnerable parts of the world, the projected impacts of climate change will likely serve as catalysts for conflict." 39

A variety of reports released from other organizations highlighted the same concerns as those originally expressed by CNA. In 2007, the German Advisory Council on Global Change (WBGU) assessed the security risks of climate change. The scope of the WBGU report is broader (particularly in their recommendations) than CNA 2007, but it presents a starker perspective on the security consequences. The core message of the WBGU report is that, without action, climate change will test many societies' capacities to adapt, potentially resulting in destabilization and violence, jeopardizing national and international security in turn. ${ }^{40}$ They further note:

climate-induced interstate wars are unlikely to occur. However, climate change could well trigger national and international distributional conflicts and intensify problems already hard to manage such as state failure, the erosion of social order, and rising violence. ${ }^{41}$

The concerns of WGBU revolved broadly around the risks presented by weak and failed states, whose societies are weakened as a result of the changing climate. WGBU argued that, although the "future social impacts of unabated climate change are unlikely to trigger "classic" interstate wars ... they will probably lead to an increase in destabilization processes and state failure." 42 As a result, the WGBU viewed international climate policy (mitigation) as a means to avert climate-induced threats to international security.

In 2007, the Center for Strategic and International Studies (CSIS) compiled three scenarios around which to conduct analysis of the security implications. These scenarios corresponded to 1.3, 2.6, and 5.6 degrees Celsius of warming, categorized as 'expected,' 'severe,' and 'catastrophic' respectively. This report concluded that climate change "has the potential to be one of the greatest national security challenges that this or any other generation of policy makers is likely to confront," which could "destabilize virtually every aspect of modern life" and is likely to breed new conflicts. ${ }^{43}$ They review a variety of dimensions under each scenario in a geo-political context, each with implications for security. They work from the premise that

${ }^{37}$ Sherri Goodman, "National Security and the Accelerating Risks of Climate Change" (Washington, DC: Center for Naval Analysis, 2014), 5.

${ }^{38}$ Ibid.

${ }^{39}$ Ibid., 8.

${ }^{40}$ Hans Joachim Schellnhuber, World in Transition-Climate Change as a Security Risk (German Advisory Council on Global Change (WGBU), 2007).

${ }^{41}$ Ibid.

${ }^{42}$ Ibid., 6.

${ }^{43}$ Kurt M. Campbell et al., "The Age of Consequences: The Foreign Policy and National Security Implications of Global Climate Change" (Washington, DC: Center for International Strategic Studies, 2007). 
"massive nonlinear events in the global environment will give rise to massive nonlinear societal events." 44

When the National Intelligence Council released Global Trends 2030 in 2012, they concluded that climate change will worsen the availability of food, water, and energy, and that "during the next 15-20 years the nexus of these [issues/factors] will deepen and become more intertwined, producing a qualitatively different world." 45 In addition, they noted that "African interlocutors are particularly worried about climate change creating new social and economic tensions that could flare into civil conflict." ${ }^{46}$ In 2012, the National Intelligence Council similarly noted that "[i]nsufficient natural resources - such as water and arable land - in many of the same countries [that have large numbers of ethnic and tribal minorities] that will have disproportionate levels of young men increase the risks of intrastate conflict, particularly in Sub-Saharan Africa.",47

Indeed, climate change adds to the fragile and volatile conditions already present in many parts of Africa. According to the Africa Climate Change, Environment and Security (ACCES) dialogue, "[t]he negative impacts of climate change combined with a growing population, poverty, the current number of existing conflicts, weak state structures, and low capacities to respond have potentially high consequences on security in Africa." 48 ACCES also observed that climate change could cause factors that increase the likelihood of conflict to interact in new ways, and thus create new combinations of risks. ${ }^{49}$ They note, " $[\mathrm{n}]$ atural disasters are increasing in number and frequency, and affect most countries in Africa." 50

Other studies have come to similar conclusions. In June 2009, the Center for a New American Century conducted a climate change themed 'war game' set in the year 2015, concluding that there is "little question that the consequences of global climate change pose many threats" and that the "consequences of climate change may come to define life for people all over the world just as much as the war between the United States and Soviet Union did for the last generation." 51 The 2006 Stern Review concluded that "[c]limate-related shocks have sparked violent conflict in the past, and conflict is a serious risk in areas such as West Africa, the Nile Basin and Central Asia." ${ }^{, 52}$ In 2010, The Center for New American Security sponsored research to generate ideas about how to ensure that policy makers understand the implications of climate

\footnotetext{
${ }^{44}$ Ibid., 76.

${ }^{45}$ National Intelligence Council, "Global Trends 2030: Alternative Worlds" (Washington, DC, 2012), iv.

${ }^{46}$ Ibid., 5 .

${ }^{47}$ Ibid., Location 144, Kindle Edition.

${ }^{48}$ ACCES, "Climate Change and Security in Africa," Manitoba: IISD, 2009, 5.

${ }^{49}$ Ibid., 37.

${ }^{50}$ Ibid., 8.

${ }^{51}$ Sharon Burke and Christine Parthemore, "Climate Change War Game: Working Paper Major Findings and Background" (Washington, DC: Center for a New American Security, 2009), 5. Other participants in this event include the following: the Brookings Institution Global Economy and Development Program, the Center for American Progress, CNA, the Heinrich Böll Foundation, McKinsey Global Institute, Oak Ridge National Laboratory, the Pew Center on Global Climate Change, the Rockefeller Brothers Fund, the Sustainability Institute, and Woods Hole Oceanographic Institution.

${ }^{52}$ N. Nicholas Herbert Stern, The Economics of Climate Change: The Stern Review (Cambridge University Press, 2007), vii.
} 
security research, and to recommend policy on how to integrate climate science into national security policy. ${ }^{53}$

It is important to note that narratives to motivate thinking on climate security risk are often created with failed or weak states in mind, or they address specific regions of the world. They hold that once climate-induced stress has surpassed some unknown threshold, a weakening of institutional and societal resilience results. This breakdown leads to worsened security, instability, and/or conflict. This perspective suggests that the long-term burden of climate response and adaptation diminishes the capacity of weakened states. In support of this view, Scheffran and Battaglini argue that,

[s]ome of the stress factors may directly threaten human health and life, such as, floods, storms, droughts and heat waves; others gradually undermine well-being over an extended period, such as, food and water scarcity, diseases, weakened economic and ecological systems. Environmental changes caused by global warming not only affect the life of human beings but may also generate larger societal effects, either by undermining the infrastructure of society or by inducing responses and adversely affecting social systems. The associated socio-economic and political stress can erode the functioning of communities, the effectiveness of institutions and the stability of societal structures. Societies which depend more on the environment tend to be more vulnerable to climate stress. The stronger the impact and the larger the affected region the more challenging it becomes for societies to absorb the consequences. ${ }^{54}$

Hendrix and Glaser differentiate the effects of climate change as follows: "First, the effects of climate change on the onset of conflict must be conceived of as (1) long term trends that may lead to a higher baseline probability of conflict, and (2) short term triggers that affect the interannual variability in that probability." $" 55$ But once the state is weakened, the severity could render the idea of resilience inadequate to withstand further stress. As Scheffran and Battaglini argue, "failing states with weak governance structures have inadequate management and problemsolving capacities," and for this reason "cannot guarantee the core functions of government, including law, public order and the monopoly on the use of force, all of which are pillars of security and stability."

By triggering a cycle of environmental degradation, economic decline, social unrest and political instability, climate change may become a crucial issue in security and conflict. In several regions of the world

\footnotetext{
${ }^{53}$ Will Rogers et al., "Lost in Translation: Closing the Gap Between Climate Science and National Security Policy" (Washington, DC: Center for a New American Security, 2010).

${ }^{54}$ Jürgen Scheffran and Antonella Battaglini, "Climate and Conflicts: The Security Risks of Global Warming," Regional Environmental Change 11, no. 1 (2011): S29.

${ }^{55}$ Cullen S. Hendrix and Sarah M. Glaser, "Trends and Triggers: Climate, Climate Change and Civil Conflict in Sub-Saharan Africa," Political Geography 26, no. 6 (2007): 696.

${ }^{56}$ Scheffran and Battaglini, "Climate and Conflicts: The Security Risks of Global Warming," S30.
} 
(notably in parts of Africa, Asia and Latin America), the decline of social order, state failure and violence could go hand in hand. ${ }^{57}$

Amplifying the point, Scheffran and Battaglini suggest that,

Disastrous events often exceed the ability of the affected societies to cope with the magnitude and speed of these events and are usually associated with a temporary local collapse of state functions which may lead to domestic political tension and conflict. Disaster management is important to control and prevent the further escalation of a crisis into conflict. ${ }^{58}$

These circumstances are concerning in regions such as MENA, where weak and politically unstable states have less ability to adapt. ${ }^{59}$ Governments in this region are among the least prepared for climate change and the least capable of responding to the consequences. ${ }^{60}$ Not to mention, this region has witnessed a variety of conflicts and experiences related challenges that obstruct economic and political development.

That being said, climate change in the Arctic will produce different security consequences for Euro-Atlantic states than climate change in the MENA region. Whereas MENA raises concerns with respect to crisis management and disaster response, and consequences span the spectrum from increased social stress, breakdown of order and lawlessness, to (potentially) civil conflict, the Arctic forebodes fundamental change in the environment, as well as other consequences that will change the nature of the security environment more generally (and in ways that will affect the North Atlantic region directly).

Taken together, the interaction of environmental, social, political, and economic systems presents challenges. John Steinbruner, the Chairman of the National Research Council's study on the security implications of climate change, offered this parsimonious characterization: "it's a complicated interaction between the vulnerability of populations, their coping ability, the reaction of [a] government, and the climate impulse, that actually produces the consequence.",61 Similarly, Briggs offers a concept that encompasses the climate security nexus. In general, climate-related security risk does not "stem from the threat of violent conflict between people," but from the potential that "overlapping ecological, social, political, and economic systems contain destabilizing feedback loops." 62 That is, the concern is "in the ability of climate change to disrupt those systems that underlie stability and human security more generally." 63

57 Ibid.

${ }^{58}$ Ibid., S31.

${ }^{59}$ National Intelligence Council 2012.

${ }^{60}$ In 2012, The US National Research Council cited Sandia National Laboratories when indicating in both 2008 and 2030 (forecasted) that 10 of the 15 countries at highest risk of state failure were in Africa. Ibid.

${ }^{61}$ Steinbruner, "World Affairs Council Keynote Address: The International Security Implications of Climate Change."

${ }^{62}$ Chad M. Briggs, “Arctic Environmental Security and Abrupt Climate Change” (Washington, DC: Global Inter-Connections, 2011), 3.

${ }^{63}$ Chad M. Briggs, “Climate Security, Risk Assessment and Military Planning,” International Affairs 88, no. 5 (2012): 1054. 
Given their relatively well-developed political and economic institutions, countries in the North Atlantic region are largely anticipated to have the resilience and adaptive capacity to adjust to a new climatological environment without internal civil strife or breakdown. However, political and military resources from Euro-Atlantic countries may be required to assist or intervene in less fortunate regions.

\section{What are the implications?}

In 2012, the IPCC Special Report on Managing the Risks of Extreme Events and Disasters to Advance Climate Change Adaptation (SREX) addressed a variety of issues concerning the increased vulnerability (people and infrastructure) to extreme weather events that results from population growth and expansion of urban centers (in addition to many other aspects). This report concluded that "the key unknown is whether improved disaster risk-management measures will be adopted to effectively cope with these changing conditions by $2030 . " 64$

However, the technical language - and focus on uncertainty - used in IPCC reports and academic publications can obscure an otherwise powerful message on the deeply concerning impact of climate change on security. Other narratives reveal the alarming impact that climate change can have on security more transparently. Among the most concrete is investigative journalism sourced to US diplomatic correspondence. In April 2016, Reveal from The Center for Investigative Reporting released an article detailing how in 2009, a "water crisis in the Middle East destabilized the region, sparking civil wars in Syria and Yemen.",65

Having a cascading effect, in September of that year, Yemen's Minister of Water described a water shortage as Yemen's biggest threat to social stability and noted that 70 percent of unofficial roadblocks by angry citizens were due to water shortages (14 of the country's 16 aquifers ran dry that year) ${ }^{66}$ He predicted that "conflict between urban and rural areas over water [would] lead to violence." ${ }^{67}$ Fewer than two years later, rebels seized two buildings in Yemen's capital: the headquarters of the General People's Congress and the main offices of the water utility. ${ }^{68}$ The president resigned, and a new government was formed. However, water-related tension continued between various groups, which eventually led to civil war. ${ }^{69}$

As the US National Research Council points out, the consequences of climate change could compel "more extensive international engagement than has yet been anticipated or organized,",70 and consequences that exceed the management capacity of human societies or global systems will, in turn, become more common in the future. ${ }^{71}$ The Chairman of this study, John

\footnotetext{
${ }^{64}$ Field et al., "Managing the Risks of Extreme Events and Disasters to Advance Climate Change Adaptation. A Special Report of Working Groups I and II of the Intergovernmental Panel on Climate Change."

${ }^{65}$ Nathan Halverson, "We're Running out of Water, and the World's Powers Are Very Worried," Reveal, April 2016.

${ }^{66}$ Ibid.

${ }^{67}$ Ibid.

${ }^{68}$ Ibid.

${ }^{69}$ Ibid.

${ }^{70}$ US National Research Council, Climate and Social Stress: Implications for Security Analysis, ed. John D. Steinbruner, Paul C. Stern, and Jo L. Husbands (National Academies Press, 2013), ix.

${ }^{71}$ Ibid., 136.
} 
Steinbruner, later expressed his personal views regarding these concerns during a keynote address in 2013. He stated that,

we must anticipate that in some societies the adaptation failures will be severe enough to induce international reaction of unprecedented magnitude; we're looking at crises that are larger than anything that we've encountered as yet.

The bottom line is the consequences of climate change are certainly going to be very large; we know that without any degree of uncertainty whatsoever ... but unfortunately the character, magnitude, timing, and location of those consequences cannot be predicted with sufficient confidence to really tell us what to do about it. ${ }^{72}$

This is the challenge for organizations that must prepare for, respond to, and confront the security consequences that arise from climate change. From the Euro-Atlantic perspective, this suggests that climate change in the Arctic, Africa, and other regions will impact Alliance countries (whether resulting from sea level rise, migration, or natural disaster) because it has "the potential to undermine human security and overwhelm adaptive capacities of societies in many world regions." 73 This eventuality should encourage affected NATO member states to give fresh consideration to a potential role for NATO to more actively and closely engage with climate aspects of international security affairs.

\section{Critical Aspects of Climate Change}

This section outlines two critical aspects of climate security: the role of the Arctic and the transboundary and international nature of the issue. Understanding these aspects is critical to evaluating the usefulness of empirical research. Both fundamentally undermine the value of such empirical models from a policy perspective. The anticipated ecological impact of climate change in the Arctic strongly suggests that the associated consequences will be non-linear and potentially abrupt. This impact will cascade globally and will thereby result in consequences that are trans-boundary (i.e. arise in one country but affect others) and international (i.e. originate in many countries and have global impact). These characteristics are not captured in contemporary econometric models used to examine climate security.

\section{The Critical Role of the Arctic}

The Arctic plays a particularly important role in regulating the global climate and ocean systems, and it is critical in understanding the effects of climate change. ${ }^{74}$ That is because changes in the

\footnotetext{
${ }^{72}$ Steinbruner, "World Affairs Council Keynote Address: The International Security Implications of Climate Change."

${ }^{73}$ Scheffran and Battaglini, "Climate and Conflicts: The Security Risks of Global Warming," S37.

${ }^{74}$ Adger et al., "Human Security," 20. As the Arctic warms, the temperature differential between the pole and the equator becomes smaller. This temperature difference creates much of the atmospheric circulation in the northern hemisphere that carries the weather (warm, cold or wet conditions) in this hemisphere; circulation gets weaker as the difference becomes smaller, which has corresponding consequences for the weather. Dim
} 
Arctic system could create cascading environmental conditions that worsen security globally, as well as create concerns within the North Atlantic region. Rising temperatures cause the release of terrestrial and oceanic methane hydrate (a greenhouse gas). The consequent atmospheric warming causes a feedback loop (further release of methane hydrate and further warming) that could increase the amount of carbon in the atmosphere by more than $50 \%{ }^{75}$ This effect speeds warming and polar ice melt, which causes (and quickens) sea level rise. Moreover, warmer temperatures increase the amount of water vapor in the atmosphere, causing more intense precipitation and also more drought. $^{76}$

Climate change in the Arctic has the potential to cause a daunting array of challenges and creates the potential for catastrophic environmental risks more generally. ${ }^{77}$ Briggs, convincingly, articulates the consequences of the melting of the Greenland ice sheet (e.g. potentially 7 meters of sea level rise) as follows: ${ }^{78}$

The cascading effects enter where change in one system (e.g. the Greenland ice sheet) results in conditions (rapid rise in sea levels) that have varying impacts elsewhere depending upon the vulnerability of the geographic region (e.g. sensitivity to flooding from low-lying coastal land), social systems (resilience to forced migration) and economic systems (fragility of infrastructure) ... Disruptions in social and economic systems then have their own cascading effects on related, complex systems. $^{79}$

The cascading effects of climate changes in the Arctic are likely to meet security definitions of Arctic states. Abrupt environmental changes will not only force a re-examination of geopolitics as transit and resource access shifts. Such changes may also overwhelm critically important

Coumou, Jascha Lehmann, and Johanna Beckmann, "The Weakening Summer Circulation in the Northern Hemisphere Mid-Latitudes," Science 348, no. 6232 (2015): 324-27.

${ }^{75}$ Briggs, "Arctic Environmental Security and Abrupt Climate Change," 1, 9. Also, as polar ice melts, heat from the sun that would have been reflected back to space (by snow and ice) is absorbed by the oceans. Coumou, Lehmann, and Beckmann, "The Weakening Summer Circulation in the Northern Hemisphere MidLatitudes."

${ }^{76}$ US National Research Council, Climate and Social Stress: Implications for Security Analysis, 61, 62. The current rate at which carbon dioxide is being added to the Earth's atmosphere is 10 times more than anything in the past 400,000 years ... [and] 28,000 times greater than the rate that drove deep ocean temperature to its maximum 55 million years ago. Steinbruner, "World Affairs Council Keynote Address: The International Security Implications of Climate Change."

${ }^{77}$ Briggs, "Arctic Environmental Security and Abrupt Climate Change," 1.

${ }^{78}$ Ibid., 9. John Steinbruner indicated that during the Eemien period approximately 130,000 years ago, when deep ocean temperatures were the same as they are today, sea levels were 4-6 meters higher; during the Plyocene period, approximately 3 million years ago, when deep ocean temperatures were only 1 degree Celsius higher than they are today, sea levels were 25 meters higher. Steinbruner, "World Affairs Council Keynote Address: The International Security Implications of Climate Change."

${ }^{79}$ Briggs, "Arctic Environmental Security and Abrupt Climate Change," 9. 
systems underlying the security of states globally, as shifts in one area may spark cascading effects that impact distant regions. ${ }^{80}$

Significant melt of ice sheets may impact energy infrastructure on the coasts, while disruptions to global ocean currents or massive releases of methane would spark situations of food insecurity, itself contributing to loss of livelihoods and government instability as far away as India. ${ }^{81}$

Said another way, the rapid loss of permanent Arctic ice could result in a cascade of climate feedbacks with global impact, and this, in turn, could create challenges for which the world is insufficiently prepared to act effectively as a collective. ${ }^{82}$ Climate change in the Arctic also causes more conventional and regional security issues. The potential for open water in the Arctic suggests increased risk as a result of commercial activity (e.g. maritime transit, as well as natural resource exploration and extraction).

\section{Trans-boundary and International Risk}

The Earth system consists of three coupled subsystems: the climate system, the natural system, and the human system. Each of these systems affects the others directly and indirectly, creating a complex (and highly uncertain) socio-environmental system. ${ }^{83}$ These characteristics suggest we should view the climate-security relationship, as Briggs notes, "as complex emergent systems." $" 84$

A complex, emergent (or adaptive) system is one comprised of a large number of entities with a high level of (mostly non-linear) interactivity, containing "manifest" feedback loops. ${ }^{85}$ Given the global nature of the climate system, the associated complex socio-environmental problems are not contained regionally, but they can have trans-boundary (or cascading) consequences at great distance from their origin. ${ }^{86}$

Systems linked to climate and upon which humans heavily depend (such as food production) create concern because they can interact to produce situations that affect security. Consider regions of the world where domestic grain production is insufficient to meet domestic demand (creating dependence on imports), such as the Middle East and North Africa. Shortages and their consequent price spikes can have significant consequences.

\footnotetext{
${ }^{80}$ Ibid., 10.

${ }^{81}$ Ibid.

${ }^{82}$ McElroy and Baker, "Climate Extremes: Recent Trends with Implications for National Security," 4.

${ }^{83}$ Maximilian Auffhammer et al., "Detection and Attribution of Observed Impacts," in Climate Change 2014: Impacts, Adaptation, and Vulnerability. Part A: Global and Sectoral Aspects. Contribution of Working Group II to the Fifth Assessment Report of the Intergovernmental Panel on Climate Change, ed. C.B. Field et al. (Cambridge, United Kingdom and New York, NY, USA: Cambridge University Press, 2014), 6; Read, "Embracing Uncertainty: Scenario Planning for Climate Change Security Challenges and Opportunities," iii.

${ }^{84}$ Briggs, "Arctic Environmental Security and Abrupt Climate Change," 2. Complex emergent systems are also referred to as complex adaptive systems. Complexity in complex adaptive systems refers to the potential for emergent behavior in complex and unpredictable phenomena.

${ }^{85}$ Ka Richardson, P. Gilliers, and Michael Lissack, "Complexity Science: A 'Gray' Science for the 'Stuff in Between," EMERGENCE 3, no. 2 (2001): 7.

${ }^{86}$ Reinette Biggs et al., "Linking Futures across Scales: A Dialog on Multiscale Scenarios," Ecology and Society 12, no. 1 (2007).
} 
A frequently cited example is the 2010 heat wave in Russia, which is believed to have contributed to the events that led to political instability in the Middle East (i.e. The Arab Spring). ${ }^{87}$ Read notes that this is "but one example of a complex web of environmental and social variables interacting and changing over a range of temporal and spatial scales to influence local, national, and international stability and security." 88 Briggs offers the following concise summary:

a critical vulnerability with global security implications concerned food production. The loss of crops from the heatwave prompted an embargo on the export of Russian grain, much of which was destined for ports in the Middle East and North Africa.

In Egypt, for example, the sudden loss of major food imports could not be made good from other sources, as world markets were already tight and US grains could not be imported for fears of invasive ragweed pollen.

The heatwave in Russia therefore led to a major price spike in grains and breads in the Middle East and North Africa, which is said to have been a contributing factor to Arab Spring revolts, as national governments unable to provide for their citizens lost legitimacy.

This illustration also demonstrates the inter-connecting nature in which climate change (both in the Arctic, and more generally) affects other regions and issues. Further, the increasing variability of temperature and precipitation expected to result from climate change, as well as globalization, creates the dynamics for situations such as these to become a more common feature of international security. Just as with the Arab Spring, some of these are likely to affect security in the North Atlantic region. On this note, Kovats and Valentini observe that "the impacts of climate change outside the European (and North Atlantic) region are likely to have implications for countries within the region." 90

From an analytic perspective, these characteristics (complex, emergent, adaptive) undermine the utility of conventional (econometric) methodologies, which have often been employed to model the relationship between climate and security. Richardson concludes that "Nonlinear interconnectivity places fundamental limitations on the ability to validate models of complex systems." "91 Briggs highlights these characteristics:

${ }^{87}$ Lester R. Brown, "The New Geopolitics of Food: From the Middle East to Madagascar, High Prices Are Spawning Land Grabs and Ousting Dictators. Welcome to the 21st-Century Food Wars," Foreign Policy (Washington, DC, April 2011).

${ }^{88}$ Read, "Embracing Uncertainty: Scenario Planning for Climate Change Security Challenges and Opportunities," 2.

${ }^{89}$ Briggs, "Climate Security, Risk Assessment and Military Planning," 1052., citing Sarah Johnstone and Jeffrey Mazo, "Global warming and the Arab Spring," Survival 53, no. 2 (2011), 11-17.

${ }^{90}$ R. S. Kovats et al., "Europe," in Climate Change 2014: Impacts, Adaptation, and Vulnerability. Part B: Regional Aspects. Contribution of Working Group II to the Fifth Assessment Report of the Intergovernmental Panel on Climate Change, ed. V. R. Barros et al. (Cambridge, United Kingdom and New York, NY, USA: Cambridge University Press, 2014), 37.

${ }^{91}$ Richardson, Gilliers, and Lissack, "Complexity Science: A 'Gray' Science for the 'Stuff in Between," 7. 
Global environmental conditions are also inextricably linked to social, political and economic systems, which can further compound uncertainty when analysts would prefer to study systems as discrete collections of isolated variables.

Thus, climate change is not merely the interaction of a few variables, where a simple, linear relationship exists between levels of atmospheric greenhouse gases and average atmospheric temperatures.

Rather, the global climate is a complex system, exhibiting emergent properties and influenced by numerous feedback effects, none of which can easily be predicted in advance. Just as with ecological systems, the climate may rest upon multiple points of stability, but these stable levels may be unsuitable for both existing human and environmental adaptation. $^{92}$

That the science underpinning environmental systems indicates multiple points of stable equilibrium leads to the conclusion that "change is more likely to be abrupt than gradual." 93 This points to additional concern with respect to potential surprises (e.g. non-linearity) and, as Briggs points out, the potential for "failure of ecological, political or economic systems[,] should conditions shift more quickly than adaptation allows." 94

Contextual factors that influence climate security risk vary widely, but can include, among other aspects, the nature of its socio-demographic impact, the timeliness and effectiveness of government response, the extent of pre-existing tensions or dissatisfaction, any real or perceived state fragility, population density, and political grievances. Analytic models attempt to capture these dimensions, although they do so imperfectly, because climate events are generally represented by absolute levels or variation in temperature and precipitation.

The resulting uncertainties are acknowledged, though not fully captured, in contemporary research, nor could they be captured given the absence of data to fully identify and understand them. A fully developed and validated model does not exist, and it is unlikely that a model that can legitimately represent the dynamics of the situation will exist in the near future.

Efforts have been made, rather unsuccessfully, to link climate models with social and political models, such as one performed by Sandia National Laboratories in $2004 .{ }^{95}$ However, Read notes both that "simulation and modeling have significant limitations, especially in replicating complex social change and down- or up-scaling conditions" "96 and that "integrated assessments have a number of limitations, including challenges dealing with uncertainty and high cost." 97

\footnotetext{
${ }^{92}$ Briggs, "Arctic Environmental Security and Abrupt Climate Change," 4.

${ }^{93}$ Richard B. Alley et al., Abrupt Climate Change, Inevitable Surprises (Washington, DC: National Academy Press, 2002). Also, see Timothy M. Lenton, "Early Warning of Climate Tipping Points," Nature Climate Change 1, no. 4 (2011): 201-209.

${ }^{94}$ Briggs, "Arctic Environmental Security and Abrupt Climate Change," 4.

${ }^{95}$ Mark Boslough et al., "Climate Change Effects on International Stability: A White Paper," SAND20045973. Albuquerque, NM: Sandia National Laboratories, 2004.

${ }^{96}$ Read, "Embracing Uncertainty: Scenario Planning for Climate Change Security Challenges and Opportunities," 2.

${ }^{97}$ Ibid., 3 .
} 
Given the adaptive and emergent nature of the climate system, unique combinations of climate and non-climate related stress will likely occur. Recognizing this alongside the other ways in which climate can interact to reduce security, the IPCC concluded that the "effect of climate change on conflict and insecurity has the potential to become a key risk." 98

The lack of clarity undermines the analytic basis upon which judgments can be made. Furthermore, the imperfect state of knowledge suggests a high degree of unpredictability and warrants concern for policymakers. In 2011, the International Institute for Strategic Studies highlighted the multi-dimensional and dynamic nature of climate change and reiterated the concern that climate change could have a profound impact on the security environment:

Climate change is not happening in a vacuum: in many areas of the world it will be accompanied by rapid population growth, resource shortages, and energy price increases. Analytically, it is difficult to separate the effects of climate change from other factors, such as food shortages, migration, ethnic tensions, and other issues that could drive violence. However, the potential impacts of climate change on water, energy, and agriculture will make it a central driver of conflict. The impacts of climate change combine to make it a clear threat to collective security and global order in the first half of the 21 st Century. ${ }^{99}$

Natural disasters can weaken government capacity, set the stage for a breakdown of security, and increase the need for international assistance. ${ }^{100}$ Migration across national boundaries could also increase the risk of conflict, as migration into an area may affect the ethnic balance, add stress to a tense area, or increase competition over scarce livelihood options. ${ }^{101}$ Food insecurity and water stress are possible consequences of climate change as well. ${ }^{102}$ Where these factors interact, the reasoning holds that tensions could increase competition for scarce resources; escalation could further limit access to resources, causing people not previously affected to face shortages, and in the process raise the likelihood of conflict. ${ }^{103}$

The problems posed by these two critical aspects of climate security-i.e. the role of the Arctic and the trans-boundary and international nature of the issue - are discussed with remarkable infrequency by researchers who attempt to empirically model the linkage between climate change and security. As mentioned at the beginning of this section, understanding these aspects is critical to evaluate the usefulness of empirical and model-based research. Both aspects fundamentally undermine the value of such models from a policy perspective, because their

\footnotetext{
${ }^{98}$ Oppenheimer, Campos, and Warren, "Emergent Risks and Key Vulnerabilities," 23.

${ }^{99}$ International Institute for Strategic Studies, "The IISS Transatlantic Dialogue on Climate Change and Security: Report to the European Commission" (London, UK: International Institute for Strategic Studies, 2011), 11.

100 Scheffran and Battaglini, "Climate and Conflicts: The Security Risks of Global Warming," S31. Schellnhuber, World in Transition-Climate Change as a Security Risk.

${ }^{101}$ Lars-Erik Cederman and Luc Girardin, "Beyond Fractionalization: Mapping Ethnicity onto Nationalist Insurgencies" (Zurich: Swiss Federal Institute of Technology, 2006); Scheffran and Battaglini, "Climate and Conflicts: The Security Risks of Global Warming," S31. Arguments that rely upon the linkage that resourcescarcity leads to conflict are known as 'Neo-Malthusian.' Homer-Dixon is typically given credit.

${ }^{102}$ Schellnhuber, World in Transition-Climate Change as a Security Risk.

${ }^{103}$ Ibid. US National Research Council, Climate and Social Stress: Implications for Security Analysis, 20.
} 
characteristics are not captured by the contemporary econometric models and methodologies used to examine climate security.

This observation will inform the remainder of this dissertation and exposes serious problems for risk governance. Indeed, the validity of econometric models that employ a linear representation to analyze the climate/security relationship comes under strain upon recognizing that the relationship is more appropriately conceived as a system or network that captures the nonlinearity and feedback loops of the climate system.

As discussed above, the anticipated ecological impact of climate change in the Arctic strongly suggests that the associated consequences will be non-linear and potentially abrupt. ${ }^{104}$ This impact will cascade globally and thus also result in consequences that are trans-boundary (i.e. arise in one country, but affect others) and international (i.e. originate in many countries and have global impact).

\section{Empirical Models of Climate Security}

Academic research on the climate-security nexus often seeks to identify and test an empirical relationship between climate variables and a security outcome of interest, which generally represents violent conflict of one intensity or another, or some quantifiable characteristic associated with weakened security. While this method diverges both in terms of analysis and purpose from policy-oriented research, it also gives comprehensive consideration to factors in seeking to understand the mechanism through which climate affects conflict. However, the complexities, the insufficient methods, and the lack of data undermine these efforts. For these reasons they have critical shortcomings and have resulted in few solid conclusions. ${ }^{105}$

When considering the relationship between climate change and a more severe worsening of security - civil or armed conflict - the IPCC found "neither the detection of an effect of climate change on civil conflict nor an assessment of the magnitude of such an effect can currently be made with a degree of confidence." 106 The IPCC rendered a similar judgment with respect to the linkage between temperature and violent crime, as well as that between climate variability and small-scale communal violence, and between climate change and migration. ${ }^{107}$ The absence of causal evidence is a common feature of empirical research on the climate-security nexus.

A principal drawback of empirical research, with respect to NATO's interest in climate security risk, is the focus on conflict, which requires coded data and datasets to establish a rigid definition for 'conflict.' While conflict is an element of security, analysis pursued solely along this dimension provides limited insight for the broader aspects of security under consideration in this dissertation. Attempts to test the climate/conflict relationship do not address the broader range of security issues that NATO would be concerned with. Moreover, 'conflict' is defined differently

\footnotetext{
104 Timothy M. Lenton, “Arctic Climate Tipping Points," Ambio 41, no. 1 (2012): 10-22.

${ }^{105}$ A. Kaitlin Shilling, "Climate Change and Conflict: Identifying the Mechanisms" (Thesis, Stanford University, 2011), 13; Briggs, "Climate Security, Risk Assessment and Military Planning," 1055.

${ }^{106}$ Auffhammer et al., "Detection and Attribution of Observed Impacts," 25.

${ }^{107}$ Ibid.
} 
according to the database employed (Correlates of War/Uppsala Conflict Data Program). ${ }^{108}$ This leads to different times for onset of conflict, which has implications for the conclusions drawn about the cause.

Much of this research focuses on inter-annual climate variation rather than variation in the longterm climate, using precipitation or temperature variability as a proxy for the environmental characteristics anticipated under climate change, to examine the relationship with conflict. Given no other data to capture the effect of climate, researchers use variability of precipitation and temperature as measured in current-year levels or year-to-year growth. Cases where variation in precipitation (and temperature) increases the risk of local conflict lead to the conclusion that, given a significant effect, predicted climatic changes will lead to more conflict. However, the extent to which temperature and precipitation variability serves a useful proxy for 'climate' remains uncertain.

Moreover, since conflict is (thankfully) a rare occurrence, the datasets are sparse. In May 2012, Scheffran et al. noted that "current debates over the relation between climate change and conflict originate in a lack of data." 109 Buhaug et al. note the difficulty of creating a generalizable model because increased likelihood of violence "depends crucially on country-specific and contextual factors." $" 110$ As a result of the lack of data and model problems, empirical analysis does not provide sufficient evidence to determine a clear causal relationship between climate impacts and security and conflict. Scheffran et al. note that "[a]lthough some quantitative empirical studies support a link between climate change and violent conflict, others find no connection or only weak evidence." 111 Theisen et al. also find that "extant studies provide mostly inconclusive insights, with contradictory or weak demonstrated effects of climate variability and change on armed conflict." ${ }^{112}$ In 2000, Barnett argued that the environment-conflict hypothesis is theoretically, rather than empirically, driven, ${ }^{113}$ but also later recognized empirical linkages. ${ }^{114}$

\footnotetext{
${ }^{108}$ The UCDP/PRIO database requires the following in defining civil war (or, 'conflict'): the state is one of the involved parties; there is an opposition organization; control of the government or territory is contested; and there is a minimum of 25 battle-deaths per year, on each side of the conflict. Peter Nils Petter Gleditsch et al., "Armed Conflict 1946 - 2001: A New Dataset," Journal of Peace Research 39, no. 5 (2002): 615-37; L. Harbom and P. Wallensteen, "Armed Conflict, 1989-2006," Journal of Peace Research 44, no. 5 (2007): 623-34. The Correlates of War project requires that national governments participate in a conflict; that there are 1,000 battle-deaths per year; that there is resistance by both sides; and that the conflict is within national territory. Meredith Reid Sarkees, "The Correlates of War Data on War: An Update to 1997," Conflict Management and Peace Science 18, no. 1 (2000): 123-44.

109 Jürgen Scheffran et al., "Climate Change and Violent Conflict," Science 336, no. 6083 (2012): 869.

${ }^{110}$ Halvard Buhaug, Nils Petter Gleditsch, and Ole Magnus Theisen, "Implications of Climate Change for Armed Conflict" (Washington, DC: World Bank, 2008), 2.

${ }^{111}$ Scheffran et al., "Climate Change and Violent Conflict," 869. Jürgen Scheffran et al., "Disentangling the Climate-Conflict Nexus: Empirical and Theoretical Assessment of Vulnerabilities and Pathways," Review of European Studies 4, no. 5 (2012): 1-13.

${ }^{112}$ Ole Magnus Theisen, Nils Petter Gleditsch, and Halvard Buhaug, "Is Climate Change a Driver of Armed Conflict?," Climatic Change 117, no. 3 (2013): 613-25.

113 Jon Barnett, "Destabilizing the Environment-Conflict Thesis," Review of International Studies 26.02 (2000): 271-88.

${ }^{114}$ Jon Barnett, "Security and Climate Change," Global Environmental Change 13, no. 1 (2003): 7-17.
} 
Dalby has long been critical of research on the environment-security nexus, precisely because of the potential for intervening factors to 1) provide more explanatory power on the security outcome, and 2) alter and create various pathways through which security issues arise as a result of environmental degradation. ${ }^{115}$ Hartmann also notes that much of the early environmentalsecurity literature "largely fails to consider the underlying economic and political causes of environmental degradation and violence." ${ }^{116}$ A troubling aspect of efforts to link environmental change and security is the apparent consensus that non-environmental factors dominate in explaining the prevalence of conflict. ${ }^{117}$

Case studies examined by Homer-Dixon suggest that while conflict has indeed occurred in areas of resource scarcity, key contextual factors played an important role. ${ }^{118}$ Hauge and Ellingsen find that economic and political factors are more important in predicting domestic armed conflict than are environmental factors. ${ }^{119}$ In 2007, Barnett and Adger assessed that the consequences of climate change are a function of the economic, human, and social capital of a society, which is influenced by access to resources, information, and technology, social cohesion, and the stability and effectiveness of institutions. ${ }^{120}$

Indeed, media dedicated to the conflict in Darfur routinely attributed the cause to climate change (rainfall). However, several researchers disagreed. In 2008, Kevane and Gray found that "[d]ata on rainfall patterns only weakly corroborate the claim that climate change explains the Darfur conflict that began in 2003." "In 2010, Brown concluded that "there is no evidence in the vegetation mapping for a worsening of the ecological situation in Western and Northern Darfur states around the outbreak of the conflict." 122 Other researchers employed different methodologies to examine the climate and conflict theme. Mahmooei and Parris, for example, use an agent-based model (with a climate interpretation) to show that "agents tend not to engage in conflict during mild resource scarcity scenarios."

These studies examined the conflict closely and identified other factors, such as a history of violence, ethnic divisions, limited economic development, and others. None of these factors emerged as most influential. However, researchers agree that government practices were more

115 Simon Dalby, "Security and Environment Linkages Revisited," in Globalisation and Environmental Challenges: Reconceptualising Security in the 21st Century, ed. Hans Günter Brauch et al., 2006.

${ }^{116}$ Betsy Hartmann, "Population, Environment and Security: A New Trinity," Environment and Urbanization 10, no. 2 (1998): 113.

${ }^{117}$ Conor Devitt and Richard S. J. Tol, "Civil War, Climate Change, and Development: A Scenario Study for Sub-Saharan Africa," Journal of Peace Research 49, no. 1 (2012): 130.

118 Thomas F. Homer-Dixon, "Environmental Scarcities and Violent Conflict: Evience from Cases," International Security 19, no. 1 (2013): 5-40.

${ }^{119}$ Wenche Hauge and Tanja Ellingsen, "Beyond Environmental Scarcity: Causal Pathways to Conflict," Journal of Peace Research 35, no. 3 (1998): 314.

${ }^{120}$ Jon Barnett and W. Neil Adger, "Climate Change, Human Security and Violent Conflict," Political Geography 26, no. 6 (2007): 639-55.

${ }^{121}$ Michael Kevane and Leslie Gray, "Darfur: Rainfall and Conflict," Environmental Research Letters 3 (2008).

${ }^{122}$ Ian A. Brown, "Assessing Eco-Scarcity as a Cause of the Outbreak of Conflict in Darfur: A Remote Sensing Approach," International Journal of Remote Sensing 31, no. 10 (2010): 2513-20.

${ }^{123}$ Behrooz Hassani Mahmooei and Brett Parris, "Why Might Climate Change Not Cause Conflict? An AgentBased Computational Response," 2013, 1. 
influential than climate variability, noting that neighboring regions experienced similar climate without suffering the same conflict. In 2011, Verhoeven suggested that attributing the conflict in Darfur to climate change masked "the long-term political-economic dynamics and Sudanese agency underpinning the crisis." ${ }^{124}$ Hartmann also agreed that the climate-conflict narrative "ignores basic elements of Sudanese political economy that helped create and sustain the conflict."

These finding are at odds with other efforts. A study conducted at Oregon State University, based on the Transboundary Freshwater Dispute Database (TFDD), shows that the likelihood and intensity of conflict increases as the rate of change within a basin exceeds the ability of the basin to absorb that change. ${ }^{126}$ Busby uses vulnerability mapping with "geo-referenced maps of sub-national climate vulnerability in Africa, using past exposure to climate-related hazards, population density, household/community resilience, and governance and political violence ... coupled with projections of future climate change using an ensemble of five general circulation models" to "demonstrate the effect of climate on security.",

Moreover, several researchers investigated more distant historical events and arrived at similar conclusions. In 2010, Buckley et al. revealed that the collapse of the Khmer empire of the 15th century corresponded to severe drought. ${ }^{128}$ In 2001, Demenocal found that changes in weather patterns occurred at the same time as the collapse of the Anasazi, the Akkadian, Classic Maya, Mochica, and Tiwanaku empires. ${ }^{129}$ In 2008, Parker found that the 17 th century was associated with more instances of political unrest and warfare than any other period, and suggests that climate change might have been a factor. ${ }^{130}$ In 2011, Zhang et al. found that climate-driven economic downturn was the cause of large-scale human crises in Europe and the Northern Hemisphere during the same time period. ${ }^{131}$

${ }^{124}$ Harry Verhoeven, "Climate Change, Conflict and Development in Sudan: Global Neo-Malthusian Narratives and Local Power Struggles," Development and Change 42, no. 3 (2011): 679-707.

${ }^{125}$ Betsy Hartmann, "Rethinking Climate Refugees and Climate Conflict: Rhetoric, Reality and the Politics of Policy Discourse," Journal of International Development 22, no. 1 (2010): 236.

${ }^{126}$ Shira Yoffe et al., "Geography of International Water Conflict and Cooperation: Data Sets and Applications," Water Resources Research 40, no. 5 (2004).

${ }^{127}$ Joshua W. Busby et al., "Of Climate Change and Crystal Balls: The Future Consequences of Climate Change in Africa," in American Political Science Association Annual Conference (Seattle, 2011), 1; Joshua W. Busby, "Who Cares about the Weather?: Climate Change and US National Security," Security Studies 17, no. 3 (2008): 468-504; Joshua W. Busby et al., "Climate Change and Insecurity: Mapping Vulnerability in Africa," International Security 37, no. 4 (2013): 132-72; Joshua W. Busby, Kaiba L. White, and Todd G. Smith, "Mapping Climate Change and Security in North Africa," Policy Brief (Washington, DC: The German Marshall Fund of the United States, 2010).

${ }^{128}$ Brendan M. Buckley et al., "Climate as a Contributing Factor in the Demise of Angkor, Cambodia.," Proceedings of the National Academy of Sciences of the United States of America 107, no. 15 (April 13, 2010): 6748-52.

${ }^{129}$ P. B. DeMenocal, "Cultural Responses to Climate Change during the Late Holocene.," Science 292, no. 5517 (2001): 667-73.

${ }^{130}$ Geoffrey Parker et al., "Crisis and Catastrophe: The Global Crisis of the Seventeenth Century Reconsidered," American Historical Review Forum October (2008): 1053-1079.

${ }^{131}$ David D. Zhang et al., "The Causality Analysis of Climate Change and Large-Scale Human Crisis," Proceedings of the National Academy of Sciences 108, no. 42 (2011): 17296-17301. 
However, limitations on historical understanding and data encumber the full assessment of the role of climate change. While these examples may not correlate to today's world, they suggest that climate change can worsen factors that affect security both directly and indirectly. Yet, the extent to which any model or dataset can genuinely capture the potential for abrupt changes and discontinuities in the climate system, how the inter-linked social and political systems will respond, and the impact of globally cascading consequences have not yet been demonstrated.

\section{Precipitation / Conflict Nexus}

A principal strategy to examine the potential for climate change to affect security and conflict is to use either absolute levels or variability of precipitation as a proxy for climate change. This approach has found mixed results. Fjelde and von Uexkull find that "large negative deviations in rainfall from the historical norm are associated with a higher risk of communal conflict," but, note cautiously, that "whether groups resort to violence in the face of environmentally induced hardship is likely to depend on the availability of alternative coping mechanisms.",132

In 2007, Hendrix and Glaser explored the empirical basis for a linkage between climate variability and conflict. ${ }^{133}$ They found that "both long term climatic trends as well as increasing inter-annual variability leads to [civil] conflict," using an approach founded on the recognition that "the environmental consequences of greater variability are declines in system predictability and stability, and increase in extreme events such as tropical storms." ${ }^{134}$ However, Hendrix and Glaser additionally assert that,

Both long term climate trends and short term triggers that affect interannual variability have a significant impact on the likelihood of conflict onset, even in the presence of controls; an analysis of marginal effects demonstrated that inter-annual variability matters more than long term changes in overall climate. ${ }^{135}$

Using conflict data from East Africa (from 1997-2009), Raleigh and Kniveton find that rainfall conditions, both increases and decreases, likely bear on the probability of conflict, but that the highest incidence of rebel conflict appears to occur in extreme dry rather than wet conditions, and communal violence appears to occur in extreme wet rather than dry conditions. ${ }^{136}$

In 2012, Hendrix and Salehyan find that rainfall variability has a significant effect on both large and small-scale instances of political conflict, and that it correlates with civil war and insurgency (wetter years are more likely to suffer violence). Moreover, they find that extreme deviations in

${ }^{132}$ Hanne Fjelde and Nina von Uexkull, "Climate Triggers: Rainfall Anomalies, Vulnerability and Communal Conflict in Sub-Saharan Africa," Political Geography 31 (2012): 444.

${ }^{133}$ Hendrix and Glaser, "Trends and Triggers: Climate, Climate Change and Civil Conflict in Sub-Saharan Africa."

${ }^{134}$ Ibid., 696.

135 Ibid.

${ }^{136}$ Clionadh Raleigh and Dominic Kniveton, "Come Rain or Shine: An Analysis of Conflict and Climate Variability in East Africa," Journal of Peace Research 49, no. 1 (2012): 62. 
rainfall are associated positively with all types of political conflict, though the relationship is strongest for violent events, which are more responsive to abundance than scarce rainfall. ${ }^{137}$

In 2012, Theisen examined data from Kenya from 1989 to 2004, finding political gain is a more important factor for large-scale inter-group violence than scarcity of land, pasture, or water resources. Specifically, he found that below average rainfall had a peaceful effect the following year, as well as the current year (although less robustly so in the latter case). The data provided by Theisen gives little support to the idea that scarcity of farmland fuels violence, but it does suggest that violence is more likely to occur in an election year. ${ }^{138}$

In 2012, O'Loughlin et al. found that wetter deviations from precipitation norms decrease the risk of violence, while drier and normal periods show no effect. Warmer than normal temperatures raise the risk of violence, but average and cooler temperatures have no effect. Moreover, while these results are statistically significant, they have only modest influence when political, economic, and physical geographic predictors are included in the model. ${ }^{139}$

In 2010, Hidalgo et al. found that adverse economic shocks, instrumented by rainfall, cause the rural poor to invade and occupy large landholdings. ${ }^{140}$ Salehyan and Hendrix find that "wetter years [see] more political violence, (not simply in Africa) ... [and] demonstrate that certain intervening political and economic factors-low levels of development, more authoritarian political institutions, and higher levels of agricultural dependence-exacerbate the effect of water availability on conflict., ${ }^{141}$

In 2012, Adano et al. examined case studies of pastoralist conflict in northern Kenya, finding "more conflicts and killings take place in wet seasons of relative abundance, and less in dry season times of relative scarcity, when people reconcile their differences and cooperate."142 However, time series data examined by Levy et al. (2005) shows a correlation between belownormal rainfall deviations and the likelihood of conflict. ${ }^{143}$

The lack of a clear pattern through which precipitation patterns may lead to conflict makes it difficult to use these insights as a basis that organizations can use for planning. Still, many of the results raise concerns and add to the larger picture of how climate might affect security in certain regions.

${ }^{137}$ Cullen S. Hendrix and Idean Salehyan, "Climate Change, Rainfall, and Social Conflict in Africa," Journal of Peace Research 49, no. 1 (2012): 35-50.

${ }^{138}$ Ole Magnus Theisen, "Climate Clashes? Weather Variability, Land Pressure, and Organized Violence in Kenya, 1989-2004,” Journal of Peace Research 49, no. 1 (2012): 81-96.

${ }^{139}$ John O’Loughlin et al., "Climate Variability and Conflict Risk in East Africa, 1990-2009," Proceedings of the National Academy of Sciences 109, no. 45 (2012): 18344-49.

${ }^{140}$ F. Daniel Hidalgo et al., "Economic Determinants of Land Invasions," The Review of Economics 92, no. 3 (2010): 505-23.

${ }^{141}$ Idean Salehyan and Cullen S. Hendrix, "Climate Shocks \& Political Violence: Is Africa Unique?," in American Political Science Association Annual Meeting, 2011.

${ }^{142}$ W. R. Adano et al., "Climate Change, Violent Conflict and Local Institutions in Kenya's Drylands," Journal of Peace Research 49, no. 1 (January 31, 2012): 65-80.

${ }^{143}$ Marc A. Levy et al., "Freshwater Availability Anomalies and Outbreak of Internal War: Results from a Global Spatial Time Series Analysis," in International Workshop on 'Human Security and Climate Change, Holmen, Norway, 2005, 21-23. 


\section{Temperature / Conflict Nexus}

Some studies that employ a temperature variable have identified significant relationships, though the results are disputed. In 2009, Burke et al. linked internal armed conflict incidence to temperature variation. With the publication of Warming Increases the Risk of Civil War in Africa, Burke et al. found "strong historical linkages between civil war and temperature in Africa" and concluded that the "historical response to temperature suggests a roughly 54\% increase in armed conflict incidence by 2030, or an additional 393,000 battle deaths if future wars are as deadly as recent wars."

Moreover, they assert "given that total loss of life related to conflict events can be many times higher than direct battle deaths, the human costs of this conflict increase likely would be much higher." Parting ways, Buhaug shows that modifications in the statistical approach lead to different results. ${ }^{144}$ In 2011, Theisen et al. demonstrated that there is no direct, short-term relationship between drought and the onset of civil war, even within contexts presumed to be most conducive to violence. ${ }^{145}$

In 2012, Butler and Gates analyzed the effects of climate change on pastoral conflict in East Africa, noting some of their findings undermine the linkage between climate and conflict. ${ }^{146}$ In 2012, Almer and Boes used data on short-term weather variability as well as long-term changes in Sub-Saharan Africa to argue that climate (change) significantly affects agricultural output, and to some extent GDP, but has no robust direct effects on civil wars. They find that negative shocks in GDP, however, do foster civil conflicts. ${ }^{147}$ In 2012 , Koubi et al. examined climate, economic growth, and armed conflict, but did not find that climate conditions affect economic growth, and drew only weak support for the idea that non-democratic countries are more likely to experience civil conflict when economic conditions deteriorate. ${ }^{148}$

While these insights give reason to pause, they also have a potentially limited application for policy, given the use of data that does not capture both the variability and the absolute levels of temperature under conditions of future climate change.

\section{Larger Climatic Trends}

In 2011, Hsiang et al. found that since 1950 the risk of intrastate warfare increases during El Niño Southern Oscillation (ENSO) periods (among countries affected by ENSO). They show

${ }^{144}$ Halvard Buhaug, "Climate Not to Blame for African Civil Wars," Proceedings of the National Academy of Sciences 107, no. 38 (2010): 16477-82.

${ }^{145}$ Ole Magnus Theisen and Helge Holtermann, "Climate Wars: Assessing the Claim That Drought Breeds Conflict Climate Wars," International Security 36, no. 3 (2011): 79-106.

${ }^{146}$ Christopher K. Butler and Scott Gates, "African Range Wars: Climate, Conflict, and Property Rights," Journal of Peace Research 49, no. 1 (2012): 23-34.

${ }^{147}$ Christian Almer and Stefan Boes, "Climate (Change) and Conflict: Resolving a Puzzle of Association and Causation" (Universitaet Bern, Departement Volkswirtschaft, 2012).

${ }^{148}$ Vally Koubi et al., "Climate Variability, Economic Growth, and Civil Conflict," Journal of Peace Research 49, no. 1 (2012): 113-27. 
that the probability of new civil conflicts throughout the tropics doubles during El Niño years relative to La Niña years. Thus, ENSO may have had a significant role in civil conflicts since 1950 and the stability of modern societies may relate strongly to global climate. ${ }^{149}$

In 2013, Hsiang and Burke found that studies best positioned to make causal claims indicate strong linkages between climate anomalies, conflict, and social instability. They posit that this effect, which includes historical and modern periods, can be generalized to populations around the globe, arises from both rapid and gradual climatic events, and influences numerous types of conflict across all spatial scales. ${ }^{150}$ In 2013, Hsiang et al. examined 60 empirical studies, which implicated climate events as a contributing factor in the onset or worsening of various types of personal violence, conflict, or social instability. They find that deviations from normal precipitation and mild temperatures substantially increase the risk of conflict, and they conclude that there is more agreement across studies on the impact of climate on human conflict than previously recognized. ${ }^{151}$

\section{Critique and Discussion of the Empirical Literature}

Findings in the empirical climate security literature vary widely and frequently, offering only distant relevance for NATO. In particular, the IPCC notes that "much of the literature on human security and climate change is informed by contemporary relationships hence is limited in understanding the implications of rapid or severe climate change." 152 That is, in seeking to establish causal connections between environmental factors and conflict, empirical research reveals little about potentially unprecedented future climate change and security. ${ }^{153}$ In short, this approach does little to answer broader questions about security, and so is largely insufficient and poorly suited for NATO policy debate. ${ }^{154}$

While empirical modeling is useful insofar as it reveals insights concerning past and present impacts of climate change, it is inadequate to represent the climate-security relationship in a way that fully captures its range and complexity. Busby observes that many approaches are rooted in

${ }^{149}$ Solomon M. Hsiang, Mark A. Cane, and Kyle C. Meng, "Civil Conflicts Are Associated with the Global Climate," Nature 476 (2011).

${ }^{150}$ Solomon M. Hsiang and Marshall B. Burke, "Climate, Conflict, and Social Stability: What Does the Evidence Say?," Climatic Change 123, no. 1 (October 17, 2013): 39-55.

${ }^{151}$ Solomon M. Hsiang, Marshall B. Burke, and Edward Miguel, "Quantifying the Influence of Climate on Human Conflict.," Science 341, no. 6151 (September 13, 2013).

${ }^{152}$ Adger et al., "Human Security," 23. Paleo-climate records indicate that the last few decades of observed climate data do not represent the full natural variability of many important climate variables. A. Lavell et al., "Climate Change: New Dimensions in Disaster Risk, Exposure, Vulnerability, and Resilience," in Managing the Risks of Extreme Events and Disasters to Advance Climate Change Adaptation. A Special Report of Working Groups I and II of the Intergovernmental Panel on Climate Change, ed. C. B. Field et al. (Cambridge, United Kingdom and New York, NY, USA: Cambridge University Press, 2012), 46. citing Bjørg Risebrobakken et al., "A High-Resolution Study of Holocene Paleoclimatic and Paleoceanographic Changes in the Nordic Seas," Paleoceanography 18, no. 1 (2003).

153 Read, "Embracing Uncertainty: Scenario Planning for Climate Change Security Challenges and Opportunities," 61; Adger et al., "Human Security."

${ }^{154}$ Read, "Embracing Uncertainty: Scenario Planning for Climate Change Security Challenges and Opportunities," 56, 57, 61. 
the concept that the range of climate conditions for a given area occur within a static envelop of variability that is defined by past extremes (stationarity), but that past conditions may be a poor indicator of how climate risks could interact with social factors to generate disasters, instability, and conflict. ${ }^{155}$ Briggs notes similarly that "scarcity-conflict models relied upon traditional models of security as interstate conflict, and largely assumed linear relationships in terms of both causality and decision-making.,"156

Though the empirical research has grown stronger over time, it suffers from shortcomings. This is, in part, because to draw a linkage between climate and quantitative indicators of conflict requires rigid definitions of conflict. Security, as defined by the number of deaths that occur under precise circumstances (a necessity for empirical research, as are coded datasets on this issue), fails to appreciate the range of security interests of concern to NATO. This creates a misalignment between the empirical and academic research, and the climate security risk addressed in this dissertation.

In fact, even the most credible quantitative analyses on climate and security do not provide the type of information necessarily needed to design policy - such as the character, magnitude, timing, and location of the security impact. That is to say the models and quantitative analyses performed to this point provide no more value from a policy planning perspective than simply assuming the consequences will be dramatic.

Much of the existing environmental security research focused on the relationship between environmental degradation, environmental change, or resource scarcity and violent or armed conflict, but it is important to note that the absence of conflict does not necessarily equate to security. Conflict, especially violent conflict, is more easily quantifiable than an absence of conflict. Similarly, security tends to be more subjective and difficult to quantify. ${ }^{157}$

While violent conflict concerns NATO, its range of security interests is broad and may not be easily captured by metrics or indicators. Moreover, many anticipated environmental challenges are potentially unprecedented in human history. Read points out that empirical research has very clear limitations when examining or anticipating events that have never happened. ${ }^{158}$ It follows that the relevant historical data is not likely a benchmark of the variety of ways in which future security challenges may arise for NATO.

\section{Conclusions}

The academic literature reveals important misalignments when considering climate security with respect to NATO. Firstly, the research evaluated is based upon historical data that is unlikely to reflect the future environment (and interaction between human and natural systems) under conditions of unprecedented climate change. Secondly, the research typically uses models that

\footnotetext{
${ }^{155}$ Busby et al., "Of Climate Change and Crystal Balls: The Future Consequences of Climate Change in Africa," 1.

${ }^{156}$ Briggs, "Arctic Environmental Security and Abrupt Climate Change," 2.

${ }^{157}$ Read, "Embracing Uncertainty: Scenario Planning for Climate Change Security Challenges and Opportunities," 47.

${ }^{158}$ Ibid., 24.
} 
assume linearity in both the climate system and the human response, and it insufficiently accounts for the globally (or trans-boundary) cascading consequences that may arise from climate variation in other regions. Thirdly, the various definitions of security used in the literature do not correspond to the definition used by NATO.

The absence of historical data to establish a causal relationship does not justify dismissing all concerns. The reasons for this are discussed in the following paragraphs, but they must be understood in light of further important considerations. Despite inconclusive empirical results, concerns regarding climate change and security are justifiable when recognizing what is known about the factors that increase the risk of conflict, and that many of those are sensitive to climate change. ${ }^{159}$

Even with the analytic challenges, the IPCC concludes that climate change will be an increasingly important driver of (human) insecurity in the future, ${ }^{160}$ and that climate change and climate variability pose risks to security (arising through diverse pathways and likely through multiple, diverse, and interacting processes). ${ }^{161}$ Additionally, IPCC acknowledges that the high level of complexity suggests that no conceptual model or theory will capture the full extent of the interactions. ${ }^{62}$

While the research suffers from the shortcomings described above, the magnitude of plausible scenarios warrants the international security community to consider what preparations may be necessary and what interventions may be required at an unknown future point. ${ }^{163}$ Institutions such as NATO will need to anticipate and react to security risks that result from climate change, as these responses can "significantly dampen or amplify the way changes in climate change and extreme events give rise to human insecurity." "164

\footnotetext{
${ }^{159}$ Adger et al., "Human Security," 17.

${ }^{160}$ Ibid., 23.

${ }^{161}$ Ibid., 22.

162 Ibid.

${ }^{163}$ According to Dupont, "Policymakers around the world now accept there is sufficient scientific data to conclude that the speed and magnitude of climate change in the twenty-first century will be unprecedented in human experience, posing daunting challenges of adaptation and mitigation for all life forms on the planet." Alan Dupont, "The Strategic Implications of Climate Change," Survival 50, no. 3 (2008): 30.

${ }^{164}$ Adger et al., "Human Security," 22.
} 


\section{Chapter 3: Taking Stock of the Situation: NATO}

\section{Introduction}

This chapter first provides an overview of NATO's current posture toward climate security risk, surveying the history of NATO's institutional transformation, its current environmental policies, and its previous engagement and activities concerning the Middle East and North Africa (MENA) region and the Arctic. Looking at the history of NATO, the record suggests that large scale institutional change and transformation comes only when NATO is confronted by dramatic events; otherwise change at NATO is achieved incrementally.

The chapter then discusses two recent foresight efforts conducted by NATO's Allied Command for Transformation (ACT): The Strategic Foresight Analysis (SFA) and the subsequent Framework for Future Alliance Operations (FFAO). I discuss the relationship between these two efforts, as well as their outcomes. In particular, I identify three Instability Situations that will serve as the basis for analysis in subsequent chapters.

I conclude the chapter with a critique of the common characteristics among these scenarios, and a discussion of how each one compares to its counterpart in the core conclusions of the IPCC Summary for Policymakers. In so doing, I establish why the NATO ACT Instability Situations serve as a reasonable proxy for the perspective of NATO Headquarters with respect to the security consequences anticipated to result from climate change.

\section{NATO's Big Picture-What Future?}

In 2014, the NATO mission in Afghanistan transferred primary responsibility for security to the Afghan security forces, while NATO's International Security Assistance Force transitioned into a training and mentoring role. With this shift, NATO finds itself without a major military operation for the first time since the early 1990s, when Yugoslavia began to disintegrate (notwithstanding a resurgent and militarily assertive Russia). The military operation in Kosovo (KFOR) is now nearing its final stage, although a small NATO presence will likely remain for several more years.

As the other commitments draw to a close, NATO must, simultaneously, consider how it will adapt to a precarious international security environment. Russia's annexation of Crimea in the early months of 2014 brought renewed meaning to NATO's role as a collective security organization. NATO's engagement in Eastern Europe will require more attention and consideration moving forward. Conflicts further afield will need to be closely monitored. The civil strife in Syria continues to unfold along the southern border of Turkey. Furthermore, political fallout and tension throughout the MENA region - as well as Iran — suggests that NATO must divide its attention among several immediate, tangible, and conventional security matters.

Climate change will affect each of these regions, as well as the Arctic, in shaping the security landscape. As the security Alliance 'of choice,' NATO must carefully consider how to adapt to 
meet demands, prepare for new situations, as well as manage the unforeseen consequences. ${ }^{165}$ The IPCC notes that if extreme climate events increase significantly, adaptation and disaster risk management are likely to require transformative change in systems and institutional arrangements. ${ }^{166}$ This could involve a change in paradigm, shifts in perception, changes in underlying norms and values, and new patterns of interaction. ${ }^{167}$ How and to what extent these changes will compel similar changes within NATO, and with what means these changes will be implemented, is a complicated question to answer. What is clear is that NATO must consider its role in the context of climate security, and whether it can integrate a climate dimension into established mechanisms.

\section{Historical development and transformation of NATO}

"Transformation" can be defined as the evolution and adaptation of an organization in response to (or, in anticipation of) a changing environment. For an international security organization such as NATO, this process is driven primarily by the changing nature of risks or 'security threats' for which it must prepare. Combined with the objectives NATO seeks to achieve, these security threats drive the development of capabilities, policies, and procedures. Transformational policies can be employed to promote adaptation, although in many cases a 'focusing event' precipitates those policies.

In the case of NATO, perhaps the most salient example of a focusing event is the end of the Cold War. NATO was established following World War II as an alliance to serve as a military and political counterweight to the Soviet Union. The fall of the Soviet Union compelled NATO to reassess its purpose when its original raison d'etre had disintegrated. The fall of the Soviet Union created new political dynamics with the independence of many Warsaw Pact countries, a re-awakening of suppressed political aspirations, and a realignment of political orientation (for many of them).

While several Warsaw Pact countries made relatively smooth transitions to democracy and aligned themselves with NATO and Western Europe, states within the former Yugoslavia witnessed their attempts to establish independence descend into civil turmoil and armed conflict that destabilized the western Balkans throughout the 1990s. These conflicts presented Western Europe and many NATO allies with an ongoing security and refugee crisis along its periphery. This new security dynamic, one very different from those confronted during the Cold War era, forced NATO to adapt (or 'transform') itself into an organization that conducts peacekeeping operations and post-conflict stabilization.

The post-Cold War era forced NATO to adopt a new ethos, develop new capabilities, establish new policies and programs, and operate in ways fundamentally different from the past. Other paradigm-shifting events, like the attacks of September 11th demonstrate that the nature in which the world changes can place new demands upon, and propel change within, organizations such as

\footnotetext{
${ }^{165}$ Rühle, "NATO and Emerging Security Challenges: Beyond the Deterrence Paradigm," 278-79.

166 O'Brien, Pelling, and Patwardhan, "Toward a Sustainable and Resilient Future," 465. IPCC:

"Transformation can be defined as a fundamental qualitative change, or a change in composition or structure that is often associated with changes in perspectives or initial conditions."

${ }^{167}$ Brian Walker et al., "Looming Global-Scale Failures and Missing Institutions," Science 325 (2009): 7-8.
} 
NATO. They force the organization to recognize and respond to a fundamentally new environment for which it must adapt its policies, political relationships, and operational concepts.

The present era introduces yet another element of uncertainty that could demand transformation within NATO: the potential for climate-induced change in the natural environment with globally cascading influence on social and political systems. While the implications are not fully known, it is evident from the contemporary literature surveyed in the previous chapter that it is now widely feared that this new environment will see greater instability and increased demand for security organizations such as NATO.

\section{NATO, Climate, and the Environment ${ }^{168}$}

Throughout the past decade, NATO has recognized the direct influence of climate on security. Yet, NATO's involvement in climate and environmental security is modest in light of the significant attention climate change receives in academic journals, by other international organizations, and from individual NATO member states. All the while, NATO efforts are mostly directed at maintaining basic awareness of the issue, sponsorship and participation in events, or providing assistance to partnership countries. ${ }^{169}$

The NATO Parliamentary Assembly has consistently supported a global response to climate change, and repeatedly called to include climate change in NATO's political agenda. ${ }^{170}$ In 2015 , the NATO Parliamentary Assembly Science and Technology Committee released a report to draw attention to the security consequences of climate change, and to encourage NATO member states to support a climate agreement during the 21st Conference of the Parties (COP21) to the United Nations Framework Convention on Climate Change (UNFCCC). ${ }^{171}$ In 2009, the NATO Parliamentary Assembly released a report on the potential security consequences of climate change. ${ }^{172}$ In 2010, 2007, and 2005, the NATO Parliamentary Assembly released reports that focused on the relevance of climate change for NATO. ${ }^{173}$ In 2014, the NATO Parliamentary

168 NATO divides its environmental perspective into two categories: Environmental Protection and Environmental Security. The focus of this dissertation falls more directly on the latter than the former. Environmental protection issues addressed by NATO have been limited largely to technical issues surrounding the environmental impact of military operations and the necessity to limit environmentally harmful consequences. NATO's efforts in this realm seek to promote cooperation and standardization of operating principles among NATO and partner countries. These measures to protect the environment range from safeguarding hazardous materials (including fuels and oils), to treating waste water and managing waste, to putting environmental management systems in place during NATO-led activities. NATO, "Environment-NATO's Stake," 2014.

${ }^{169}$ In the context of NATO, 'partners' refers to nations who are involved with NATO through the Partnership for Peace Program.

${ }^{170}$ NATO Parliamentary Assembly, "Climate Change, International Security and the Way to Paris (2015 Draft Special Report)," 2015.

${ }^{171}$ Ibid.

${ }^{172}$ NATO Parliamentary Assembly, "Climate Change and Global Security,” 2009.

${ }^{173}$ NATO Parliamentary Assembly, "Security at the Top of the World: Is There a NATO Role in the High North?," 2010; NATO Parliamentary Assembly, "Climate Change: Thinking Beyond Kyoto," 2007; NATO 
Assembly Science and Technology Committee visited the IPCC Secretariat in Geneva, Switzerland to discuss the IPCC Fifth Assessment Report. ${ }^{174}$

The 2010 Strategic Concept, ${ }^{175}$ which identifies crisis management as one of NATO's core tasks, contains a reference to climate change, as do the Declarations from the 2014 Wales Summit, the 2012 Chicago Summit, and the 2010 Lisbon Summit. The Lisbon Summit, in particular, noted that,

[k]ey environmental and resource constraints, including health risks, climate change, water scarcity, and increasing energy needs will further shape the future security environment in areas of concern to NATO and have the potential to significantly affect NATO planning and operations. $^{176}$

Current and previous Secretaries General have acknowledged the potential security consequences of climate change. For example, in 2008, Secretary General Jaap de Hoop Scheffer acknowledged the potential for security concerns that no single nation could address independently expected from climate change. ${ }^{177}$ Shortly thereafter, NATO Secretary General, Anders Fogh Rasmussen raised the issue of climate-induced security consequences in 2009, suggesting that NATO become a "clearing house for the security-related challenges of climate change," and noting that dealing with the security consequences of climate change is not a choice. $^{178}$

NATO has used the Science for Peace and Security program to understand the environmental aspects of defense issues since $1969,{ }^{179}$ and to facilitate discussion amongst climate scientists beginning in the 1980s. The latter initiatives include support for multiple workshops and other events on climate security and environmental change, as well as projects to assess vulnerable regions and to help partner countries prepare for environmental challenges. ${ }^{180}$ The Science for Peace and Security program also sponsored a series of research projects on Environmental Security. $^{181}$

Parliamentary Assembly, "Climate Change in the Arctic: Challenges for the North Atlantic Community," 2005.

${ }^{174}$ NATO Parliamentary Assembly, "Climate Change, International Security and the Way to Paris (2015 Draft Special Report)."

${ }^{175}$ NATO, "Strategic Concept," Generic, (2010).

176 NATO, "Wales Summit Declaration," 2014; NATO, "Chicago Summit Declaration," 2012; NATO, "Lisbon Summit Declaration," 2010.

${ }^{177}$ Jaap De Hoop Scheffer, "NATO: The Next Decade Speech by NATO Secretary General, Jaap de Hoop Scheffer, at the Security and Defence Agenda" (Brussels: NATO, 2008).

${ }^{178}$ Anders Fogh Rasmussen, "NATO and Climate Change" (Brussels: Huffington Post, 2010).

${ }^{179}$ NATO, "NATO_Topic : Environmental Security," 2011.

${ }^{180}$ A catalog of research and workshops sponsored or conducted under the auspices of Science for Peace and Security for the period 2002-2012 can be found here: http://www.nato.int/science/2012/scientific_publications.pdf

181 A list of the research produced as a result of this series can be found here: http://www.nhbs.com/series/159431/nato-science-for-peace-and-security-series-c-environmental-security. 
National representatives in NATO committees and working groups have responsibility for climate- and environment-related issues.

- NATO's Military Committee Working Group on Meteorology and Oceanography helps NATO members and partner countries understand how, with national civil or military capabilities or within a collective capability, to assess and prepare for climate change and related national security threats. ${ }^{182}$

- NATO's Civil Emerging Planning Committee (CEPC) provides NATO with civilian expertise in consequence management, humanitarian and disaster response, and protection of critical infrastructure. The CEPC also oversees the Euro-Atlantic Disaster Response Coordination Centre (EADRCC), ${ }^{183}$ which coordinates disaster relief efforts among NATO and partner countries, and in countries where NATO operates. ${ }^{184}$

NATO has responded to natural disasters or assisted civil emergencies in the past, ${ }^{185}$ including incidents caused by extreme weather events, such as those estimated to become more frequent (and severe) as a result of climate change.

- Since 2000, the EADRCC has organized natural disaster response exercises, and coordinated live response operations, on multiple instances-including several where extreme weather conditions played a role. ${ }^{186}$

- In September and October 2005, aircraft from the NATO Response Force delivered supplies to assist in the US response to Hurricane Katrina. ${ }^{187}$

- From October 2005 to February 2006, aircraft from the NATO Response Force provided an air bridge to deliver nearly 3,500 tons of supplies to Pakistan, following a devastating earthquake. Engineers and medical personnel were also deployed to assist in the relief effort. $^{188}$

- NATO operated an air bridge for humanitarian assistance to help Pakistan cope with unprecedented monsoon flooding in 2010. ${ }^{189}$

- In 2016, NATO deployed ships to the Aegean Sea to assist with the crisis of migrant smuggling from Syria. NATO agreed to monitor migrant flows and share information with Greek and Turkish coast guards, as well as the EU border control agency. ${ }^{190}$

\footnotetext{
${ }^{182}$ NATO, "Meteorology and Oceanography," 2011.

${ }^{183}$ The EARDCC was established in 1998. NATO, "Civil Emergency Planning," 2014.

${ }^{184}$ NATO, “Civil Emergency Planning Committee (CEPC),” 2011.

${ }^{185}$ The Euro-Atlantic Disaster Response Coordination Center is often used. In addition to the Civil Emergency Planning Committee, NATO also uses the Defense and Environmental Experts Group to focus on areas such as infrastructure and property issues arising from the management of defense estates, and the impact on soldiers of climatic and biological threats.

${ }^{186}$ NATO, "Euro-Atlantic Disaster Response Coordination Centre (EADRCC),” 2014.

${ }^{187}$ NATO, "NATO Response Force," 2014.

${ }^{188}$ Ibid.

${ }^{189}$ NATO, "NATO Aircraft to Deliver Humanitarian Relief Goods to Pakistan,” 2010.
} 
NATO's International Staff and International Military Staff have worked with non-governmental organizations and independent experts on climate by participating in roundtables and other initiatives:

- NATO is a member of the European Security Roundtable, which held an event on the security aspects of climate change in November 2013 entitled, "Challenges and Capabilities: Towards a European Response to Climate Insecurity.",191

- In 2004, NATO joined the Environment and Security Initiative (ENVSEC); ${ }^{192}$ other members include the United Nations Environment Program (UNEP), the United Nations Development Program (UNDP), the Organization for Security and Co-operation in Europe (OSCE), United Nations Economic Commission for Europe (UNECE), and the Regional Environment Center for Central and Eastern Europe (REC).

Following the Chicago Summit in 2012, where allies agreed to "work together towards significantly improving the energy efficiency of our military forces," the Emerging Security Challenges Division (ESCD) launched the NATO Smart Energy Team (SENT), which seeks to identify national energy efficiency projects to pursue on a multinational basis. ${ }^{193}$ In 2012 , the ESCD also hosted a roundtable on climate security risks, ${ }^{194}$ and a workshop on energy and environmental risks facing the Alliance. ${ }^{195}$

Other initiatives work on similar goals. The multinational NATO Military Engineering Centre of Excellence (Ingolstadt, Germany), and the Energy Security Centre of Excellence (Vilnius, Lithuania), devote part of their work to energy efficiency by developing policies, training courses, and concepts. In 2003, NATO held a workshop to discuss "Security issues related to desertification in the Mediterranean region." 196

${ }^{190}$ Politico Brussels, "Playbook Cocktails with Jens Stoltenberg” (Brussels, 2016); Yuri M. Zhukov, "NATO’s Mediterranean Mission: What the Alliance Is Doing in the Aegean Sea," Foreign Affairs, 2016, https://www.foreignaffairs.com/articles/europe/2016-02-21/natos-mediterranean-mission.

191 “European Security Round Table," n.d., http://www.security-round-table.eu/esrt/index.php.

192 ENVSEC focuses on eastern and southeastern Europe, the South Caucasus, and Central Asia. Their climate change work involves technical assistance to enhance knowledge of climate change impacts and their interrelation with security: vulnerability assessments of climate change induced security impacts; support to regional dialogue and cooperation; information sharing and regional coordination; strengthening policies, institutions and capacities on national and regional levels to address climate change risks and develop regional adaptation strategies; and facilitating risk communication and raising awareness on security impacts of climate change: information dissemination, establishment and support to knowledge networks. See http://www.envsec.org

193 NATO, "NATO's Energy Security Agenda," NATO Review Magazine, 2014, http://www.nato.int/docu/review/2014/NATO-Energy-security-running-on-empty/NATO-energy-securityagenda/EN/index.htm.

194 "Round Table on Climate Security Risks, March 21, 2012 NATO HQ, Brussels" (Brussels, 2012).

${ }^{195}$ NATO, "NATO Workshop Focuses on Energy and Environmental Risks Facing the Alliance," 2012.

${ }^{196}$ NATO, "Security Issues of Desertification in the Mediterranean Region Debated at NATO Workshop" (2003), 2 Dec. 2003. 


\section{NATO and Middle East/North Africa}

With a longstanding relationship with several North African countries in the Mediterranean, assistance to the African Union (with respect to Darfur), humanitarian support in Somalia, and the 2011 military intervention in Libya, NATO has recognized that it must be available to play a role in African security affairs. NATO's principal platform for engagement in the region is the Mediterranean Dialogue. However, it also partnered with the African Union to provide airlift for peacekeepers to the UN Mission in Darfur. NATO's intervention in Libya helped end the dictatorship of Muammar Gaddafi, although relations with the African Union suffered as a result. NATO ships, submarines, and planes patrolled Libya's coast to enforce the UN arms embargo, and NATO planes enforced the UN-mandated no-fly zone over Libya. ${ }^{197}$

\section{NATO and the Arctic}

The melting of the polar ice caps will enable enhanced maritime access and natural resource exploration in the Arctic region, where the impact and rate of change (stemming from climate change) are significant, and where temperatures have been increasing at about twice the global rate over the past four decades. ${ }^{198}$ In 2013, Smith-Windsor also recognized these characteristics and their implications for NATO:

by virtue of the Washington Treaty, all 28 member states have a collective interest and responsibility [in the Arctic] ... [T] he particularly challenging operating conditions of the High North, where no one nation has the capacity to act alone, also explain the logic of more, not less Allied collective engagement, leveraging shared capacities and experience. ${ }^{199}$

NATO Secretary General Jaap de hoop Scheffer cited these issues and their potential consequences in 2009 in his statement at a NATO conference on security in the high north. ${ }^{200}$ The acknowledgement that the Arctic region will require more attention from the Alliance moving forward was noteworthy, Smith-Windsor observes, because "it represented the first serious consideration of the Alliance's interest and role in the region since the conclusion of the Cold War."201

A 2010 report from the NATO Parliamentary Assembly noted that, while the Arctic was important strategically during the Cold War, it became less important post-1989, and it has only

${ }^{197}$ Anders Fogh Rasmussen, “'Hungry for Security: Can NATO Help in a Humanitarian crisis?'-Speech by NATO Secretary General at Erasmus University, Rotterdam, the Netherlands" (Rotterdam: NATO, 2011).

${ }^{198}$ Daniel G. Huber and Jay Gulledge, "Extreme Weather \& Climate Change: Understanding the Link and Managing the Risk" (Arlington, Virginia: Center for Climate and Energy Solutions, 2011), 1.

${ }^{199}$ Brooke A. Smith-Windsor, "Putting the 'N' Back into NATO: A High North Policy Framework for the Atlantic Alliance?" (Rome: NATO Defense College, 2013), 10.

${ }^{200}$ Jaap De Hoop Scheffer, "Speech by NATO Secretary General Jaap de Hoop Scheffer on Security Prospects in the High North" (Brussels: NATO, 2009).

${ }^{201}$ Smith-Windsor, "Putting the 'N' Back into NATO: A High North Policy Framework for the Atlantic Alliance?," 1. 
now re-emerged in importance as a result of a changing climate. ${ }^{202}$ This report cites fisheries and tourism as interests for North Atlantic countries in the region, in addition to those de hoop Scheffer noted above, identifying China's considerable interest in the Arctic, since the Northern Sea Route and the Northeast and Northwest Passages will allow for shorter shipping routes that provide access to the ports of Europe and the east coast of North America. This report acknowledges Russia's assertiveness in exploring and claiming territory, its military presence and activity, and the amount of Russian natural resources in the area.

While the Arctic does not appear in the 2010 Strategic Concept and is absent from the 2012 Chicago Summit Declaration, the 2010 Group of Experts report identified NATO's need to enhance its situational awareness in the High North. ${ }^{203}$ Other observers recognize that "air and maritime surveillance platforms operated by the military could contribute significantly in Arctic security." ${ }^{204}$ NATO's presence in the High North includes the NATO Integrated Air Defense System (NATINADS), which includes fighters on Quick Reaction Alert (QRA), AWACS airborne early warning flights, and exercises in Norway and Iceland. ${ }^{205}$

In January 2009, NATO members gathered in Iceland to consider the changing maritime domain in the Arctic, ${ }^{206}$ and Norway supported a role for NATO in the Arctic in a NATO Parliamentary Assembly session in Oslo in May 2009. ${ }^{207}$ Norway has actively promoted NATO's capabilities, interoperability, operational experience, and partnership frameworks (along with Russia) to fill the Arctic's 'collective' security void. ${ }^{208}$ Norway has particular interest in Arctic security, given both its coastline and a border with Russia in the area. ${ }^{209}$ Since 2006, NATO conducted cold

${ }^{202}$ NATO Parliamentary Assembly, "Security at the Top of the World: Is There a NATO Role in the High North?"

${ }^{203}$ NATO, "NATO 2020: Assured Security; Dynamic Engagement. Analysis and Recommendations of the Group of Experts on a New Strategic Concept for NATO," Generic, (2010), 41.

${ }^{204}$ Luke Coffey, "NATO in the Arctic: Challenges and Opportunities" (Washington, DC: The Heritage Foundation, 2012), 2.

${ }^{205}$ Sven G. Holtsmark, "Towards Cooperation or Confrontation? Security in the High North" (Rome: NATO Defense College, 2009), 10.

${ }^{206}$ Klaus Dodds, "A Polar Mediterranean? Accessibility, Resources and Sovereignty in the Arctic Ocean," Global Policy 1, no. 3 (2010): 306.

${ }^{207}$ NATO Parliamentary Assembly, "Security at the Top of the World: Is There a NATO Role in the High North?," 15.

${ }^{208}$ Smith-Windsor, "Putting the 'N' Back into NATO: A High North Policy Framework for the Atlantic Alliance?," 5. Note, however, that the US and Canada have an Arctic Cooperation framework, and Norway, Denmark, Sweden, and Finland have a Nordic Air Policing mission. Sweden and Finland are non-NATO. A variety of types of military cooperation also takes place among the Scandinavian countries under the umbrella of 'Nordic Defense Cooperation' which merged previous transnational military and security related contacts among Nordic countries in 2009. Ann-Sofie Dahl, "NORDEFCO and NATO: 'Smart Defense' in the North?" (Rome: NATO Defense College, 2014).

${ }^{209}$ Coffey, "NATO in the Arctic: Challenges and Opportunities," 2. According to Smith-Windsor, "Concerns about provoking the Russian Federation (at the time already engaged in a substantial northern rearmament program of its own) and about giving countries with no High North geography undue influence in the region, were apparently at the heart of the Canadian policy calculus." Smith-Windsor, "Putting the 'N' Back into NATO: A High North Policy Framework for the Atlantic Alliance?" 
weather exercises termed 'Cold Response,' which incorporate a range of scenarios, including one involving resource-led conflict in the Arctic Ocean. ${ }^{210}$

Coffey observed (in 2012) that Russian air and submarine patrol activity in the Arctic and the North Sea has returned to Cold War levels, pointing out that "the North Sea Fleet is now the largest fleet in the Russian navy. Recently, Russia announced the reopening of airbases on archipelagos above the Arctic Circle that were closed at the end of the Cold War.",211

\section{Creation of NATO's Emerging Security Challenges Division}

In 2010, NATO established the Emerging Security Challenges Division (ESCD) to focus on nontraditional security threats. ${ }^{212}$ ESCD also maintains a strategic analysis capability to support political consultation among allies on potential crisis areas and to work with other organizations, such as the European Union, the United Nations, the Organization for Security and Co-Operation in Europe, and other partners, to 'head off' a crisis in advance. ${ }^{213}$ NATO's Deputy Assistant Secretary General for Emerging Security Challenges noted that, "the issues for which ESC has responsibility are not handled solely, or even primarily, by defense ministries or foreign ministries, which are the traditional interlocutors or channels through which NATO operates."214 The security consequences of climate change fall within the scope of this definition.

This section illustrates that NATO has clear interests in the environment and its relationship to security, and highlights two regions that are predicted to be severely impacted by climate change: MENA and the Arctic. NATO has recognized that the strategic importance of these interests could require military resources and new policy initiatives to protect its members under conditions of climate change. These examples also demonstrate that NATO has both recognized the influence of climate on international security and has previously contributed resources to security events that arise as a consequence of it. Indeed, NATO has a variety of established program and policy mechanisms (and military resources) through which it can prepare itself and its partners to play an important role within the climate-security context.

210 Dodds, "A Polar Mediterranean? Accessibility, Resources and Sovereignty in the Arctic Ocean,” 306.

${ }^{211}$ Coffey, "NATO in the Arctic: Challenges and Opportunities," 2.

212 NATO, "New NATO Division to Deal with Emerging Security Challenges," n.d. Also, the following provides a tidy overview and summary of the role of the Emerging Security Challenges Division: "'Emerging Security Challenges' has become a term used at NATO and in public policy debate to deal with potential, upcoming, non-traditional threats to our security. At NATO, they are defined as covering the issues of cyber security, counter terrorism, and energy security. But there is no consensus on substance and scope of these issues to be dealt with by the organization. These challenges are real, but meeting them does not fit into any traditional policymaking. Thus, the 'real' emerging challenge seems to be whether and how we have to change our policy patterns to effectively provide security from such threats." Partnership for Peace Consortium of Defense Academies and Security Studies Institutes, "Emerging Security Challenges," n.d., http:/www.pfpconsortium.com/\#! emerging-security-challenges/c1sda.

213 Jamie Shea, “Q\&A about NATO's New Division for Emerging Security Challenges," Atlantic Community (YouTube), 2011, https://www.youtube.com/watch?v=FziXbYrmAdk.

214 Ibid. 
While the 2011 intervention in Libya demonstrates that NATO is capable and willing to employ its resources in Africa when necessary, in an era of increasingly austere defense budgets throughout the alliance, NATO likely does not want to create expectations that it is available for regular military operations or long commitments in Africa. That NATO deflected a request for involvement in Mali in 2013 suggests either a high threshold to take action or that very specific interests must be at stake before it agrees to commit forces in Africa.

Russia's annexation of Crimea in Ukraine (early 2014) forced greater urgency for Arctic nations to shift their thinking with respect to Russia, and fundamentally altered the perspective on Russia more generally. For instance, Canada has long maintained a policy that precluded NATO in the Arctic. However, this position may have softened following Russia's annexation of Crimea. Given these circumstances and dynamics, the real question is then whether NATO needs to further develop a collective, institutional commitment to the region. ${ }^{215}$ NATO's initial focus appears to be on improving coordination of security-related issues, such as search and rescue. ${ }^{216}$

\section{NATO Foresight Efforts: The Future Security Environment}

In recent decades, NATO has employed foresight methodology ${ }^{217}$ to better understand the security challenges of the future, and to better understand how the Alliance may be required to adapt and transform. ${ }^{218}$ These efforts include NATO's Long Term Requirements Study ${ }^{219}$ (conducted in 2005), a 2009 scenario analysis by NATO's Allied Command Transformation (ACT) - 'Multiple Futures', ${ }^{220}$ and a 2011 study by NATO's Research and Technology

${ }^{215}$ NATO Parliamentary Assembly, "Security at the Top of the World: Is There a NATO Role in the High North?," 17.

${ }^{216}$ A good discussion of NATO in the Arctic can be found in Exner et al., who note that the "EU and NATO have been examining the issues of governance and security in the Arctic." Heather Exner-Pirot et al., "Climate Change \& International Security: The Arctic as a Bellweather" (Arlington, Virginia: Center for Climate and Energy Solutions, 2012), 3.

${ }^{217}$ Foresight methodology refers to the means used to conduct future studies to support long-term planning. Note the following observation of the IRGC (and that NATO's foresight efforts are consistent with the conceptual foundation of risk governance): "Humans have the ability to design different futures, i.e. construct scenarios that serve as tools for the human mind to anticipate consequences in advance and change, within constraints of nature and culture, the course of actions accordingly." Ortwin Renn, "Risk Governance-Towards an Integrative Framework" (Geneva: International Risk Governance Council, 2013), 23. Indeed, Briggs observes that "Despite the preponderance of effort spent on operational and tactical intelligence in government, the knowledge that is often most needed are long-term trends and ideas concerning 'what the world around us' will look like in the future. This is the purpose of foresight efforts, and the resultant scenario planning. Chad M. Briggs, "Environmental Security, Abrupt Climate Change and Strategic Intelligence" (Washington, DC: US Department of Energy, 2009), 4.

${ }^{218}$ These efforts have been conducted either by NATO's Research and Technology Organization, or by an NATO's Allied Command for Transformation; in both cases, their primary objective was to draw conclusions with respect to the operational or technological preparedness of the Alliance.

${ }^{219}$ Stephan De Spiegeleire et al., "NATO Future Worlds An Input into the NATO Long-Term Requirements Study," vol. 212 (The Hague, 2005). NB: I was unable to find the actual Long Term Requirements Study, which is unlikely to be publicly available; however, this product described a scenario analysis effort in support of it.

${ }^{220}$ NATO ACT, "Multiple Futures Project-Final Report,” 2009. 
Organization (RTO) entitled, 'Joint Operations 2030 '221 as well as a conference entitled 'Long Range Forecasting of the Security Environment,' to review national and international perspectives, methods, and supporting analytical techniques for long-range forecasting of the security environment. ${ }^{222}$

Other NATO foresight efforts have assessed emerging and disruptive technologies. ${ }^{223}$ For example, on 1 January 2015, the NATO Science and Technology Organization began a lecture series focused on 'Horizon Scanning and Strategic Futures Analysis,' to discuss methodologies, tools, and techniques on the current best practice in horizon scanning and strategic futures (HSSF) analysis. In 2011, the NATO Research and Technology Organization held a conference on risk-based planning. ${ }^{224}$

Since 2012, NATO ACT has conducted two additional foresight initiatives. The first of these, the Strategic Foresight Analysis, resulted in the NATO Strategic Foresight Report (SFA) 2013. The second initiative, which builds upon the first, is the Framework for Future Alliance Operations (FFAO). ${ }^{225}$ The joint SFA/FFAO efforts attempt to craft and exploit a unified view of the future security environment for the purpose of NATO strategic planning. The Strategic Foresight Analysis sought to understand the contours of the future strategic environment. The FFAO effort seeks to develop a conceptual framework for future NATO operations. ${ }^{226}$

Taken together, these two initiatives seek to shape thinking about the strategic environment, scenarios, and concept of operations for NATO in the year 2030. To be clear, that NATO ACT created the Instability Situations does not imply that they have been embraced by NATO Headquarters - even though they are fairly generic, and similar scenarios (and associated concerns) are expressed throughout the literature on climate change and security. Therefore, the Instability Situations should be viewed as a proxy for NATO (and the institutional perspective of the associated risks).

${ }^{221}$ NATO Research and Technology Organisation, "Joint Operations 2030-Final Report (Opérations Interarmées 2030-Rapport Final).”

${ }^{222}$ This effort brought together participants from 15 NATO and partner nations, and it featured presentations of papers submitted by subject matter experts from across the Alliance, industry and academia; it also considered the ways foresight analysis can be used to influence national defense policy; briefings are available here: https://www.cso.nato.int/pubs/rdp.asp?RDP=RTO-MP-SAS-088

${ }^{223}$ For instance, the May 2011 initiative on "Emerged/Emerging 'Disruptive' Technologies"; briefings available at https://www.cso.nato.int/pubs/rdp.asp?RDP=RTO-MP-IST-099

224 NATO, "NATO Risk Based Planning Conference (SAS-093)," 2011, https://www.cso.nato.int/Activity_Meta.asp?ACT=1714.

${ }^{225}$ Note that the 'futures' work conducted by NATO ACT (comprised of the SFA and FFAO) efforts seeks to establish a methodology to examine the future security environment with the intent to have the results support and inform the NATO Defense Planning Process, NATO ACT, "Framework for Future Alliance Operations Workshop \#2 Read-Ahead: Military Implications in a Complex Security Environment—Forging the Future Leading; NATO Military Transformation," 2013, 5. Also, The International Risk Governance Council includes the building of a capacity for surveillance (early warning) and foresight - as NATO has attempted to do-among eleven themes for improving the management of emerging risks. International Risk Governance Council, "Improving the Management of Emerging Risks" (Geneva, 2011).

${ }^{226}$ A variety of workshops have been held to push forward this effort. 
These initiatives recognize that the world is changing in ways that create new challenges and paradigm scenarios for NATO. They also reveal insight into how NATO views the underlying drivers of change, and the manner in which such changes threaten security in the future. Ultimately, their objective is to understand how NATO can best operate in the anticipated future environment. A quotation from the third Strategic Foresight Workshop captures the scope and intent of both the SFA and FFAO, succinctly:

[F]uture readiness and planning future capabilities in a complex and constantly evolving security environment demands extending the current mid-term 2020 planning horizon toward 2030 and beyond, where a different future security environment, its security and military implications and new broad strategic operating requirements are anticipated. ${ }^{227}$

Though the precise methodology is not described, both the SFA and FFAO convened with a wide range of participants. The Strategic Foresight workshops identified a variety of 'drivers' of the future security environment, with corresponding 'Security Implications.' The FFAO workshops built upon this work and created several 'Instability Situations' (and, later, 'Comprehensive Instability Situations'), three of which include climate/environmental change as a factor.

Seventy-eight (78) participants from twenty one (21) nations attended the SFA initiative, as well as personnel representing the NATO International Staff, NATO International Military Staff, NATO Allied Command Operations-Comprehensive Crisis and Operations Management Centre (CCOMC), NATO Allied Command Transformation, national ministries of defense, and national delegations to NATO. ${ }^{228}$ The FFAO initiative included national representatives, the NATO Military Committee, and the NATO Defense Policy and Planning Committee. ${ }^{229}$ Both also had participation from NATO Centers of Excellence (COE), think tanks, and from within academia.

Despite the participation from the NATO International Staff, the NATO International Military Staff, various other NATO components, and national delegations to NATO, policy planning efforts at NATO Headquarters are not bound to include the results of the workshops - or the corresponding insights - in their considerations. Political guidance approved by the Heads of NATO member states and governments provides direction on the number, scale, and nature of the operations the Alliance should be able to conduct. ${ }^{230}$ It also sets the aims and objectives to be met by NATO, defines the qualitative capability requirements, and includes associated priorities and timelines for policy planning. ${ }^{231}$ Two sets of political guidance (from 2006 and 2011) are in

${ }^{227}$ NATO ACT, "Strategic Foresight Analysis Workshop \#3 Final Report: The Shared Perspective of the World in 2030 and Beyond Security Implications," 2012, 2.

${ }^{228}$ NATO ACT, "Strategic Foresight Analysis Workshop \#1 Final Report: The World in 2030 and Beyond," $2012,2$.

${ }^{229}$ NATO ACT, "Framework for Future Alliance Operations Workshop \#1 Read Ahead: Ensuring a Mission Ready Alliance-Forging the Future, Leading NATO Military Transformation," 2013, 3-4.

230 NATO, "The NATO Defence Planning Process," 2014, http://www.nato.int/cps/en/natohq/topics_49202.htm.

${ }^{231}$ Ibid. 
effect as of mid-2016. However, both are broad enough to encompass the Instability Situations examined in this dissertation. ${ }^{232}$

This dissertation now focuses on the scenarios resulting from these two exercises to discuss the climate-related challenges seen as being most likely to develop and evolve with time. The analysis conducted in this dissertation complements, and further builds upon, the baseline perspective established in the SFA/FFAO efforts. It does this by diving deeply into one area that the Strategic Foresight Analysis Team acknowledged is a principle driver of the future security environment: climate. ${ }^{233}$

\section{NATO ACT Strategic Foresight Analysis}

The Strategic Foresight Analysis (SFA) effort comprised a series of workshops facilitated by NATO's Allied Command for Transformation (ACT) to map the contours of the future security environment. The overarching aim of the effort was to identify the principal themes (drivers) that would influence the world in 2030, create a shared perspective, identify the most likely scenarios that could present a risk (security implication), and describe them in a common language. ${ }^{234}$

Reaching consensus on the drivers that influence the future security environment was one objective of the Strategic Foresight Analysis initiative. ${ }^{235}$ By identifying and analyzing the defense and security implications that will shape the Alliance through 2030 and beyond, the SFA serves as a foundation to create a long-term perspective on the security environment for the Alliance. ${ }^{236}$ The examination of themes, trends, and implications, as well as their interactions, supports the alignment of future national and collective defense planning and capability development. $^{237}$

The Strategic Foresight Analysis (SFA) studied a range of publications on 'futures' to analyze similarities, differences, and gaps in their perspective of threats, challenges, and opportunities. The SFA workshops identified twenty 'drivers' of change, which were sorted into four groupings: Political, Human, Physical and Resources, and Economy. ${ }^{238}$ Eleven (11) drivers were

${ }^{232}$ NATO, "Comprehensive Political Guidance," 2006; NATO, "Political Guidance on Ways to Improve NATO's Involvement in Stabilisation and Reconstruction," 2011.

${ }^{233}$ NATO is focused on understanding the drivers that will shape the future security environment, according to page 3 of the following text: NATO ACT, "Strategic Foresight Analysis Workshop \#1 Read Ahead: Global Review," 2012.

${ }^{234}$ NATO ACT, "Strategic Foresight Analysis Workshop \#1 Final Report: The World in 2030 and Beyond," 2.

${ }^{235}$ NATO ACT, "Strategic Foresight Analysis Workshop \#1 Read Ahead: Global Review," 3.

${ }^{236}$ NATO ACT, "Strategic Foresight Analysis 2013 Report," 2013, 34.

${ }^{237}$ NATO ACT, "Framework for Future Alliance Operations Workshop \#1 Read Ahead: Ensuring a Mission Ready Alliance-Forging the Future, Leading NATO Military Transformation," 3,4. and NATO ACT, "Strategic Foresight Analysis 2013 Report," 34. According to page 3 of the latter document, the "Strategic Foresight Analysis sought to inform NATO's Political Guidance in accordance with AC/281-N(2012)0154REV9(R) Enhancing the NATO Defense Planning Process, 12 March 2013."

${ }^{238}$ Note that the 'change' referenced here does not solely refer the external security environment; while not precisely defined, in addition to security aspects, it also concerns changes within NATO member states and demographic/political dynamics that will affect the way the organization operates, such as the absence of a 
used to distill the future security implications most relevant to NATO: technology, global power dynamics, shared threat perceptions, global interconnections, demographics, resource competition, globalization of finance, health, disasters, weapons of mass destruction, and climate. $^{239}$

Climate was identified as a 'driver' of the future security environment across six (6) streams of publications (International Organizations, National Organizations and Governments, NGOs, Academic Institutions, and Industry) ${ }^{240}$ The literature revealed that the implications of climate change appeared most frequently, ${ }^{241}$ which the workshops characterized as increasing global temperatures, rising sea levels, warming oceans, receding glaciers, frequent droughts, and extreme weather events. ${ }^{242}$

The security risks of climate change identified by the SFA Workshop included the following: ${ }^{243}$

Driver: Climate Change. Extreme weather events increase in frequency and intensity. Increased occurrences of tropical cyclones, severe storms and tornadoes, coastal flooding, and drought cause extensive damage to infrastructure, arable land, habitat, and feedstock, creating conditions for insecurity and instability. Famine, drought, or flood driven populations force migration exacerbated by expanding transnational criminal and extremist activity, and border tensions will be a recipe for conflict.

Rising temperatures will contribute to the increasingly accessible Arctic and Antarctic regions. Ocean warming and reduced sea ice will foster greater access to and exploitation of previously inaccessible natural resources in the Arctic and Antarctic regions. Additionally, reduced seasonal ice no longer restricts use of maritime global trade routes prompting possible resource competition, which may expand beyond

shared threat perspective that could encumber the consensus process in the future. Moreover, the 'drivers' identified were not clearly delineated from each other, and several of the drivers were influenced by other drivers - climate change is listed as a driver, which has very clear potential to increase natural disasters and could also influence migration; however, both 'disasters' and 'migration' were listed as 'drivers' separately without reference to climate. NATO ACT, "Framework for Future Alliance Operations Workshop \#1 Read Ahead: Ensuring a Mission Ready Alliance-Forging the Future, Leading NATO Military Transformation.”

${ }^{239}$ Ibid., 4.

${ }^{240}$ NATO ACT, "Strategic Foresight Analysis Workshop \#1 Read Ahead: Global Review," 6. Note, there was no explanation as to what distinguished "National Organizations" from "Governments."

${ }^{241}$ Ibid., 4. The SFA effort reviewed 48 documents pertaining to the nature of the future security/operating environment. The sources for these documents varied widely, including think tanks, national and international governmental organizations, and the private sector. One publication came from Shell Corporation, one from India, and yet another from the Russian Academy of Sciences. A full list of the documents reviewed can be found at the following link: http://www.act.nato.int/images/stories/events/2012/fc_ipr/sfa_literature_review.pdf.

${ }^{242}$ NATO ACT, "Strategic Foresight Analysis Workshop \#2 Read Ahead: The Shared Perspective of the World in 2030 and Beyond Themes and Drivers," 2012, 3.

${ }^{243}$ NATO ACT, "Framework for Future Alliance Operations Workshop \#1 Read Ahead: Ensuring a Mission Ready Alliance-Forging the Future, Leading NATO Military Transformation," 8. 
traditional Arctic Council nations and affect NATO members with regional interests or actual territorial claims.

The SFA final report noted the impact of climate change is "becoming apparent throughout the world and is projected to intensify; record numbers of climate events and extreme weather will demand an increase in humanitarian assistance, disaster relief and recovery operations." 244 Moreover, the SFA also recognized the impact of broader environmental change, noting "other environmental threats like air and water pollution or deforestation may contribute to insecurity and instability.",245

The final Strategic Foresight Analysis report (2013) paid significant attention to climate change. Although the perspective expressed in the final report lacks the precision one may find in academic publications, it demonstrates an awareness of the big picture and its implications. The following includes the most relevant points from the final report with regard to climate:

Although the exact consequences of this warming are unknown, climate changes are expected to have adverse, unstable and unpredictable effects on land, sea, and the atmosphere ...

Impacts on the environment from increasing temperatures will be profound. Increased seawater temperature and melting ice worldwide, especially from the polar icecaps, will increase average global sea-levels. Nations will face the challenge of protecting growing mega-cities, most of which are near coastlines, from the impact of rising seas. Although warmer atmospheric conditions will increase precipitation in some areas, there will be less freshwater available in others. Due to the overall temperature increases, severe weather events are likely to become even more extreme (e.g. hurricanes and other storms will intensify, while floods and droughts become more common). These changes will reshape the environmental landscape, agriculture patterns and available land for human habitation.

Notwithstanding the longer term environmental effects of a changing climate, the threat of unforeseen catastrophic disasters is ever-present. These include natural events such as massive earthquakes or tsunamis (e.g. as experienced by Japan in 2011, which brought about the Fukushima nuclear plant meltdown), or man-made actions (e.g. the Chernobyl nuclear plant explosion). The resulting devastation will be greatly magnified in heavily populated areas or mega-cities, and will require significant international aid and assistance in the post-event recovery period.

Global environmental change and its impacts are becoming readily apparent and are projected to increase in the future. In some areas these changes could present benefits, such as less energy requirements for heating, longer growing seasons that allow increased agricultural

\footnotetext{
${ }^{244}$ NATO ACT, "Strategic Foresight Analysis Workshop \#3 Final Report: The Shared Perspective of the World in 2030 and Beyond Security Implications," 7.

${ }^{245}$ NATO ACT, "Strategic Foresight Analysis 2013 Report," 2.
} 
production, and the opening of the Arctic for resource exploration and shipping traffic. However, these benefits are likely to be offset by negative effects elsewhere, including coastal inundation, desertification, deforestation and other ecological effects that will have a direct impact on the world's fresh water and food. Water stress is expected to be the most inevitable near-term impact of climate change.

IMPLICATIONS a. Increased humanitarian assistance and disaster relief operations due to extreme weather events. More frequent hurricanes, typhoons, flooding and droughts will cause significant environmental and infrastructure damage, and human suffering. These events create conditions of insecurity and instability that can lead to mass population movement, and an increased demand for humanitarian assistance and disaster relief operations which will strain Nations' diminishing economic and military resources.

b. Increased access to the Arctic region. Ocean warming and melting ice packs will potentially allow increased exploitation of natural resources in previously inaccessible regions. Seasonal ice may no longer restrict the use of Arctic maritime trade routes, significantly reducing transit time, notably between Europe and Asia. More activity in the Arctic will raise issues over environmental impact, search and rescue responsibilities, and resource competition. This will require increased public safety and security awareness by Alliance nations bordering this region, or other nations with interests in the region.

c. Increased potential conflict due to water scarcity. Water scarcity already affects almost every continent and more than $40 \%$ of the people in the world. By 2030, 47\% of the world's population are forecast to be living in areas of high water stress. Most population growth will occur in developing countries in regions already experiencing water scarcity. Competition to access and control water sources will increase the possibility of conflict and instability in those regions.

NATURAL DISASTERS: The effects of natural disasters will become more devastating. Natural disasters (e.g. earthquakes, tsunamis, volcanic eruptions, meteor strikes) will occur with devastating impacts on humanity. Increased population and infrastructure in disaster prone areas will magnify the consequences of these natural disasters.

IMPLICATIONS: An increased requirement for international responses to catastrophes. Major natural disasters, which cause large-scale devastation, result in a serious loss of life and substantial destruction of infrastructure with severe consequences to the economy and security of affected nations. Although primarily a national responsibility, the international community would normally respond and NATO may be requested to provide assistance as part of a comprehensive or integrated approach. ${ }^{246}$

${ }^{246}$ Ibid., $30-32$. 
The foregoing summary is set forth in broad brushstrokes to capture the range of security risks that could arise from climate change. The security implications generated through the SFA process were later refined during the first FFAO workshop and categorized according to their relevance to NATO's three (3) core tasks: Collective Defense, Cooperative Security, and Crisis Management. $^{247}$

\section{NATO ACT_Framework for Future Alliance Operations}

The NATO FFAO initiative is a continuation of the Strategic Foresight Analysis. ${ }^{248}$ If the SFA was foundational in setting the strategic context by establishing a shared perspective of the longterm future, then the FFAO developed its corresponding concept for how NATO will operate in that future. ${ }^{249}$ The FFAO seeks to deliver four (4) outputs: (1) a Future Organizing Concept, informed by (2) a set of Broad Strategic Insights, and (3) associated capability implications, pursuant to (4) an assessment of mission types to inform a future capability hierarchy framework. $^{250}$

The first FFAO workshop grouped the twenty-eight (28) security implications identified in the SFA according to NATO's three (3) core tasks (Collective Security, Crisis Management, and Cooperative Security). The security implications also served as a basis to craft Future Characteristics Models (futures scenarios) from which to identify Broad Strategic Requirements and implications for military capabilities. ${ }^{251}$

Crisis Management was divided into two (2) areas of responsibility: The first area included Counter-Terrorism, Peace Keeping, Peace Enforcement, and Conflict Prevention; the climaterelevant security implications were grouped in the second area, which included Consequence Management, Humanitarian Assistance, Disaster Relief, Extraction Operations, Enforcement of Sanctions and Embargoes. ${ }^{252}$ Within this context, participants determined (and ranked) the

${ }^{247}$ Note that the categorization referenced in this sentence was not specifically evident in any of the Strategic Foresight Analysis documents publicly available. However, the final report for the first FFAO Workshop indicated that this occurred. NATO ACT, "Framework for Future Alliance Operations Workshop \#1 Final Report-Leading NATO Military Transformation," 2013.

248 The FFAO is a qualitative approach to requirements development; note that Joint Operations 2030 attempted this and failed.

${ }^{249}$ NATO ACT, "Framework for Future Alliance Operations Workshop \#1 Read Ahead: Ensuring a Mission Ready Alliance-Forging the Future, Leading NATO Military Transformation," 9-10. Note that the Annex of this document contains a useful description of NATO's three 'Core Tasks' in addition to explanatory examples.

${ }^{250}$ NATO ACT, "Framework for Future Alliance Operations Workshop \#1 Final Report-Leading NATO Military Transformation," 10.

${ }^{251}$ NATO ACT, "Framework for Future Alliance Operations Workshop \#1 Read Ahead: Ensuring a Mission Ready Alliance-Forging the Future, Leading NATO Military Transformation," 3-4. This document notes that the process proceeded "iteratively and transparently."

${ }^{252}$ NATO ACT, "Framework for Future Alliance Operations Workshop \#1 Final Report-Leading NATO Military Transformation," 6-7. 
security implications according to their impact with respect to military support to civilian authorities (and, thus, the Comprehensive Approach): ${ }^{.25}$

[N] atural and man-made disasters emerged as the top ranked security implication, having the greatest impact in terms of scope and breadth and ties to the results of climate change. Issues surround the use of NATO forces in this capacity and the challenges concerning law enforcement versus military authority were vigorously discussed. This same point was also reflected in the discussion of UN mandated versus NATO mandated operations. The group acknowledged that in most cases international organizations, non-governmental organizations (IO/NGO) are better suited for humanitarian assistance and disaster relief (HA/DR) missions than were NATO assets.

Extreme weather resulting from climate change ranked third and was expected to not only result in more HA/DR missions, but also be a factor in conducting all operations under harsher environmental conditions. The group conceded that NATO's involvement will be interest driven, political will vs. public support reflecting the resource and capability constraints as well as commitment to assist those in need.

Resource competition was ranked by the syndicate as the fourth highest concern. The group pondered the question; do different resources have a different impact? This may suggest an influence on cohesion among member nations and may have crucial operational overall. Note: this raised the issue of the need for broader policies on critical infrastructure protection and intervention when conflicts over resources affected Alliance stability and security.

Note that it appears the Strategic Foresight Analysis report (2013) was released in the period between the first and second FFAO workshops (between February and July 2013). In the latter, the workshop document refers to "5 themes, 15 trends, and 34 implications for NATO" which, though consistent with the publicly released version of the Strategic Foresight Analysis, differs from the "10 drivers and 28 implications" that the SFA workshops had produced. One of the key differences between these two FFAO workshops is that the " 5 themes, 15 trends, and 34 implications for NATO" present themselves largely as external security factors for which the Alliance must prepare, with the exception of a mild reference to 'multiple threat perceptions.'

Just as in the final SFA report, the environmental theme includes the following: ${ }^{254}$

Environmental/Climate Change: Global environmental change and its impacts are becoming readily apparent and are projected to increase in the future. Increased humanitarian assistance and disaster relief operations due to extreme weather events. Increased access to the Arctic region. Increased potential conflict due to water scarcity.

\footnotetext{
253 Ibid.

${ }^{254}$ NATO ACT, "Framework for Future Alliance Operations Workshop \#2 Read-Ahead: Military Implications in a Complex Security Environment—Forging the Future Leading; NATO Military Transformation," 11.
} 
Natural Disasters: The effects of natural disasters will become more devastating. The increased requirement for international responses to catastrophes.

The second FFAO Workshop developed nine (9) Future Characteristics Models (FCMs, which are 'futures scenarios') of which three (3) appear as phases of a larger interrelated trend, when interpreted along the climate dimension.

The first scenario, 'Approaching Storm,' is an extension of today's world. That is to say, the least resilient states are at risk of the greatest climate impact, population growth leads to migration, increasingly frequent and severe weather events require specific capabilities for humanitarian assistance and disaster relief, and resource depletion increases competition for resources in the High North. ${ }^{255}$

The second scenario, 'Snowball Effect,' sees population growth interact with natural disasters, resource scarcity, and environmental change to induce migration that leads to urbanization, fractured identities, and changing demographics. The maturation of this scenario is reflected in the third scenario, 'Metropolis' in which a highly urbanized (regional/global) society (a consequence, in part, of environmental/climate change and natural disasters) and the corresponding demographic and development challenges present new features to the security landscape.

The FCMs serve as the narratives from which the third FFAO workshop derived six (6) Broad Strategic Insights, all of which have policy (and risk governance) implications for the political level of NATO:

Strategic Awareness: a deliberate focus on strategic level challenges and opportunities to synchronize and align military planning and organization with political intent. Institutions and states face a rapidly growing range of security challenges including those presented by transnational and nonstate actors. At the same time, individuals may be less connected to the state and traditional institutions. These related trends, coupled with greater interconnectedness, increase uncertainty and unpredictability on a global level. However, they may also prompt opportunities. A comprehensive and long-term understanding of the environment and associated cultures would enable greater strategic awareness to address those challenges.

Strategic Narrative: the planned engagement of specific audiences with messages that impact NATO's Core Tasks to synchronize and align military planning and organization with political intent. Currently, the Alliance has a diversified mix of strategic messages that are not necessarily synchronized or arranged to support Core Tasks. Maximizing understanding of NATO's purpose and goals involves incorporating Alliance messages within a plan of engagement. Such planning promotes complementary action to align with political intent by a range of distinct audiences. NATO could develop and implement a Strategic Narrative that

${ }^{255}$ NATO ACT, "Framework for Future Alliance Operations Workshop \#5 Read Ahead-Strategic Military Perspectives," 2014, 5. 
clarifies Alliance positions and policies by establishing communication and engagement goals, identifying and understanding relevant audiences, and providing straightforward content. Implementing such an engagement strategy is a key to success in the battle of the narrative.

Focused Protection: limited NATO protection for specific groups of people, infrastructure, organizations, and capacities-confined in scope, scale, and duration of action. Focused Protection anticipates a future when NATO could extend early limited protection to those people or things that could, if left unprotected, lead to a decline in Alliance security. Therefore, Focused Protection would advance in different phases and could begin before a crisis event occurs. Such early action requires the development of advanced predictive analysis capabilities and global knowledge networks for situational awareness. The awareness requirement creates a need for developing and maintaining relationships with like and non-likeminded nations to understand and protect the flow of goods and services.

Shared Resilience: sufficient reserve capacity across the defense and security community to provide a shared ability to withstand strategic shock. Resilience should also include structures and systems, with the capability for rapid recovery, and the constant ability to analyze and process data throughout crises despite potential interruption. The future security environment (FSE) requires increased resilience in acting as interoperable entities by empowering different actors. One foundation of shared resilience is a comprehensive and adaptive decision-making process. Another foundation is a certain degree of trust between the involved entities. This trust should enhance mutual transparency and enable a coordinated response to any threat or opportunity.

Coordinated Security: coordination, cooperation, and interoperability between NATO and a wide network of defense, security, and other relevant actors to strengthen complementary actions. Since NATO may not be the primary actor in a future conflict or crisis, the Alliance could function as an integrator or facilitator of actors within defense and security networks. NATO could provide a clearinghouse function, beyond Partnerships, for crisis management, where people, organizations, and states achieve improved cooperation. Such a security model would require more interconnected relationships with a wider range of actors, thus necessitating tools beyond partnership and cultural cooperation.

Adaptive Shaping: ability to anticipate and counter a diversified range of potential threats, depending on the scope, scale, and attribution. This may require a strategic approach, in conjunction with other intergovernmental decision-making bodies, and a combination of soft and hard power solutions to deal with multi-layer hybrid and dynamic trans-national groups in an expanded engagement space. Adaptive shaping may encompass a broadened deterrence posture, which could increase NATO's ability to deter adaptive adversaries who may be operating in less attributable domains such as cyber or space. The ability to adapt shaping 
actions to a variety of identified threats is critical in a future characterized by a decreased time to respond to security challenges and opportunities in current and new domains. ${ }^{256}$

The fourth FFAO workshop used the 15 trends in the SFA 2013 final report to distill ten (10) comprehensive instability situations (i.e. hazards), three (3) of which include environmental and climate change and/or natural disasters as a contributing factor. These three instability situations are included below, and they are discussed and analyzed using a risk governance framework in the following chapter.

Working from these ten instability situations, the fifth FFAO workshop identified common challenges among them by noting that "the number and variety of crises will increase due to climate change, increasing populations and the resulting strain on infrastructure" and that "Potential adversaries may take advantage of insufficient infrastructure and inadequate security, particularly in the wake of a natural or man-made disaster." 257 These common challenges are the basis for the sixth, and presumably final, FFAO workshop, from which participants will consider and formulate 'Strategic Military Perspectives.' The final report for the sixth workshop has not been released at time of writing, although NATO ACT released the capstone report in August $2015 .^{258}$

\section{Instability Situations-(Hazards)}

The fourth NATO Framework for Future Alliance Operations (FFAO) workshop used the 15 trends (and associated defense and security implications) identified in the NATO Strategic Foresight Analysis (SFA) 2013 Report to develop 50 instability situations in the future security environment. ${ }^{259}$ These 50 Instability Situations were consolidated into ten comprehensive instability situations (from this point forward, referred to simply as 'instability situations'), among which three (3) recognize climate or environmental change as a driving factor, including 1) access and use of global commons challenged, 2) disruptive impact of migration, and 3) largescale disaster. ${ }^{260}$

These situations straddle two of the three primary NATO mission areas: crisis management and cooperative security (and potentially collective defense as well-depending on context). The following three sections include the characteristics for each of the three instability situations that NATO released to the public.

\footnotetext{
${ }^{256}$ NATO ACT, "Framework for Future Alliance Operations Workshop \#3 Final Report: Long-Term Military Transformation Broad Strategic Insights Workshop," 2013, 3.

${ }^{257}$ NATO ACT, "Framework for Future Alliance Operations Workshop \#4 Final Report-Instability Situations in the Future Security Environment" (Budapest, 2014), 8.

${ }^{258}$ NATO ACT, "Framework for Future Alliance Operations," 2015.

259 NATO ACT, "Framework for Future Alliance Operations Workshop \#4 Final Report-Instability Situations in the Future Security Environment," 2.

${ }^{260}$ Ibid., 5, 8, 10.
} 


\section{Access and Use of Global Commons Challenged}

Statement of Context: The increased globalization, technological advancement, and interconnectedness of countries make global access both more valuable and more vulnerable. Indeed, actions that constrain access to the global commons could have great impact on global financial markets, transportation networks, and energy supplies. With the increased dependence on the global commons, states and non-state actors may be able to disrupt the flow of commerce, communication, and resource collection/distribution, thereby affecting military operations as a means of gaining leverage or for financial gain. Access to newly-available trade routes and resources, e.g. the Arctic, may also generate more competition within the global commons.

Main Contributing Trends: Polycentric World, Increased Access to Technology, Globalization of Financial Resources, Increased Resource Scarcity, Decreasing Defense Expenditures, Environmental/Climate Change.

Who: State and non-state actors, including multinational corporations, will compete for access to the global commons. Extremist groups, criminal organizations, such as pirate networks, and states using proxy groups, may seek to disrupt access to common areas.

Why: All actors will seek to gain financial, political, or military leverage by controlling global commons. They will seek to control the commons to extend influence and provide a counterbalance, or simply a disruption, to the operations of the Alliance. They will demonstrate power through economic, civil, political, and military means, and they may deny access to the global commons in retaliation for political or military actions. States that lack energy supplies will seek new options for acquiring and controlling access to resources. To reduce damage to the climate, extreme environmentalists will seek to disrupt resource discovery and extraction by using new technology.

How (Ways and Means): Actors may disrupt lines of communications and distribution networks to deny natural resources to states. They will challenge maritime freedom of navigation and commerce (e.g. pirates, undersea robots, and sea mines) extending their reach beyond the littorals to blue water. They will seek to increase their technical capabilities to disrupt trade. They will interrupt the air freedom of movement via widely available air defense and missile systems, unmanned vehicles, and computer technology that provides global reach. They will work to control the cyber domain to interdict satellite and voice communications, undermine financial electronic systems, and degrade intelligence collection systems. It will be more expensive in the future to prevent or counter an adversary's use of low cost technology, such as the use of improvised explosive devices.

Where: Actors will seek greater access to common use areas, with a particular focus on new areas of exploration, resource development, and trade. Examples of these new areas include the Arctic, outer space, and cyberspace.

What is new in 2030? Non-state actors will have more ability to exert some measure of influence over common areas, due to increased access to technology. Multinational corporations and criminal organizations will be more competitive, due to increasing economic power relative to states, and will have greater global reach due to technology. The scarcity of resources will entice criminal and private security groups to develop more successful business models to control access to the commons. Coordinated competition will exist simultaneously in the physical 
dimensions, like air, polar regions, sea and outer-space, and also in the non-physical dimension of cyberspace. Legal aspects over commons will be disputed as more actors become dependent on international trade. ${ }^{261}$

\section{Disruptive Impact of Migration}

Statement of Context: Mass human migration caused by demographic, environmental, economic or political change, and/or armed conflict, will exceed the ability of governments to protect and provide services for their resident populations. This uncontrolled migration will increase the potential for inter-ethnic, cultural, racial, and religious tensions.

Main Contributing Trends: Changing Demographics, Urbanization, Human Networks/Transparency, Fractured Identities, Environmental/Climate Change, and Natural Disasters.

Who: Nations with limited resources or infrastructure that have weak immigration control could become target nations for migrant source nations. Other nations could expel their populations to cause civil unrest in a target nation. Extremist, criminal, and ethnic organizations interested in creating instability will establish networks with large, displaced, urban populations.

Why: Rapidly changing environments (economic, political, or physical) will cause massive migration. People will move to avoid epidemic, poverty, inequality, political oppression, climate change, or natural disaster. Government authorities are under-resourced to respond adequately to large migrant populations. Groups will use population displacement to gain power through ethnic cleansing.

How (Ways and Means): Actors will cause mass demonstrations to disrupt life support within urban areas. The increased communication and human networking capabilities available through the Internet and social media will accelerate disputes within migrant populations. Migrants will use a range of transportation means (e.g. air, rail, road, and sea) to move to urban areas. Open borders, global transportation networks, and ease of movement will enable rapid migration between countries. Political groups, state actors, and/or criminal networks will use migration as a means to achieve organizational goals.

Where: People are moving from rural to urban areas. Megacities within poor countries will be less able to manage the mass of migrants. Regions at high risk for earthquakes, hurricanes, and other natural disasters, underdeveloped countries with autocratic regimes, and lightly-defended borders, especially near coastal areas, as well as regions with politically oppressed populations, will be the migrant source areas.

What is new in 2030? Control over the flow of mass migration will become a widespread security issue, especially within urban areas. More areas will be at tipping points, where thresholds leading to crises will be more easily exceeded. More populations will be at risk due to greatly increased urban population growth, accelerating climate change, and political unrest. The speed and rate of movement and the size of migrant groups will increase, thus degrading the

${ }^{261}$ Ibid., 5 . 
ability to control migration. Multiple migration flows will occur simultaneously. Migrants provide the opportunity for host nations to address declining populations by increasing human capital and supporting population growth. Disruptive migration also has the ability to increase the internal strife between government and immigrants, as well as between residents from different subnational groups. ${ }^{262}$

\section{Large-Scale Disaster}

Statement of Context: Large-scale disasters, such as deadly pandemics (natural or manmade), famine, or natural disasters result in governments seeking external support in the provision of health, security, and welfare of governed populations. Entities like nations, criminal organizations, or extremist groups exploit the chaos to achieve goals.

Main Contributing Trends: Urbanization, Human Networks, Environmental/Climate Change, and Natural Disasters.

Who: The government and people who live within an area impacted by a disaster will be the most involved and impacted. However, a disaster will attract a range of opportunistic groups, including state and non-state actors, extremists, and criminal organizations. Also, a large number of other actors will respond to, or be impacted by, the disaster more peripherally, including state military and disaster relief agencies, international organizations (IO), non-governmental organizations (NGO), private sector or commercial entities, and security organizations.

Why: Although disasters negatively affect the people in impacted regions, such crises also create opportunities for others. Since heavy urbanization increases vulnerability to a disaster, limited resource availability, weak governments, any disruption of transportation, energy supply, or communications may challenge civil services and degrade the ability to respond. This lack of control allows state or non-state actors to use disaster as an opportunity to destabilize a government. In addition, as a consequence of globalization, populations tend to concentrate and people can move rapidly between urban population centers, thus increasing the potential for epidemic or pandemic. Climate change will increase the frequency and severity of weatherrelated natural disasters.

How: Large-scale disasters (natural or manmade) will significantly increase the flow of people, creating mass movement of populations. National capabilities in underdeveloped areas will be unable to cope with large-scale disasters, and some regions will experience transnational impacts that could cascade across borders and lead to widespread humanitarian catastrophes. Some actors will take advantage of such situations to gain or consolidate influence over established governments, or to take control of vital infrastructure for example. Such a regional or global disaster provides a profit opportunity for business or criminal organizations by providing relief at a premium cost to impacted people. Opportunistic actors will seek to control resource distribution and may engage in hoarding or extreme market inflation of food, water, medical supplies, housing, and energy. Competition for and authority over resource allocation during the chaos of a disaster will challenge security providers.

${ }^{262}$ Ibid., 8 . 
Where: Large-scale disasters (natural or man-made) can occur anywhere, but are especially challenging to governmental control in locations with high densities of population and in littoral areas. Disasters in such regions can rapidly become a global challenge, calling for a global response. Also, the continued and effective operation and populations of any one of the world's financial or commercial centers are especially vulnerable to large-scale disaster.

What is new in 2030? The frequency and severity of large-scale disasters will increase due to climate change and urbanization. The threshold is reduced for responsiveness and proactive planning to the collapse of a state or region. Increased globalization, urbanization, and interconnectedness make the spread of disease easier and more devastating. Faster information flows will spread fear and panic at an accelerated rate. Multinational corporations and criminal organizations will play a bigger role in disaster relief. Megacities in weaker states will raise the probability of a collapse. Private security organizations will play an increased role in providing security. $^{263}$

\section{Review \& Critique of the Instability Situations}

The FFAO workshop identified three (3) security implications with climate change as a driving factor: 1) access and use of global commons challenged, 2) disruptive impact of migration, and 3) large scale disaster. These suggest the potential for new roles and geographic presence. ${ }^{264}$ The Instability Situations and Scenarios of the Arctic and Natural Disasters are relevant for the immediate interests of the organization. The implied role or response remains broadly consistent with NATO's core tasks or other missions NATO has conducted.

Each individual security implication is emerging slowly and at different rates. For example, increasingly frequent and severe natural disasters have already emerged or have begun to reveal their future impact. In the future, migration could alter the long-term sociological landscape within which NATO must operate. The effect of climate on migration and the resultant urbanization that NATO identified is of greater concern in the more distant future, and it is thus the most speculative of the three situations identified.

The security consequences in the Arctic are perhaps more transparent (also more conventional) and the political challenges are therefore more stark. The melting of the polar icecaps will open the region to commercial shipping traffic as well as oil and gas exploration. However, the use of the Arctic for commercial maritime activity is potentially years away (though natural resource exploration and extraction is taking place presently).

The melting of the polar ice caps has already raised concerns, particularly with respect to political engagement with Russia. Whatever the consequences of this scenario, however, they stand in contrast to those that may result along NATO's southern flank. On the southern flank, a different range of potential climate-induced problems may be included in the Instability Situations that consider the impact of migration and the potential consequences of increased natural disasters.

${ }^{263}$ Ibid., 10.

${ }^{264}$ This dissertation makes no effort to validate or determine the extent to which climate is a driving factor in the emergence of these situations. 
Seeming division in the focus of NATO and academic research in the future security environment is apparent. Both the practitioner and academic communities emphasized the idea that conflict will arise in the future as a result of climate change. While this is potentially true, and not entirely absent from the NATO perspective, the SFA/FFAO concerned itself just as much with identifying the nature of the environment in which NATO will find itself in the future and understanding what this implies in the absence of violent conflict.

None of the situations identified by the FFAO workshop addressed the issue of surprise. While the instability situations are broad and encompass many potential situations, there was also no discussion of cascading impacts. Instability situations concerning the 'Global Commons' (Arctic) were particularly scant on detail and unspecific, considering what is known about the risks. They were highly general, not insightful, and lacked specificity in terms of the risk for NATO.

\section{To What Extent do the NATO ACT Instability Situations Represent NATO Perspective?}

That NATO ACT created the Instability Situations does not imply that they have been embraced by NATO Headquarters - even though similar scenarios (and associated concerns) are expressed throughout the literature on climate change and security. While NATO ACT created these Instability Situations with input from a broad range of experts, including members of the International Staff and International Military Staff at NATO Headquarters (as well as national delegations to NATO and national ministries of defense), NATO Headquarters is not bound to include them — or the corresponding insights — in their policy planning considerations.

Therefore, the Instability Situations should be viewed as illustrative examples of concern for NATO (and the institutional perspective of the associated risks). Despite that NATO is a single organizational entity, a distinct division exists between the political headquarters in Brussels and the military organizations that fall beneath it (among which NATO ACT is one). Although NATO ACT intends for the SFA/FFAO efforts to enhance the Defense Policy Planning Process at NATO Headquarters, cooperation between NATO ACT and NATO Headquarters is not always seamless. $^{265}$

The SFA/FFAO documents were selected because NATO Headquarters had not released any similar scenario documents into the public domain, and the SFA/FFAO reports were the most recent NATO ACT scenario documents available at the time the research began. I wanted to preserve a linkage to NATO's institutional perspective (of climate-related risks) by sourcing NATO documents to the greatest extent possible, rather than look to a non-NATO source or design scenarios independently (both of which would have been inconsistent with the IRGC Risk Governance Framework).

To further assess the rightness of fit of using the NATO ACT scenarios in this dissertation, I examined the core conclusions of the Summary for Policymakers of the IPCC Fifth Assessment Report. The IPCC creates Summary for Policymakers through a consensus process (similar to

${ }^{265}$ This creates a potential misalignment from the perspective of risk governance (although this institutional aspect is not addressed in this dissertation). 
NATO), and all NATO member states are also IPCC members. Therefore, the extent to which the core features of the Summary for Policymakers are reflected in the foundation of the Instability Situations allows for additional insight into the ability of the Instability Situations to serve as a proxy for the NATO perspective on climate change and its security impact.

- Arctic: In 2014, the IPCC Working Group II Summary for Policymakers concluded that "with increasing warming, some physical systems or ecosystems may be at risk of abrupt and irreversible changes," ${ }^{266}$ while also noting (with confidence) the reduction in ice volume in Arctic glaciers and decreasing Arctic sea ice in summer. ${ }^{267}$ The IPCC also judged (with medium confidence) that Arctic ecosystems are already experiencing irreversible regime shifts. ${ }^{268}$ In particular, they noted the "potential for a large and irreversible sea level rise from ice sheet loss"269 and further judged (with very high confidence) that "[d]ue to sea level rise projected throughout the 21 st century and beyond, coastal systems and low-lying areas will increasingly experience adverse impacts such as submergence, coastal flooding, and coastal erosion." 270

- Migration: The IPCC judged (with medium evidence and high agreement) that climate change over the 21 st century is projected to increase displacement of people, ${ }^{271}$ noting that changes in migration patterns can be responses to both extreme weather events and longer-term climate variability and change, and migration can also be an effective adaptation strategy. The IPCC also noted (with medium confidence) that many global risks of climate change are concentrated in urban areas. ${ }^{272}$

- Large Scale Disaster: The IPCC judged (with high confidence) that climate-changerelated risks from extreme events, such as heat waves, extreme precipitation, and coastal flooding, are already 'moderate,' and will be 'high' with $1{ }^{\circ} \mathrm{C}$ additional warming (medium confidence). ${ }^{273}$ Moreover, they noted that with increased warming, "some physical systems or ecosystems may be at risk of abrupt and irreversible changes," noted the following two key risks (with high confidence) related to natural disasters: 1) systemic risks due to extreme weather events leading to breakdown of infrastructure networks and critical services such as electricity, water supply, and health and emergency services, ${ }^{275}$ and 2) risk of food insecurity and the breakdown of food systems linked to warming, drought, flooding, and precipitation variability and extremes, particularly for

\footnotetext{
${ }^{266}$ Intergovernmental Panel on Climate Change, "Summary for Policymakers," in Climate Change 2014: Impacts, Adaptation and Vulnerability - Contributions of the Working Group II to the Fifth Assessment Report, ed. C. B. Field et al. (Cambridge, United Kingdom and New York, NY, USA: Cambridge University Press, 2014), 12.

${ }^{267}$ Ibid., 32.

${ }^{268}$ Ibid., 12.

${ }^{269}$ Ibid.

${ }^{270}$ Ibid., 17.

${ }^{271}$ Ibid., 20.

${ }^{272}$ Ibid., 18.

${ }^{273}$ Ibid., 12.

${ }^{274}$ Ibid.

${ }^{275}$ Ibid., 13.
} 
poorer populations in urban and rural settings. ${ }^{276}$

Moreover, the IPCC Working Group II Summary for Policymakers concluded that "climate change is projected to amplify existing climate-related risks and create new risks for natural and human systems,"277 and that "climate change can indirectly increase risks of violent conflicts in the form of civil war and inter-group violence by amplifying well-documented drivers of these conflicts, such as poverty and economic shocks (medium confidence)." ${ }^{278}$ The IPCC further concluded in the same document that,

[i] mpacts from recent climate-related extremes, such as heat waves, droughts, floods, cyclones, and wildfires, reveal significant vulnerability and exposure of some ecosystems and many human systems to current climate variability (very high confidence). Impacts of such climate-related extremes include alteration of ecosystems, disruption of food production and water supply, damage to infrastructure and settlements, morbidity and mortality, and consequences for mental health and human well-being. ${ }^{279}$

Even without considering the cascading impacts among and between these three situations (that sea level rise as a result of polar ice melt can lead both to migration and large scale disaster, and that large scale disasters, in non-sea level rise scenarios, can lead to migration), the core foundation upon which NATO ACT created the Instability Situations is fairly well supported by the conclusions of the IPCC.

\section{Conclusions}

This chapter reviewed the history of NATO's institutional transformation and provided an overview of NATO's posture toward climate security risk. NATO's history of institutional transformation demonstrates its ability to adapt its policies, programs, and military operations to changes in the security environment. However, without a 'focusing event' (such as 11 September 2001) or a paradigm shift (such as the end of the Cold War), change happens slowly. Indeed, NATO's deployment of forces to the Balkans - which transformed NATO into an organization that conducts out-of-area peacekeeping operations - gathered momentum over a period of years, and in response to circumstances that compelled change.

The chapter also detailed two foresight efforts conducted by NATO ACT: The Strategic Foresight Analysis and the subsequent Framework for Future Alliance Operations (FFAO). To establish the context to understand the Instability Situations that were identified as having climate change as a driving factor, I discussed NATO policies with respect to environmental issues and NATO's interest in the MENA region and the Arctic.

Throughout the past decade, NATO has recognized the influence of the physical environment on international security, and it has contributed resources to security events that arose when other

\footnotetext{
276 Ibid.

${ }^{277}$ Ibid., 14.

${ }^{278}$ Ibid., 20.

${ }^{279}$ Ibid., 6.
} 
regions lacked the capacity to respond to natural disasters and related crises. Indeed, NATO has program, policy mechanisms, and military resources through which it can play a role in the climate-security context. Moreover, NATO has clear political and security interests in the MENA region and the Arctic, and it has recognized that protecting those interests could require military resources and new initiatives.

I concluded the chapter with a discussion and critique of common characteristics among the three (3) Instability Situations that serve as the basis for analysis in subsequent chapters. Indeed, NATO sought to understand how various 'drivers' of security can act either individually or collectively to form trends and/or alter future security and operating landscapes. To further address the appropriateness of using the NATO ACT scenarios to serve as a proxy for the NATO perspective on climate change and its security impact, I examined the core conclusions of the Summary for Policymakers of the IPCC Fifth Assessment Report.

A more difficult question to answer is what can or should NATO do at the headquarters level to anticipate, avert, alter, or mitigate predictable or unpredictable outcomes that result from these drivers. ${ }^{280}$ The FFAO workshops did not engage with this question. To attempt to answer this question, the analysis in the following chapters will consider the Instability Situations identified by the FFAO workshops in the context of the International Risk Governance Council's Risk Governance Framework.

${ }^{280}$ NATO ACT, "Strategic Foresight Analysis Workshop \#2 Read Ahead: The Shared Perspective of the World in 2030 and Beyond Themes and Drivers," 2. 


\section{Chapter 4: Methodology \& Context}

\section{Introduction}

This chapter discusses why a risk governance approach is appropriate for the problem of climate security risk, bringing together aspects of the preceding two chapters to illustrate how the nature of climate security risk favors the IRGC risk governance framework in particular. The IRGC risk governance framework is ambitious. It seeks to provide "guidance for the development of comprehensive assessment and management strategies to cope with risks, in particular at the global level." 281 The global dimensions and deep uncertainties associated with climate security risk suggest that it provides an opportunity to test the framework against a problem that is worthy of the IRGC's ambition level.

In addition, this chapter discusses seven (7) case studies that used the IRGC Risk Governance Framework, as well as other aspects of climate security risk that are integral to understanding the risk governance context for NATO, including: 1) the landscape of international institutions that have an interest in the governance of climate security risk, 2) the climate change-related policies and activities of NATO member states, and 3) the internal decision-making process of NATO. The characteristics of climate security risk illustrate the suitability of using a risk governance framework to analyze the problem. However, NATO is constrained by a consensus-based decision-making process, and the climate security risk landscape is crowded with institutions with overlapping responsibility.

Unlike a conventional policy analysis dissertation, I do not discuss the details of the methodology (the IRGC Risk Governance Framework) in this chapter. Although I touch briefly upon the elements of the framework in this chapter, I provide a more thoroughgoing discussion of each dimension of the framework in Chapters 5 and 6, and (in each instance) proceed immediately to the analytic discussion. This approach is consistent with the established precedent for analysis using this framework. A critique of the IRGC Risk Governance Framework is provided in Chapter 6.

\section{Why Risk Governance? NATO \& Climate Security Risk}

Risk governance is the process by which risks are identified, assessed, communicated, and managed. It considers the environmental, economic, and societal factors that influence how a risk may materialize and can be addressed. Aspects of risk governance consider the actors, rules, conventions, processes, and mechanisms concerned, including how relevant risk information is collected, analyzed, and communicated, and how management decisions are made. Risk governance encompasses the technical aspects of risk assessment and management, as well as normative, qualitative, and subjective knowledge about a risk. ${ }^{282}$

\footnotetext{
${ }^{281}$ Renn, "Risk Governance-Towards an Integrative Framework," 11.

${ }^{282}$ Ibid., 22. Risk governance includes matters of institutional design and role, organizational capacity, stakeholder involvement, collaborative decision making, and political accountability.
} 
Employing a risk governance framework to conduct this analysis addresses a problem identified by Jon Barnett, who said that "without a useable framework for analysis, policy action and discussion will remain difficult and a policy paralysis may result."283 As opposed to grounding the analysis within a single theoretical framework, a risk governance perspective integrates a range of perspectives and complementary analyses, to allow for the diverse, uncertain, and complex realities of risk problems. This approach helps to address the shortcomings of more conventional methods (often found in academic literature). These shortcomings were considered by Read, who argued that:

the scientific method tells us much about the past and present physical and social impacts of climate change, but is often not suitable for predicting, forecasting, or planning for future climate change and its implications because it relies on historic relationships and the presumption that the future is determined by past trends. Anticipating and planning for climate change-security issues is not well suited for most traditional research methods. 284

It is important to point out that risk governance does not exclude the incorporation of, or conclusions based upon, a theoretical perspective. However, the fact that climate security risk is emerging (and in a complex-adaptive manner) suggests that, without considering the wider risk landscape, and various potential scenarios, conclusions driven (solely) by a theory would offer less prospective utility to discover and illuminate options to address the challenges.

Given the nature of climate security risk, the associated challenges, and the objective to distill actions for NATO, a risk governance framework allows (to the extent possible) the breadth and flexibility to account for the wide range of factors inherent in the issue. The framework helps organizations to grapple with the scope of climate change and its consequences. Gulledge, for instance, observes that:

Climate change is very complex, non-linear, long-term, [and] intergenerational. It is about as difficult and uncertain a problem as you can find, and it is loaded with risk. So a risk-management framework is really the appropriate way of approaching the problem of climate change. ${ }^{285}$

Indeed, climate security risk poses a demanding case. While systemic risks require an integrated approach, the emerging nature of the problem renders it particularly intractable because the scope, uncertainties, complexity, and interdependencies are not fully understood. As discussed in Chapter 2, cases such as climate change are not well suited to an analysis based upon empirical methods, because the future conditions affecting the problem are likely to be unprecedented. ${ }^{286}$

${ }^{283}$ Jon Barnett and Stephen Dovers, "Environmental Security, Sustainability and Policy," Pacifica Review: Peace, Security \& Global Change 13, no. 2 (2001): 157-69.

${ }^{284}$ Read, "Embracing Uncertainty: Scenario Planning for Climate Change Security Challenges and Opportunities," 25.

${ }^{285}$ Jay Gulledge, "Scientific Uncertainty and Security Risks of Climate Change," in Proceedings on Climate \& Energy: Imperatives for Future Naval Forces, 2010, 48.

${ }^{286}$ Read, "Embracing Uncertainty: Scenario Planning for Climate Change Security Challenges and Opportunities," 24. 
In Read's words, quantitative methods are "not sufficient because they exclude the complexity of the interactions between nature and humans that can be neither modeled nor predicted." 287

\section{The IRGC Risk Governance Framework}

The IRGC Risk Governance framework seeks to provide guidance for the development of comprehensive assessment and management strategies to cope with risks, in particular at the global level. ${ }^{288}$ Moreover, it is intended for cases of systemic risks and to go "beyond simple cause-effect risk analyses by stressing the importance of the interdependencies between different dimensions of risks, networks of actors, and the public." 289 The IRGC framework was developed to establish the conceptual framework to approach real-world problems with these characteristics. ${ }^{290}$ It aims to be applied across a wide range of risks, as it is an applied framework. $^{291}$

The IRGC framework accounts for scientific evidence and economic considerations, risk perceptions, social concerns, and societal values in seeking to provide a comprehensive and integrated view of risk governance. ${ }^{292}$ It is an "integrated analytic framework to provide guidance for the development of comprehensive assessment and management strategies to cope with risks at both the local and, in particular, the global level." ${ }^{293}$ This integration allows for a variety of methods that may have shortcomings of their own, but may contain valuable information (within a specific context) to be joined into a whole analytic methodology. Canvassing the risk landscape allows the IRGC framework to serve as a roadmap to evaluate organizational posture vis-à-vis an identified risk problem.

Climate security risk, in this context, requires the broad perspective of the IRGC framework. Individual methods employed thus far, with respect to the climate change-security nexus, have "not adequately dealt with high levels of uncertainty in the associated complex systems." "294 That is to say that conclusions reached thus far regarding climate security and their associated risks cannot be usefully separated from the methods employed to analyze them. This is because contemporary methodologies fail to capture the emergent, adaptive nature of the climate system and the uncertain human response to changes within it. Yet, some of this analysis is revealing and potentially important.

\footnotetext{
${ }^{287}$ Ibid., 54.

${ }^{288}$ Renn, "Risk Governance-Towards an Integrative Framework," 11.

${ }^{289}$ Renn, "Risk Governance-Towards an Integrative Framework."

290 Ibid.

${ }^{291}$ Ibid., 19.

292 Ortwin Renn and Katherine Walker, eds., Global Risk Governance. Concepts and Practice Using the IRGC Framework (Heidelberg: Springer Science \& Business Media, 2008), 337.

${ }^{293}$ Renn, "Risk Governance-Towards an Integrative Framework," 11.

${ }^{294}$ Read, "Embracing Uncertainty: Scenario Planning for Climate Change Security Challenges and Opportunities," 11.
} 
The IRGC framework is comprised of four characterization and evaluation, and management. ${ }^{295}$

(4) phases: pre-assessment, appraisal,

- The pre-assessment phase includes four (4) components: 1) risk framing, 2) early warning and monitoring, 3) pre-screening, and 4) pre-assessment. This phase seeks to capture issues that stakeholders associate with a risk, as well as existing indicators, routines, and conventions that act as a filter for what is addressed as risk. ${ }^{296}$

- The risk appraisal phase, which includes risk assessment and risk estimation, provides the knowledge upon which to base a decision on whether a risk should be taken, and how a risk can be reduced or contained. Risk appraisal comprises a scientific assessment of both the risk and of questions concerning its social and economic implications. ${ }^{297}$

- The risk characterization and evaluation phase aims to judge the acceptability and/or tolerability of a risk. Risk evaluation assesses broader value-based aspects that influence the acceptability/tolerability judgment. ${ }^{298}$

- The risk management phase designs and implements the actions and remedies to address risks with an aim to avoid, reduce, transfer, or retain them. ${ }^{299}$

A further element, risk communication, unites the above phases. Risk communication is the "exchange of information between risk assessors and managers, between scientists and policy makers, between academic disciplines and across institutional barriers - and for the "outside world' of those affected by the process. ${ }^{300}$ The IRGC notes that risk communication "can have a major impact on how well society is prepared to cope with risk and react to crises and disasters., ${ }^{301}$

In the case of climate change and security, the IRGC framework was chosen because of its stated emphasis on risk areas of global relevance (i.e. trans-boundary, international, and ubiquitous risks) that include large-scale effects (including low-probability, high-consequence outcomes), require multiple stakeholder involvement, lack a superior decision-making authority, and involve the potential to cause wide-ranging concerns. ${ }^{302}$ These characteristics are present in the problem of climate-related security risk. It is trans-boundary, international, and ubiquitous. Issues, such as natural disasters and migration, and the subsequent consequences, may arise and occur in one region, such as MENA, but the consequences could affect the North Atlantic region, and so would require a coordinated international response. Working more closely throughout the

\footnotetext{
${ }^{295}$ Renn, "Risk Governance-Towards an Integrative Framework," 12.

${ }^{296}$ Ibid., 13.

${ }^{297}$ Ibid.

${ }^{298}$ Ibid., 14.

${ }^{299}$ Ibid.

${ }^{300}$ Ibid., 15.

${ }^{301}$ Ibid.

${ }^{302}$ Ibid., 19.
} 
Alliance and with other members of the international community is a feature of NATO's Comprehensive Approach and the 2011 Political Guidance. ${ }^{303}$

Recall, chapter 2 discussed the research on climate security and emphasized the characteristics of the climate system, as well as the inevitable shortcomings of empirical approaches. Chief among these shortcomings was the fact that "the causal chain from climate related stress to human and societal impacts is complex and not fully understood." ${ }^{304}$ Moreover, any single method would not provide a comprehensive understanding of the problem, which is critical for decision makers. Review of the literature demonstrates that the framing of the problem matters significantly in determining whether and how climate change presents a threat to security. Quantitative research offers no guarantee that its perspective and definitions will be consistent with the disposition of NATO.

The case of the climate change-security nexus could be considered a 'stress test' for the concept of risk governance. This provides a further motivation to employ the IRGC framework. Given its relatively recent development in 2013 , and ambition to address global issues, the results of this analysis may serve to strengthen its future development and application. ${ }^{305}$ In the words of the International Risk Governance Council, "testing of the framework's efficacy will involve its application in areas where the risks appear not fully understood or where there is a desire or need to improve risk governance." ${ }^{306}$ This is the circumstance that NATO faces with respect to climate security risk.

To ignore the methodological inadequacies would be facile. To ignore the conclusions based upon them, or how they may complement insights from other risk governance dimensionsparticularly as more data becomes available and the methods become more developed-would undermine their potential relevance and value. To adequately handle climate security risk, then, decision makers must focus on what is known, but also take a comprehensive and critical view of any epistemological claim. In the case where very little is known - such as in the case of climate security risk - they must understand the elements and nature of the risk landscape that make it so. This knowledge is the groundwork to support action to improve the posture vis-à-vis the risk. The IRGC framework provides the structure for this.

\section{Summary of Characteristics: NATO, Climate Security, and Risk Governance}

The IRGC's aim is to offer guidance on how to approach risk issues and to promote a wider understanding with respect to emerging systemic risks. ${ }^{307}$ The OECD describes a risk as systemic when reaction to it entails significant economic, social, and even political consequences. ${ }^{308}$ Renn

\footnotetext{
303 NATO, "Political Guidance on Ways to Improve NATO's Involvement in Stabilisation and Reconstruction"; NATO, "Implementation of the Comprehensive Approach Action Plan and the Lisbon Summit Decisions on the Comprehensive Approach," 2011.

${ }^{304}$ Scheffran and Battaglini, "Climate and Conflicts: The Security Risks of Global Warming," S37.

${ }^{305}$ Renn, "Risk Governance-Towards an Integrative Framework."

${ }^{306}$ Renn, "White Paper No. 1: Risk Governance-Towards and Integrative Approach," 5.

${ }^{307}$ Ibid., 64.

${ }^{308}$ OECD, "Emerging Risks in the 21st Century, An Agenda for Action” (Paris: OECD Publishing, 2003).
} 
notes that systemic risks require a comprehensive approach, which takes account of this complexity. ${ }^{309}$

The following characteristics of climate change serve to define it as a 'systemic' risk.

- Climate change is widely anticipated to cause security consequences, yet a clear and conclusive study linking climate change to security consequences has not been produced. Even the most convincing analysis suffers from uncertainty. Nevertheless, it is undeniable that periods of instability follow episodes of natural disasters, and the potential for drought, food insecurity, and other environmental factors suggests increased migration and potential instability in the Middle East and North Africa region, presenting a security concern for countries along NATO's Mediterranean coastline and southern flank. Also, the melting of the polar ice caps will cause rising sea levels and greater variability in temperature and precipitation, in addition to increased competition for natural resources in the Arctic, more frequent use of waterways, and a higher potential for maritime confrontation and environmental emergencies in the Arctic.

- No reliable dose-response relationship has been identified (how much climate change, and in what manner, in what locations, leads unambiguously to specific corresponding security consequences). There is no established threshold value for the climate change to security consequence relationship. This suggests that the 'solution' (policy and program) pursued must be complex and flexible to take into account the potential variability of the relationship.

- The entire global population is exposed to the climate as it changes, although to varying degrees (and impact), since it is (by definition) a global phenomenon. However, not all members of the global population will face the same effects, particularly with respect to security.

- Climate change and variation occurs naturally. The security consequences of climate change, however, can be serious - both for the economy and for society. This is true throughout the North Atlantic region and globally, though the effect can vary regionally and across countries.

\section{Previous Application of the IRGC Risk Governance Framework}

This section summarizes seven (7) case studies that used the IRGC framework, which were included in the 2014 publication of Global Risk Governance. Concepts and Practice Using the IRGC Framework by Ortwin Renn and Katherine Walker. ${ }^{310}$ The IRGC Risk Governance Framework was applied to analyze instances that address genetically modified crops, naturebased tourism, listeria in raw milk soft cheese, management of the Nagara River estuary barrage in Japan, acrylamide in Germany, energy security in the Baltic, and nanotechnology.

\footnotetext{
309 Ortwin Renn, "Acrylamide: Lessons for Risk Management and Communication," Journal of Health Communication 8, no. 5 (2003): 435-41.

${ }^{310}$ Renn and Walker, Global Risk Governance. Concepts and Practice Using the IRGC Framework.
} 
In general, the previous case studies benefited from a technical or scientific basis for which data was available or models could assist in understanding the risk. Several emphasize education strategies as a way of reducing risk. Not every situation fulfilled all dimensions of the framework. That is because the framework is both comprehensive and a-la-carte; one or two facets of the framework typically dominate a particular situation, and some cases went no further than to focus on only one or two aspects.

- Genetically Modified Crops: This case study applies the IRGC framework to regulation of genetically modified crops. ${ }^{311}$ It examines the history of the regulatory approach to genetically modified crops in Europe and the United States, and it considers each one retrospectively through the lens of the IRGC framework. Dramatically different risk governance processes in Europe and the United States produced correspondingly different outcomes: Europe allows very few genetically modified (GM) crops. ${ }^{312}$ However, the risk management options implemented in Europe had little to do with an evidence-based assessment of the risks. Their approach focused on societal concerns about potential risks, rather than being based on evidence of problems incurred as a result of the risk. ${ }^{313}$

Framing of the issue and the associated risk emerged and became highly politicized, resulting in a situation that was beyond the control of a risk governance process. ${ }^{314}$ This problem is particularly difficult, where conflicting value and ideologies are involved. The industry framed genetically modified crops as a "benefit," while regulators framed them as a "risk." With GM crops, the risk assessment, risk evaluation, and risk management stages were influenced heavily by the perceptions and concerns of a vocal minority. ${ }^{315}$ The author noted that if a pre-assessment and framing of the risk had been performed at an early point in their development, regulators and policy makers would have had greater control of later stages of the analysis. 316

- Nature-Based Tourism: This case study applied the IRGC framework to risks associated with nature-based tourism. ${ }^{317}$ The 'risk' in nature-based tourism is the altered social fabric that can result as communities of rural people (who previously might have been subsistence farmers, for instance) transition into a cash economy, driven by tourism. Other risks that occur in this context include the risk of disease for tourists, external risks, such as increased petroleum prices (which increases cost of travel), or disease outbreaks

311 Joyce Tait, "Risk Governance of Genetically Modified Crops-European and American Perspectives," in Global Risk Governance. Concepts and Practice Using the IRGC Framework (Heidelberg: Springer, 2008), 133.

${ }^{312}$ Ibid.

${ }^{313}$ Ibid., 143.

${ }^{314}$ Ibid., 146.

${ }^{315}$ Ibid., 146, 147.

${ }^{316}$ Ibid., 146.

${ }^{317}$ Caroline Kuenzi and Jeff McNeely, "Nature-Based Tourism," in Global Risk Governance. Concepts and Practice Using the IRGC Framework, ed. Ortwin Renn and Katherine Walker (Heidelberg: Springer Science \& Business Media, 2008), 155-75. 
(such as severe acute respiratory syndrome(SARS)) that have the potential to decrease tourism. $^{318}$

The transition to a tourist-based economy also creates dependencies, which create risk for the broader community. The region where tourism takes place becomes dependent on tourists and their ability and willingness to travel. Tourists are dependent on the region being safe, disease-free, and affordable. The petroleum industry is dependent on consumer demand, which is a function of tourists who want to travel and a region to which they can travel affordably and safely. This is also true for hotel operators, tour agencies, other people that make tourism possible, or NGOs that want to safeguard the environment. Each community frames nature-based tourism in ways that are most relevant to their interests. ${ }^{319}$

Thus, the stakeholders are interdependent. However, the functioning of each of these communities is governed by a mosaic of regional and multilateral conventions, and international agendas, each of which touch upon aspects of national law and policy. This is an unwieldy and all-encompassing sets of risks. They are so sweeping and lacking in precision as to defy analysis with structured methodology. ${ }^{320}$ The complexity exceeds the scope and authority for any single entity to govern effectively, and problems in one system cascade into other, seemingly unrelated, systems.

- Listeria in Raw Milk Soft Cheese: This case study uses the risk governance for raw milk soft cheese to evaluate the IRGC Risk Governance Framework. ${ }^{321}$ That it defined the risk as a single pathogen (listeria monocytogenes) provided a scientific basis upon which to understand the nature of the risk. Because the risk is reasonably well defined, has a scientific basis, and has a known origin that falls under the authority of government agencies, risk reduction measures can be designed to address the risk. This was not an emerging risk, but rather one that was quite well established and understood. The narrowness and precision of the risk enabled a grounded and specific analysis, and it allowed the actual risk to be communicated straightforwardly.

- Nagara River Estuary Barrage: The authors apply the IRGC framework retrospectively to a water resource management problem in Japan for flood control and protection of the water supply in the construction of the Nagara River Estuary Barrage. ${ }^{322}$ The key concerns voiced by those who objected to the project were whether it would legitimately contribute to flood control and the environmental impact of the dam. ${ }^{323}$

\footnotetext{
318 Ibid., 156.

319 Ibid., 162.

${ }^{320}$ Ibid., 156.

321 Andrew J. Knight et al., "Listeria in Raw Milk Soft Cheese: A Case Study of Risk Governance in the United States Using the IRGC Framework," in Global Risk Governance. Concepts and Practice Using the IRGC Framework, ed. Ortwin Renn and Warren E. Walker (Heidelberg: Springer Science \& Business Media, 2008), 179-215.

${ }^{322}$ Norio Okada, Hirokazu Tatano, and Alkiyoshi Takagi, "Nagara River Estuary Barrage Conflict," in Global Risk Governance. Concepts and Practice Using the IRGC Framework, ed. Ortwin Renn and Katherine Walker (Heidelberg: Springer Science \& Business Media, 2008), 221.

${ }^{323}$ Ibid., 224-225.
} 
The analysis takes the approach of predicting how the outcome might have changed, had the IRGC framework been applied. Although it is interesting to see how the authors believe the IRGC framework might have helped, there is little or no discussion as to how the authors arrived at their conclusions. This type of counterfactual analysis requires meeting rigorous criteria to have validity. Thus, the analysis conducted here is perhaps better considered as insight, as opposed to conclusions drawn from carefully-applied methodology.

- Acrylamide Risk Governance in Germany: This case examines the acrylamide in food crisis in Germany, and it offers a reasonably comprehensive step-by-step analysis using the IRGC framework. ${ }^{324}$ It effectively provides a history on the uses and characteristics of acrylamide, a summary of events that led to its discovery in foods, and the manner in which the public became aware. The study also discusses the institutional structures of consumer protection and risk governance of acrylamide in Germany before offering a retrospective counterfactual analysis to qualitatively assess whether the risk could have been better handled if the IRGC framework had been applied.

- Energy Security in the Baltic: This case study focused on Baltic energy security from the perspective of the IRGC's risk governance framework, with particular emphasis on the pre-assessment phase. ${ }^{325}$ The context addressed the closure of a power generating facility in Lithuania (that will make the region more dependent on imported natural gas from Russia), the probability of interruption in the supply of such energy materials, and the impact of an interruption in supply. At the time the case study was written, the Baltic countries were connected to the Russian electricity grid, as opposed to the continental European grid or the Scandinavian grid. Essentially, the Baltic region wants to avoid dependence on Russia for electricity. The analysis offers a descriptive overview of the context and related considerations. An appendix includes a discussion of the means needed to assess the risks using a probabilistic scenario analysis with generalized equilibrium energy models.

- Nanotechnology Risk Governance: This case study describes the risks from nanotechnology prospectively. ${ }^{326}$ The authors use a corrective and adaptive approach to identify risk management strategies, and they include high-level risk governance recommendations - and suggestions for their implementation-addressed to governmental, business, scientific, civil, and communication actors who share concerns about nanotechnology governance.

The case studies offered insight into the relevance of the IRGC framework in specific circumstances, and they serve as a generic model for the analysis in this dissertation. However,

${ }^{324}$ Sabine Bonneck, "Acrylamide Risk Governance in Germany," in Global Risk Governance. Concepts and Practice Using the IRGC Framework, ed. Ortwin Renn and Katherine Walker (Heidelberg: Springer Science \& Business Media, 2008), 231-67.

${ }^{325}$ D. Warner North, "Energy Security for the Baltic Region," in Global Risk Governance. Concepts and Practice Using the IRGC Framework, ed. Ortwin Renn and Katherine Walker (Heidelberg: Springer Science \& Business Media, 2008), 275-87.

${ }^{326}$ Mihail Roco, Ortwin Renn, and Jager Alexander, "Nanotechnology Risk Governance," in Global Risk Governance. Concepts and Practice Using the IRGC Framework, ed. Ortwin Renn and Katherine Walker (Heidelberg: Springer Science \& Business Media, 2008), 301-25. 
they are largely retrospective and offer precious little insight for the analysis of NATO and climate change. None of the cases used scenarios like the ones that NATO ACT created (discussed in Chapter 3), and none dealt with physical security problems. This is the primary contribution of this dissertation. It conducts a case study analysis of an emerging problem using the IRGC Risk Governance Framework that is considerably more extensive than any previous publicly available case studies that the author has been able to locate.

As a further aim, this analysis seeks to test the IRGC framework by applying it to a problem wherein the risks are complex and highly uncertain. In doing this, I assess how well the IRGC framework supports an understanding of the risks and how well it facilitates the development of policy options. ${ }^{327}$ In turn, this analysis advances the underlying goal of the IRGC framework, which is to provide guidance for the development of comprehensive assessment and management strategies to cope with risks, in particular at the global level. ${ }^{328}$

Heretofore, the IRGC framework has been applied (mostly) retrospectively in relatively welldefined problems that fall within the purview of a single or small number of government ministries. It has not been applied prospectively to a larger risk issue that has a significant number of global dimensions and cascading impacts. The fundamental objective of this dissertation is to address the following question: Can the IRGC Risk Governance Framework add policy-relevant insight for NATO if applied in real-time to a phenomenon as broad, uncertain, and complex as climate change-induced security risk (and, if so, how)?

The remainder of this chapter provides a discussion of three (3) contextual aspects that factor heavily into NATO's risk governance of the security consequences of climate change, including 1) the landscape of international institutions that have an interest in the governance of climate security risk, 2) the climate-change-related policies and activities of NATO member states, and 3 ) the internal decision-making process of NATO.

\section{Risk Governance: Institutions \& Context}

The IRGC emphasizes that risk governance is context-specific and intends for the framework to be used flexibly. The context-specific nature of its application is especially true in the case examined here, where a range of factors-including the nature of the risk itself, how different governments assess and manage risks, institutional decision-making constraints, and the level of acceptance or aversion to risk, among other considerations-shape the circumstance and the resulting availability of options. ${ }^{329}$

When viewing the problem of climate security risk from the perspective of NATO, one must understand that other organizations also have a similar role or share responsibility for the events

\footnotetext{
${ }^{327}$ Thus, the analysis is potentially just as useful for the future development and refinement of the framework as it is in helping NATO understand the dimensions of risk governance related to climate and security. As a result, this project will also contribute to the assessment of the framework's "practicability," an effort that followed the 2013 release of the white paper describing the prototype framework.

${ }^{328}$ Renn, "White Paper No. 1: Risk Governance-Towards and Integrative Approach."

${ }^{329}$ International Risk Governance Council, "Risk Governance Deficits: An Analysis and Illustration of the Most Common Deficits in Risk Governance," 4.
} 
and consequences that may unfold. It is important to identify these to avoid unnecessary duplication of responsibilities within the international system. The following discussion is not meant to be comprehensive but illustrative of the considerations necessary to delineate NATO's responsibilities with respect to policy formulation for climate security risk.

Moreover, NATO's decision-making process is highly restrictive from a risk governance perspective, in that it requires all twenty-eight (28) members of the organization to offer their 'consent' through a unique procedure established at NATO. I discuss this institutional decisionmaking process, and the constraints that it poses to NATO, below.

\section{The Institutional Structures}

The institutional actors who have potential responsibility in the domain of climate and security, whose decisions influence the identification, assessment, management, monitoring, and communication of risks related to climate and security, as well as necessary actions for adaptation and mitigation, are numerous and diverse. While interdependent, each institution has its own rules, procedures, principles, responsibilities, and objectives.

Thus, the wider existing 'governance system' is not comprised of a single, overarching mechanism. Instead, it is a mosaic composed of national, multilateral, and international agendas that each touch upon specific, sometimes overlapping, aspects of the problem. The network of these various organizations, their perspectives, and their responsibilities make delineating a role - and governance of the risks - regarding climate and security a challenge. These organizations include agencies of the United Nations, ${ }^{330}$ the EU, OECD, OSCE, nongovernmental organizations, think tanks, research institutions, as well as national governments and militaries. 331

In addition to member state militaries, many NATO governments have an emergency response organization (in the United States, it is the Federal Emergency Management Agency (FEMA)), with responsibility to respond domestically, and potentially internationally, given the context. Development agencies often have responsibility to engage with foreign counterparts to help with capacity building, particularly in the context of disaster response and migration, although many

\footnotetext{
${ }^{330}$ The IPCC notes that "there are two main mechanisms at the international level that are purpose-built and dedicated to disaster risk management and climate change adaptation. These are the United Nations International Strategy for Disaster Reduction (UNISDR) and the United Nations Framework Convention on Climate Change (UNFCCC), in particular in its adaptation components." I. Burton et al., "Managing the Risks: International Level and Integration across Scales," in Managing the Risks of Extreme Events and Disasters to Advance Climate Change Adaptation. A Special Report of Working Groups I and II of the Intergovernmental Panel on Climate Change, ed. C. B. Field et al. (Cambridge, United Kingdom and New York, NY, USA: Cambridge University Press, 2012), 396.

${ }^{331}$ Other organizations in NATO's Environmental Area of Interest include the following: European Defence Environmental Network (DEFNET), European Defence Agency (EDA), European Union Military Staff (EUMS). In 2004, NATO became an associate member of the Environment and Security Initiative (ENVSEC); other members include the United Nations Environment Program (UNEP), the United Nations Development Program (UNDP), the Organization for Security and Co-operation in Europe (OSCE), United Nations Economic Commission for Europe (UNECE) and the Regional Environment Center for Central and Eastern Europe (REC).
} 
do not have a dedicated response capability (the US is perhaps an exception with the US Agency for International Development (USAID) Office of Foreign Disaster Assistance).

Individual agencies of the United Nations have dedicated responsibility towards issues of migration and disaster response, while the Arctic Council has authority for the Arctic (but has neither a security mandate nor independent geopolitical weight). The European Union too has various agencies, while the OECD and OSCE are perhaps marginal players.

Nevertheless, there appears to be room for additional efforts. On this issue, the IPCC concluded the following:

Closer integration at the international level of disaster risk reduction and climate change adaptation, and the mainstreaming of both into international development and development assistance, could foster efficiency in the use of available and committed resources and capacity (high confidence). Neither disaster risk reduction nor climate change adaptation is as well integrated as they could be into current development policies and practices. Both climate change adaptation and disaster risk reduction might benefit from sharing of knowledge and experience in a mutually supportive and synergistic way. Climate change adaptation could be factored into all disaster risk management, and weather-related disasters are becoming an essential component of the adaptation agenda. ${ }^{332}$

Yet the burden of responsibility to act in this domain, particularly as it concerns disaster response and migration issues, does not fall exclusively on NATO. National governments, and other international organizations, have more immediate responsibility than NATO. But the division of labor is not well delineated, and certain circumstances would require NATO to play a more immediate and substantive role.

Disaster response and humanitarian assistance (DR/HA) is a longstanding function of NATO. That NATO is not necessarily the first responder in this respect has the potential to obstruct and obscure the perspective of member states. They may, for instance, not view the issue of disaster response and humanitarian assistance in a uniform manner. And this, in turn, influences, and potentially muddles, the level of responsibility for NATO to absorb.

\section{Climate Policies \& Plans: NATO Militaries \& Defense Ministries}

Recognition among NATO member states (read: militaries and defense ministries) of the security consequences that may result from changes in climate and the natural environment has resulted in rhetorical commitment, programmatic initiatives, and the incorporation (or attempted incorporation) of climate aspects into planning. All of these endeavors are justified in their own right. As noted by Briggs,

climate change represents a disruptive force that has the potential to make [military] operations more costly and time-intensive, and to require further

\footnotetext{
${ }^{332}$ Ibid., 396-397.
} 
deployments as part of humanitarian assistance and disaster response (HA/DR) operations. Even when the probabilities are unknown, the risks to strategic interests and operational goals are often significant enough to be included in planning. ${ }^{333}$

Several NATO member states - in particular the United States - have explicitly acknowledged in public documents the intention to include the impact of climate change on the security environment, or have already done so. ${ }^{334}$ The United States has established perhaps the most comprehensive portfolio of policies and plans to address security issues related to climate change. The projected impacts of climate change are included in the US National Security Strategy and Defense Strategic Guidance, including National Intelligence Estimates. Additionally, all US federal agencies have been directed to "evaluate the most significant climate change-related risks to, and vulnerabilities in, agency operations and missions in both the short and long term, and outline actions that agencies will take to manage these risks and vulnerabilities. 335

In 2008, the United States Congress directed the US Department of Defense to address the national security implications of climate change in the Quadrennial Defense Review. ${ }^{336}$ A variety of successive US national policy documents address climate and security issues; these include the 2010 and 2015 US National Security Strategy, ${ }^{337}$ the 2010 and 2014 Quadrennial Defense Review, ${ }^{338}$ and the 2010 Quadrennial Diplomacy and Development Review. ${ }^{339}$ The 2015 US National Security Strategy listed climate change as one of the top strategic risks of the United States. $^{340}$

The 2014 Quadrennial Defense Review (QDR) identified the effects of climate change as "threat multipliers that will aggravate stressors abroad such as poverty, environmental degradation, political instability, and social tensions - conditions that can enable terrorist activity and other forms of violence." ${ }^{441}$ The 2008 QDR also made similar observation.

In the 2010 Quadrennial Defense Review, the US Department of Defense stated that "climate change will contribute to food and water scarcity, will increase the spread of disease, and may

\footnotetext{
${ }^{333}$ Briggs, "Climate Security, Risk Assessment and Military Planning," 1054.

${ }^{334}$ US Department of Defense, "Quadrennial Defense Review” (Washington, DC, 2010).

${ }^{335}$ Goodman, "National Security and the Accelerating Risks of Climate Change," 8.

${ }^{336}$ United States House of Representatives, National Defense Authorization Act for Fiscal Year 2008 (Washington, DC, 2008).

${ }^{337}$ Barack Obama, "National Security Strategy" (Washington, DC: The White House, 2010); Barack Obama, "National Security Strategy" (Washington, DC: The White House, 2015).

${ }^{338}$ US Department of Defense, "Quadrennial Defense Review," 2010; US Department of Defense, "Quadrennial Defense Review" (Washington, DC, 2014).

${ }^{339}$ US Department of State, "Quadrennial Diplomacy and Development Review (QDDR): Leading through Civilian Power," 2010.

${ }^{340}$ Obama, "National Security Strategy," 2015, 2.

${ }^{341}$ US Department of Defense, "Quadrennial Defense Review," 2014.
} 
spur or exacerbate mass migration." ${ }^{342}$ Since that point, a variety of policies have been created. CNA Corporation observed this state claiming that,

We are encouraged to see US policymakers preparing for the changing Arctic. Planning documents now cover the full spectrum of strategic and operational concepts of operations (CONOPS) in the Arctic, including: the National Strategy for the Arctic Region and its Implementation Plan; the Department of Defense Arctic Strategy; the US Navy Arctic Roadmap for 2014 to 2030; and the US Coast Guard Arctic Strategy. ${ }^{343}$

In October 2014, the US Department of Defense released the Climate Change Adaptation Roadmap, which is comprehensive in scope, striking at many of the elements suggested as necessary by the risk governance framework employed in this dissertation. While principally focused on ensuring that infrastructure is ready for the new environment, it also mentions the need to create indicators to better understand how climate affects the security environment, as well as to engage with other countries for training and capacity building.

The 2014 Climate Change Adaptation Roadmap was also important for highlighting the immediacy of the problem. A departure from other organization's literature, it emphasizes the urgency of acting now, rather than an indeterminate time in the future. Moreover, it is resolute in its conviction about the multifaceted challenges that climate change poses for security. In January 2016, the US Department of Defense released their DOD Directive (4715.21) on climate change adaptation and resilience. This document established policy and assigned responsibilities to provide the DoD with the resources necessary to assess and manage risks associated with the impacts of climate change, with respect to implementing the 2014 DoD Climate Change Adaptation Roadmap. ${ }^{344}$

In 2011, the United States Defense Science Board released a report on the implications of climate change on national and international security, which examined "the political consequences of climate change as it relates to national and international security, with special attention to the African continent." 345 It offered recommendations for comprehensive US government efforts to become better informed with respect to climate change, listed the risks that it poses, and recommended measures to implement in preparation. The report acknowledges that the Defense department is not the lead in the US climate effort, but it offers some considerations about how the department may work across US government agencies to support efforts. The Defense Science Board report offers recommendations for an improved and

\footnotetext{
${ }^{342}$ US Department of Defense, "Quadrennial Defense Review," 2010, 85. As noted in previous a previous citation from Michael Ruhle, the security consequences of climate change have been acknowledged by NATO officials, as well. In Europe, however, the European Union appears have taken the initiative and shown a more significant interest in the issue of climate change (as well as its potential security consequences). Betsy Hartmann has been critical of military involvement of the climate security issue. Betsy Hartmann, "Lines in the Shifting Sand: The Strategic Politics of Climate Change, Human Security and National Defense," Rethinking Security in a Changing Climate (Oslo: University of Oslo, 2009); Hartmann, "Rethinking Climate Refugees and Climate Conflict: Rhetoric, Reality and the Politics of Policy Discourse."

${ }^{343}$ Goodman, "National Security and the Accelerating Risks of Climate Change," 19.

${ }^{344}$ US Department of Defense, "DOD Directive 4715.21: Climate Change Adaptation and Resilence," 2016.

${ }^{345}$ Defense Science Board, "Trends and Implications of Climate Change for National and International Security" (Washington, DC, 2011).
} 
better-coordinated climate monitoring system that is consistent with WBGU and a publication of the National Research Council, Climate and Social Stress.

The US intelligence community also explored the security implications of climate and environmental change. In 2008, the National Intelligence Council released a study on the impact of climate change for North Africa (and a corresponding report concerning the geopolitical implications). ${ }^{346}$ From the 2009 Annual Threat Assessment, Chairman of the National Intelligence Council, Dennis Blair wrote that,

climate change alone is unlikely to trigger state failure in any state out to 2030, but the impacts will worsen existing problems such as poverty, social tensions, environmental degradation, ineffectual leadership, and weak political institutions. Climate change could threaten domestic stability in some states, potentially contributing to intra- or, less likely, interstate conflict, particularly over access to increasingly scarce water resources. We judge economic migrants will perceive additional reasons to migrate because of harsh climates, both within nations and from disadvantaged to richer countries. ${ }^{347}$

Amplifying this point, Shea argues that NATO's focus on operations diverts attention away from emerging security challenges - listing cyber and energy security as examples - and that as certain issues become increasingly important for NATO member states, and feature prominently in their national security strategies - even if NATO has no major role in addressing them-there is a danger of a disconnect between NATO-Brussels and national capitals of NATO member states. $^{348}$

Given the increasing importance of incorporating climate change into the national security strategy for NATO member states, the exploration of the security implications of climate and environmental change, such as those given above, provide additional impetus for this aspect to be given greater consideration by NATO.

\section{The Context of NATO Decision Making: Consensus and the Silence Procedure}

The IRGC emphasizes that risk governance is context-specific. This is especially true in the case of NATO, given its decision-making process. NATO's decision-making process is highly restrictive from a risk governance perspective. It requires all twenty-eight (28) members of the organization to offer their 'consent' through a unique procedure established by NATO.

\footnotetext{
${ }^{346}$ National Intelligence Council, "North Africa: The Impact of Climate Change to 2030" (Washington, DC, 2009). National Intelligence Council, "North Africa: The Impact of Climate Change to 2030 - Geopolitical Implications" (Washington, DC, 2009).

${ }^{347}$ Dennis C. Blair, "Annual Threat Assessment of the Intelligence Community for the Senate Select Committee on Intelligence" (Washington, DC: Office of the Director of National Intelligence, 2009).

348 Jamie Shea, "Why Does NATO's New Strategic Concept Matter," Atlantisch Perspectief 34, no. 8 (2010): $8-13$.
} 
Specifically, the North Atlantic Council (NAC), NATO's highest body, makes decisions based on a requirement for consensus, which is achieved through a process in which no government raises its objection. ${ }^{349}$ This process is known as the 'Silence Procedure,' and it governs almost all decisions taken by the NAC. In other words, it consists of a formal vote in which each government states their position is not taken. ${ }^{330}$ This procedure allows governments to avoid confronting other allies by explicitly objecting to a policy. Consensus achieved through this process is clearly differentiated from unanimity, which would require an actively stated vote in favor of a measure.

As NATO's highest decision-making body, the NAC has final discretion as to how security is defined in a given context, and what threatens it. That this body is comprised of 28 member states allows the possibility for divergence of perspective. To the extent that the lack of a shared perception or common understanding of the security environment impedes consensus within the North Atlantic Council, the consequences could be far-reaching, as explained in this excerpt from NATO ACT:

NATO's ability to reach consensus and act rapidly will in large part depend on a common understanding of the new security environment. Different national threat assessments within the Alliance may impede consensus, which would weaken perceptions of NATO's value, relevance, and cohesion. ${ }^{351}$

The silence procedure thus presents NATO with a risk to its ability to make decisions quickly. The plurality of viewpoints within its 28 NATO member states suggests that constant negotiation is necessary to find consensus. ${ }^{352}$ The IRGC notes the consequence of this dynamic - the requirement for member states to find common ground on policy-in the context of risk governance:

An excessive emphasis on inclusiveness can slow down the process of risk assessment, leading to efficiency losses and diminished trust in the process; it can also have the effect of concealing responsibility or shifting it away from the managers and elected and appointed officials accountable for risk decisions. ${ }^{353}$

In 2013, NATO recognized the drawbacks of its decision-making mechanism:

[On] NATO adaptability: As a consensus organization, slow reactions in cooperation with others will remain one of NATO's weaknesses, which gives opponents an asymmetric advantage. Consequently, adaptive cooperation and interoperability will be one of the biggest aims to achieve

${ }^{349}$ Paul Gallis, "NATO’s Decision-Making Procedure" (Washington, DC: Congressional Research Service, 2003).

350 Ibid.

351 NATO ACT, "Framework for Future Alliance Operations Workshop \#4 Final Report-Instability Situations in the Future Security Environment," 6-7.

${ }^{352}$ Gallis, "NATO’s Decision-Making Procedure."

${ }^{353}$ International Risk Governance Council, "Risk Governance Deficits: An Analysis and Illustration of the Most Common Deficits in Risk Governance," 21. 
in the future (in theatre, nationally, and globally). This should enhance partners' ability to adapt rapidly and reduce technology disparity with partners. ${ }^{354}$

NATO's decision-making process is perhaps the most distinctive characteristic of the organization, and it is one of the most restrictive encumbrances from the perspective of risk governance. While the requirement for consensus is a source of strength once policy is agreed upon, it also obstructs the advancement of policy concerning problems not yet fully manifested.

\section{NATO in the context of a new environment}

The responsibility for managing climate security risk spans a diverse group of member states and international and non-governmental organizations, suggesting a multi-faceted approach is required. While these entities are free to approach the climate-security problem individually, for each to actively pursue its objectives independently would be to lose sight of the need to coordinate and the notion that cooperation and new relationships will be necessary to address future challenges.

A great deal of effort has been expended to conceive ways in which NATO forces can work together more effectively, but the way that NATO interacts with other members of the international community has not received the same attention. Contrary to the formal scenarioexercises conducted by NATO about the future security environment and what it implies for resources and operations, there have been comparatively few similar systematic exercises about how the policies and programs of NATO Headquarters must adapt to meet future situations. ${ }^{355}$ This general trend was previously noted, but little detailed attention has been given to the issue of institutional capabilities and frameworks that determine the policies affected by a changing climate. $^{356}$

Climate security risk presents new imperatives and serves as an impetus to take a considered approach to cooperation. By virtue of its multilateral nature and its established processes to address a wide range of security challenges, it so happens that NATO is well situated to coordinate among relevant organizations. Renn and Walker provide helpful context in this regard:

The UN Security Council was established in an environment where the dominant global risk was the threat of war and nuclear weapons. Since that time, trans-boundary risks have multiplied and arguably represent

\footnotetext{
${ }^{354}$ NATO ACT, "Framework for Future Alliance Operations Workshop \#1 Final Report—Leading NATO Military Transformation," 9.

${ }^{355}$ In April 2014, NATO held a high level meeting in Paris entitled the "Transformation Seminar Conference." While this event discussed NATO in the context of an increasingly volatile security environment, there was seemingly no discussion of climate issues, and little appetite for new roles. Fondation pour la Recherche Strategique, "NATO Transformation Seminar Conference Report, 7-9 April 2014" (Paris, 2014).

${ }^{356}$ UK Royal Commission on Environmental Pollution, “Adapting Institutions to Climate Change.”
} 
larger risks than the risk of war. Will we see new global structures addressing this new risk complexity ${ }^{357}$

It is evident that the international institutions that are already established will be the ones that must face the challenges of climate change. There simply will not be time to establish a new set of institutions to counteract the security challenges that climate change will bring. Some of these challenges will fall into the gaps of the present institutional arrangement. To minimize the likelihood of this scenario, current institutions will need to take on new responsibilities and work together to address new challenges. What remains pivotal is that much of NATO's present activity coordinates the activities of individual nations (and organizations); this is consistent with NATO's comprehensive approach and could be applied more broadly in a new context. ${ }^{358}$

\section{The Potential for Confoundedness}

One of the principal confounding aspects about any potential NATO engagement on climate security risk is how to distinguish between what value may be contributed by a NATO policy from the value contributed by other international organizations or individual NATO member states. When bilateral development agencies of individual member states, international organizations, the European Union, or multi-lateral development banks already have programs that aim to mitigate the potential security consequences of climate change, what distinct value can NATO provide without impeding efforts?

A related intellectual stumbling block, when attempting to view this problem through the prism of NATO, is that NATO actions are typically implemented by individual member states that agree to act collectively (or in a coordinated fashion), unless the action falls within the narrow remit of capabilities that NATO operates on behalf of members states (i.e. AWACS). ${ }^{359}$

In a manner of speaking, NATO already is taking action on the issue of climate and security through its member states, despite the lack of an official NATO policy. The United States operates Africa Command, and it has done extensive planning with respect to the Arctic. Canada and Norway are leaders among NATO militaries with respect to Arctic operations. The French maintain a military presence in Africa as a result of their colonial history. The British run a variety of activities. European and North American bilateral development agencies operate programs in Africa and the Middle East, and NATO itself has been involved in a variety of endeavors on the African continent.

Moreover, a significant amount of joint and bilateral training already occurs among NATO members in the Arctic. Norway relocated its Armed Forces Operational Headquarters to Bodo, north of the Arctic Circle, in 2009. ${ }^{360}$ Additionally, NATO's military headquarters (SHAPE) can conduct planning for a variety of contingencies, including those that the FFAO effort identified as driven or worsened by climate change. Thus, a fundamental consideration for the remainder of

\footnotetext{
${ }^{357}$ Renn and Walker, Global Risk Governance. Concepts and Practice Using the IRGC Framework.

${ }^{358}$ NATO, "Implementation of the Comprehensive Approach Action Plan and the Lisbon Summit Decisions on the Comprehensive Approach."

${ }^{359}$ AWACS stands for Airborne Early Warning and Control.

${ }^{360}$ Page Wilson, "Between a Rock and a Cold Place? NATO and the Arctic" (E-International Relations, 2013).
} 
this dissertation is whether agreement within the North Atlantic Council is the only distinction between what is happening at the moment and a formal NATO role.

However, even though any particular policy or action considered for NATO within this research could be performed by another international organization or sovereign state, this fact should not deter NATO from instituting a policy aimed at the same objectives. With the exception of its original purpose as a military alliance to counter the presence of the Soviet Union, nearly every policy that NATO has adopted - from military intervention in the Balkans and Afghanistan, to Science for Peace - could have conceivably been implemented by a sovereign or another international organization. While recognizing that NATO generally seeks a harmonious relationship with the rest of the international community, it need only consider whether its future actions promote its own interests, with respect to safeguarding against the consequences of potential instability in the Middle East and North Africa, and other issues related to the Arctic.

Moreover, NATO has one attribute that individual member states cannot achieve independently, and that is the legitimacy associated with the multi-lateral nature of the organization. NATO provides a political engagement platform that is often viewed favorably by potential partners because of its multi-lateral nature and its track record of programs that promote peaceful security engagement.

That being said, the circumstances of some nations' relationships with NATO may have a narrow source of inspiration. When attempting to assess the willingness of eastern European and central Asian nations to cooperate with NATO, as compared to those elsewhere, such as in Africa, one may wonder whether the former pursued NATO cooperation as a gesture of political rejection of Russia, rather than because of any potential expertise NATO may provide.

For some eastern European states, and certainly for those in the Balkan Peninsula, the perception that NATO partnership (and eventual membership) was viewed as a stepping-stone to membership with the European Union provided an incentive for cooperation. In the context of climate and security, NATO will fail to benefit from a similar circumstance with respect to establishing a basis for cooperation, and therefore cooperation in the context of climate change will need to add inherent value to both NATO and the partnering nation.

\section{Conclusions}

This chapter discussed why a risk governance approach was selected to conduct the analysis in this dissertation, in particular the IRGC framework, and provided an overview of the risk governance context for NATO with respect to climate security.

NATO finds itself in a complicated and crowded institutional environment in the context of climate security risk. A variety of international organizations - as well as NGO and member state agencies - share responsibility for the potentially adverse and wide ranging impact of a changing climate. Yet, NATO has the resources and relationships to allow it to play a role in shaping, guiding, and implementing actions on the climate-security nexus.

The landscape of institutions with responsibility or interest in climate change and security is comprised of a mosaic of organizations. It should, therefore, come as no surprise that these 
organizations have so far been unable to find a coordinated response. NATO will also struggle to articulate a formal position on climate change and security because of its consensus-based decision-making process. Still, a risk governance analysis can facilitate a discussion because it harnesses a broad array of risk considerations that could promote insights on whether NATO has adequately addressed the climate security risk it faces.

The problem of climate security risk requires difficult tradeoffs of attention and resource allocation. Policy makers must weigh various dimensions to make decisions. Even though the comprehensive view is preferred to individual analytic conclusions, information on climate security risk is nevertheless insufficient to render a complete understanding of the scope and implications because the location and magnitude of risks to be mitigated are deeply uncertain, global in nature, and highly complex (discussed in Chapter 2).

The key takeaway here is that these characteristics of the problem aligned with the intent of the IRGC Risk Governance Framework. Thus, the analysis in this dissertation facilitates a second, dual purpose of testing the feasibility of the framework for the type and scope of problem for which it claims to have been created. The IRGC framework purports to allow a macro view of risk dimensions and facilitates the considerations needed to develop comprehensive assessment and management strategies to cope with risks at the global level: it reveals what is known, what is not known, and what may never be known about the risks. 


\section{Chapter 5: A Risk Governance Case Study}

\section{Introduction}

This chapter presents a case study of the security consequences of climate change, particularly as they concern NATO, conducted through the prism of the International Risk Governance Council (IRGC)Risk Governance Framework. Risk governance frameworks provide an analytic structure from which to systematically approach risk and situate judgments about risk management within a broader context. ${ }^{361}$ In seeking to improve risk outcomes, the IRGC framework is intended to be applied to a spectrum of risk management issues from assessment through to management. ${ }^{362}$

The case study is drawn from the climate aspects of the NATO Allied Command Transformation (ACT) Strategic Foresight Analysis (SFA) 2013 Report and its corresponding workshop documents, as well as those generated by NATO ACT's Framework for Future Alliance Operations effort (FFAO). In particular, three (3) Comprehensive Instability Situations (from this point forward, referred to as 'Instability Situations') identified in Chapter 3 have been selected to represent the hazards that lead to the risk (security implications) of climate change, namely: access and use of global commons challenged, disruptive impact of migration, and large-scale disaster. $^{363}$

Using Instability Situations identified by NATO ACT in recent foresight initiatives, this analysis examines what is known about the risks that are thought to result from climate-induced change in the natural environment. The analysis reveals and examines what is known about the risks that may emerge from climate-induced change in the natural environment, as well as NATO's posture and ability to manage them.

The IRGC framework is divided into four (4) phases: Pre-Assessment, Risk Appraisal, Tolerability and Acceptability, and Risk Management. Proceeding according to the four phases, I discuss how NATO fulfills (or lacks the means to fulfill) the risk governance required by the framework, or how the characteristics of the problem (or the institutional dynamics and constraints of NATO) encumber or obstruct this work.

The final two phases are particularly challenging to examine this problem without privy access, as much of the information needed (particularly concerning policy documents and discussion within NATO) is not publicly available. Specifically, the information required for an analysis of risk management options is not publicly available from NATO.

${ }^{361}$ Lavell et al., "Climate Change: New Dimensions in Disaster Risk, Exposure, Vulnerability, and Resilience," 44. The IPCC notes "This process [referring to the risk governance process described in Renn 2008, which was the precursor and forerunner to the framework employed in this dissertation] is consistent with those in the UNISDR Hyogo Framework for Action (UNISDR, 2005), the best known and adhered to framework for considering disaster risk management concerns."

${ }^{362}$ Renn, "Risk Governance-Towards an Integrative Framework."

${ }^{363}$ These instability situations are 'Access to the Global Commons' (the context of climate change I have interpreted to refer to security issues in the Arctic), 'Natural Disasters', and the consequences of (mass, unprecedented) 'Migration'. 
Also, the Tolerability and Acceptability Judgment is highly dependent on context and circumstance, and it is thus difficult to consider ex-ante. Yet, given that a changing natural environment is a driving factor, NATO doesn't have a choice as to whether to 'accept' the risk. NATO needs, therefore, to consider what options may be available when — or if - the day of reckoning comes.

\section{Phase 1: Pre-Assessment}

The IRGC Risk Governance Framework identifies four (4) elements of pre-assessment: problem framing, early warning, screening, and scientific conventions. All four are relevant in the case of NATO and climate change. Pre-assessment develops a common basis for discussing the risks by capturing issues that stakeholders and society associate with a certain risk, as well as existing indicators, routines, and conventions that may narrow the scope of what is addressed as risk. ${ }^{364}$

Therefore, before confronting a risk as it relates to the context of climate security, NATO would seek to answer the following two questions:

1. What is understood by the term 'risk'? The IRGC describes risk as

$\ldots$ an uncertain consequence of an event or an activity with respect to something that humans value, consisting of a combination of two components: the likelihood or chance of potential consequences and the severity of consequences of human activities, natural events or a combination of both. ${ }^{365}$

The IRGC further distinguishes 'risks' from 'hazards,' describing the latter as "the potential for harm or other consequences of interest.",366

2. What indicators are there for the existence of a risk? As noted by the IRGC, "The scarcity of resources obliges societies to select particular topics to undergo the process of risk governance. This choice is not easy, because opinions may vary widely ... [as to] ... what counts as a risk." 367

In the context of NATO and climate change, the risk is not precisely defined, although its contours can be inferred. Security throughout the region is what the population values in the NATO member states, so the risk (i.e. uncertain consequence) is that a changing climate will worsen the North Atlantic security environment or the regions that affect it, either directly, or indirectly. ${ }^{368}$

\footnotetext{
${ }^{364}$ Ibid., 13.

${ }^{365}$ Ibid., 19. The 'event or activity' is the Risk Agent, or the source of the risk: climate change. Note that Briggs, and others, would add 'uncertainty' to the two factors listed here (likelihood and severity) to the definition of risk.

${ }^{366}$ Ibid.

${ }^{367}$ Renn, "White Paper No. 1: Risk Governance-Towards and Integrative Approach."

${ }^{368}$ Renn, "Risk Governance-Towards an Integrative Framework," 19.
} 
The IPCC refers to risks that arise out of complex climate and socioeconomic systems emergent risks. ${ }^{369}$ Emergent risks can be categorized by type, such as those arising from multiple interacting stressors and systems, as well as by indirect impacts, trans-boundary impacts, and impacts occurring a long-distance from the location or event that causes them. ${ }^{370}$ Certain issues - such as migration - contain all three of these properties.

To understand better NATO's risks, NATO's concept of the term 'security' must also be clarified. The Strategic Foresight Analysis workshops suggest the following as a point of reference:

The futures team defines security implications for NATO as the challenges to and opportunities for attaining the level of ambition as outlined in the Strategic Concept ... "[to] safeguard the freedom and security of all its members..." and defined by the core tasks, and in maintaining the viability of the Alliance as a political and security organization with particular emphasis on sustaining Article 5. Security, as a condition, is the degree of resistance to, or protection from, harm. It applies to any vulnerable and valuable asset, such as a person, dwelling, community, nation, or organization. ${ }^{371}$

Thus, security for NATO is determined according to the extent to which the level of ambition in the Strategic Concept is threatened, whereby the threat to the level of ambition is defined with respect to the three (3) core tasks: Collective Defense, Crisis Management, and Cooperative Security. However, this is problematic from the perspective of risk governance. Not only does this formulation include a wide spectrum of responsibilities, the 'level of ambition' in the Strategic Concept, and what might threaten it, is not explicitly stated - it must be inferred.

Moreover, the Strategic Concept is, at best, a hybrid document that fuses military insight with consensus-driven Alliance political interests: it was not developed for the purpose of making explicit risk management judgments, and it allows for a range of interpretations. This is perhaps by necessity, as the Alliance cannot confidently foresee or predict the circumstances in which it will find itself, and so must retain the flexibility to react and adapt to new situations. To the

${ }^{369}$ Oppenheimer, Campos, and Warren, "Emergent Risks and Key Vulnerabilities," 8. Note that the IRGC, the OECD, and others have also focused on the issue of emerging risk. Among them are the following reports: International Risk Governance Council, "Improving the Management of Emerging Risks.", and OECD, "Emerging Risks in the 21st Century, An Agenda for Action." NATO has also established a division to focus on Emerging Security Challenges, under the leadership of Dr. Jamie Shea. See NATO, "New NATO Division to Deal with Emerging Security Challenges."

${ }^{370}$ Oppenheimer, Campos, and Warren, "Emergent Risks and Key Vulnerabilities," 8.

${ }^{371}$ NATO ACT, "Framework for Future Alliance Operations Workshop \#1 Read Ahead: Ensuring a Mission Ready Alliance-Forging the Future, Leading NATO Military Transformation," 9-10., and NATO ACT, "Strategic Foresight Analysis Workshop \#3 Read Ahead: The Shared Perspective of the World in 2030 and Beyond Security Implications," 2012, 2. Note that the Annex of this document contains a useful description of NATO's three 'Core Tasks' in addition to explanatory examples. Maintenance of security in the North Atlantic region is by no means controversial; it is the primary objective of the Alliance and is enshrined in the North Atlantic Treaty. As signatories of the treaty, all NATO member states subscribe to this overarching purpose. NATO's three core tasks are the following: 1) Collective Defense (NATO members will assist each other against attack, in accordance with Article 5 of the Washington Treaty), 2) Crisis Management, and 3) Cooperative Security. 
extent that NATO holds responsibility for collective action in the context of international security, responsibility for risk management accrues to it as a function of the role and purpose it serves.

With respect to other operating definitions for our purposes here, the IRGC definition above refers to a 'hazard' as 'a potential source of harm,' and expands upon that definition as follows:

In conceptual terms, hazards characterize the inherent properties of the risk agent and related processes, whereas risks describe the potential effects that these hazards are likely to cause. ${ }^{372}$

Thus, in the pre-assessment phase, a hazard in this case would be aspects of climate change that may interact with human (social and political) systems as well as the natural system to worsen the security environment. Specifically, the hazard in the case of climate change is that the changing climate alters the natural environment in such a way that the social and political systems within which it interacts shift to points of greater friction, competition, or potential breakdown, such that negative political, economic, or physical security consequences are more likely to result.

Climate change itself is not a risk. Rather, climate change and related hazards interact with the evolving vulnerability and exposure of systems to determine the level of risk. ${ }^{373}$ In this case, the hazards are the Instability Situations identified in the Framework for Future Alliance Operations workshops (included in Chapter 3). These describe the characteristics by which they threaten to negatively affect security. NATO identified climate as a driving factor for 1) access and use of global commons challenged, 2) disruptive impact of migration, and 3) large scale disaster. ${ }^{374}$

The IRGC notes the importance of distinguishing between hazards and risks, but also performing identification (i.e. establishing a cause-effect link) and estimation (i.e. determining the strength of the cause-effect link) for hazards and risks separately. Importantly, the estimation of risk depends on an exposure and/or vulnerability assessment. ${ }^{375}$ 'Exposure' refers to the contact of identified hazards with the individuals, ecosystems, buildings, etc. of concern (referred to as the 'target'), while 'vulnerability' describes the various degrees of harm the target can experience as a result of exposure. ${ }^{376}$

It is important to note that NATO SFA/FFAO efforts did not perform identification or estimation of the hazards. Empirical researchers have attempted to perform identification and estimation for the climate and security risk generally (often focusing on violent conflict), although not for NATO's exposure and vulnerability to the hazards in question. NATO's exposure and vulnerability in this regard are also dynamic - likely functioning in ways that we don't

${ }^{372}$ Renn, "Risk Governance-Towards an Integrative Framework," 19.

${ }^{373}$ Oppenheimer, Campos, and Warren, "Emergent Risks and Key Vulnerabilities," 11. (Citing IPCC SREX:) There is an excellent listing of the hazards that result from climate change on pages 83 to 100 of Oppenheimer, Campos, and Warren, "Emergent Risks and Key Vulnerabilities."

${ }^{374}$ These instability situations are 'Access to the Global Commons' (the context of climate change I have interpreted to refer to security issues in the Arctic), 'Natural Disasters,' and the consequences of (mass, unprecedented) 'Migration'.

${ }^{375}$ Renn, "Risk Governance-Towards an Integrative Framework," 27.

376 Ibid. 
understand or that cannot be captured in a model - and they are different for each of the three Instability Situations under consideration. ${ }^{377}$ Therefore, in addition to the two critical aspects of climate change discussed in Chapter 2, it is not clear that the identification and estimation requirement is feasible in the instances under consideration here. The IPCC describes the difficulties of this endeavor more generally in the following passage:

Projecting future vulnerability and response capacity involves predicting the trends and changes in underlying causes of human vulnerability and the behavior of complex human systems under potentially stressful and novel conditions. ${ }^{378}$

This suggests a formidable task in the context of the three Instability Situations that NATO identified. Moreover, security analysis at this level of sophistication and detail is not typical. That these aspects can vary with time adds further complexity. In 2012, the IPCC also noted that:

climate extremes, exposure, and vulnerability are characterized by uncertainty and continuous change, and shifts in any of these components of risk will have implications for the impacts of extreme events. Generally, there is limited literature on the potential future impacts of extreme events; most literature analyzes current impacts of extreme events. This focus may result in part from incomplete knowledge and uncertainties regarding future changes in some extreme events as well as from uncertainties regarding future exposure and vulnerabilities. ${ }^{379}$

The incomplete knowledge surrounding the exposure and vulnerability to the three Instability Situations under consideration is significant. Moreover, the fact that they will change with time undermines the use of extensive resources to track and model their development in a detailed manner. An ensemble of scenarios (including worst-case) may better serve the practical interests of NATO.

\section{Risk (or, Problem) Framing}

The first component of pre-assessment is risk framing. The IRGC notes that 'risk framing' places particular importance on the need for all interested parties to share a common understanding of

${ }^{377}$ In 2009, Briggs noted that "Understanding the risks and impacts of abrupt climate change requires interdisciplinary cooperation among researchers, which is often hampered by disciplinary boundaries and organizational fragmentation at universities and research centers. Security impacts of abrupt climate change are even more difficult to coordinate, owing to a nascent field of environmental security (which does not even possess its own research journals [circa 2009]), and historic lack of cooperation between environmental scientists and those specializing in traditional security fields." Briggs, "Environmental Security, Abrupt Climate Change and Strategic Intelligence," 5.

378 Lavell et al., "Climate Change: New Dimensions in Disaster Risk, Exposure, Vulnerability, and Resilience," 46.

${ }^{379}$ J. Handmer et al., "Changes in Impacts of Climate Extremes: Human Systems and Ecosystems," in Managing the Risks of Extreme Events and Disasters to Advance Climate Change Adaptation. A Special Report of Working Groups I and II of the Intergovernmental Panel on Climate Change, ed. C. B. Field et al. (Cambridge, United Kingdom and New York, NY, USA: Cambridge University Press, 2012), 239. 
the risk being addressed or, otherwise, to raise awareness among those parties of the differences in what is perceived as a risk. To achieve a common understanding, actors need to agree with the underlying goal of the activity (or event generating the risk), and be willing to accept the risk's foreseeable implications on that goal. ${ }^{380}$ While this may seem a simple matter prima facie, reaching an agreement and being willing to accept the relevant risk is not only highly nuanced, but crucial to all that follows. As the UK Royal Commission on Environmental Pollution defined it,

[f]raming a problem involves recognizing its existence, and understanding its nature and its direct and indirect implications for the particular institution. This is perhaps the most challenging aspect of building adaptive capacity. ${ }^{381}$

NATO ACT's Strategic Foresight Analysis (and FFAO) efforts sought to advance a common view of the future security environment to serve as a baseline upon which to begin forming a consensus perspective. In so doing, NATO ACT made an effort to understand how the security environment can generate risks that concern the Alliance. Reaching consensus on the drivers that influence the future security environment was one objective of the Strategic Foresight Analysis initiative. ${ }^{382}$ This effort serves as the platform for NATO to "share a common understanding of the risk being addressed or, otherwise, to raise awareness amongst those parties of the differences in what is perceived as a risk," as noted above. NATO ACT's SFA/FFAO work is a start, but it is not sufficient to frame the risk directly in the context of NATO that would enable adaptation (this requires, at the very least, further discussion and agreement in the NAC).

The difficulty in framing the risk in a way that is relevant to NATO is a critical shortcoming. Moreover, without risk framing, the remaining steps in this phase (and others) cannot reasonably be taken. The IRGC explanation of risk framing is written from the context of an organization having control over some issue or technology that generates risk. However, in the case of NATO and climate change, the "goal of the activity or event generating the risk" (i.e. a changing climate) is not under the control of NATO. True, NATO can set the degree of ambition in pursuit of the strategic concept, but its primary activity is to sustain the organization and provide a consistent level of security to the population. It is only in that context, then, that NATO can seek to understand how, and can prepare for, the security consequences that arise from a changing climate. Understanding how the consequences arise from climate change is in many respectsthough, not entirely - a prerequisite for preparing for them.

More problematic for NATO, however, is the manner and variance in how threats to security are perceived. Threats are not absolute, undeniable facts. Instead, they are judgments based on perceptions by many different political actors. Using the Strategic Concept and the core tasks as a point of reference to judge 'security' poses a challenge for risk governance, because the concepts involved encompass a wide spectrum of potential threats and risks, and so they are subsequently subject to diverse perspectives. In actuality, the severity and manner in which security is perceived to be threatened is dependent on context and circumstance, varying

\footnotetext{
${ }^{380}$ Renn, "Risk Governance-Towards an Integrative Framework," 13.

${ }^{381}$ UK Royal Commission on Environmental Pollution, “Adapting Institutions to Climate Change," 76.

382 NATO ACT, “Strategic Foresight Analysis Workshop \#1 Read Ahead: Global Review,” 3.
} 
according to the geographic location of member states (i.e. the proximity of the 'threat'), influenced by historical experience, and weighed in light of economic and political interests. ${ }^{383}$

The SFA/FFAO workshops recognized the problems that result from the absence of a single, shared threat perspective, noting that:

Multiple threat perceptions amongst NATO members exist. Diverging national, regional and functional priorities and perceptions makes NATO increasingly ineffective at the POLMIL [political-military] level and subsequently unprepared at the military, operational level. Absence of a shared perspective may result in regionalization and emergence of ad-hoc coalitions. ${ }^{384}$

The potential for a lack of shared threat perspective has a potentially deeper and more profound impact on the Alliance. Considering the near-term consequences for this potential issue, the first FFAO workshop concluded that:

Multiple threat perceptions amongst NATO members exist: Different priorities between nations drive nations apart. Differences in national interests detract from unified action and Alliance wide progress and could divide and delay support for capability development. ${ }^{385}$

In other words, if NATO actors cannot agree on the threats or risk, NATO actors cannot agree on the collective solutions, and so are restricted in coordination and acting. The UK Ministry of Defense also recognized the potential consequences of multiple perspectives that are inherent in the organization (and potentially diverging), writing that:

NATO is likely to remain the key organization for military crisis management, although its cohesion may be challenged by diverse threat perceptions, a US focus on Asia and internal disagreement on its global

${ }^{383}$ Note that any member of the Alliance can invoke Article 4 of the North Atlantic Treaty (a request to convene a meeting of the North Atlantic Council to 'consult' with Allies) so long as it 'feels' that its security is threatened; it is entirely based upon the perception of the member state. NATO, "The North Atlantic Treaty," 1949.

${ }^{384}$ NATO ACT, "Framework for Future Alliance Operations Workshop \#1 Final Report-Leading NATO Military Transformation," 12 . The following point was raised on page 5 of this source, which has impact on the issue of common threat perspective: "Shifting Migration patterns yield diverse effects on NATO. As NATO nations integrate larger immigrant populations, there is an increase in pressure to intervene or not intervene out of area to shape events in immigrant lands of origin. Also, migration might destabilize and radicalize countries outside NATO and pressure the Alliance to intervene. The migrant population alters the personnel base and potentially challenges the corporate culture within NATO Nations military." However, a later workshop in this series (\#4) expressed a slightly different perspective with respect to migration: "Natural, economic and man-made events yield diverse effects. Economics induced migration could revive western societies, compensate for declining indigenous populations thus supporting workforce and skills base; and/or internal unrest caused by immigrants' inability or resistance to culturally assimilate. Transnational extremist and criminal organizations may exploit this seam." NATO SACT, Framework for Future Alliance Operations Workshop \#4 - Instability Situations in the Future Security Environment, 13.

${ }^{385}$ NATO ACT, "Framework for Future Alliance Operations Workshop \#1 Final Report-Leading NATO Military Transformation," 4. 
role. The Alliance could be reinvigorated by the need to band together to address a deteriorating security situation in Europe's near abroad. ${ }^{386}$

Effective planning, engagement, and response requires that NATO establish a common perspective on the security threats posed by climate change and the policies or measures required in response, and incorporate that perspective into the NATO defense policy planning process. Response capacity refers to NATO's ability to react following a security incident or a natural hazard and respond to it. Effective response typically requires ex-ante planning and investment in preparedness and early warning to build the appropriate capacity. ${ }^{387}$

Increasingly frequent and severe natural disasters caused by climate change suggest that NATO forces could be asked to assume an expanded role with respect to natural disaster response and assistance. Particularly on the African continent, extreme climate events can potentially overwhelm local efforts to address and cope with any resulting crisis or emergencies. ${ }^{388}$ In the Arctic, environmental emergencies (particularly in the maritime domain) could require military response capacity, and few NATO militaries are trained or equipped to operate in the region.

\section{Early Warning}

The second step in the pre-assessment phase, early warning and monitoring, establishes whether signals exist to indicate the realization of the risk. It also investigates the institutional means to monitor the environment for early warning signals. ${ }^{389}$ NATO has recognized the imperative of early warning, noting in the 2010 Strategic Concept that the "best way to manage conflicts is to prevent them from happening. NATO will continually monitor and analyze the international environment to anticipate crises.",390

The NATO Intelligence Warning System (NIWS) was established to provide indication of potentially concerning security issues for NATO. However, given the relative neglect of climate issues at NATO, the NIWS may not be well suited or configured for the specific problem of climate or environmental risk. It is likely that this could be better achieved through collaboration between the climate science community and the national security community. However, the possible inadequacy of the NIWS system speaks just as much to the complexity of the problem as to a failing of NATO.

\footnotetext{
${ }^{386}$ UK Ministry of Defence, "Global Strategic Trends - Out to 2045" (London, UK, 2014), xxiii.

${ }^{387}$ O. D. Cardona et al., "Determinants of Risk: Exposure and Vulnerability," in Managing the Risks of Extreme Events and Disasters to Advance Climate Change Adaptation. A Special Report of Working Groups I and II of the Intergovernmental Panel on Climate Change, ed. C. B. Field et al. (Cambridge, United Kingdom and New York, NY, USA: Cambridge University Press, 2012), 74, 75.

${ }^{388}$ US National Research Council, Climate and Social Stress: Implications for Security Analysis, 21.

${ }^{389}$ Renn, "Risk Governance-Towards an Integrative Framework," 13. Note that Briggs (among others) has observed that the military community can play a key role in strategic scenario planning and developing early warning systems for environmental security in a climate context. Chad M. Briggs, "Environmental Change, Strategic Foresight, and Impacts on Military Power," Parameters Autumn (2010): 1. citing John T. Ackerman, "Climate Change, National Security, and the Quadrennial Defense Review. Avoiding the Perfect Storm," Strategic Studies Quarterly Spring (2008): 56-96.

${ }^{390}$ NATO, "Strategic Concept," 19-20.
} 
While the NIWS system is potentially sufficient to maintain awareness of maritime and air activity in the Arctic, it is only so because these are conventional (not emerging) aspects of the three Instability Situations under consideration. The capability to monitor maritime and air activity is reasonably well established (although not necessarily in the Arctic, yet). However, indications alone are not sufficient to understand the security implications, particularly where they concern the presence of military forces, a judgment of intent is more important. As noted by Renn, "[e]ven if there is agreement of what should be framed as a risk, there may be problems in monitoring the environment for signals of risks." 391

With respect to migration and natural disaster (particularly outside of the North Atlantic region), the extent to which early warning indications should be taken to signal a risk to the Alliance are less clear. NATO may need to develop the capability to understand these potential risks, or partner with other institutions that are better positioned and resourced to evaluate the implications of various indicators.

Previously, the Global Energy and Environment Strategic Ecosystem program (Global EESE) of the US Department of Energy created a process to provide early warning of energy- and environmental-related stability, which sought to leverage outside experts rather than in-house expertise. This platform would potentially require only modest funding and thus could be a model for NATO. ${ }^{392}$ Briggs describes the system this way:

The system ... was meant to provide early warning of potential instabilities at home and abroad, identifying key uncertainties and areas where more monitoring would be needed in order to avoid strategic surprises. This required identifying key vulnerabilities in energy and environmental systems by translating scientific data into security risks. ${ }^{393}$

Other organizations and disciplines provide examples for NATO of ways to effectively monitor emerging situations that could signal the emergence of security problems. For instance, the International Crisis Group produces CrisisWatch and the Famine Early Warning Project as developed by USAID. These programs monitor the conditions and status of identified issues and they make use of indicators (often with subjective components within them, in one form or another) to serve as an early-warning tool.

There is an increasing integration of weather and climate forecasting products into early warning systems, including heat wave and health warnings designed to predict possible outcomes and identify triggers. ${ }^{394}$ However, in 2014 the IPCC noted that monitoring has been, and continues to

\footnotetext{
${ }^{391}$ Renn, "Risk Governance-Towards an Integrative Framework," 24.

392 Briggs, "Environmental Change, Strategic Foresight, and Impacts on Military Power," 3.

393 Ibid., 3,4. In 2011, Briggs noted "The US Department of Energy sponsored a prototype early warning system from 2007-2010, the Global Energy and Environment Strategic Ecosystem (GlobalEESE), while US military services are attempting to address emerging risks from environmental changes in the Arctic. This includes the Navy's Task Force Climate, and the Air Force's Minerva Program." Briggs, "Arctic Environmental Security and Abrupt Climate Change," 11.

394 Ian Noble and Saleemul Huq, "Adaptation Needs and Options," in Climate Change 2014: Impacts, Adaptation, and Vulnerability. Part A: Global and Sectoral Aspects. Contribution of Working Group II to the Fifth Assessment Report of the Intergovernmental Panel on Climate Change, ed. C. B. Field et al. (Cambridge, United Kingdom and New York, NY, USA: Cambridge University Press, 2014), 17.
} 
be, inadequate to detect and attribute the effect of climate change on human systems, with the exception of food production. ${ }^{395}$ The National Research Council concluded a study in 2013 that focused on the social stress associated with climate change. The Chair, Dr. John Steinbruner, noted that a system capable of collecting the information needed to truly understand the security implications of climate is not presently available:

We need to develop a monitoring system worthy of the problem. We're not monitoring the details of climate change and social change associated with that in anything like the precision that would be required to understand them. This would require bringing together the various assets we have to create an integrated system monitoring climate variables and related social variables so that we can watch on a high-resolution basis as these situations develop. ${ }^{396}$

While it is the case, then, that NATO's early warning capability may not be perfectly configured for a situation where climate factors have increasing salience for security, a variety of other initiatives provide a foundation upon which future action and policy initiatives within NATO could be based.

\section{Screening}

The third step in pre-assessment - screening - concerns the practice of conducting preliminary probes into hazards or risks. Once this is carried out, the risk can be assigned to pre-defined assessment and management channels based on prioritization schemes and existing models for dealing with risk. ${ }^{397}$

To the extent that the management 'route' of pre-screening exists within the present NATO processes (beyond the situational awareness performed by NATO's Intelligence Division), an issue can be raised within the Alliance (generally by a member state) for consideration by the NAC, which can, in turn, request analysis of the situation from another NATO agency or a division within NATO Headquarters. Once the NAC deems it understands the issue and surrounding factors, it can task an appropriate committee to generate options. ${ }^{398}$

\footnotetext{
${ }^{395}$ Auffhammer et al., "Detection and Attribution of Observed Impacts," 19.

${ }^{396}$ Steinbruner, "World Affairs Council Keynote Address: The International Security Implications of Climate Change." Using national intelligence assets for the purpose of monitoring the impact of climate change was also suggested by Simon Dalby in 1995. Simon Dalby, "Security, Intelligence, the National Interest and the Global Environment," Intelligence and National Security 10, no. 4 (1995): 175-97.

${ }^{397}$ Renn, "Risk Governance_-Towards an Integrative Framework," 13.

${ }^{398}$ The IRGC notes that finding agreement (consensus) on what requires consideration as a risk depends on the legitimacy of the selection rule. Acceptance of the selection rules rests on two conditions. First, all actors need to agree with the underlying goal. Second, the actors need to agree with the implications that the identified hazard can have on the desired goal.
} 


\section{Scientific Conventions}

As the final element of Pre-Assessment, the IRGC framework seeks to determine the assumptions and parameters of scientific modeling to further evaluate methods and procedures for assessing risks and concerns. It also seeks to understand the emotions associated with assessing the risk. ${ }^{399}$

A formal scientific convention by which to judge precisely the nature and severity of a threat in the context of climate security generally has not yet been firmly established. However, a metric can be created with respect to NATO's security interests in the Arctic, as it involves many components of conventional security problems. As climate security concerns migration and natural disasters, however, conventions would need to be developed or adapted to fit the context. $^{400}$

Thus far, academics, international organizations, research institutes, and public scientific organizations have analyzed available data to create indicators and measures for a variety of climate-related issues. In addition to the two cited in the Early Warning section above, there are measures for climate impacts, resilience, and fragility for other parts of the world. ${ }^{401}$

In one particular example, the University of Texas-Austin hosted a project on Climate Change and African Political Stability, funded by the US Department of Defense MINERVA Initiative to create products to measure and assess the impacts of climate change. ${ }^{402}$ The project mapped regional vulnerability (for political stability in Africa) using geographic information systems (GIS), which can help stakeholders visualize the impacts of climate change and also serve an early warning function. ${ }^{403}$

The Failed State Index ${ }^{404}$ (Fund for Peace, Foreign Policy) and the Corruption Perception Index (Transparency International) can be used to characterize institutional vulnerability and governance failure. ${ }^{405}$ There are a series of related indices designed to assess relative disaster

${ }^{399}$ Ibid., 13, 26.

${ }^{400}$ Note that the IRGC posits that "increasingly rapid oscillations between extreme states (e.g. increasing market or social volatility) is a potential predictor of a slow developing catastrophic risk (presumably in the later stages ... when it emerges as an observable problem); IRGC further notes, however, that the use of these indicators as predictive tools applied to social and economic change is still at an early stage. International Risk Governance Council, "Preparing for Future Catastrophes: Governance Principles for Slow-Developing Risks That May Have Potentially Catastrophic Consequences" (Lausanne, 2013), 3.

${ }^{401}$ See USAID, "Measuring Fragility," 2005; USAID, "Fragile States Indicators: A Supplement to the Country Analytical Template" (Washington, DC: USAID, 2006); Javier Fabra-Mata and Bo Jensen, "Governance Measurements for Conlict and Fragility" (Oslo: United Nations Development Programme, 2012).

${ }^{402}$ See https://strausscenter.org/ccaps/.

${ }^{403}$ Noble and Huq, "Adaptation Needs and Options," 21.

${ }^{404}$ Note that the Failed State Index has been criticized for failing to predict the Arab Spring in December 2010.

${ }^{405}$ Other metrics include the following: Dimensions of Vulnerability by Downing et al., 1995; the Index of Human Insecurity (IHI) by Lonergan et al. 1999; the Vulnerability-resilience indicators by Moss et al., 2001; the Environmental Sustainability Index of the World Economic Forum, 2002; and the Country-level risk measures by Brooks and Adger, 2003. 
risks across countries and regions. ${ }^{406}$ Other research identified and defined the key components of a vulnerable system, with particular reference to the natural environment. ${ }^{407}$

Each of these examples serves to demonstrate that methodologies to begin to measure the impacts of climate change have been developed and are advancing. Although these were not developed precisely in the context that NATO views security, they illustrate that it is possible to create a baseline point of reference upon which agreement may ultimately be found.

Despite not being immediately relevant to NATO, these methodologies and tools could be adapted for NATO, rather than developing them by itself or from scratch. The challenge would be to harness the capabilities of these methodologies or tools that have already been developed or are now being developed. ${ }^{408}$ This model of leveraging outside capabilities was previously developed and employed in the context of climate-related security risk by the US Department of Energy's (DOE) Global Energy and Environment Strategic Ecosystem (Global EESE) program. $^{409}$ Briggs notes that:

$\ldots$ in 2007 the US Department of Energy established its Energy and Environmental Security Directorate, charged with tackling the full complexity of these security issues and their risks, and with developing a strategic foresight capability on energy and environmental security. The project was disbanded in March 2010. ${ }^{410}$

However, as noted above, perspectives differ concerning whether the methods accurately capture the problem in a useful way. In particular, many indices of state fragility or climate-related disaster risks are lagging indicators, not dynamic risk-tracking tools. The Failed States Index, mentioned above, received criticism for failing to predict the Arab Spring in 2010. However, the developers of the index responded that:

[T] he Failed States Index did not predict this [the Arab Spring]... nor does it try. The Failed States Index measures social, economic, political and military pressures on states. Its data collection period extends from January to December of the previous year, especially notable in this

\footnotetext{
${ }^{406}$ Ibid., 25. These include the Disaster Risk Index (UNDP, 2004); Hotspots Index (Dilley et al., 2005); the Americas Index (Cardona, 2005); and an index for South Asia (Moench et al., 2009). The IPCC notes "there has been little effort to further analyze, validate, or compare these metrics." Further discussion on the development of climate relevant metrics can be found at the following: Lavell et al., "Climate Change: New Dimensions in Disaster Risk, Exposure, Vulnerability, and Resilience," 42., Noble and Huq, "Adaptation Needs and Options," 27., Cardona et al., "Determinants of Risk: Exposure and Vulnerability," 92.

${ }^{407}$ Briggs, "Environmental Change, Strategic Foresight, and Impacts on Military Power," 4. He mentions Piers Blaikie et al., At Risk: Natural Hazards, People's Vulnerability and Disasters. (Routledge, 2004)., and Hans-Martin Fussel, "Vulnerability: A Generally Applicable Conceptual Framework for Climate Change Research," Global Environmental Change 17, no. 2 (2007): 155-67.

${ }^{408}$ Note that the 2014 Report from CNA Corporation recommended that the US Department of Defense undertake a somewhat related effort, although it was offered in a purely national-vice NATO - context; they state, "In addition to DOD's conducting comprehensive assessments of the impacts of climate change on mission and operational resilience, the Department should develop, fund, and implement plans to adapt, including developing metrics for measuring climate impacts and resilience."

${ }^{409}$ Briggs, "Environmental Change, Strategic Foresight, and Impacts on Military Power," 3.

${ }^{410}$ Ibid., 13, footnote 9.
} 
instance since much of the tumult in the [MENA] region did not manifest itself in violence and severe instability until after the sample period for the 2011 Index had closed. ${ }^{411}$

This instance demonstrates the fallibility of quantitative security models. As mentioned, particularly concerning is that climate change and natural hazards present societies with dynamic vulnerability, in which case the processes and factors to be analyzed are not static. Traditional indicators are insufficient and ill-suited to this task, or, at the very least, they need to be interpreted as a snapshot at a given point or as part of a larger trend. ${ }^{412}$

The IRGC suggests the following dimensions for consideration in this phase of the analysis:

- The social definition of what is to be regarded as adverse. For example by defining the 'No Adverse Effect Level' in this particular situation, is not available (also, the context is not precisely relevant in the context of climate). To the extent that NATO would determine an adverse effect level for each of the three Instability Situations, it's not clear how the threshold level would be established (or what precisely would be monitored).

- The extrapolation of data for the future security environment. Given the complex adaptive nature, it is unclear the extent to which empirical data can be extrapolated to the climate and security environment of the future. Efforts to model and understand the characteristics of the future security environment are ongoing, although identifying discontinuities and the effect of abrupt changes (including feedback loops) is problematic.

- Determination of models to extrapolate high-dose response relationships and identify thresholds (or lack thereof). Modeling of climate change and security is ongoing, as social and political scientists are attempting to model the relationship. Models exist, although they extend beyond pure science to social science, where relationships are more difficult to identify and uncertainty is greater. But a social scientific model that draws linkage between climate, social tension, and worsening security outcomes, as would seemingly be relevant for the MENA region, is likely to be unassailable.

- Methodological rules for assessing concerns. As noted above, the development of analytic methodologies is ongoing: testing and detection methods could become scientifically established in the future, although they are unlikely in the near term given that the pathways through which climate change leads to security consequences are uncertain.

- A selection rule to determine which potentially negative situations should be considered in the risk governance process. Recognizing that an infinite number of negative outcomes can be potentially connected with anticipated climate events, a clearly established rule is unlikely. Whether there exists a threat to security in the North Atlantic region is determined subjectively by the NAC. Any further detailed selection rule is unlikely, as

\footnotetext{
${ }^{411}$ Nate Haken, "The Arab Spring: Where Did That Come From?," Fund For Peace (Failed States Index), 2011, http://library.fundforpeace.org/fsi11-arabspring.

${ }^{412}$ Robin M. Leichenko and Karen L. O. Brien, "The Dynamics of Rural Vulnerability to Global Change: The Case of Southern Africa," Mitigation and Adaptation Strategies for Global Change 7 (2002): 1-18.
} 
ambiguity has value at NATO and is often intentional within policy documents. Unhelpful in this case, this ambiguity allows enough flexibility for a wide range of potential issues, and it provides for interpretation that is sufficiently broad to gain consensus.

- $\quad$ Valid risk assessment methods and techniques for measuring perceptions and concerns. Detecting the physical impact of climate change is possible, but assessing precisely the risk that these changes lead to a security consequence exceeds the present state of knowledge. To the extent that methods for measuring perceptions and concerns can be incorporated into the NATO process, they would be reflected in the position of each respective NATO Ambassador.

The IRGC notes that decisions on these points, which under other circumstances would be developed by consensus between experts and the involvement of relevant institutions, are indispensable for the later step of Risk Appraisal. Without agreement on these conventions, discord is likely to encumber the process.

\section{NATO's ability to perform pre-assessment}

The IRGC notes that the purpose of the pre-assessment phase is to capture both the variety of issues that stakeholders associate with a certain risk as well as existing indicators, routines, and conventions that may prematurely narrow down, or act as a filter for, what will be addressed as risk.

Pre-assessment is challenging for NATO for several reasons. Firstly, the Instability Situations described in the FFAO documents fail to describe the pathway from the situation (hazard) to the security implications (risk). The framework requires one to precisely identify how the risk results from the hazard. Knowing the extent of risk in advance is not genuinely possible without fidelity on the severity and nature of the risk, its geographic distribution, as well as the response capacity and political resilience of member states in any individual circumstance. ${ }^{413}$

NATO's early warning system (NIWS) is not presently configured for this type of problem (nor is it clear that an adequate one exists); the screening mechanism (NAC discretion) is based upon subjective judgment (perhaps justifiably); and scientific conventions do not really exist (although indicators could potentially be created). However, to move forward on this aspect (and improve NATO's own early warning capacity), it could harness the international community: public science, thinks tanks, and a variety of other organizations monitor various aspects of the security environment, and publish on issues of concern. ${ }^{414}$

\footnotetext{
${ }^{413}$ Renn, "Risk Governance-Towards an Integrative Framework," 19.

${ }^{414}$ However, lack of coordination among the relevant entities has been problematic previously and historically. Briggs notes that "Lack of information sharing among and within agencies is problematic even for traditional security concerns, but it is especially ill-fitting for environmental science issues that rely upon free flow of data, and where expertise exists not in the government agencies, but among international communities of researchers." Briggs, "Environmental Security, Abrupt Climate Change and Strategic Intelligence," 5. Perhaps this is one possible reason why NATO would be a good venue to host collaboration
} 
Risk framing is potentially one of the most critical shortcomings for NATO with respect to preassessment of risk governance (and, perhaps, overall). The difficulty comes in establishing a unified view of a risk and the precise manner in which it may change or influence the actions that NATO will be required to take. Risk framing, therefore, will likely suffer from the fact that each of the 28 member states could have individual perspectives on the risk. Without a common understanding of this problem, it will be difficult to find the political willingness to plan action or response in the absence of a clear crisis.

This is not a failing of the framework or NATO necessarily, but it speaks to the challenge of addressing the problem with the resources and knowledge available in the present. This critique holds true for many contemporary policy issues - both information and knowledge about the problem are incomplete and continually emerging. Moreover, the nature and complexity of the problem itself suggests that there are few concrete alternatives at the ready.

Yet, just as with other security problems, incomplete information does not excuse the necessity to plan and prepare for situations that may nevertheless arise. A great deal of information is available to begin to make an assessment of particular situations. There is a large, well trained, transparent, and globally networked community of researchers focusing on climate change. In fact, there is both less uncertainty as to what causes climate change and more clarity on its expected trajectory, founded upon a scientific basis (although this too contains uncertainty), than for conventional security risks.

That extensive research exists on climate security risk suggests that it is neither too difficult nor too early to begin serious effort. However, the range of perspectives on how the security consequences arise, and what NATO can do, is likely to undermine efforts to find the common understanding necessary for informing decisions. While a detailed understanding remains elusive, in particular regarding what constitutes a threat to security in a given context, further effort could lead to greater fidelity of knowledge and awareness.

NATO has a body (the North Atlantic Council) with decision-making authority, a reasonably clear process by which decisions are made, access to a vast amount of public research concerning climate change (and associated security consequences), and an indication and warning system that could be adapted and configured for the circumstance. Despite the relatively wellestablished mechanisms to address questions of international security, the characteristics of this particular problem remain problematic.

Though indicators and measures are useful for situational awareness, for the purpose of NATO, whether security is threatened in the North Atlantic region is a subjective decision ultimately determined by the NAC. The IRGC Risk Governance Framework suggests that the absence of scientific conventions for assessing the seriousness of the risk will hamper risk governance decisions. Without a more robust scientific basis, or significantly more developed scenarios (than the Instability Situations created by NATO ACT), the process of deciding how to respond to or address a particular circumstance will struggle to move forward before the specific circumstances of a situation present themselves.

on climate security researchers - it already has the established committees and organizational design to coordinate issues across a wide variety of domains. 
A pre-assessment, as proposed by the IRGC framework, can only be fulfilled in a limited way for the case of climate and security for NATO. These shortcomings, while not necessarily a failing on the part of NATO, contribute to difficulties in the risk governance process. From a risk governance perspective, many of the necessary elements and capabilities already are within NATO's existing structure to conduct pre-assessment. However, the nature of this problem and NATO's lack of attention on the particular (climate) dimension accounts for the shortcomings.

\section{Phase 2: Risk Appraisal}

In the IRGC framework, risk appraisal consists of two components, risk assessment and concern assessment, which themselves include the scientific assessment of the risks and an accounting of stakeholder concern regarding social and economic implications. Collectively this phase intends to produce a scientific estimate of the physical, economic, and social consequences of a risk, and to provide the knowledge for a decision on whether or not a risk should be taken. ${ }^{415}$

More precisely, it's a two-stage process: first, natural and technical scientists estimate the physical harm that a risk may induce; second, social scientists and economists identify and analyze the concerns that either individuals or society link with a certain risk. ${ }^{416}$ The IRGC notes that secondary impacts are of major concern to those who are obliged to cope with the consequences of being accountable (such as NATO may be considered in this instance), and they are a source of concern that likely cannot be accounted for in a clear, objective, manner. ${ }^{417}$

\section{Risk Assessment}

In ideal circumstances, risk assessment links a potential source of harm - a hazard - with likely consequences, ${ }^{418}$ and it produces an estimate of the risk in terms of a probability distribution of the modeled consequences. ${ }^{419}$ This objective presents a distinct challenge for the problem of

${ }^{415}$ Renn, "Risk Governance-Towards an Integrative Framework," 13, 35. In the case of climate change, society at this point does not have a choice as to whether the 'risk' should be taken. Risk Governance issues, and Risk Assessment, in the context of security have also been examined on multiple instances by the OECD: Regina Schröter, Aleksandar S. Jovanovic, and Ortwin Renn, "Social Unrest" (Paris: OECD Publishing, 2012); OECD, "Managing Risks in Fragile and Transitional Contexts" (Paris: OECD Publishing, 2012); OECD, "Linking Security System Reform and Armed Violence Reduction" (Paris: OECD Publishing, 2011); OECD, "Investing in Security" (Paris: OECD Publishing, 2011); OECD, "Conflict and Fragility The State's Legitimacy in Fragile Situations. Unpacking Complexity" (Paris: OECD Publishing, 2010); OECD, "Future Global Shocks" (Paris: OECD Publishing, 2011); OECD, "Emerging Risks in the 21 st Century, An Agenda for Action"; OECD, "Preventing Violence, War and State Collapse" (Paris: OECD Publishing, 2009); OECD, “Armed Violence Reduction" (Paris: OECD Publishing, 2013).

${ }^{416}$ Renn, "Risk Governance-Towards an Integrative Framework," 34.

${ }^{417}$ Ibid., 35.

${ }^{418}$ Ibid., 14.

${ }^{419}$ Ibid., 26. Note that the probabilities with respect to security implications of climate change are not clear. The observations of Briggs are relevant: "If one treats foresight as an exercise in risk assessment, the bias of past experience must be taken into account. This bias, which applies both to risk perception and to 
climate security. As discussed in detail in Chapter 2, the methods to link the hazard directly to the security consequences through modeling are not yet settled. ${ }^{420}$ The causal chain is not obvious or necessarily apparent. Indeed, although narratives can explain a cause-effect relationship in clear and dramatic terms, it is difficult to establish such relationships empirically.

Moreover, in the context of climate security, risk assessment analysis presents further challenges in that past conditions (which are represented by historical probabilities and causal chains) are poor predictors of future events when the boundary conditions - or the rules of the game-have changed. ${ }^{421}$ Therefore, the uncertainty surrounding historical probabilities and causal chains is also a component of risk. ${ }^{422}$

This creates problems for the validity of the results. In circumstances such as these, the IRGC recommends that existing knowledge be characterized and categorized with respect to the degree and causes of complexity, remaining uncertainties, and ambiguities. ${ }^{423}$ This approach, then, seeks to describe "the state and quality of knowledge available about both hazards and risks," 424 to clarify the nature of the challenge posed and to make clear the impact for risk assessment and risk management.

The IRGC (citing Weitzman, 2008) acknowledges there may be situations such as the issue of climate security risk where too little is known about a system or set of scenarios to permit useful modeling, and attempts to quantify losses in situations of high uncertainty-rendering them unpredictable or immeasurable - may not form a useful basis for action. ${ }^{425}$ Indeed, Renn notes

construction of methodological tools, results in underestimation of future risk probabilities. Probability estimations are based upon past experience and familiarity, and in general people do not expect nor plan for those events with which they have had little experience. The bias can be made structural by the manner in which assessments are constructed, where only certain measurements and observations are considered, while others are largely ignored." Briggs, "Environmental Security, Abrupt Climate Change and Strategic Intelligence," 5. However, in discussing this matter for the 2014 CNA Corporation paper on climate change and National Security, Retired Admiral Frank Bowman noted "Managing risk is seldom about dealing with absolute certainties but, rather, involves careful analysis of the probability of an event and the resultant consequences of that event occurring. Even very low probability events with devastating consequences must be considered and mitigation/adaptation schemes developed and employed."

${ }^{420}$ Note that the IPCC concluded (specifically in the context of disaster) that "climate change will make it more difficult to anticipate, evaluate, and communicate both probabilities and consequences that contribute to disaster risk, in particular that associated with extreme events." With extreme events (those likely to result in disaster), their infrequency makes it difficult to estimate probabilities and consequences, while climate change worsens this challenge in that it is anticipated to change their frequency and character. Lavell et al., "Climate Change: New Dimensions in Disaster Risk, Exposure, Vulnerability, and Resilience," 46. As such, climate change is expected to reduce the accuracy of past observations - to the extent that they were useful as predictors for future risk.

${ }^{421}$ Briggs, "Environmental Change, Strategic Foresight, and Impacts on Military Power," 6.

422 Ibid.

${ }^{423}$ Renn, "Risk Governance-Towards an Integrative Framework," 29. In cases where probabilities are not known in advance (as the case of preparations / planning for security), or the dose/response relationship is difficult to identify, scenarios are often used to explore different possible pathways from which a risk agent can lead to various consequences.

${ }^{424}$ Ibid.

${ }^{425}$ International Risk Governance Council, "Risk Governance Deficits: An Analysis and Illustration of the Most Common Deficits in Risk Governance," 30. 
that risks should be treated differently when they are inherently uncertain, complex, and/or ambiguous, since they cannot be addressed with traditional assessment and decision-making tools. 426

The identification and estimation of the hazard also warrant Risk Appraisal including an assessment of related exposure and/or vulnerability. ${ }^{427}$ NATO has neither identified nor estimated the hazards in as precise a manner. It has not performed the exposure and vulnerability assessment, and it has only - in a very generic sense - performed risk estimation. More generally, the IPCC notes that:

[t]he numerous (vulnerability) assessments that have been carried out have led to increased awareness among decision makers and stakeholders of climate risks and adaptation needs and options. But this awareness is often not translated into the implementation of even simple adaptation measures within ongoing activities or within risk management planning. ${ }^{428}$

Note, a detailed discussion and characterization of each risk (Instability Situation) is included in Phase 3 (Tolerability \& Acceptability Judgment) in the following chapter.

\section{Complexity}

'Complexity' refers to identifying and quantifying causal links between potential causal agents and specific observed effects, and it is particularly relevant with respect to hazards as well as risks. IRGC cites the risks of critical loads to sensitive ecosystems as an example of a highly complex risk. ${ }^{429}$ As mentioned in Chapter 2, academic researchers have struggled to establish both the existence of the cause and effect linkage between climate and a variety of security consequences (typically, conflict in Africa) and its respective strength. They are criticized for not fully accounting for feedback loops or using data that fails to capture the range of potential variability anticipated under climate change.

The case of climate change and security yields considerable complexity: the difficulty of establishing whether and to what degree a changing climate is the cause of a worsened security environment encumbers this phase of the analysis. Without a precisely identified cause/effect relationship, it is difficult to draw a direct linkage between climate change and security consequences (other than through a reasoned narrative). Despite that difficulty, this linkage is largely believed to exist throughout the community of international security and development professionals. Nonetheless, the lack of an analytic mechanism to conclusively establish the relationship, fully understand its strength, and identify its consequences remains problematic.

Complexity can sometimes be resolved if all knowledge is brought together in what IRGC calls epistemological discourse, for instance, with Delphi interviews. ${ }^{430}$ Discourse in the North

\footnotetext{
${ }^{426}$ Renn and Walker, Global Risk Governance. Concepts and Practice Using the IRGC Framework, 78.

${ }^{427}$ Renn, "Risk Governance-Towards an Integrative Framework," 14.

${ }^{428}$ Noble and Huq, "Adaptation Needs and Options," 21.

${ }^{429}$ Renn, "Risk Governance-Towards an Integrative Framework," 29.

${ }^{430}$ Ibid., 51, 52.
} 
Atlantic Council allows for all members to present their views and to engage in discussion to find common ground. This can potentially be viewed as a proxy for the Delphi process.

The necessity to identify a causal linkage with respect to climate and security was identified in a previous study by the National Research Council and is a notable deficiency. This study concluded,

$[\mathrm{u}]$ nderstanding the connections between harm suffered from climate events and political and social outcomes of security concern is arguably the most important aspect of climate change from a national security perspective, but it has received relatively little scientific attention until now. ${ }^{431}$

In the quote above, the National Academy of Science recognized the need for an effort that integrates modern analytic methods with traditional security analysis in the context of climate change. The National Academy's recognition of the necessity of crafting security policy as it relates to climate change (at least insofar as it can be derived from structured analysis) is revealed throughout their research. ${ }^{432}$ As the IRGC Risk Governance Framework suggests, this is critical from the perspective of risk governance. In that spirit, Steinbruner et al. point to the necessity for an organization, such as NATO, to direct its attention to this question. They note "effective response is a key determinant of whether an extreme climate event becomes a humanitarian crisis."

\section{Uncertainty}

The IRGC framework refers to uncertainty as "a lack of clarity over the scientific or technical basis for decision making." ${ }^{434}$ The IPCC and others have attempted to provide a scientific and technical basis from which to understand climate change, but the technical basis upon which to judge the security implications has not been firmly established (particularly from the perspective of NATO), as noted above in the 'scientific conventions' section of the pre-assessment phase. The issue of climate security is a case where knowledge is incomplete and uncertain. Even still, security and development practitioners strongly assert that climate changes will have a serious impact on human security, despite the fact that empirical models are often largely unable to confirm this prediction.

When considering the climate models available, as well as the other research on the security consequences of climate change, a number of uncertainties can be identified. These include 1) uncertainty in the methodology and input data used in climate models (error in modeling the climate system), 2) uncertainty of the impact of climate change and the response of natural

\footnotetext{
${ }^{431}$ US National Research Council, Climate and Social Stress: Implications for Security Analysis, 8.

${ }^{432}$ US National Research Council, Climate and Social Stress: Implications for Security Analysis.

${ }^{433}$ Ibid., 116.

${ }^{434}$ Renn, "Risk Governance-Towards an Integrative Framework," 30.
} 
systems, and 3) uncertainty in the response of social systems (error in modeling the climatesecurity relationship) and in technological change and advancement. ${ }^{435}$

These suggest that while it may be possible to understand the direction of future change, it is not possible to accurately estimate its magnitude and rate. ${ }^{436}$ Thus, even if it were possible to understand the changes in the climate system, it may not be possible to understand perfectly how the natural world will respond. For that reason, institutions must understand the uncertainties and grapple with the associated risk. ${ }^{437}$

There is also (irreducible) uncertainty as a result of the fact that the climate system seems to be moving beyond what was previously recognized as the system boundaries, which results in a situation of ignorance or non-knowledge regarding this issue. The last two factors play a role in this context and, as a consequence, the estimation of the resulting risk is unclear. Nonetheless, the nature of the uncertainty presented by climate and security can be broadly characterized. Yet the uncertainties can only perhaps be described qualitatively, which creates difficulties to include in a formal risk analysis and thus problems for later stages of risk governance. ${ }^{438}$

The IRGC distinguishes two types of uncertainty: aleatory (irreducible) and epistemic uncertainty. Epistemic uncertainty can be reduced by scientific research while aleatory uncertainty cannot. ${ }^{439}$ The IRGC includes natural disasters (one of the Instability Situations under consideration) as an example of a situation with high uncertainty (particularly aleatory uncertainty). ${ }^{440}$

If uncertainty, in particular the aleatory components, plays a large role then the estimation of risk becomes fuzzy. The validity of the end results is questionable and, for risk management purposes, additional information is needed such as a subjective confidence level in the risk estimates, potential alternative pathways of cause-effect relationships, ranges of reasonable estimates, loss scenarios and others. ${ }^{441}$

The emerging nature of climate security issues, combined with the relatively limited understanding of discontinuities and feedback loops in the climate system (as well as how abrupt changes may affect social and political systems and therefore the corresponding hazards), and the dynamic nature of those systems, suggests that the climate-security nexus has unresolved uncertainty.

As previously noted by John Steinbruner, the security consequence depends on the "interaction between the vulnerability of populations, their coping ability, the reaction of their government, and the climate impulse," which suggests that a change in any one of these could create 'new' risk with respect to any decisions taken at a particular point (a decision taken at one equilibrium

\footnotetext{
${ }^{435}$ UK Royal Commission on Environmental Pollution, “Adapting Institutions to Climate Change,” 66.

436 Ibid.

${ }^{437}$ Ibid.

${ }^{438}$ Renn, "Risk Governance-Towards an Integrative Framework," 28.

${ }^{439}$ Ibid.

${ }^{440}$ Ibid., 30.

${ }^{441}$ Ibid.
} 
may not be appropriate when the system settles at a different equilibrium). Indeed, the resilience of societies to withstand climate impacts is thought to decrease over time, if the associated stress or adaptation burden is not relieved or supported in some fashion. The IPCC identified this problem, noting

several interacting sources of uncertainty mean that future climate change and its impacts will not be known with precision for the foreseeable future. Some uncertainties involve the path of global socio-economic development, the way it affects the commitment by countries to use energy-efficient technologies and how greenhouse-gas emissions might respond to specific climate-related policies. Other uncertainties involve internal variability and incomplete understanding of the climate system and broader Earth-system feedbacks. Still other uncertainties involve the way that changes in climate translate to impacts such as changes in water availability, agricultural production, sea-level rise or heat waves in different parts of the world. A final set involves the evolution of assets at risk (exposure) both in physical and in monetary terms and the level of protection that can be undertaken to reduce their vulnerability to potential losses (that is, adaptation measures). The implication of these interacting sources of uncertainty is that choosing among climate policies is intrinsically an exercise in risk management. ${ }^{442}$

The uncertainty in the relationship between climate change and any resulting security impact is formidable. It, moreover, implies strongly that other forms of analysis are necessary to create an appropriate basis upon which an organization like NATO can understand the problems that could arise.

\section{Ambiguity}

Ambiguity occurs when values, priorities, or limitations cannot be agreed upon (according to the IRGC usage of the term). It can also occur as the result of divergent or contested perspectives on the severity or wider 'meanings' associated with a given problem or when different actors evaluate risk assessments differently. ${ }^{443}$ Situations with high complexity and uncertainty favor the emergence of ambiguity. ${ }^{444}$

The IRGC distinguished two forms of ambiguity:

a) Interpretative ambiguity has to do with a single risk assessment provoking differing interpretations. This is characterized by a lack of clarity as to whether an effect is adverse or not.

b) Normative ambiguity arises as a consequence of a confluence of concepts about what can be regarded as tolerable in terms of ethics, quality of life parameters, distribution of

\footnotetext{
${ }^{442}$ Howard Kunreuther et al., "Risk Management and Climate Change," Published Articles \& Papers, 2013, 1.

${ }^{443}$ Renn, "Risk Governance-Towards an Integrative Framework," 30.

${ }^{444}$ Ibid., 31 .
} 
risks and benefits, and so on.

Both forms of ambiguity are apparent in climate security. First, that there is no established cause/effect relationship (among researchers) obstructs the creation of a common perspective to the extent that it is an open question as to whether an effect exists. Thus, it also affects whether a changing climate has an adverse impact upon security (or, indeed, the extent to which NATO would need to create a policy to address it). Second, to the extent that the cause/effect relationship exists, and is adverse, what severity level would be considered intolerable is also unclear, beyond what could be identified in an actual situation.

High ambiguity encumbers the risk management process. Furthermore, the IRGC sees highly ambiguous problems as requiring the risk evaluation process to be open to public participation, consultation, and participative discourse. This recommendation runs counter to NATO's usual business practice and the conduct of security affairs generally, which is ordinarily conducted away from the public. That NATO has thus far had difficultly coming to a common position on climate is an indication of the lack of unity on what role NATO could play. It likely serves the interest of future deliberation to avoid a public discussion before NATO's own internal thinking is established.

The IRGC notes that complexity, uncertainty, and ambiguity make precise risk assessment more challenging, and they demand both analytical and organizational innovation from participants in risk governance. ${ }^{445}$ It also acknowledges the context-dependent nature of risk assessment, although the SFA/FFAO workshops may serve as a proxy for this requirement. ${ }^{446}$

The foregoing analysis suggests that climate security risk has complexity, uncertainty, and ambiguity. It suggests that the various perspectives of NATO member states will influence whether and how NATO decides to assume a role with respect to climate and security. The SFA analysis had observed the influence and impact of perceptions, noting that:

Multiple threat perceptions amongst NATO members could adversely affect the ability of the Alliance to reach consensus... An absence of a shared threat perspective among Nations can complicate NATO defense planning and investment, since diverse and often financially-driven national priorities may directly impact the Alliance's overall ability to maintain, develop and use current and future capabilities... However, this diversity of national perceptions could also represent an opportunity for the Alliance to develop more flexible options in dealing with emerging issues. $^{447}$

NATO recognizes that it may be required to transform its purpose, objectives, and means of operating in light of changes in the global political and security environment. After all, this was the purpose for the establishment of Allied Command Transformation: to understand how NATO will need to continually adapt to a new environment, although it tends to concern itself with military aspects rather than the larger institutional level of NATO. However, the halting and

\footnotetext{
${ }^{445}$ International Risk Governance Council, "Risk Governance Deficits: An Analysis and Illustration of the Most Common Deficits in Risk Governance," 12.

${ }^{446}$ Renn, "Risk Governance-Towards an Integrative Framework," 33.

${ }^{447}$ NATO ACT, "Strategic Foresight Analysis 2013 Report," 14.
} 
unsure manner in which its adaptation has sometimes been achieved has drawn both criticism and concern, and this is a point routinely considered:

NATO's role as a defense and security provider may come under scrutiny as the evolving global political landscape and shifting nature of power bring about changes in national political priorities ... As was successfully addressed at the end of the Cold War, NATO could again be challenged to transform itself in a changing world to maintain its relevance as a defense and security organization to its members and the global community. ${ }^{448}$

NATO's future transformation is dependent, in many respects, on a common view of the world and the threats that it presents, coupled with a corresponding common view of the role of NATO in the context of that environment. This can perhaps only be reached by having a common set of values to drive a collective and uniform perspective on both aspects. That values will be challenged in the future was identified in the Strategic Foresight Analysis Workshops \#1 and \#2, the Final Report for Workshop \#3, which noted that:

The Alliance's common values consensus will be challenged. New powers will assert a "value challenge" while the Alliance is in danger of experiencing an eroding common-value base. This situation could affect the cohesion of the Alliance. ${ }^{449}$

Cuccia describes the absence of consensus on what is perceived as a threat as tantamount to NATO's biggest threat. ${ }^{450}$ Moreover, the last of these Workshops (\#3) identified the implications that stem from a lack of a common perception for NATO, which include the challenge it presents to defense planning and investment, ${ }^{451}$ as well as potential opportunities:

Multiple and varied threat perceptions could pull NATO in the direction of too many national, regional and functional priorities ... [which justifies] ... why a continuous strategic dialogue is essential among the 28 nations ... [however] ... Absence of a shared perspective presents an opportunity for NATO to explore future ways to become a more dynamic and flexible organization, able to provide regional solutions to conflicts. NATO could identify a group of clusters of "shared threats" to facilitate debate on how the Alliance should face selected strategic challenges. ${ }^{452}$

448 Ibid., 11.

449 NATO ACT, "Strategic Foresight Analysis Workshop \#3 Final Report: The Shared Perspective of the World in 2030 and Beyond Security Implications," 3. A related point from the first Workshop in this series: “NATO's ability to achieve strategic power projection degrades. NATO's collective ability is weakened by individual nations deploying capabilities in support of national interest to mitigate their own perceived risks and threats. NATO's ability to perform strategic power projection is challenged as perceived threats change." NATO ACT, "Framework for Future Alliance Operations Workshop \#1 Final Report-Leading NATO Military Transformation,” 12.

450 Phillip R. Cuccia, "Implications of a Changing NATO” (Washington, 2010).

451 NATO ACT, "Strategic Foresight Analysis Workshop \#3 Read Ahead: The Shared Perspective of the World in 2030 and Beyond Security Implications," 5-6.

452 NATO ACT, "Strategic Foresight Analysis Workshop \#3 Final Report: The Shared Perspective of the World in 2030 and Beyond Security Implications," 3. 
The character of the risk and the inclusive decision-making requirements of NATO pose both significant challenges and constraints on charting the way forward with respect to climate change and its associated security risk.

\section{Concern Assessment}

The IRGC framework recommends that concern assessment include research on concerns about, and perceptions of risk by, interested societal groups, an understanding of potential economic effects, and the courses of action for addressing them. Concern assessment complements risk assessment with insights from risk perception studies (e.g. knowledge of concerns, emotions, hopes, and fears) and analyses of social consequences, economic implications, and political responses. ${ }^{453}$ Risk Managers must consider contextual aspects, such as risk perceptions, when designing risk reduction measures. ${ }^{454}$

Concern assessment is perhaps not immediately relevant to NATO, at least not in the precise context as conceived by the IRGC. To the extent that varying perceptions of risk would affect a discussion of the topic at NATO, the public perception of risk in the member states would be represented and incorporated into the perspective of the member state Ambassadors.

Concern surrounding climate change and any consequent security risk could be categorized as 'high' (although, perhaps not uniformly so) when viewing the literature released from various government agencies (including defense ministries) within individual NATO member states. However, this concern has not yet been translated into new policy or discussion of the associated risks at NATO. Public concern is also influenced by various external stakeholders (think tanks, NGOs, and other sources of research), as well as national agencies that have conducted climate research. NATO has attempted to raise awareness and communicate the risk of climate change on security (SecGen OpEds, Videos, workshops, press releases), but it has no authority to require that individual member states do the same.

The issue of perception, however, is troublesome for NATO more generally. The twenty-eight (28) member states have 28 distinct perspectives driven by 28 different sets of political reality, 28 distinct political cycles, and 28 varying (although occasionally overlapping) economic interests. Each member state has its own corresponding concerns regarding climate security. For instance, instability and migration from MENA will affect the southern European nations more than the northern European or North American nations; Arctic security will be a greater concern to Norway, Canada, Denmark, and the United States than it will be to Greece or Turkey; and natural disasters could occur just about anywhere.

\footnotetext{
${ }^{453}$ Renn, "Risk Governance-Towards an Integrative Framework," 14. IRGC notes that concern assessment is a social science activity to provide insights and a comprehensive diagnosis of concerns, expectations, and perceptions that individuals or groups link to the hazard; social scientific analysis should be submitted to methodological scrutiny and peer review, and it should not be confused with eliciting stakeholder feedback or providing platforms for participatory processes.

${ }^{454}$ Ibid., 31.
} 
Public attitudes regarding climate are routinely surveyed, at least among the western European NATO Allies and in North America as well. ${ }^{455}$ Surveys reveal wide divergence of opinion among European nations, as well as between European nations and North America (and regional differences within North America). ${ }^{456}$ The IPCC concluded that "[o] ne of the major determinants of popular support for climate policy is whether people have an underlying belief that climate change is dangerous" and "the extent to which people believe it is possible to actually influence the future appears to be a major determinant of their support for both individual and collective actions to respond to climate change. ${ }^{457}$ Additionally, the IPCC notes that substantial empirical evidence suggests that support or opposition to proposed climate policies is determined primarily by emotional factors and past experience rather than cost/benefit calculations. $^{458}$

As a matter of public debate and scrutiny, the issue is likely to become more prevalent as the consequences of climate change become more apparent. Indeed, "lay people weigh probabilities subjectively; for instance, the belief that the probability of an event is higher if it can more easily be imagined or if it has already been experienced." 459 Perhaps at that point circumstances will allow NATO an opportunity to take on a larger role with respect to the security aspects of the problem.

A good example of the challenge here is the current situation within the United States. Just as in Europe, a significant amount of information in the US demonstrates a need for concern about climate-related issues, but the media generates controversy by providing alternative perspectives, many of which contradict science or are driven by a poor understanding of the issue. Mooney shows how the political right in the United States has ignored and misrepresented scientific knowledge to serve its political agenda. ${ }^{460}$ Antilla examined the trend in US media to falsely portray disagreement among the scientific community regarding the reality of anthropogenic climate change. ${ }^{461}$

${ }^{455}$ As an example in the United States, see "Yale Project on Climate Change Communication" (Yale University, 2015), http://environment.yale.edu/poe/v2014/. and Cary Funk et al., "Public and Scientists" Views on Science and Society" (Washington, DC: Pew Research Center, 2015).

${ }^{456}$ Irene Lorenzoni and Nick F. Pidgeon, "Public Views on Climate Change: European and USA Perspectives," Climatic Change 77 (August 2006): 73-95. "Yale Project on Climate Change Communication."

${ }^{457}$ Howard Kunreuther and Shreekant Gupta, "Integrated Risk and Uncertainty Assessment of Climate Change Response Policies," in Climate Change 2014: Mitigation of Climate Change. Contribution of Working Group III to the Fifth Assessment Report of the Intergovernmental Panel on Climate Change, ed. O. Edenhofer et al. (Cambridge, United Kingdom and New York, NY, USA: Cambridge University Press, 2014), 52, 53.

458 Ibid.

${ }^{459}$ Holger Schütz and Hans Peter Peters, "Risiken Aus Der Perspektive von Wissenschaft, Medien Und Öffentlichkeit.," Aus Politik Und Zeitgeschichte 10-11 (2002): 40-45. as cited by Renn and Walker, Global Risk Governance. Concepts and Practice Using the IRGC Framework. The following report demonstrates this: Funk et al., "Public and Scientists' Views on Science and Society."

${ }^{460}$ Chris Mooney, The Republican War on Science (Basic Books, 2005).

${ }^{461}$ Liisa Antilla, "Climate of Scepticism: US Newspaper Coverage of the Science of Climate Change," Global Environmental Change 15 (2005): 338-52. 
In the United States, despite the fact that some media outlets appear to obscure the existence or severity of problems such as climate change, the US defense establishment has moved forward with a variety of climate policies to advance adaptation and preparation (principally from the perspective of infrastructure resilience, although some documents acknowledge the necessity that climate aspects will be a component of future security engagement as well). The highly technical nature and scientific basis of climate research suggests that the public is largely incapable of distinguishing the merits of this information. People are thus reliant on the simplifications provided by mass media. This reality influences election and political platforms and therefore the legislative bodies and governments that make national policy represented in places like NATO.

It should thus be evident that public perception of risk is not based on sophisticated procedure. However, no systematic or direct concern assessment is likely to be conducted (by NATO proper) for a topic such as climate security, for which NATO presently has no identified or agreed role. NATO's concern could be reflected or evident in their recognition (through the SFA/FFAO workshops) that climate will be a driver of the future security environment. Concern is also imputed through the Ambassador who serves as a sort of second-order concern assessor. Although this saves NATO from having to reckon directly with the disparate concerns of the public, the manner in which NATO would conduct concern assessment is at odds with that prescribed by the IRGC Risk Governance Framework.

\section{NATO's ability to perform Risk Appraisal}

NATO is in a challenging position. NATO cannot itself do anything with respect to 'climate change,' although it bears responsibility in certain instances for responding to its consequences. Risk assessment of climate-induced security consequences is highly challenged by the complexity, uncertainty, and ambiguity of the problem (and, even the idea that it is a 'problem'). Moreover, direct concern assessment is outside the remit of NATO, although it can potentially be reflected through the position of the member states (including their national security and scientific publications), as well as the literature of think tanks and others who serve the public interest.

Although NATO has not conducted a formal risk appraisal, the literature reviewed in the previous chapters serves as a useful proxy for the review and evaluation of a wide range of related risks. Increasingly sophisticated techniques have been employed (and methods to advance understanding are continually being developed), but so far there is unclear, albeit growing, evidence of harm (although this is potentially due to shortcomings of the methods). ${ }^{462}$ The failure of this research is that it has yet to demonstrate that potential hazards will trigger security issues. It has, however, led to further research, perhaps based on the exceptionally strong narrative of probability and the resulting ambition to acquire greater clarity on what the future may hold in this respect.

The fidelity of knowledge with respect to climate security is not sufficiently developed to the point where it would satisfy the identification and estimation requirements of the Risk Assessment phase of the IRGC framework. Therefore, the degree to which the hazard might directly and unequivocally pose a threat is unclear. The uncertainty of the research is also a

${ }^{462}$ The Arab Spring and massive flooding in Bosnia and Herzegovina in 2015 are but two examples. 
source of discord among the decision makers, as is the chasm that exists between the judgments that empirical research can support and the assertive perspective of security and development practitioners.

\section{Phase 3: Tolerability and Acceptability Judgment}

Judging whether a risk is tolerable or acceptable involves two steps: risk characterization and risk evaluation. Whereas risk characterization compiles scientific evidence based on the results of the risk appraisal, risk evaluation assesses broader value-based issues that also influence judgment. ${ }^{463}$ The IRGC notes that this two-part phase is often the most controversial part of risk governance, particularly if the risk is characterized by complexity, uncertainty, and ambiguity, as it is with climate security. An 'acceptable' risk means that no further measures need to be taken to reduce it. A 'tolerable' risk, by contrast, is one that is viewed as reasonable, but further measures to reduce the risk are necessary.

In the case of NATO, public information suggests little consideration of a potential role vis-à-vis climate security and, following from that, any judgment of acceptability and tolerability. Admittedly, there are some indications that NATO acknowledges the security impact of climate change (such as a video concerning climate change ${ }^{464}$ ), as well as including climate change as a factor in various scenario development efforts. It is likely that internal discussions took place following the statements by Anders Fogh Rasmussen shortly after he became Secretary General, although the issue received little further public mention from NATO. Perhaps NATO did not pursue further action because there was no consensus as to whether it was an appropriate role for NATO, as opposed to whether it was tolerable and acceptable.

\section{Risk Characterization \& Evaluation: Climate \& Security for NATO}

Characterizing and evaluating risks is the process of rendering a judgment about the acceptability of the risk. This process relies on both values and evidence. What should be tolerated or accepted can never be determined solely from the evidence (it must be considered in light of values). Yet, evidence is essential to know whether a value has been violated (or to what degree). ${ }^{465}$ For purely natural hazards (as some of the Instability Situations considered here are), the terms 'tolerable' and 'acceptable' may have little meaning since NATO has no choice in tolerating or accepting the risk. ${ }^{466}$ The only decision within its remit is whether its members attempt to use and advance what knowledge and understanding is available to plan their preparations and future investments. In that sense, the tolerability judgment (i.e. whether they should take action of some form) is probably disputed or potentially overshadowed by more pressing and immediate security concerns.

\footnotetext{
${ }^{463}$ Renn, "Risk Governance-Towards an Integrative Framework," 14.

${ }^{464}$ NATO, "Climate Change (Video Clip) —Copenhagen Spot," 2009.

${ }^{465}$ Renn, "Risk Governance-Towards an Integrative Framework," 36, 37.

${ }^{466}$ Ibid., 37.
} 
With respect to values and evidence, the IRGC distinguishes three cases: ${ }^{467}$

Case 1: Interpretative ambiguity: ambiguity on evidence but not on values.

Case 2: Normative ambiguity: ambiguity on values but not on evidence.

Case 3: Interpretative and normative ambiguity: ambiguities on values and evidence.

As an example for the third case, the IRGC cites the interpretative and normative implications of global climate change (i.e. the drivers of the 'risk' under consideration in this dissertation). ${ }^{468}$ The Intergovernmental Panel on Climate Change (IPCC) has articulated and characterized a variety of associated risks and their uncertainties.

\section{Risk Characterization}

The IRGC describes risk characterization as collecting and summarizing all relevant evidence necessary to make an informed choice on tolerability or acceptability of the risk and suggesting options for dealing with the risk from a scientific perspective. ${ }^{469}$ This can include such information as point estimates of risks (a quantification of the risk), descriptions of remaining uncertainties (in empirical or other types of models), and understanding the potential outcomes of various scenarios. ${ }^{470}$

It can also include risk-risk comparisons (and trade-offs), the identification of discrepancies between risk assessment and risk perceptions, as well as potential equity violations - the manner in which the risk affects the interests of various stakeholders and groups. ${ }^{471}$ Risk characterization seeks to understand what is known about a risk, what is not known about a risk, and what never will be known about a risk.

Risk characterization also asks scientists to design a multi-criteria risk profile, make a judgment about its seriousness, and suggest potential options to address it. ${ }^{472}$ To characterize the risk, NATO must identify its vulnerabilities and exposure in each of the three Instability Situations, an exercise that is not likely to be revealed to the public. ${ }^{473}$

\footnotetext{
${ }^{467}$ Ibid., 37-39.

${ }^{468}$ Ibid., 39.

${ }^{469}$ Ibid., 43.

${ }^{470}$ Ibid., 39.

${ }^{471}$ Ibid.

472 Ibid.

${ }^{473}$ Briggs notes that vulnerability definitions for policy can be divided into four components: risk/hazard, sensitivity, resilience, and fragility. Sensitivity is the extent to which the hazard affects a group or region, while resilience is the ability to return to the baseline condition within a reasonable timeframe following exposure to the hazard. The final component, fragility, represents the extent to which a group or region can be stressed before its underlying resilience is irreparably weakened. An assessment for NATO would need to proceed region by region (MENA, Arctic, elsewhere) to grasp these aspects in the context of climate and security. Briggs, "Arctic Environmental Security and Abrupt Climate Change," 5. The following offers a
} 
For the purpose of this dissertation, characterization of the risks (the Instability Situations) can only be conducted in a broad sense using qualitative descriptions based upon what is known publicly. Each Instability Situation is emerging slowly, to be sure, but they are all emerging at an increasing pace. Each Instability Situation is also highly uncertain, with respect to the changing climate but also in the human response and in ways that can perhaps only be captured with general description.

Further, the idea that scarcity as a result of climate-induced crisis (as might be the case in the 'large scale natural disaster' and 'migration' Instability Situations) in the developing world renders those affected as prone to violence (as opposed to cooperation) has been criticized. ${ }^{474}$ Indeed, Hartmann notes a body of case studies that challenge the sinister narrative about scarcity and violence (in Africa), while mentioning that the similar circumstances in affluent countries are assumed to lead to institutional and technological innovation. ${ }^{475}$

However, each Instability Situation will present a chronic concern if it arises. Increasingly frequent and severe natural disasters are perhaps already evident. The Arctic is becoming more accessible with each passing year, and climate-induced mass migration has not yet revealed itself in the manner that NATO finds concerning (perhaps that is because this instability situation is the most speculative of the three that include climate as a factor).

While the Instability Situations attempt to be comprehensive, they are nevertheless a simplification of the real world, based on an imperfect understanding of the future. NATO ACT's foresight efforts strike at the following issue identified by the IRGC:

In an interdependent world, the risks faced by any individual, company, region, or country, depend not only on its own choices but also on those of others. Nor do these entities face one risk at a time: they need to find strategies to deal with a series of interrelated risks that are often ill defined or outside of their control. ${ }^{476}$

The following sections examine the Instability Situations identified by NATO ACT and characterize and discuss the risks related to each. A precise explanation of how the Instability Situations lead to risk (a security implication) is not explicit in the source documents - a critical shortcoming for each. For that reason, I discuss the implied impact on NATO and the nature of the situation, and I ask what geographic areas are potentially affected.

good overview of resilience: Simin Davoudi et al., "Resilience: A Bridging Concept or a Dead End? 'Reframing' Resilience: Challenges for Planning Theory and Practice Interacting Traps: Resilience Assessment of a Pasture Management System in Northern Afghanistan Urban Resilience: What Does It Mean in Planni," Planning Theory \& Practice 13, no. 2 (June 2012): 299-333. According to the IPCC, "The "standard approach" to assessment has been the climate scenario-driven impacts-based approach, which developed from the seven-step assessment framework of the IPCC (Carter et al., 1994; Parry and Carter, 1998): (1) Define problem (including study area and sectors to be examined), (2) select method of problem assessment, (3) test methods/conduct sensitivity analyses, (4) select and apply climate change scenarios, (5) assess biophysical and socio-economic impacts, (6) assess autonomous adjustments, and (7) evaluate adaptation strategies." Noble and Huq, "Adaptation Needs and Options," 20.

${ }^{474}$ Hartmann, "Rethinking Climate Refugees and Climate Conflict: Rhetoric, Reality and the Politics of Policy Discourse."

${ }^{475}$ Ibid.

${ }^{476}$ Renn, "Risk Governance-Towards an Integrative Framework," 48. 


\section{Instability Situation 1: Characterization \& Analysis: Access and Use of Global Commons (Arctic) $^{477}$}

The characteristics of this situation are emerging slowly but at an increasing pace that corresponds with changes in the air and water temperature in the Arctic. Of the three (3) Instability Situations identified to have climate as a component, it is issues stemming from the Arctic that have implications for NATO that touch upon all three of the Core Tasks, namely: Crisis Management, Collective Defense, and Cooperative Security. The Arctic poses both traditional and unconventional challenges to the North Atlantic region. While this Instability Situation outlines characteristics and possibilities for the future, it failed to identify precisely how it would pose 'risk' to NATO.

To be sure, climate change will present new economic opportunities and create new security concerns in the Arctic. ${ }^{478}$ Greater accessibility to natural resources in the region will attract economic interest and potentially offer an important transit option for maritime transportation to and from Asia. With increased commercial interest comes political interest and an implied responsibility to ensure that the region is secure.

The commercial and strategic implications in the Arctic have drawn attention not only from countries with territory in the region, but also from countries such as Japan and China ${ }^{479}$ China sees the melting Arctic as an opportunity for its international trade, which is highly dependent on

\footnotetext{
${ }^{477}$ The definition of 'Global Commons' in this Instability Situation is broad, and includes a variety of aspects (such as cyber and out-space) not significantly impacted by climate change. The dissimilarity of issues is striking: cyber is essentially a functional domain while outer space generally requires distinct consideration. NATO identified climate change as a driving factor in this Instability Situation; to that extent, the Arctic is the only aspect that would be significantly impacted. There would be no single policy, capability, or insight that could address all three (cyber, outer space, Arctic) areas; each would have ones distinct to its situation. The resources, capabilities, programs, and relationships needed for Arctic maritime access are fundamentally different than what is required to maintain access to cyber or outer space; there don't appear to be any aspects (or, many) that tie climate to cyber or outer space. This dissertation considers only the aspects that regard the Arctic, as the intent is to examine NATO's posture with regard to the risks posed by climate change, to the extent they can be reasonably distinguished and suggest a role for NATO to consider or a situation for which it must be concerned. Publication with respect to climate security risk in the Arctic is not empirical, and it is often found in policy-oriented grey literature.

${ }^{478}$ Dodds notes the differing perspectives about whether the Arctic is a global common, and the potential for various sovereignty claims and conflict over associated resource rights, and their interplay with shipping routes and transit passage. Dodds, "A Polar Mediterranean? Accessibility, Resources and Sovereignty in the Arctic Ocean."

${ }^{479}$ Olga Alexeeva and Frédéric Lasserre, "China and the Arctic," Arctic Yearbook, 2012, 80.
} 
international shipping. ${ }^{480}$ Access to the Northern Sea Route (over Eurasia) and the Northwest Passage (over North America) would reduce ocean transit times by thousands of miles. ${ }^{481}$

Each of these factors suggests an increased responsibility for security in the region. This is geopolitically significant even in the absence of direct conflict. Indeed, increasingly accessible sub-sea oil and gas reserves may give rise to contested territorial claims. Commercial activity, such as increased shipping raises, the possibility for related disasters (collision, pollution, other environmental impacts, etc.), suggest a need for emergency response (search and rescue) capabilities. $^{482}$ NATO ACT identified several of these concerns:

Rising temperatures will contribute to an increasingly accessible Arctic and Antarctic regions. Ocean warming and reduced sea ice will foster greater access to and exploitation of previously inaccessible natural resources in the Arctic and Antarctic regions. Additionally, reduced seasonal ice no longer restricts use of maritime global trade routes prompting possible resource competition, which may expand beyond traditional Arctic Council nations and affect NATO members with regional interests or actual territorial claims. ${ }^{483}$

Access to sea routes, competition for natural resources, and issues concerning territorial sovereignty will directly impact the North Atlantic region and present a variety of new challenges. Future activity in the region will require managing a difficult relationship with Russia and will likely bring NATO into closer interaction with China.

The overarching concern among NATO nations, and presumably others, is to prevent military confrontation in the region (as well as to ensure that national military assets and other resources can be coordinated in crisis or emergency situations). This implies an issue of interest for NATO in managing risk associated with security in the region (and the political aspects surrounding it), regardless of the degree of cooperation with Russia. However, because the context of NATO in the Arctic has implications for NATO's relationship and interaction with Russia (and perhaps China), it has a larger political component than the other two Instability Situations.

That being said, no international organization has responsibility for security in the region. In a manner of speaking, NATO has de facto responsibility for multi-lateral security affairs in the Arctic. Article 5 of NATO's Washington Treaty applies in the High North. Four of the five countries with littoral regions in the Arctic are members of NATO (the exception is Russia); the former view NATO (and, perhaps, the NATO-Russia Council) as a potential format in which Arctic security can be discussed and coordinated, while the contrary is probably true for the latter.

${ }^{480}$ Nong Hong, "The Melting Arctic and Its Impact on China's Maritime Transport," Research in Transportation Economics 35, no. 1 (2012): 1. China sent an icebreaker on its third Arctic expedition in 2008. ${ }^{480}$ Scott G. Borgerson, "The Great Game Moves North," Foreign Affairs, March 25, 2009, https://www.foreignaffairs.com/articles/global-commons/2009-03-25/great-game-moves-north.

${ }^{481}$ Scott G. Borgerson, "Arctic Meltdown The Economic and Security Implications of Global Warming," Foreign Affairs 87, no. 2 (2008): 69.

${ }^{482}$ Adger et al., "Human Security," 21.

${ }^{483}$ NATO ACT, "Framework for Future Alliance Operations Workshop \#1 Final Report-Leading NATO Military Transformation," 16. 
The CNA 2014 report noted "the rapidly changing Arctic region is a clear example where such international cooperation and change is imperative." ${ }^{484}$ NATO ACT's first Strategic Foresight Analysis workshop recognized the potential issue:

Climate Change has already rendered the Northwest Passage navigable most of the year. This raises questions concerning what extent Russia's Arctic Brigades will drive NATO to maintain a presence in the region and its subsequent effect on funding or allocation of resources. ${ }^{485}$

The Arctic was contentious between NATO members and the Soviet Union during the Cold War, with submarines patrolling the region and bombers conducting continual surveillance. ${ }^{486}$ In 2001 , Russia submitted a claim to territory in the Arctic, approximately equal to the combined area of California, Indiana, and Texas. ${ }^{487}$ In 2008, Russia resumed strategic bomber flights over the Arctic for the first time since the Cold War. It also maintains a fleet of eighteen (18) icebreakers, and it has more recently maintained a routine (and somewhat provocative) military presence in the region. $^{488}$

Beyond access and use of the Arctic, climate change in this region will have wider impact (discussed in detail in Chapter 2). Melting of the Greenland ice-sheet (and others) is anticipated to cause sea-level rise (as well as raise potential issues related to thermohaline circulation), and the release of terrestrial and oceanic methane hydrate could increase the amount of carbon in the air by more than $50 \%$, which could create a feedback loop that accelerates and prolongs subsequent warming. ${ }^{489}$ This Instability Situation failed to take this eventuality into consideration, which is perhaps the most foreboding aspect of climate change in the Arctic.

The effect of sea-level rise has broad and potentially very dangerous consequences. ${ }^{490}$ In cases of rising sea level in coastal areas, the long-term consequences depend upon whether the situation returns to 'normal.' However, there may never be a return to 'normal.' Accordingly, within the context under consideration here, the consequences would be subsumed by the migration and natural disaster Instability Situations.

The problems anticipated to result from climate change in the Arctic will be a chronic feature of the security landscape in the future, and will, increasingly, require active management in the region. While many military tasks that are potentially required in the Arctic are conventional, the resources and capabilities needed to perform them will need to operate in cold temperatures.

${ }^{484}$ Goodman, "National Security and the Accelerating Risks of Climate Change," 10.

${ }^{485}$ NATO ACT, "Strategic Foresight Analysis Workshop \#1 Read Ahead: Global Review," 5.

${ }^{486}$ Hong, "The Melting Arctic and Its Impact on China's Maritime Transport," 53.

${ }^{487}$ Borgerson, "The Great Game Moves North," 63.

${ }^{488}$ Borgerson, "Arctic Meltdown The Economic and Security Implications of Global Warming," 63.

${ }^{489}$ Briggs, "Arctic Environmental Security and Abrupt Climate Change," 9.

${ }^{490}$ Among the Mediterranean cities at risk of flooding are Alexandria (Egypt), Istanbul (Turkey), Benghazi (Libya), Casablanca (Morocco), Smyrna (now Izmir, Turkey), Algiers (Algeria), and Rabat (Morocco). More generally throughout the MENA region, low-lying coastal areas in Tunisia, Qatar, Libya, UAE, Kuwait, and Egypt are at particular risk. 
Impact/Relevance of the Instability Situation (\& Security Implication of) Access and Use of Global Commons (Arctic) on NATO Core Tasks:

1. Cooperative Security: Security Coordination will be required for the Arctic, including maritime patrols, surveillance, search and rescue.

2. Collective Defense: National resources and exploration are at stake in the Arctic. While the military component of Collective Defense may not be particularly apparent or relevant, the political component of Collective Defense has higher potential relevancy.

3. Crisis Management: An environmental disaster in the Arctic would likely require military assets or resources in response. Climate change in the Arctic also has trans-boundary impacts resulting from sea-level rise and the potential for increased amounts of greenhouse gases to be released via oceanic and terrestrial methane hydrate.

\section{Instability Situation 2: Characterization \& Analysis: Large Scale Disaster}

Among the three Instability Situations identified to have climate as a component, natural disasters are both directly consistent with one of NATO's core tasks (Crisis Management) and also have a clear linkage to climate. Evidence of this trend can be found in the impact of Hurricanes Katrina and Sandy in the United States (as well as extensive flooding in Bosnia in 2014). These events forebode the emergence and possibly chronic nature of this environmental characteristic moving forward.

The IPCC anticipates extreme weather events and associated natural disasters to occur more frequently and with greater intensity as a consequence of climate change. These characteristics suggest there will be more frequent incidents of crisis management and perhaps higher demand for the resources to address those situations. Climate projections are dramatic and the accompanying narratives that describe the magnitude and frequency of large-scale disasters are even more so. NATO ACT's FFAO Workshop recognized the implications for NATO:

Extreme weather event occurrences increase in frequency and intensity. Increased occurrence of tropical cyclones, severe storms and tornadoes, coastal flooding, and drought cause extensive damage to infrastructure, arable land, habitat, and feedstock creating conditions for insecurity and instability. Famine, drought or flood driven populations forced migration exacerbated by expanding transnational criminal and extremist activity and border tensions will be a recipe for conflict. ${ }^{491}$

As the events in the United States and Bosnia demonstrate, both NATO and NATO partnership countries will be directly affected. Climate projections for Europe suggest that it will not be among the most severely affected regions, although the potential for severe environmental events on the continent is nevertheless concerning. This is particularly true with respect to the impact of sea level rise for coastal cities in The Netherlands. Although it is unlikely that situations in these

${ }^{491}$ NATO ACT, "Framework for Future Alliance Operations Workshop \#1 Final Report—Leading NATO Military Transformation," 15. 
areas would lead to a breakdown of security, military response capacity may nevertheless be necessary.

Large-scale disasters in regions further afield (West Africa, for instance) could conceivably draw NATO's attention (and, potentially, resources), depending on the severity and abruptness of the incident. The narrative presented in NATO ACT's Instability Situation appears to be directed at undeveloped regions of the world, as opposed to member states. Increasingly severe natural events could require NATO to respond more frequently to large-scale disasters, placing increased demand on resources. NATO ACT acknowledged this in the FFAO process:

NATO's resilience in response operations will be tested. Major disasters causing large-scale devastation, extensive loss of life, and massive infrastructure damage will stress the economies and security of affected member states. These events may include earthquakes, tsunamis, volcanic eruptions, solar flares, gamma ray bursts, large meteor impacts and/or man-made incidents such as major oil spills, and industrial, toxic, or nuclear accidents. Although a national responsibility to react to such events, NATO may be requested to support increased humanitarian and disaster relief operations. ${ }^{492}$

In less developed regions, vulnerable groups often do not have the resources to migrate from areas exposed to the risks from extreme weather events. ${ }^{493}$ While risks are likely to be greater in regions that have lower levels of institutional capacity, anecdotal evidence (such as Hurricane Katrina in the United States) seems to suggest that a breakdown of order can occur quickly as a result of environmental impacts.

However, empirical support for a relationship between natural disasters and a security consequence (particularly conflict) is uncertain. In 1998, Drury and Olson used time series data (dating from 1966 to 1980) to test for a relationship between disasters and political instability. They found "a direct and positive linkage between disaster severity and ensuing levels of political unrest." ${ }^{494}$ In 2008, Nel and Righarts found a positive, robust relationship between natural disasters of all types and internal armed conflict [both major (more than 1,000 killed) and minor (less than 1,000 killed)] occurring in the same year as the disaster, and in the year following the disaster. When they limited their analysis to climate-type disasters only, they found a correlation with major armed conflict, not minor. ${ }^{495}$

A departure, in 2012, Slettebak concluded that countries affected by climate-related natural disasters face a lower risk of civil war. ${ }^{496}$ In 2012, Berg and Lujala found that climate-related natural disasters have a negative (and considerable) effect on economic growth, but that climate-

\footnotetext{
${ }^{492}$ Ibid., 16.

${ }^{493}$ Adger et al., "Human Security," 24.

${ }^{494}$ A. Cooper Drury and Richard Stuart Olson, "Disasters and Political Unrest: An Empirical Investigation," Journal of Contingencies and Crisis Management 6, no. 3 (1998): 153.

${ }^{495}$ Philip Nel and Marjolein Righarts, "Natural Disasters and the Risk of Violent Civil Conflict," International Studies Quarterly 52, no. 1 (2008): 159-85.

${ }^{496}$ Rune T. Slettebak, "Don't Blame the Weather! Climate-Related Natural Disasters and Civil Conflict," Journal of Peace Research 49, no. 1 (2012): 163-76.
} 
related natural disasters do not increase the risk of onset of armed conflict. ${ }^{497}$ Similarly, Landis found no support for the claim that natural disasters increase the risk of civil war, but that a country that experiences increasing numbers of natural disasters is more likely to initiate a militarized interstate dispute. ${ }^{498}$

This situation is essentially an enhanced and elevated version of the crisis response and management role that NATO currently plays. In the absence of rapid onset that requires military assets in response, engagement for security cooperation, or stabilization intervention, other member states or other international organizations would be more appropriately postured and have more direct responsibility than NATO to address most of the implications of this Instability Situation.

Impact/Relevance of the Instability Situation (\& Security Implication of) Large Scale Disaster on NATO Core Tasks:

1. Cooperative Security: Increasingly frequent and severe natural disasters necessitate that Allies will need to cooperate more closely, as a NATO response is potentially required more often. NATO may consider engaging more intensively with countries from regions that are likely to be most heavily affected, as well as other international organizations that could be expected to respond to similar events.

2. Collective Defense: Uncertain.

3. Crisis Management: Increasingly frequent and severe natural disasters necessitate that NATO will be required to respond more frequently to assist member states, partners, or other nations in response to these situations.

\section{Instability Situation 3: Characterization \& Analysis: Disruptive Impact of Migration}

This Instability Situation assumes that climate will be a component of future mass migration which increasingly urbanizes regional and global society, giving rise to fractured (and therefore less stable) societies. It has a long-term impact on NATO in that the increasingly-fractured societies have greater instability and therefore a higher risk of a requirement for NATO intervention. The factors that will drive and create this situation are emerging slowly, although abrupt changes or natural disasters could be acute and result in a 'chronic' problem once they appear.

That migration interacts with urbanization is presumed to result in ethnic fractures within urbanized areas that lead to instability, friction, and unrest (presumably dependent on whether the political system in the receiving regions is able or willing to integrate and govern a

${ }^{497}$ Drago Bergholt and Päivi Lujala, "Climate-Related Natural Disasters, Economic Growth, and Armed Civil Conflict," Journal of Peace Research 49, no. 1 (2012): 147-62.

498 Steven Landis, "Natural Disasters, State Capacity, and Armed Conflict...? A Closer Look at the Foundations of the Climate Change-to-Conflict Debate," in A Closer Look at the Foundations of the Climate Change-to-Conflict Debate (August 5, 2012). APSA 2012 Annual Meeting Paper, 2012. 
heterogeneous population). ${ }^{499}$ Beyond natural disaster, sea level rise would be a potential driver with respect to permanent displacement and the resultant large-scale migration, which would be dramatic with respect to large coastal cities. Food insecurity could also compel migration, as could coastal erosion and long-term environmental change, generally.

Migration resulting from environmental change is not new and not necessarily a threat to security. ${ }^{500}$ Briggs proposes that "the security concern is not that migration will lead to interstate conflict, but the impact on the stability and dynamics of the receiving communities." 501 One frequently cited scenario suggests that "an increasing desertification and drought forcing people from northern and sub-Saharan Africa into Europe ... [where] immigration issues are already a source of major tension" provides a heuristic with which to begin thinking about consequences of climate change in Africa. ${ }^{502}$ Cillier, Hughes, and Moyer suggest "the possibility of destabilizing migration flows and terrorism" among reasons for European interest in Africa. ${ }^{503}$

The IPCC's Fifth Assessment report included a high confidence judgment that climate change will have large consequences for migration, but it also noted that there is insufficient literature to project region-specific consequences that will result from climate change. ${ }^{504}$ The FFAO documents failed to specify the geographic area under consideration, although considering NATO's traditional 'neighborhood' and immediate area of interest, this Instability Situation is potentially relevant throughout the eastern and southern Mediterranean rim, and the Sahel, or regions in West Africa.

While NATO does not have primary responsibility for migration, the consequences of it may require NATO to stage a stabilization intervention in the future. In theory, NATO could respond globally. However, the further from the North Atlantic region, the less likely it is that a NATO response will be requested or viewed as appropriate. The severity of any potential incident would also be a factor. If there were an unprecedented emergency, NATO could potentially be willing to respond globally. The likelihood of a NATO response could be thought of as concentric circles where the probability of a NATO response decreases with each ring away from the epicenter.

If NATO takes an expanded view of its area of interest, Bangladesh is worrisome in terms of the potential for migration as a result of climate-relevant factors, particularly sea level rise. However, given the current events in the Middle East, the concern for NATO to include migration among their Instability Situations is somewhat abstract. ${ }^{505}$ As of July 2016, several million Syrians have been displaced within Syria, and another several million Syrian refugees

${ }^{499}$ The OECD has examined aspects of reducing armed violence in urban areas. OECD, "Preventing and Reducing Armed Violence in Urban Areas” (Paris: OECD Publishing, 2011).

${ }^{500}$ Jon Barnett and Michael Webber, "Accommodating Migration to Promote Adaptation to Climate Change" (Washington, DC: The World Bank, 2010).

${ }^{501}$ Chad M. Briggs, "Climate Change and Environmental Migration, Briefing for OSCE Workshop on Migration" (The Hague, 2009), 1.

${ }^{502}$ US National Research Council, Climate and Social Stress: Implications for Security Analysis, 20.

${ }^{503}$ Cilliers, Hughes, and Moyer, "African Futures 2050 The Next Forty Years," 9.

${ }^{504}$ Oppenheimer, Campos, and Warren, "Emergent Risks and Key Vulnerabilities," 22-23.

${ }^{505}$ NATO's Euro-Atlantic Disaster Response Coordination Center received a request from Turkey in 2012 to coordinate aid and assistance for the situation; however, other members of the international community stepped forward to share the burden, and NATO has not mobilized resources. 
have been scattered throughout Europe and the Middle East, among which more than 1.7 million are reportedly in Turkey, ${ }^{506}$ a NATO ally. While this refugee crisis is a strain on the surrounding countries and the aid agencies attempting to care for the refugees, so far the migration throughout the region has not required action from NATO, although it may create characteristics of longterm concern that fall within this Instability Situation.

Climate-induced migration is addressed frequently in the literature. The IPCC Fifth Assessment Report notes that projections of specific positive or negative outcomes (anticipatory migration or permanent versus temporary displacement) are not available. ${ }^{507}$ However, current events and historical data are not necessarily a good indicator of future circumstance and context, particularly in a world changing as quickly, and with as many potentially discontinuous, climatedriven, environmental changes, as the one in which we find ourselves.

The IPCC's Fifth Assessment Report notes that "extreme weather events are the most direct pathway from climate change and migration," but additionally acknowledges that only a portion of the climate- and weather-induced displacement leads to more permanent displacement. ${ }^{508}$ However, this conclusion appears to assume that the area/region from which the people are displaced remains habitable and desirable. But this may not be true in all cases moving forward.

The IPCC observed that "extreme weather events have in the past led to significant population displacement, and changes in the incidence of extreme events amplify the challenges and risks of such displacement." ${ }^{509}$ According to the United Nations High Commissioner for Refugees (UNHCR), climate change led to as many as 11.4 million refugees in 2008. In 2007, the German Advisory Council on Global Change noted that climate could thus create more migration hotspots around the world, each a potential site for unrest. Whether societies are able to cope with the impacts depends on their ability to solve associated problems. ${ }^{50}$

The US National Intelligence Council echoed these insights. In 2009, the National Intelligence Council (NIC) concluded that flooding along the Mediterranean coast is anticipated to increase in both intensity and frequency by 2050 , and that the impact of sea level risk in North Africa is expected to be stronger in terms of social, economic, and ecological factors. ${ }^{511}$ The NIC noted that a warmer climate and changing precipitation patterns, and a corresponding reduction of cropland and access to water, could intensify migration pressure in North Africa. ${ }^{512}$

Just as NATO did, the NIC cites the concern that increased urbanization could make accommodating the needs of growing populations more difficult, and it may also result in ethnic, racial, or religious tension or conflict. ${ }^{513}$ In 2012, the NIC concluded, "[c]limate-change-driven migration is likely to affect Africa ... far more than other continents because of dependence on

\footnotetext{
506 "Syria Regional Refugee Response Inter-Agency Information Sharing Portal” (United Nations High Commissioner for Refugees, n.d.), http://data.unhcr.org/syrianrefugees/regional.php.

${ }^{507}$ Oppenheimer, Campos, and Warren, "Emergent Risks and Key Vulnerabilities," 22.

${ }^{508}$ Adger et al., "Human Security," 12.

${ }^{509}$ Ibid., 24.

${ }^{510}$ Schellnhuber, World in Transition-Climate Change as a Security Risk.

${ }^{511}$ National Intelligence Council, "North Africa: The Impact of Climate Change to 2030," 2009, 4.

512 Ibid.

${ }^{513}$ Ibid.
} 
agriculture in Africa" and added that "interlocutors in Africa pointed to the growing numbers of migrants already from the Sahel region as it experiences increasingly drier conditions.",

Impact/Relevance of the Instability Situation (\& Security Implication of) Disruptive Impact of Migration on NATO Core Tasks:

1. Cooperative Security: The highly urbanized environment in which this situation occurs is ethnically fractured and potentially unstable. Greater instability in NATO's area of interest suggests that Allies will need to act collectively to help affected regions adapt.

2. Collective Defense: Uncertain.

3. Crisis Management: The environment for which this has relevance is a highly urbanized society with potentially higher amounts of ethnic fracture and political instability. The increased instability suggests that these societies can be destabilized more easily and may potentially require NATO intervention or involvement.

\section{Risk Evaluation}

The second component of the tolerability and acceptability judgment of the IRGC framework, risk evaluation, determines the value-based component for making this judgment. This invites including pre-risk aspects, such as choice of technology, social need for the specific risk agents (questioning whether substitution is possible), risk-benefit balances, political priorities, potential for conflict resolution, and social mobilization potential. The objective is to make a judgment on tolerability and acceptability by balancing pros and cons, testing potential impacts on quality of life, discussing development options for the economy and society, and weighing competing arguments and evidence claims. ${ }^{515}$

The IRGC notes that an elaborate risk evaluation procedure is only necessary if tolerability and acceptability are disputed, and if society faces major dissent and conflicts among important stakeholders. ${ }^{516}$ In this sense, it is not clear whether risk evaluation is applicable to the case of NATO. The risk evaluation phase, as it is described here, seems to be concerned with a 'risk' that is under the control of some authority, as if taking the 'risk' is a choice. This is not the case for climate and security, particularly for NATO, which only has authority to prepare for and respond to the consequences.

However, the 'values' of NATO are important to the cohesiveness of the organization, and they have a great impact on its ability to make decisions and to take collective action. While the NATO FFAO workshop does not explicitly consider a scenario that is uniquely driven by climate (not that it is possible, given the complex interaction of forces necessary to produce a security

\footnotetext{
${ }^{514}$ National Intelligence Council, "Global Trends 2030: Alternative Worlds,” 23.

${ }^{515}$ Renn, "Risk Governance-Towards an Integrative Framework," 39-40.

${ }^{516}$ Ibid.
} 
consequence from climate), they nevertheless identify the importance of common values throughout the organization, in terms of willingness to act, as shown in this statement:

The following three security implications were discussed [in the workshop] with much controversy, and seem to be closely connected to Crisis Management: 1) NATO's common values consensus is challenged, 2) Internal tensions challenge NATO's cohesion and 3) Multiple threat perception among NATO members.

The main issue with all three [of these] security implications in the context of Crisis Management is the question of legitimacy versus common values and national interests. Political interests explain the willingness to act. In the future, NATO may see a development where political willingness trumps legitimacy.

The syndicate asked a series of questions to add context to the security implications: What does legitimacy mean in the future? Is it reached by the constituency, or [by] the governments, or [by] international law? What are NATO values? Are there only national interests and our nations' benefit from being part of the Alliance? Is it easier to agree on values than on interests? ${ }^{517}$

The point about values is relevant for risk governance, both in terms of evaluating the risk as well as in terms of the discourse among stakeholders recommended by the IRGC framework. The passage above suggests that legitimacy, however defined, cannot operate (or, propel action) without a corresponding political interest.

\section{NATO's ability to perform Tolerability and Acceptability}

NATO has the ability to perform the actions necessary for the Tolerability and Acceptability Judgment. Indeed, discussion and evaluation of security risk is a core purpose of the North Atlantic Council (NAC). However, to prepare for any decision, a key task for NATO is to identify where the understanding of the Instability Situations would need to be further developed to better govern the associated risks.

Specifically, NATO will need to develop a better appreciation (estimate) for how the Instability Situations impact the Level of Ambition in the Strategic Concept (as defined by the Core Tasks) and create concern for NATO in maintaining the viability of the Alliance as a political and security organization (with particular emphasis on sustaining Article 5). Although it is possible to imagine circumstances where these risks arise, without identifying the precise impact there will be an impediment to the process through which actions are identified and implemented.

Further questions remain unanswered. For example, in what specific way does NATO have responsibility to take action? Is there a specific mission that NATO could be asked to perform or

\footnotetext{
${ }^{517}$ NATO ACT, "Framework for Future Alliance Operations Workshop \#1 Final Report-Leading NATO Military Transformation," 5.
} 
policy that may help mitigate potential impact or capability that may allow for an enhanced understanding or awareness of the timeliness of this emerging problem? Does this imply anything with respect to new relationships for NATO?

The evaluation of the risk will need to take into account the fact that exposure and vulnerability are 'dynamic', and so it is not clear in what way it is vulnerable or if the causal influences can be predicted ex-ante. The IRGC raises a further concern related to the dynamic nature of vulnerability, arguing that:

The possibility that the circumstances of the risk situation vary over time in an unforeseeable way and that people will thus make decisions in relation to changing hazards - sometimes they may even change in an unsystematic, unpredictable manner-leads to unresolved or remaining uncertainty. ${ }^{518}$

Thus, if a decision concerning a risk is taken (optimized) over a single set of circumstances upon which it is dependent, a change in those circumstances then creates a risk. The original context may no longer apply and it may be unknown whether the original decision will be appropriate for the new circumstance. Decisions need to be robust.

This suggests NATO will need to maintain constant awareness of the manner in which the security environment is changing. Moreover, particularly with respect to the effect of sea-level rise and its consequent natural disasters and migration, one potential step for NATO would be to focus on the risks of abrupt shifts in climate systems and consequent impact on adaptive capacity in the affected communities. ${ }^{519}$ As Briggs points out, the coastal areas most at risk from sea level rise are easily mapped, but that the cascading effects of large-scale dislocation must be assessed and measured according to regional social, economic and political systems. ${ }^{520}$ This will be a core component for NATO's understanding of the risk.

\section{Phase 4: Risk Management}

As the foregoing discussion has revealed, efforts outside of NATO are ongoing to advance understanding of the impact of climate change (both collecting data and improving analytic methods) and to better understand the corresponding security risks.

Risk management is the creation and evaluation of options to prevent harm to humans and what they value. A major component of the relevant knowledge required to perform this is the results of risk assessments, although risk managers must also be prepared to act in situations of insufficient knowledge about potential outcomes. ${ }^{521}$

\footnotetext{
${ }^{518}$ Renn, "Risk Governance-Towards an Integrative Framework," 28.

519 Briggs, "Climate Change and Environmental Migration, Briefing for OSCE Workshop on Migration,” 1.

${ }^{520}$ Briggs, "Arctic Environmental Security and Abrupt Climate Change," 7.

${ }^{521}$ Renn, "Risk Governance_-Towards an Integrative Framework," 21.
} 
The Intergovernmental Panel on Climate Change describes climate change as "a challenge of managing risks. ${ }^{, 522}$ Chapters 2 and 3 discussed that climate change is anticipated to worsen or lead to the emergence of new security risks, and that NATO has identified concerning scenarios in the future where climate is a driving factor.

However, given the scope and interdependencies of climate, it is not feasible to fully understand and predict all possible pathways and security consequences. ${ }^{523}$ Some risks will arise unexpectedly and response capability developed could thus be insufficient. It follows that there will be unexpected security consequences that NATO and others must contend with in the future.

When all the phases of the Risk Governance Framework have been applied and the necessary information processed and collected, risk management faces one of the following three (3) possible risk situations:

- Intolerable: The risk source needs to be abandoned. In cases where that is not possible, as with natural hazards, vulnerabilities and exposure need to be reduced.

- Tolerable: The risks need to be reduced or handled within the limits of reasonable resource investments (ALARA). The precautionary principle might also be applied in selecting actions.

- Acceptable: The risks are small, perhaps regarded as negligible - meaning risk reduction effort is unnecessary.

Whether the risk is intolerable or tolerable, the distinction for NATO is perhaps moot. Even if the risk were judged to be tolerable, it would not preclude reducing vulnerabilities and exposure. ${ }^{524}$ The case of NATO and climate security represents a situation where NATO and national representatives have not fully determined the necessity or scope of a potential NATO role or actions. Although further effort and investigation regarding climate and security is warranted and in the long-term interest of NATO, there is seemingly no consensus on what the role for NATO may be.

${ }^{522}$ Intergovernmental Panel on Climate Change, Video on the Working Group II Contribution to the Fifth Assessment Report, 2014.

${ }^{523}$ Kunreuther et al., "Risk Management and Climate Change," 1. "There is a growing recognition that today's policy choices are highly sensitive to uncertainties and risk associated with the climate system and the actions of other decision makers. The choice of climate policies can thus be viewed as an exercise in risk management."

${ }^{524}$ Note that the IPCC has concluded with high confidence that "vulnerability and exposure are dynamic, vary across time and space, and depend on economic, social, geographic, demographic, cultural, institutional, governance, and environmental factors." The IPCC additionally noted that risk management practices will be more successful if they account for this characteristic, and include an explicit characterization of uncertain and complexity. Cardona et al., "Determinants of Risk: Exposure and Vulnerability," 67. This corresponds to the recommendation and protocol of the IRGC framework. Page 88 of the same source "The timing of events may also create 'windows of vulnerability,' periods in which the hazards are greater because of the conjunction of circumstances (Dow, 1992). However, a key challenge for enhancing knowledge of exposure and vulnerability as key determinants of risk requires improved data and methods to project and identify directions and different development pathways in demographic, socioeconomic, and political trends that can adequately illustrate potential increases or decreases in vulnerability with the same time horizon as the changes in the climate system related to physical-biogeochemical projections (see Birkmann et al., 2010b).” 
The SFA recognized the danger of climate change as a driver of the future security environment. That nothing has come of it does not mean that NATO de facto 'tolerates' or 'accepts' the risk that it poses, but that the situation potentially warrants continued monitoring before a viewpoint will coalesce within the Alliance.

The IRGC framework discusses generic risk management approaches to consider, as well as measures to involve stakeholders depending on the type of risk, the results of the assessments, and the extent to which the risks are complex, uncertain, or ambiguous. ${ }^{525}$ In the instances of complexity and ambiguity, the IRGC recommends a discourse-based approach to arrive at a better understanding of how to manage risk. However, there is a cost to such an approach. The IRGC argues that:

An excessive emphasis on inclusiveness can slow down the process of risk assessment, leading to efficiency losses and diminished trust in the process; it can also have the effect of concealing responsibility or shifting it away from the managers and elected and appointed officials accountable for risk decisions. ${ }^{526}$

If major ambiguities are associated with a risk problem, as with climate security, the IRGC advises that the process of risk evaluation should be open to public input and employ 'participative discourse,' which starts with revisiting the question of risk framing. ${ }^{527}$ As mentioned previously, including the public in discourse within NATO is not within its operating paradigm. However, the requirement for consensus in most decisions serves as a proxy for this type of discourse, although it assumes that national public opinion is represented through the democratic process of Ambassadors at NATO.

Moreover, that the NAC would consult with military authorities or other experts is consistent with the IRGC recommendations that "[i]f the risk is characterized by major unresolved

\footnotetext{
525 "Based on the dominant characteristic of each of the four risk categories ('simple,' 'complexity,' 'uncertainty,' 'ambiguity'), it is possible to identify specific safety principles and, consequently, design a targeted risk management strategy. 'Simple' risk problems can be managed using a 'routine-based' strategy that draws on traditional decision-making instruments, best practices, as well as time-tested trial-and-error. For 'complex' and 'uncertain' risk problems it is helpful to distinguish the strategies required to deal with a risk agent from those directed at the risk-absorbing system: complex risks are thus usefully addressed on the basis of 'risk-informed' and 'robustness-focused' strategies, while uncertain risks are better managed using 'precaution-based' and 'resilience-focused' strategies. Whereas the former strategies aim at accessing and acting on the best available scientific expertise and at reducing a system's vulnerability to known hazards and threats by improving its buffer capacity, the latter strategies pursue the goal of applying a precautionary approach to ensure the reversibility of critical decisions and of increasing a system's coping capacity to the point where it can withstand surprises. Finally, for 'ambiguous' risk problems the appropriate strategy consists of a 'discourse-based' strategy which seeks to mutual understanding of conflicting views and values with a view to eventually reconciling them." Renn, "Risk Governance-Towards an Integrative Framework," 14.

${ }^{526}$ International Risk Governance Council, "Risk Governance Deficits: An Analysis and Illustration of the Most Common Deficits in Risk Governance," 20.

${ }^{527}$ Renn, "Risk Governance-Towards an Integrative Framework," 52.
} 
uncertainties and if the results lead to highly diverse interpretations of what they mean for society, it is advisable to let risk managers take the lead." ${ }^{, 528}$

The IRGC recommends that risks characterized by multiple and high uncertainties should be managed by the precautionary approach ${ }^{529}$ They, additionally, advise that for 'risk absorbing systems,' as NATO may be considered, the objective is to make them resilient to withstand or tolerate surprises. In contrast to robustness, where potential threats are known in advance and for which the system can prepare, resilience is a strategy against unknown or highly uncertain hazards. ${ }^{530}$ NATO has adopted few precautions specific to the additional risk that may arise from climate change above and beyond its normal posture, suggesting that it may have given little attention to the related potential surprises.

In situations of high and multiple uncertainties, which share many characteristics with climate security risk, the IRGC advises risk managers to include the main stakeholders in the evaluation process to find consensus on the extra margin of safety in which to invest to avoid potentially catastrophic consequences. This type of deliberation-called 'reflective discourse'-relies on a collective reflection about balancing the possibilities for over- and under-protection. ${ }^{531}$ This, too, is consistent with the deliberative process used in the NAC.

The IRGC notes that in this circumstance the question asked previously regarding conventional security capabilities, 'how much is enough?,' is replaced by the question of 'how much uncertainty should be accepted in exchange for some given benefit?' ${ }^{532}$ The framing of this classic question, explicitly in terms of risk rather than capability, could be a new consideration for NATO.

\section{NATO's ability to perform Risk Management}

NATO has extensive ability to perform risk management: the ability to generate options, to assign responsibilities to committees, to manage fluid, emerging, complex, and chaotic situations, and the ability to perform risk assessment and risk management separately as recommended by the IRGC. However, the uncertainty of what may be considered the risk estimates (the scenarios created by NATO) affects risk evaluation. Further, that the precise contribution of climate change cannot be identified encumbers and inhibits the development of management options in this context.

How can NATO judge the severity of an instability situation when the potential impact and its probability are highly uncertain? This issue has the potential to create problems, given the consensus philosophy of NATO. Decisions taken specifically along the dimension of climate security would potentially be unfamiliar for many member states. Thus, categorizing risks (complex, uncertain, or ambiguous) according to the quality and nature of available information and what it implies for the Alliance may be contested.

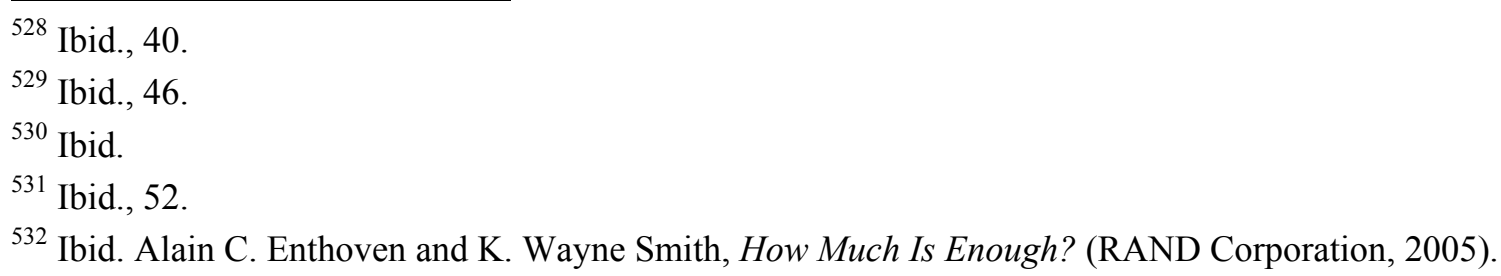




\section{Risk Communication}

Risk communication seeks to assist stakeholders in understanding risk assessment results and risk management decisions, and to help them make judgments that reflect the underlying evidence in the context of their interests and values. ${ }^{533}$ The purpose of risk communication is to ensure the decision-making process accounts for all available and relevant information. ${ }^{534}$ The IRGC notes that the form of communication must reflect the risks under consideration, their context and whether they raise societal concern. ${ }^{535}$ Risk communication therefore should ensure that 1) those who are central to risk framing, risk appraisal or risk management understand the scope of the situation, how they are to be involved, and, what their responsibilities are, and, 2) the risk is communicated appropriately to the outside world. ${ }^{536}$

Since 2007, The NATO Review has focused attention and cultivated discussion on the security consequences of climate change and climate-induced food shortage (as well as to the food and energy nexus), produced videos, as well as hosted conferences and workshops on the security aspects of climate change. Moreover, the 2010 Strategic Concept, ${ }^{537}$ which identifies crisis management as one of NATO's core tasks, contains a reference to climate change, as do the Declarations from the 2014 Wales Summit, the 2012 Chicago Summit, and the 2010 Lisbon Summit. ${ }^{538}$ The Lisbon Summit, in particular, noted that,

[k]ey environmental and resource constraints, including health risks, climate change, water scarcity, and increasing energy needs will further shape the future security environment in areas of concern to NATO and have the potential to significantly affect NATO planning and operations. ${ }^{539}$

However, both the 2016 Warsaw declaration on Transatlantic Security and the Warsaw Summit Communique failed to mention climate change. ${ }^{540}$ In spite of this, the Communique mentioned that the flow of migrants from Syria "present challenges and threats for international stability, security, and prosperity" and committed to ensure that "NATO has the full range of capabilities necessary to fulfill the whole range of Alliance missions" and "adapt to the challenges and threats from all directions." ${ }^{441}$ NATO also committed to "improve strategic anticipation by enhancing our situational awareness, particularly in the east and south and in the North Atlantic ... [which is] essential to enable timely and informed political and military decisions" and to "contribute more to the efforts of the international community in projecting stability and

${ }^{533}$ OECD, "OECD Guidance Document on Risk Communication for Chemical RiskManagement" (Paris: Organization for Economic Cooperation and Development, 2002).

${ }^{534}$ Renn, "Risk Governance-Towards an Integrative Framework," 109.

${ }^{535}$ Ibid., 55.

${ }^{536}$ Ibid.

${ }^{537}$ NATO, "Strategic Concept."

${ }^{538}$ NATO, "Lisbon Summit Declaration"; NATO, "Chicago Summit Declaration"; NATO, "Wales Summit Declaration."

${ }^{539}$ NATO, "Lisbon Summit Declaration."

${ }^{540}$ NATO, "The Warsaw Declaration on Transatlantic Security" (Warsaw: NATO, 2016); NATO, "Warsaw Summit Communique" (Warsaw: NATO, 2016).

${ }^{541}$ Ibid. 
strengthening security outside our territory., ${ }^{252}$ At the Warsaw Summit, NATO also issued a statement regarding their Commitment to Enhance Resilience against the full spectrum of threats, although it was limited to the context of armed attack. ${ }^{543}$

Current and Previous Secretaries General have acknowledged the potential impact of the security consequences of climate change. In 2008, Secretary General Jaap de Hoop Scheffer acknowledged the potential for security concerns that no single nation could address independently, as a result of climate change. ${ }^{544}$ Shortly thereafter, NATO Secretary General Anders Fogh Rasmussen raised the issue of climate-induced security consequences in 2009, suggesting that NATO become a "clearing house for the security-related challenges of climate change," and noting that dealing with the security consequences of climate change is not a choice. $^{545}$

NATO Secretary General Jaap de hoop Scheffer cited these issues and their potential consequences in 2009 in his statement at a NATO conference on security in the high north. ${ }^{546}$ Among his concerns were that open sea routes in the Arctic will increase demand for search and rescue operations and lead to a corresponding increase in the potential for ecological/environmental disasters. Secretary General de hoop Scheffer noted the Allied response capability and NATO's Euro-Atlantic Disaster Response Coordination Center (EADRCC) as resources that could be applied in this context. He also identified intelligence fusion, international and regional cooperation, consequence management, critical infrastructure protection, and 'projecting stability,' as roles where NATO could add value, as well as providing a forum for consultation for energy security in the High North. ${ }^{547}$

Secretary General Rasmussen envisioned a NATO role on climate as revolving around consultation, adaptation, and operation: consultation on the consequences of climate change on NATO's agenda and intensified dialogue with other institutions, NGOs, and the scientific community. NATO's relationships with countries and institutions worldwide make the Alliance suited for such a role (noting that such a forum does not exist elsewhere). According to Rasmussen, NATO must reduce the carbon footprint of forces and ensure they are prepared to respond in the new environment driven by climate change, since military forces are often the "first responder" to natural disasters. NATO must also work with other international organizations to enhance their capabilities.

In 2011, Secretary General Rasmussen raised further ideas for NATO in a climate context. He said:

The security implications of climate change need to be better integrated into national security and defense strategies - as the US has done with its Quadrennial Defense Review; planners should assess potential impacts,

\footnotetext{
542 Ibid.

${ }^{543}$ NATO, "Commitment to Enhance Resilience" (Warsaw: NATO, 2016).

${ }^{544}$ Scheffer, "NATO: The Next Decade Speech by NATO Secretary General, Jaap de Hoop Scheffer, at the Security and Defence Agenda."

${ }^{545}$ Rasmussen, "NATO and Climate Change."

${ }^{546}$ Scheffer, "Speech by NATO Secretary General Jaap de Hoop Scheffer on Security Prospects in the High North."

${ }^{547}$ Ibid.
} 
update their plans accordingly and consider the capabilities they might need in future. It means increasing preparedness to respond to natural and humanitarian disasters, at home or internationally, with all that that implies for training, equipment, and cooperation with civilian agencies.

We might also consider adapting our Partnerships to take climate change into account as well. What about also including cooperation that helps build capacity in the armed forces of our Partners to better manage big storms, or floods, or sudden movements of populations? And we should start simply by bringing the security aspects of climate change to the NATO table for discussion, to get a shared view of what the challenge is, and what the best ways forward might be. The security challenges being discussed today are big [especially concerning climate change], and they are growing. They ... will take ... a lot more cooperation. ${ }^{548}$

In 2011, Rasmussen further stated that "at NATO we have also increasingly understood that crisis prevention is a means of protecting our own security,",549 and "floods, food shortages and riots do not only constitute a humanitarian crisis, but also a security challenge." ${ }^{550}$ These statements acknowledge a potential NATO role within the climate context and suggest how NATO can prepare itself and its partners for the security consequences of climate change. ${ }^{551}$ NATO member states felt differently, however.

In June 2016, Secretary General Stoltenberg indicated that,

climate change is also a security threat because it can really change the conditions for where people live, create new migrant and refugee crises and scarce resources, water, can fuel new conflicts. So climate change is

\footnotetext{
${ }^{548}$ Anders Fogh Rasmussen, "Speech by NATO Secretary General Rasmussen on Emerging Security Risks Lloyd's of London," Manuscript (London: NATO, 2009). With respect to the 2010 Quadrennial Defense Review cited by the NATO Secretary General above, it notes that "While climate change alone does not cause conflict, it may act as an accelerant of instability or conflict, placing a burden to respond on civilian institutions and militaries around the world. In addition, extreme weather events may lead to increased demands for defense support to civil authorities for humanitarian assistance or disaster response both within the United States and overseas."

${ }^{549}$ Rasmussen, “'Hungry for Security: Can NATO Help in a Humanitarian crisis?'-Speech by NATO Secretary General at Erasmus University, Rotterdam, the Netherlands."

${ }^{550}$ Ibid. "NATO disaster response capabilities are frequently employed. Over the past 12 years the Alliance has responded to over 50 requests for assistance from nations. In the summer of 2005, NATO flew aid to the US to help New Orleans, following hurricane Katrina. In the same year, NATO delivered 3500 tons of aid after the earthquakes in Pakistan, and when floods hit Pakistan in 2010, NATO contributed to the relief operation. NATO also responded to requests for aid as a result of floods, fires, and earthquakes from a range of countries including, Tajikistan, Poland, Israel, and Montenegro." Also, Dupont notes that "When Hurricane Katrina devastated New Orleans in August 2005, a full US Army division, the famed 82nd Airborne, was called in to restore order and assist in emergency relief." Dupont, "The Strategic Implications of Climate Change," 39.

${ }^{551}$ NATO held a workshop in 2012 to examine and better understand the environmental risks facing NATO, of which some result from climate change. See NATO, "NATO Workshop Focuses on Energy and Environmental Risks Facing the Alliance."
} 
also about preventing conflicts and creating more stability and prosperity, which is good for peace and stability. ${ }^{552}$

However, Stoltenberg noted that NATO is not the first responder on climate change, and stopped short of suggesting that NATO play a distinct role in any potential crisis or conflict that results from a changing climate, mentioning that NATO's immediate contribution is limited to increasing energy efficiency military operations. ${ }^{553}$

\section{NATO's ability to perform Risk Communication}

The IRGC lists four (4) functions of risk communication: 1) education and enlightenment, 2) training and inducement of behavioral change, 3) creation of confidence in institutions responsible for assessing and managing risks, and 4) to involve stakeholders in risk-related decisions and resolution of conflict. ${ }^{554}$ Within each function, the IRGC indicates that risk communication should include a variety of elements, namely:

- explain the concept of probability and stochastic effects;

- explain the difference between risk and hazard;

- deal with stigmatized risk agents or highly dreadful consequences;

- cope with long-term effects;

- provide an understanding of synergistic effects with other lifestyle factors;

- address the problem of remaining uncertainties and ambiguities;

- cope with the diversity of stakeholders and parties in the risk appraisal and management phase; and

- cope with inter-cultural differences within pluralist societies and between different nations and cultures. ${ }^{555}$

NATO is exceptionally skilled at crafting its message to the public and communicates effectively in the context of its role. However, addressing many of the elements listed above will not enhance the clarity or effectiveness of their message to the public. Moreover, NATO is coordination body for its member states, and communicating the risk associated with climate change, at least insofar as it was previously conceived, appears to have dropped off the collective agenda for the Alliance.

\footnotetext{
552 Politico Brussels, "Playbook Cocktails with Jens Stoltenberg."

${ }^{553}$ Ibid.

${ }^{554}$ Renn, "Risk Governance-Towards an Integrative Framework," 57. ${ }^{555}$ Ibid.
} 


\section{Conclusions}

This chapter conducted a case study of climate security risk as it concerns NATO using the International Risk Governance Council (IRGC) Risk Governance Framework, and offered a prospective analysis of NATO and the anticipated climate-induced security challenges. Each phase, section, and sub-section analyzed aspects of the risks that NATO is anticipated to face as a result of climate change. The final two phases are particularly challenging to address, because much of the information needed - policy documents and indications of related discussion within NATO - is not publicly available. In particular, the information concerning risk management options is not publicly available from NATO.

Literature from international organizations, national governments, and NGOs is highly consistent in concluding that serious security consequences will result from the changing climate. Many have assessed that climate change and its potential consequences will worsen security dynamics, and when those consequences require a response, NATO will be expected to contribute.

For the purpose of viewing the problem from the perspective of risk governance for NATO, whether the climate/conflict linkage can be empirically established is important. The linkage would provide the basis upon which judgments can be made and initiatives can be pushed forward. In its absence, organizations responsible for international security must act on the precautionary principle (i.e. considering various scenarios, consequences, and responses).

Moreover, it has been concluded on many occasions, including by the National Research Council in 2013, that the monitoring system that is required to collect the quality of information that will enable a full understanding of any given situation is not presently available. ${ }^{556}$ This suggests that the data presently available from which to draw conclusions is insufficient, as opposed to providing evidence for the absence of an empirical relationship. In other words, that relationship could still be found empirically.

For NATO, this implies little, other than that there is a need for enhanced data collection and a need to analyze its implications in the context of NATO's responsibility for international security. Otherwise, the basis upon which to move forward - that is, to put in place measures to prevent hazards - would be based upon scientific extrapolation or hypothetical scenarios rather than scientific evidence.

Using the three Instability Situations identified by NATO ACT in the SFA/FFAO foresight initiatives, I characterized and analyzed what is known about the risks, and identified aspects that may have salience for NATO's three core tasks. A precise explanation of how the Instability Situations lead to risk (a security implication) is not explicit in the source documents - a critical shortcoming for each. For that reason, in this chapter I discussed the nature of each Instability Situation to provide more context to the implied impact on NATO.

The melting of the polar icecaps in the Arctic was identified as a critical aspect of climate change in Chapter 2. However, climate-induced environmental change in the Arctic has more tangible relevance to NATO as well. Greater accessibility to natural resources in the Arctic will attract economic interest; access to the Northern Sea Route (over Eurasia) and the Northwest Passage

\footnotetext{
${ }^{556}$ US National Research Council, Climate and Social Stress: Implications for Security Analysis.
} 
(over North America) would reduce ocean transit times by thousands of miles. ${ }^{557}$ With increased commercial interest comes political interest and an implied responsibility to ensure that the region is secure.

Increasingly accessible sub-sea oil and gas reserves may give rise to contested territorial claims, and commercial activity such as increased shipping raises the possibility for related disasters (e.g. collision, pollution, and other environmental impacts), which suggest a need for emergency response (i.e. search and rescue) capabilities. ${ }^{558}$ Access to sea routes, competition for natural resources, and issues concerning territorial sovereignty will directly impact the North Atlantic region.

Large-scale disaster could conceivably draw NATO's attention and resources to regions further afield, depending on the severity and abruptness of the event. Chapter 3 detailed a variety of instances where NATO contributed to disaster response and crisis management efforts outside of the North Atlantic area. The Large-Scale Disaster Instability Situation suggests an enhanced version of the crisis response and management role that NATO has historically played. While risks are likely to be greater in regions that have lower levels of institutional capacity, instances such as Hurricane Katrina in the United States demonstrate that a breakdown of order can occur quickly as a result of environmental impacts. In the absence of rapid onset that requires military assets in response (e.g. specialized equipment such as heavy-lift helicopters, or ships loaded with humanitarian relief supplies), engagement for security cooperation, or stabilization intervention, other member states or other international organizations would likely be more appropriately postured and have more direct responsibility than NATO to address most of the implications of this Instability Situation.

The Disruptive Impact of Migration Instability Situation proceeds from the basis that climate will induce mass migration that increasingly urbanizes regional and global society, giving rise to fractured (and therefore less stable) societies. Increasingly fractured societies create greater instability and therefore higher need for NATO intervention. The factors that drive this situation are emerging. Current events, such as the war in Syria, have created a migration crisis that is, in part, driven by climate change. Although in Syria the role of climate is confounded by other factors like poor governance, the concern articulated in Instability Situation remains valid, if somewhat abstract and difficult to plan for in a structured and concrete manner. ${ }^{55}$

Finally, the context of the Risk Tolerability and Acceptability phase of the framework is not well suited for NATO's posture concerning this climate security risk. NATO does not necessarily have a choice as to whether to accept or tolerate the risks that will result from climate-induced change to the natural environment. The only decision NATO can make within its remit is whether it should attempt to use and advance what knowledge and understanding is available to prepare and to plan its future investments. To the extent that NATO has identified risk management options with respect to climate security risk and that they are not publicly available obstructs any thoroughgoing analysis of their risk governance posture.

\footnotetext{
${ }^{557}$ Borgerson, "Arctic Meltdown The Economic and Security Implications of Global Warming," 69.

${ }^{558}$ Adger et al., "Human Security," 21.

${ }^{559}$ NATO's Euro-Atlantic Disaster Response Coordination Center received a request from Turkey in 2012 to coordinate aid and assistance for the situation; however, other members of the international community stepped forward to share the burden, and NATO has not mobilized resources.
} 


\section{Chapter 6: Major Findings}

\section{Introduction}

This final chapter provides concluding observations of NATO's risk governance posture with respect to the security consequences of climate change. The preceding chapters provide a foundation to discuss the elements of the IRGC Risk Governance Framework. They analyze how the complexity and uncertainty of climate security risk affects NATO's risk governance posture and how the complexity and uncertainty may encumber or obstruct its further advancement. Accordingly, this chapter ties together insights from the previous analysis (Chapters 2 to 6) to capture a risk-informed understanding of NATO's environment and what effects that understanding. This discussion is structured to match the sections of the IRGC Risk Governance Framework.

In addition, I distill recommendations for NATO based on the results of the analysis, and I also offer a critique of the IRGC Risk Governance Framework. I identify how NATO can improve risk governance in a security environment in which climate is increasingly salient, and I identify actions that may assist NATO in this new environment. I assess the strengths and weaknesses of the IRGC framework for the purpose of analyzing the risk posed by climate change for NATO, and ascertain whether the IRGC framework can contribute to improved risk governance outcomes for NATO. In so doing, I provide suggestions as to how the IRGC framework can contribute to improved risk governance outcomes for NATO. ${ }^{560}$

As this dissertation has shown, a broad range of factors influence climate change and its consequent security impact. Among these include the anticipated change in the natural environment (and the human response), the context that influences how a risk would materialize, and the institution that determines how the risk would be addressed. ${ }^{561}$ Any analysis of the climate-security nexus must take these factors into account. In this dissertation, I find that the characteristics of the problem - i.e. the range of factors to consider, an insufficient evidentiary and methodological basis, as well as further institutional constraints - encumber the performance of all aspects of risk governance as required by the IRGC Risk Governance Framework.

The conclusions expressed regarding NATO's ability to fulfill the requirements of the IRGC framework (or, to govern risk, generally) are provisional and partial, given that the details of the NATO Crisis Response System, the Crisis Response System Manual, ${ }^{562}$ and other internal NATO documents are not publicly available. NATO's charter for crisis management - and the

\footnotetext{
${ }^{560}$ The IRGC framework provides guidance "intended to promote thinking about whether an organization has the right procedures in place to deal with risks as they are recognized, even risks that are only vaguely known or the full ramifications of which are not yet understood." International Risk Governance Council, "Risk Governance Deficits: An Analysis and Illustration of the Most Common Deficits in Risk Governance," 10.

561 "The IRGC framework integrates a variety of aspects and recommends a formal scientific risk assessment (including environment, health, and safety and ethical, legal and other social issues) and concern assessment (assessment of risk perception and the societal context of risk, as well as political and security issues and human development issues)." Renn and Walker, Global Risk Governance. Concepts and Practice Using the IRGC Framework, xix.

${ }^{562}$ NATO, “AJP-01(D) Allied Joint Doctrine,” 2010, 4-4.
} 
existence of the NATO Crisis Response System and associated documents — suggests that NATO developed robust crisis management mechanisms to coordinate on emerging security issues. The conclusions I draw, therefore, identify actions and considerations that are suggested by analyzing publicly available information using the IRGC Risk Governance Framework.

Risk governance of the security consequences of climate change (from the perspective of NATO), however, is problematic. Risk governance in this instance is inhibited by the lack of historical data from which to draw empirical judgments, as well as the non-linearity and complexity of the climate system. However, an increasing scientific consensus concerning climate change and its relation to security concerns suggests that these uncertainties can be reduced with increased data. In the interim, these uncertainties suggest that governance of climate security risk must be precautionary, as with conventional security problems. Similarly, the potentially severe human impact and unclear pathways also suggest that a resilience-based approach is needed.

This analysis is, however, the opening salvo of what is likely to be a complicated process that will span many years, if not decades. It has succeeded in identifying near-term actions that can improve NATO's risk governance posture, which will provide a basis upon which longer-range considerations can be based. Specifically, I suggest that NATO pursue at least two initial actions with respect to climate security risk. The first component requires using the available knowledge and scenario techniques to support near-term actions to better inform NATO about climaterelated exigencies. The second component focuses on employing NATO capabilities and adapting NATO processes to monitor and understand the emerging climate security problem.

\section{Findings: Climate Change and International Security: NATO's Risk Governance}

This section synthesizes the analysis from Chapters 2 to 6 to capture the insights that allow NATO a risk-informed understanding of its environment and what impacts it. The following subsections are structured to match the sections of the IRGC Risk Governance Framework.

A risk governance approach to climate security risk reveals NATO's respective capacities ${ }^{563}$ (of options and resources), exposes the inadequacy of present data and analytic methods, and allows for a modest critique of the IRGC framework. An evaluation of risk governance posture seeks to assess whether an organization has the capacity and procedures to handle risks as they are recognized, even when risks are unclear or the full ramifications of potential or present risks are not yet understood. ${ }^{564}$

NATO has the capabilities and institutional structures to implement the requirements of the IRGC Risk Governance Framework. Given NATO's extensive history addressing security risks,

\footnotetext{
${ }^{563}$ According to the IRGC, risk governance deficits result when there is a lack of scientific evidence about the risk, or of the perceptions that individuals and organizations have of the risk; application of inappropriate methods, models or scenarios to derive this evidence; and failure to understand or take account of available knowledge. International Risk Governance Council, "Risk Governance Deficits: An Analysis and Illustration of the Most Common Deficits in Risk Governance," 11.

${ }^{564}$ Ibid., 10-11.
} 
the processes in place are similar to those prescribed under the IRGC framework. The architecture, the processes, the committees, and decision-making rules are established, as are many of the relationships between NATO and various international organizations, as well as other nations (i.e. MENA countries, Australia, New Zealand, etc.).

However, the incomplete methodological and evidentiary basis (e.g. the inadequate historical data) for climate risk-related decision making is a significant problem for risk governance. Moreover, the consensus requirement of NATO's decision-making process and the variety of values and perspectives among NATO's member states also encumbers the risk governance process. Little in NATO's processes would prohibit discussion or consideration of aspects included in the framework, although they may need to be considered in a new light. However, the dimensions of the framework need to be adapted to the circumstances NATO confronts, its philosophy, its capacity and the issue of climate security.

The deficits include using historical data to understand future events. Specifically, the use of linear models to understand complex, non-linear, global systems when empirical models do not capture the cascading impacts, or non-linearity. Not to mention the various definitions of security used in academic literature that do not correspond to the broad security concerns of NATO. This results in an incomplete understanding of hazards and exposures (which is troubling in itself), but it also complicates coordination within a fragmented structure of international institutions that have ultimate responsibility for issues related to climate security risk.

The resulting uncertainties suggest that governance of climate security risk must be precautionary, as with conventional security problems. The uncertainty of severity, potentially severe human impact, and unclear pathways also suggest that a resilience-based approach is needed. If the severity and consequences are unknown (but potentially unprecedented), then the capacity and resources must be sufficient for a worst-case scenario. This raises the question of 'how much is enough?' in terms of resources (or resilience) needed.

However, unlike many conventional security problems, the scientific basis for climate-related security risk suggests that some uncertainty can be reduced with increased data collection and analysis. Development of standards, metrics, and indicators to judge impacts and climate-related stress, and a specific framework to address the issue in the context of NATO, can help decisionmakers grapple with the available information. In the absence of tools to provide better awareness of emerging situations, NATO runs the risk of indecision and the unforeseen challenges (and effectiveness) of ad hoc responses as situations unfold.

NATO, then, should use all means available to anticipate the changing demands of the environment and decrease the likelihood of surprise. A variety of NATO programs and capabilities are well-suited for this purpose, such as the Science for Peace and Security program, the Science and Technology Organization (STO), and extensive relationships with researchers and institutions throughout the international community.

\section{Pre-Assessment}

The IRGC criteria are only partially met for each aspect of Pre-Assessment, which would establish the basis to understand the risks for NATO. These shortcomings create difficulties for subsequent phases and reveal several problematic aspects. Pre-Assessment is encumbered by 
issues concerning NATO's early warning system, the lack of scientific conventions to define an appropriate basis for decision making, as well as framing climate security risk in the context of NATO. Further, the uncertainty and ambiguity of the underlying science obstructs accurate assessment of the environmental change and its potential for human impact (including societal response).

- The difficulty in framing the risk in a way that is relevant to NATO is a critical shortcoming throughout the analysis: perception of the risk matters greatly in PreAssessment, and, without risk framing, the remaining steps in this phase (and others) cannot reasonably be taken. That multiple framings of the risk have emerged (from think tanks and other analytic organizations) could hamper NATO's framing of the problem. While several efforts (including the SFA/FFAO workshops) have included climate as a factor, it remains insufficient from the perspective of risk governance.

- Pre-assessment is also encumbered by a lack of scientific conventions to define the appropriate basis for decision making. Although the uncertainty of the underlying scientific information is decreasing, it nevertheless contributes to debate about the research findings. ${ }^{565}$ Despite having spent a great deal of time, effort, and energy examining the climate security risk issue, a conclusive understanding of climate risk (particularly in the case of NATO, but also for humans generally) is not presently available. The uncertainty and ambiguity in climate security risk will likely only be reduced with the passage of time and enhanced collection of data. The same is true for understanding the response of the natural and human systems.

- NATO's early warning system (NIWS) meets the basic infrastructure requirements and intent of the IRGC. ${ }^{566}$ This system disseminates information provided by member states and the limited amount of analysis produced within NATO, albeit it is supported by modest analytic resources, particularly with respect to the impact of climate on security. The former information potentially includes completed security analysis of situations affected by climate. The basic problem that remains for NATO is how it would look for something (i.e. a risk resulting from climate change) if it does not fully understand it. ${ }^{567}$

Should NATO apply the IRGC framework, it would pursue a comprehensive Pre-Assessment of climate security, including the framing of the risk, an examination of issues related to monitoring and early warning, judgments about the inadequacy of resources currently available, the creation of scientific conventions, and the identification of relevant assumptions.

${ }^{565}$ Risk Governance deficiency B1, Responding to early warnings. The IRGC defines this deficiency as the failure to respond and take action when risk assessors have determined from early signals that a risk is emerging. This risk management deficit arises when signals indicating a risk is emerging are picked up and assessed, but no decisions or actions are taken to prevent or mitigate the risk. The detection of early warnings is useful only if they are then prioritized and followed by a response that is commensurate with the significance of the potential risk. The failure to respond may occur for a variety of reasons. In this case, NATO was prevented by a lack of consensus. International Risk Governance Council (2009), 35.

${ }^{566}$ John Kriendler, "NATO Intelligence and Early Warning” (Watlington: Conflict Studies Research Centre, 2006).

${ }^{567}$ International Risk Governance Council, "Risk Governance Deficits: An Analysis and Illustration of the Most Common Deficits in Risk Governance," 12. Risk Governance deficiency A1—Early warning system. 
Two factors will likely help moving forward: discussion and agreement within NATO to frame climate security risks for the organization, and agreement on the basis (i.e. scientific conventions) upon which these risks can be judged. A sanctioned framing of the issue would help NATO to engage more deeply with other organizations to use the Science for Peace and Security Program to sponsor research, to partner with other organizations, or to undertake increasingly serious consideration of the issue in both scenario development and resource planning (particularly within the Defense Policy Planning Committee).

Despite the limitations of the data, the development of methods to improve the understanding of climate security risk in ways that correspond to the IRGC strictures is ongoing. NATO could engage these efforts and potentially enhance them in ways appropriate for NATO, or adopt them in full while also providing a basis for the risk appraisal phase. The results could then help NATO adapt its early warning system. ${ }^{568}$ Researchers could translate climate-security-related information into analytic products directly relevant to NATO, thereby enhancing its risk governance posture and awareness of the climate security problem.

\section{Framing Climate Security Risk}

The framing of the climate security risk is likely to be among the most challenging (and most important) aspects of the problem for NATO because a common framing of climate security risk is needed for NATO to achieve consensus. For that reason, I give it special attention. For any risk, and particularly for those risks without precedent, framing by the organizations responsible is important. Publications on climate-related security risk reveal a disparity between grey literature, which includes dramatic narratives concerning the security consequences of climate change, and the judgments supported by empirical research.

The risk is real but also diffuse: climate change worsens factors that impact security but not in a concentrated, specific, or singular manner. Nevertheless, NATO must adapt to the new security environment, which is very different from the one in which it previously operated and was designed to address. Therefore, a scenario-building process that identifies the impacts of climate change and identified environmental situations with clear security consequences would better serve the goal of assessing the security risk.

International organizations have been leaders in researching the impact of climate change and explaining the potential consequences for the broader, impacted societies. Military organizations have, increasingly, taken responsibility for communicating the security risk over the past five to seven years. NATO, however, has not been at the forefront. Concern regarding the security consequences of climate change is rising and NATO member states have taken action independently, rather than in a unified manner in the context of NATO. As with any emerging risk, there is little previous experience about how to handle the risk. This has eventuated in the actions taken being based on theory rather than on evidence or experience.

The potential array of perspectives among NATO member states has implications for risk governance, where a common understanding of a risk, including the nature and strength of the cause-effect relationship, is important. Ideally, policy makers take the lead in framing emergent

${ }^{568}$ OECD, "Preventing Violence, War and State Collapse," 3. 
risks. However, the contrary has so far occurred in the case of climate security, when think tanks, the media, and a variety of other organizations (including the defense ministries of its member states) have framed climate security risk in place of NATO.

In framing the risks, NATO is likely to encounter several problems:

- The evidentiary basis for decision making is uncertain. In particular, historical information is insufficient to understand what risks (specifically) will emerge from new interactions of climate-socio-economic-political factors. And, in what timeframe? While there is growing recognition of the importance of monitoring climate-related risk, the methods are largely incapable of discerning how rapidly the risk is developing and predicting precisely how and where they will unfold. Data is insufficient to reliably and consistently understand the security impact of a changing climate. A further complication with using data to assess the relevant relationships is that the risk is emerging slowly but it is potentially catastrophic.

- NATO member states have differing priorities and interests. Given the slow emerging nature of the risk, perhaps only those with a vested (and stark) interest in the issue and outcome will be prepared to discuss potential NATO engagement in the near- to midterm future. Moreover, North America (the United States, particularly) and Europe have two very different risk governance cultures and two very different military cultures. There are likely to be difficulties (such as Secretary General Rasmussen faced at the beginning of his term) convincing stakeholders of the value of engagement on this issue, when other matters are more urgent, like risk tradeoff.

- Some member states are more likely to focus on the cost of a NATO role rather than the actual risk and its potential consequences. Some nations may fear having yet another organization pressuring member states to advance climate change policies. Other nations do not want to militarize the topic of climate change, thinking that organizations such as the EU and the UN are better suited than NATO to facilitate discussion and action.

- There may be a variance in perspective of the relevant security risk precedents, and how climate change compares to other security risks. Conventional security threats offer a dramatic contrast, but also similarities, in the approach taken with respect to climate security risk. Any new, emerging, poorly understood threat would serve as a precedent of the situation. In the case of nuclear weapons, terrorism, and cyber issues, each offers more uncertainty than climate change. However, vast amounts of resources are dedicated to the sponsoring of research, understanding the threat, and the preparations for potential consequences. The contrary is true for the potential security impact of climate change.

\section{Risk Appraisal}

The second phase of the framework involves risk appraisal (comprised of risk assessment and concern assessment), which collects the information necessary to evaluate the risk. Little publicly available information suggests that NATO has conducted or pursued a formal risk assessment, beyond a consideration of climate factors in scenario analysis and foresight efforts. The lack of data is problematic and obstructs the demonstration of a link between human 
exposure to climate change and an increased probability of conflict or worsening of security. Numerous studies suggest that climate factors are important in the worsening of security, but its likelihood must be viewed in light of other circumstances and contextual factors in the security environment. An insufficient understanding exists of the potential environmental and security risks anticipated from climate change. ${ }^{569}$

Risk assessment, the first component of risk appraisal, is the generation of knowledge linking specific risk agents with uncertain but possible consequences. ${ }^{570}$ This has not been conducted in an analytic way from the perspective of NATO, nor is it clear that the data and methodologies exist to do so. Moreover, even the most credible quantitative analyses on climate and security do not provide the type of information needed to design policy (for example, the character, magnitude, timing, and location of the security impact). That is to say that the models and quantitative analyses performed to this point provide no more value from a policy planning perspective than simply assuming the consequences will be dramatic.

However, in the SFA/FFAO workshops, NATO ACT identified the hazard, although it did not fully estimate it. It has not performed exposure and vulnerability assessment, and only in a very generic sense has it estimated the additional risk of climate change through scenarios. The lack of data and broad definition of security employed by NATO undermines a quantitative approach, as does the potential for climate change to have non-linear and unprecedented impact on populations. ${ }^{571}$ These characteristics undermine the basis upon which NATO can judge its exposure and vulnerability to climate security risk.

However, NATO considered a qualitative description of future security risks, having their basis in scenarios and Instability Situations identified by NATO ACT, as well as in workshops conducted by NATO HQ throughout the past several years. Three of these Instability Situations included climate change as a driving factor, although they did not identify precisely how the situation would impact NATO. That climate change will lead to worsened security is assumed in

\footnotetext{
${ }^{569}$ This is risk governance deficiency A2-Factual knowledge about risks: The IRGC defines this as the lack of adequate knowledge about a hazard, including the probabilities of adverse events and the associated consequences, or the extent of damages that can result, or may occur because of insufficient efforts, or the requisite knowledge may be difficult to obtain. This risk governance deficit is most likely to occur when risks are in their emergent phase, when the cause-effect relationship is not yet established, such as with climate change. Also, risk governance deficit A9 is relevant - the use of formal models (over- or underreliance on models and/or a failure to recognize that models are simplified approximations of reality). Despite the usefulness of models, there may be situations where too little is known about a system or set of scenarios to permit useful modeling. Climate change and its consequent security risk is just such a situation. International Risk Governance Council, 2009, 14, 29-30.

${ }^{570}$ Lester B. Lave, "Health and Safety Risk Analyses: Information for Better Decisions," Science 236, no. 4799 (1987): 291-95; John D. Graham and Lorenz Rhomberg, "How Risks Are Identified and Assessed," The Annals of the American Academy of Political and Social Science, 1996, 15-24.

${ }^{571}$ This is risk governance deficiency A7-Understanding complex systems: The IRGC defines this as a lack of appreciation or understanding of the potentially multiple dimensions of a risk and of how interconnected risk systems can entail complex and sometimes unforeseeable interactions. Also, a risk governance deficit A10 is relevant, assessing potential surprises. This occurs when decision makers and risk assessors fail to overcome cognitive barriers to imagining events outside of accepted paradigms ("black swans"). Given the relatively modest understanding of climate security, it is reasonable that consideration of "black swan" events remains in its infancy. International Risk Governance Council, "Risk Governance Deficits: An Analysis and Illustration of the Most Common Deficits in Risk Governance," 32.
} 
the scenarios and Instability Situations developed. While it is not possible to identify all the possible ways in which problems may arise, a list of the most likely or concerning impacts would enhance understanding of the manner in which climate and environmental change could increase risk. It would also provide a foundation from which to judge the types of responses that may be necessary.

The Instability Situations developed by ACT were not comprehensive in their scope, but rather characterized circumstances that compel concern. Scenario analysis is essential in scoping the range of effects regarding human actions and climate change, and it can be performed without quantifying the uncertainty of the unknown parameters. ${ }^{572}$ Identifying impacts would provide a clearer understanding of the types of situations NATO may respond to and could seek to prevent. Appropriately constructed scenarios will enable consideration of impacts for situations where climate is relevant (and planning at subordinate levels of NATO, for example, at the military headquarters, SHAPE), despite the absence of a formal risk assessment, or a tool to capture climate-related security risk. The manner in which they would do so is no more uncertain than for other security crises.

One aspect that NATO ACT assumed and implied - but did not fully articulate - in the source documents for this dissertation is that the Instability Situations are not mutually exclusive. Largescale disaster is frequently associated with migration and vice versa, and one of the most tangible consequences of the melting of the Arctic is the possibility that increased commercial activity could require enhanced disaster response capabilities. The Instability Situations are thus illustrative concepts of the future situations rather than instances with distinctly identified problems.

However, the cause-effect relationships (i.e. climate and security relationship) in each of the instability situations that NATO identified are difficult to discern, as not all changing of climate results in a security consequence. Therefore, the effect is difficult to interpret and has great variability. There could also be long delays between cause and effect, particularly with respect to the potential destabilizing impact of mass migration, although this is potentially a problem in the Arctic as well. This obscures the results and poses a problem for validation of a risk assessment.

Concern assessment is the second component of risk appraisal. The North Atlantic Council (NAC) serves as NATO's forum to include the opinion of member states (i.e. the stakeholders), and the consideration of their concerns is mandated by the consensus requirement of NATO. Actual risk as a result of climate change is likely to be high, whereas perception of the risk varies. The extent to which these elements influence NATO's Defense Policy Planning Process is not evident in public information.

Many of the deficits are a function of the uncertainty of the data and that the situation is still emerging. This has corresponding implications for the research, analysis, and interpretation of the risk. ${ }^{573}$ Among the most apparent risk governance deficits are the uncertain and/or unknown

\footnotetext{
${ }^{572}$ Kunreuther and Gupta, "Integrated Risk and Uncertainty Assessment of Climate Change Response Policies," 37.

${ }^{573}$ This is risk governance deficiency A8-Recognizing fundamental or rapid changes in systems. The IRGC defines this as the failure to reassess in a timely manner fast and/or fundamental changes occurring in risk systems. Risk assessment is most straightforward when the analyst uses established tools in a stable environment. When risks emerge unexpectedly, reactions are often slow or non-existent because analysts
} 
implications of climate and its effect on the human condition, including the human response. There is a lack of an established mechanism through which organizations can address such uncertainties and the consequent risk.

\section{Risk Characterization \& Evaluation (Tolerability Judgment)}

For the third phase of the framework, publicly available information (i.e. NATO statements, publications, or press releases) fails to suggest that a systematic judgment has thus far determined whether climate security risk is viewed as 'acceptable' or 'tolerable.' Public statements and other media clearly show that NATO regards climate change as potentially dangerous. This feeling is clearly illustrated by the recent scenario efforts conducted by NATO ACT. However, the lack of engagement at NATO headquarters on this point is more appropriate for the management of a tolerable or acceptable risk, while the literature suggests that climate change presents risks that likely won't be tolerable or acceptable.

That NATO has not evaluated the tolerability of the potential risk is unrelated to a formal risk assessment, as discussion of climate issues was seemingly prevented by political opposition. Whether risk reduction measures have been considered, beyond commitment to the core tasks and providing security in accordance with the Strategic Concept, is not publicly available. Planning for climate security risk on the part of NATO member states, particularly with respect to the Arctic, has moved forward individually, potentially unevenly, and perhaps without the breadth of coordination that the NATO format offers.

Given Secretary General Rasmussen's initial efforts to direct NATO's attention toward climate security, it seems that the opinions of member states were considered and probably influential in stopping his initiative. Among Allies, perspectives on climate security, as well as the appropriateness of NATO's involvement, fall along a wide spectrum. Other interested parties, principally think tanks and non-governmental organizations, have developed analyses and judgments on this issue, which have the potential to influence NATO's thinking.

\section{Risk Management}

While the risk management phase is integral to the IRGC risk governance framework, an evaluation of options is largely beyond the scope of this dissertation. Public information fails to reveal that NATO took formal steps beyond scenario analysis and the occasional workshop to account for the additional risk anticipated to result from a changing climate. For this reason, the analysis in this dissertation is unable to evaluate risk management options created by NATO.

Although NATO's standing policies, crisis management, and planning capabilities are impressive, a posture of 'no further action is needed' is appropriate only for a tolerable or acceptable risk, as opposed to one anticipated to pose unprecedented challenges. While the absence of further preparation to address climate-specific considerations suggests the lack of a risk management strategy in this context, NATO established a Comprehensive Crisis and

and decision-makers do not expect or recognize them. International Risk Governance Council, "Risk Governance Deficits: An Analysis and Illustration of the Most Common Deficits in Risk Governance," 27. 
Operations Management Centre (CCOMC) circa 2013. ${ }^{574}$ This organization is divided into groups focusing on Crisis Identification, Current Operations, Estimations and Options, and Response Direction and Crisis Review. As a consequence, NATO is potentially able to "monitor emerging challenges in a more comprehensive and effective way.", 575

NATO's response options do not differ based on the hazard, but are instead based on the nature of the security consequence independent of what caused it. However, NATO's ability to understand and therefore prepare for risk is based on knowledge of the hazard and how it can result in a specific consequence. And therein lies a serious problem: preparation requires taking action with incomplete knowledge of the impact that the hazard has on the desired goal. If action is not taken until there is full agreement, which requires a more complete understanding of the situation, it could be too late.

Without understanding the precise ways in which climate change will affect security, it is difficult for NATO to identify pre-emptive actions to address the risk, or even to know what to monitor. In a situation where there is no complete data, such as the one concerning climate and security, the challenge is to define the factual basis for making risk management decisions and devising options. ${ }^{576}$

This is NATO's challenge, and the challenge that institutions in general face with respect to the anticipated impact of climate change. Additionally, the feeling that there is a need for NATO engagement and action must coalesce throughout the Alliance before NATO itself can act. For this to happen, there must be: (1) a basis upon which NATO can understand the problem that is directly relevant to its interests, (2) a reasonably well-defined role NATO can play to address the problem or action, and (3) a reason to address the problem that is directly relevant to NATO'S interests. The following recommendations seek to ground the foundation upon which these three criteria can be fulfilled.

\section{Recommendations: A Basis for Prospective Risk Management Options}

The management of, and preparation for, potentially concerning situations can be approached using two complementary principles common in the climate context: adaptation and mitigation. ${ }^{577}$ Adaptation is the transformation that NATO can undertake to change its own posture, resources, capabilities, programs, and policies to ensure that it is prepared for new situations as they unfold. Mitigation is the external action that NATO can take to reduce the

574 NATO, "NATO's Military Committee Visits the CCOMC at SHAPE," 2013, http:/www.aco.nato.int/natos-military-committee-visits-the-ccomc-at-shape.aspx. Note that CCOMC was established at NATO's military headquarters (SHAPE), as opposed to the political headquarters.

575 Ibid.

576 Renn, "Risk Governance-Towards an Integrative Framework," 45.

577 Intergovernmental Panel on Climate Change, "Synthesis Report: Summary for Policymakers," in Climate Change 2014. Contribution of Working Groups I, II and III to the Fifth Assessment Report of the Intergovernmental Panel on Climate Change, ed. R. K. Pachauri and L. A. Meyer (Cambridge, United Kingdom and New York, NY, USA: Cambridge University Press, 2014), 17. 
likelihood of intervention or unnecessary burden to respond, such as partnership programs and engagements to enhance the capacity of non-NATO states in affected regions.

This analysis has suggested that NATO should pursue a two-prong strategy with at least two initial actions with respect to climate security risk. The first component requires using the available knowledge and scenario techniques to support near-term actions to better inform and prepare NATO for climate-related exigencies. The second component focuses on employing NATO capabilities and adapting NATO processes to monitor and understand the emerging problem. On the latter point, NATO must also conduct the intermediate steps of problem framing, data collection and analysis, and risk appraisal (or form partnerships to this end) to enable a better understanding of the environment, before it can create precise risk management options.

In the intervening period, as those systems, data, capabilities and relationships are established, NATO must conduct further scenario analysis with enhanced emphasis on climate and environmental change. A process that uses an understanding of climate change and its impacts to identify, with reasonable precision, those concerning situations will allow for more immediate actions to mitigate risk until the organization develops a greater appreciation for the scope of potential problems.

In the next two sub-sections, I will discuss what actions NATO can take in the context of climate security using the principles of adaptation and mitigation. In both cases, I draw upon the IRGC Risk Governance Framework to propose actions that provide the foundation for a more complete understanding of the risk environment.

\section{Adaptation}

Principles established by the IRGC allow for the conception of a silhouette of basic, preliminary steps that can improve NATO's posture vis-à-vis climate security risk. The IRGC indicates that for uncertainty induced risk problems (like climate security risk) a resilience-focused risk management strategy for a risk absorbing system would include preparedness for adaptation. ${ }^{578}$ Indeed, NATO's Warsaw Summit Communique indicated that "Institutional adaptation underpins NATO's political and military adaptation. The objective is an Alliance adaptable by design, where the capacity to anticipate, and react to, change is integral to how we operate." ${ }^{579}$

As a preliminary step in the context of climate security risk, the foregoing analysis suggests that NATO should take measures to fulfill the requirements of the IRGC framework. Fulfillment of the framework will improve NATO's awareness and posture with respect to climate security risk. Furthermore, the IRGC recommends that, in cases where there is no consensus on a particular risk, let alone a cluster of risks, a detailed (i.e. worst-case) analysis of options of how to monitor the problem may be the only available compromise. ${ }^{50}$

\footnotetext{
${ }^{578}$ Renn, "Risk Governance-Towards an Integrative Framework," 47.

${ }^{579}$ NATO, "Warsaw Summit Communique."

${ }^{580}$ Renn, Risk Governance-Towards an Integrative Framework, 52-53.
} 
The latter suggestion has relevance for NATO and requires two initial steps. The first, which echoes the conclusions of the 2013 National Research Council study on climate and social stress, is to consider the best way forward to detect adverse effects and to evaluate the strength of surveillance systems to monitor the problem. This step could offer prospective ways to enhance the NATO Intelligence Warning System (NIWS), to better understand the environment. The intent is to create a process or system that delivers the fidelity of information needed to make better-informed judgments.

A principal differentiator of the 'new' environment is the increasing relevance of environmental factors and their influence on the human condition. Enhanced knowledge of how and where this interaction is likely to worsen security will inform where a NATO response could be required and what resources will be needed to address it. NATO must have a better understanding of climate change and its potential impacts to allow this judgment.

Although it seems to go without saying, advancing understanding of climate security risk and the demands of the new environment requires information. The scientific basis of climate security risk suggests that an enhanced analytic understanding is possible. With more data and advances in methodology it stands to reason that such an analytic understanding is, increasingly, achievable. Whether this information is collected and assessed by NATO, by member states, or by other international organizations, it needs to be translated into a context with relevance for NATO as efficiently and effectively as possible.

The NATO Crisis Response Manual, which is not available to the public, sets a precedent in terms of establishing a procedure to manage crises. Similar documents - such as a NATO Allied Joint Publication-have been effective resources, and can be developed for climate issues with the agreed mechanism for understanding the risk and the concept or process by which it is evaluated.

The Science for Peace and Security program, and the NATO Science and Technology Organization (STO), provide the mechanism to sponsor research that could synthesize the available publications and conduct new analyses to draw conclusions for NATO. ${ }^{581}$ Further potential actions could include partnerships with academia, member state agencies, and other relevant organizations. ${ }^{582}$ Even with the shortcomings detailed throughout this dissertation, NATO can devise or adopt a standardized approach that harnesses the available information, consider the dimensions of the problem, and anticipate the impact. Indeed, in 2011, NATO's STO included climate as a component of the future security environment and concluded that:

NATO must look to the fields of economics, psychology, sociology, management science, political sciences, ethics and legal studies for insights into how to grapple with problems such as: Measuring, analyzing and predicting risk in a complex environment; Generating coherent and

\footnotetext{
${ }^{581}$ SPS was originally established to bring scientists together on common security challenges. Climate change presents some similarities.

582 The World Bank has established a wide range of activity with respect to Disaster Risk Management. The objective of these efforts, to reduce the risk associated with natural disaster as a result of climate change, is consistent with the interests of NATO. "The World Bank-Disaster Risk Management," accessed April 17, 2015, http://www.worldbank.org/en/topic/disasterriskmanagement.
} 
integrated policy options; and Developing adaptive organizational structures to reflect changing circumstances and evolving objectives. ${ }^{583}$

NATO is well-positioned to act as a hub for the coordination of scientific research and social science research for the North Atlantic community on the issue of climate and security, in much the same way that it does for conventional security issues it faces. The established programs and agencies, such as the Science for Peace program and the STO, can move in this direction with very little adaptation, and leverage a large body of climate and social science researchers. STO concluded that many of the answers to this problem lie in social scientific research, as opposed to technical analysis, suggesting a possible redirection or expansion of NATO-sponsored research efforts.

This observation opens a variety of potential avenues for NATO, some of which have previously been identified, such as mapping coastal areas most at risk from sea level rise, as well as understanding the cascading, and potentially negative, impacts of any subsequent population displacement. ${ }^{584}$ Member states could conduct baseline climate impact assessments, while NATO itself could conduct or sponsor similar studies for the regions and states of most concern and/or direct relevance for NATO operations. ${ }^{585}$ Further engagement based upon this analysis could be included in the partnership cooperation menu, such as capacity building to address deficiencies.

While the data and methods are being developed to allow an improved analytically-based understanding, well-crafted scenarios are necessary. This point speaks to the need for an alternative and enhanced approach to understand the risks in the absence of a strong analytic foundation. For this, NATO could articulate a list of the most concerning climate change scenarios (specifically with identified impacts) and consider how the consequences would suggest a capability requirement - whether that be a policy, a program, or a physical resourcefrom NATO. A more extensive analysis of this type, designed to emphasize climate-related risks, would begin to reveal vulnerabilities, exposures, and how NATO's role might need to be adapted, including building new relationships with other parts of the world or closer cooperation with other international organizations. ${ }^{586}$

- NATO's previous scenario efforts (including the FFAO Instability Situations) provide a point of entry and a basis upon which to move forward. However, NATO needs to

583 NATO Research and Technology Organisation, "Joint Operations 2030-Final Report (Opérations Interarmées 2030-Rapport Final)," 47.

${ }^{584}$ Briggs, "Arctic Environmental Security and Abrupt Climate Change," 7; Briggs, "Environmental Security, Abrupt Climate Change and Strategic Intelligence," 2.

${ }^{585}$ Chad M. Briggs et al., "Project Descriptions and Final Status Report (UNCLASSIFIED)" (Montgomery: USAF AIR University MINERVA, 2012). Cutter \& Osman-Elasha note "Prior to the development and implementation of management strategies and adaptation alternatives, local entities need baseline assessments on disaster risk and the potential impacts of climate extremes." S. Cutter et al., "Managing the Risks from Climate Extremes at the Local Level," in Managing the Risks of Extreme Events and Disasters to Advance Climate Change Adaptation. A Special Report of Working Groups I and II of the Intergovernmental Panel on Climate Change, ed. C. B. Field et al. (Cambridge, United Kingdom and New York, NY, USA: Cambridge University Press, 2012), 320.

${ }^{586}$ Events of this nature have been conducted previously. "Expect the Unexpected: The Scenario Creation Workshop on Energy and Environmental Security Risks Facing the Alliance" (Brussels: NATO, 2012). 
understand, with significantly more granularity, how and to what extent each situation affects NATO member states or a region of concern, and the associated responsibilities for NATO. Detailed articulation of these desiderata is needed for each Instability Situation to serve as a foundation upon which to construct prospective risk management options, and to assess the resources needed to implement them.

- To fulfill the requirements of the framework, NATO needs to identify the expected impact in the Instability Situations to anticipate the role of NATO in that context. This would help identify in what specific way NATO has responsibility to take action, whether there is a specific mission that NATO could be asked to perform, or capability that may allow for an enhanced understanding or awareness of the timeliness of this impact. Furthermore, it would start to reveal implications regarding new relationships for NATO.

- NATO can then evaluate whether it has the policies and programs in place to mitigate, respond appropriately, or engage in advance. Without prior understanding of the demands that will be placed upon the organization as a result of the Instability Situations, a true assessment of the policies required will not be available. Briggs notes that "[f]rom a practical standpoint, adequate risk foresight means taking a broad view of security while at the same time being specific about potential impacts and vulnerabilities." 587 The Instability Situations and other scenarios above failed to identify specific impacts and risks, and there is little discussion of vulnerability (as that information is likely classified).

The observation that identification of the precise impacts of each Instability Situation is needed to anticipate future requirements implies that strategic level tour d'horizon scenario analysis is not a useful starting point for climate-related transformation at NATO. Analysis of NATO's historical evolution in Chapter 3 revealed that NATO responds in a characteristically pragmatic way to its security environment, and that concrete operational necessities have forced the organization to transform since the early 1990s, as opposed to theories, ideas, or data-driven analysis.

Focusing on clearly grounded, precise impacts - and the response needed - will help a risk governance discussion move beyond any potential obstruction posed by uncertainty of the data, or the complex nature in which climate security risk will arise. Moreover, it can allow NATO to sidestep or reduce the problem of framing climate security risk and to design potential (i.e. risk management) actions based on the operational requirement to respond.

It is worth reiterating the basic contours of the anticipated consequences of climate change discussed in Chapter 2, including melting of the polar ice caps and more frequent and extreme weather events in many areas of the globe, ${ }^{588}$ should be inherent to the impact identified. Furthermore, the severity of the expected impact should be in keeping with conclusions drawn from those consequences, such as those expressed by John Steinbruner, as follows:

... we must anticipate that in some societies the adaptation failures will be severe enough to induce international reaction of unprecedented

\footnotetext{
${ }^{587}$ Briggs, "Climate Security, Risk Assessment and Military Planning," 1055.

${ }^{588}$ Intergovernmental Panel on Climate Change, "Climate Change 2007: Impacts, Adaptation and Vulnerability."
} 
magnitude; we're looking at crises that are larger than anything that we've encountered as yet. ${ }^{589}$

That is to say, the impacts should identify the basic contour for NATO to respond with more resources, at higher levels of intensity, for longer periods of time, with greater frequency, requiring deeper cooperation with the international community, and in new geographical regions. These contours follow naturally from the most thorough and authoritative research performed to date on the issue of climate change and security, namely the IPCC and the US National Research Council.

To craft a comprehensive approach in response to a situation with an impact that fully reflects these contours would require operational innovation, more resources, fresh consideration of how NATO cooperates with its partners and the international community, and new policies. Planning for this situation would directly implicate both policy aspects and operational issues, and thus it would require close coordination under a new paradigm between the operational level of NATO and political leadership in Brussels.

\section{Mitigation}

While the impacts of climate change are anticipated to become more severe, the type of response required by NATO moving forward may be similar to the crisis response, management, and coordination role that it now plays. However, the additional risk brought by climate change suggests these actions may be required at heightened levels or in new regions, driven by new factors and interdependencies.

Indeed, the IRGC notes that "[i]n an interdependent world, the risks faced by any individual, company, region or country depend not only on its own choices but also on those of others ... [and for that reason] they need to find strategies to deal with a series of interrelated risks that are often ill-defined or outside of their control." 590 The IRGC cites how risks faced by airlines in the context of terrorism are affected by lax security at other carriers or airports, demonstrating that interdependence does not require proximity, and that the antecedents to catastrophes can be quite distinct and distant from the actual disaster. ${ }^{591}$

Applying this perspective to the circumstances here can serve as the basis for new components to NATO partnership programs and other engagements. ${ }^{592}$ This could entail deeper engagement with partners and other organizations, to coordinate activities and support how they adapt to the new environment. ${ }^{593}$

${ }^{589}$ Steinbruner, "World Affairs Council Keynote Address: The International Security Implications of Climate Change."

${ }^{590}$ Renn, "Risk Governance_-Towards an Integrative Framework," 48.

591 Ibid.

${ }^{592}$ NATO ACT, "Strategic Foresight Analysis 2013 Report," 11. ACT observed "NATO could capitalize on such changes by establishing new partnerships and exploring opportunities for new forms of co-operation."

${ }^{593}$ The OECD suggests that resilience can be improved through risk governance; NATO can potentially assist in the response or emergency management component that requires military support. OECD, "Boosting 
Africa and the Middle East will be deeply affected by a changing climate and could see increased natural disasters and climate-induced migration. NATO may consider enhanced cooperation with African nations or working with other international organizations to improve the civil emergency response and planning capacity of security forces in affected regions. NATO engagement and security cooperation could affect how, and with what capabilities, a potential MENA partner nation may respond.

The Arctic will also be deeply affected. Monitoring maritime activity and maintaining access to waterways will potentially be a key task for NATO nations, and of special importance for those with coastline in the region. It seems evident that natural resource exploration could draw interest in the area and create an opportunity for friction. Holtsmark considered aspects of Arctic security cooperation that may be suitable for NATO involvement:

The aim of surveillance and intelligence is to create a basis for adequate situational awareness, a key factor in the maintenance of regional stability. This starts with the elaboration of framework analyses of regional developments over a wide spectrum of security-related issues, and ends up with real time surveillance of the movements of civilian and military activities. As mentioned above, some of these tasks may present areas for cooperation with Russia. In other areas it should be explored to what degree Allied resources, such as maritime and aerial surveillance and patrolling, may be further developed to supplement efforts by the Arctic states themselves. The same applies to intelligence. ${ }^{594}$

NATO has established political and policy frameworks upon which to perform the coordination, and conduct dialogue and strengthen relationships with international organizations and many of the world's most politically- and economically-developed nations. Security organizations operate under great uncertainties and seek to reduce risk. In the case of NATO, this can be pursued through engagement with partner nations and with other international organizations, as well as research institutions and non-governmental organizations.

Given the present level of fidelity and information, it is difficult to precisely identify a role for NATO. Nevertheless, it is clear that, as an organization, it is well-positioned and equipped to contribute in various ways, given what is known about climate change. NATO is among the most successful multilateral organizations, and it has an existing partnership program that can serve as a platform for engagement. Moreover, actions taken by member states could yield a template that other NATO nations could model, could be standardized by NATO, and/or could serve as a platform for engagement.

\section{Discussion: Assessment of the IRGC Framework}

This analysis applied the IRGC framework from an ex-ante perspective to evaluate NATO's risk governance posture in the context of an emerging security problem. The IRGC framework itself

Resilience through Innovative Risk Governance" (Paris: OECD Publishing, 2014); OECD, "Future Global Shocks."

${ }^{594}$ Holtsmark, "Towards Cooperation or Confrontation? Security in the High North," 11. 
encompasses the context of risk and gives structure to what is a complex, uncertain, ambiguous, and multi-dimensional problem: climate security. The IRGC framework helps to identify aspects that encumber decision-making in regards to climate security. In this case, the IRGC framework provides a basis to capture the dimensions of climate security risk, to identify aspects to improve risk governance, and to enhance NATO's posture toward the risk. The IRGC framework provides the structure to evaluate risk, to understand the various dimensions of risk, and to diagnose risk governance deficiencies.

The study of climate security risk for NATO demonstrates that the IRGC framework is an effective structure through which to examine the issues surrounding an ensemble of emerging security risks, and to identify the gaps in institutional capability to understand or address the problem. This case demonstrates that two major advantages of the IRGC framework are that it establishes a comprehensive view of the risk landscape and it provides a basis from which to make judgments about future action to improve risk governance posture.

The IRGC framework supports basic policy development. The current absence (or inadequacy) of an institutional capacity to perform the step or phase necessary has major policy implications. Stated plainly: that the institution develop or acquire the means necessary to do so. That being said, the details are specific to the context of the situation. The IRGC framework also supports actions at the political level, including policy decisions, such as building new relationships with other organizations.

Applying the framework to the risks related to climate security met a number of difficulties. For the IRGC framework to have more direct significance for NATO, it would need to adapt to the context of, and account for, the requirements of the organization and decisions related to international security. The IRGC guidance to create risk management options is generic, recommending discourse-based strategies. A discourse-based strategy is what NATO pursues presently for all issues. The NAC meets several times per week to discuss events, programs, and to determine whether they are sufficient for the tasks for which they have been designed.

The numerous IRGC references to stakeholders (i.e. Pre-Assessment, Concern Assessment, Risk Characterization, and Risk Evaluation) were not clearly transferable to the NATO context. The IRGC defines stakeholders as socially organized groups affected by the outcome of the event, the activity from which the risk originates, and/or by the risk management options taken to counter the risk. According to the IRGC, involving stakeholders is not enough, however. Other groups, including the media, cultural elites, and opinion leaders, the non-organized affected public, and the non-organized observing public, all have a role to play in risk governance. ${ }^{595}$

This is not appropriate in the context of NATO. Therefore, it is not clear how to interpret the requirement for concern assessment and other components of the framework that advocate engagement with stakeholders or the public. It is doubtful that the inclusion of the public in the debate over climate security risk would be an explicit component of the NATO process. NATO does not interact directly with public stakeholders in the same way that another public agency or organization might. NATO is, however, inclusive with the member states, but decision making and deliberation are not transparent to the public. As a matter of standing procedure, NATO uses the consensus requirement for decision making among member states.

${ }^{595}$ Renn, "Risk Governance-Towards an Integrative Framework," 49. 
While it is prudent to consider the manner in which concern may vary throughout the member states, the IRGC offers precious little in the way of deciding how to account for this variation. For example, suppose there is a wide disparity of concern on a particular issue - what does an organization do other than negotiate to find common ground? And what if the variance in those concerns has little relation or demonstrates poor understanding of the scientific basis that would otherwise justify serious concern?

Neither is it clear how the IRGC framework promotes systemic thinking or interdependencies. Yes, they are mentioned but it hasn't been developed as to how this is done, which the IRGC recommends. An understanding of the systemic nature of the climate system is required to understand why contemporary efforts to model and analyze the climate security relationship are inadequate. The IRGC also indicates that handling systemic risks-i.e. ones stemming from interrelated and interdependent risk fields - requires data from different risk sources to be either geographically or functionally integrated into one analytical perspective. ${ }^{596}$ However, it is not clear how such a functional integration is to be implemented.

For a risk-absorbing system such as NATO, the IRGC (somewhat unhelpfully) recommends improving robustness, ${ }^{597}$ that is, the ability to address and respond to all known potential situations. ${ }^{598}$ Risk-absorbing systems should be made resilient to withstand surprises, in a strategy against unknown or highly uncertain hazards. Risks characterized by multiple and high uncertainties should be guided by the precautionary approach. ${ }^{599}$

While a number of publications emphasize resiliency as an adaptation measure to prepare for the security impacts of climate change, that security organizations seek 'resilience focused' as well as 'robustness focused' 'precaution based' and 'risk informed' strategies is inherent in their role. And so it is a rather empty statement that lacks teeth and substance. Indeed, it is difficult to imagine a more complete example of the robustness of NATO's strategy than the one articulated in the Warsaw Summit Communique. ${ }^{600}$

Moreover, these are not mutually exclusive. Indeed, strategies for the provision of security attempt to incorporate all of these elements. For any given security risk, a strategy will be informed by an understanding of risk to the extent that it can be, as well as precaution-based to account for the uncertainty. They will also seek to be robust so that they can respond to the variety of situations that may arise. Finally, they must be resilient to the severity and longevity of any risk event.

A further aspect to consider regarding risk management in the context of security is the uncertainty of the utility of the various policy options. With any security activity, a program may achieve the desired effect, achieve no effect, or make things worse. ${ }^{601}$ While potentially less of a problem with respect to humanitarian action, increased NATO activity in the Arctic could

\footnotetext{
${ }^{596}$ Ibid., 19.

${ }^{597}$ Ibid., 45.

${ }^{598}$ Ibid., 46.

${ }^{599}$ Ibid.

${ }^{600}$ NATO, "Warsaw Summit Communique."

${ }^{601}$ The OECD has considered various means for international actors to "do no harm" in the context of international support. OECD, "Do No Harm. International Support for Statebuilding" (Paris: OECD Publishing, 2012).
} 
potentially worsen tensions with Russia and any potential threat of insecurity, as opposed to diminishing it.

Moreover, the framework would be employed in a circumstance where the risk management organization does not 'control' the risk agent, effectively making it responsible for coping with the consequences only. Note that the IRGC framework focuses on physical risks and physical consequences, and their secondary implications, namely human life, health, and the natural and built environment. While this focus is relevant for two of the situations under consideration here-i.e. migration and natural disasters - the consequences of climate change in the Arctic also have significant political and economic aspects. ${ }^{602}$

The IRGC framework complements NATO's comprehensive approach to security operations by bringing the problem together for a comprehensive understanding of related risk, just as it helps to avoid considering the various aspects in isolation. Still, the problem addressed in the case of climate security presents decision makers with difficult tradeoffs, particularly concerning the attention they devote to it (or indeed can). A second tradeoff is between focusing on security in the North Atlantic area on the one hand and concerns about greater socio-economic, environmental, and security impacts on the other.

My analysis has sought to advance the goal of the IRGC Risk Governance Framework to provide guidance for the development of comprehensive assessment and management strategies to cope with risks, in particular at the global level. ${ }^{603}$ It has tested the IRGC in a particularly difficult context: the context of issues and problems surrounding climate security. For this reason, it has been useful in structuring the assessment of climate security risk, although it is not particularly useful in developing a risk management strategy. For climate-security analysis, it may be necessary to supplement the IRGC framework with an additional framework for specialized analysis and framing of the issue. In this case, the National Research Council framework in Chapter 2 of Climate and Social Stress is useful.

\section{Closing Remarks}

The case under consideration in this dissertation has explored a future security environment, specifically as it relates to climate and environmental change, in which NATO will likely find itself. By casting NATO into that world, a central question that this case study has hoped to answer is whether and how the IRGC framework could provide NATO insight with respect to actions to address new security risks (or worsening of pre-existing ones) that arise from climate change and the corresponding changes in the physical environment.

The analysis revealed what is known, what is not known, and what might never be known about the risk, and whether NATO has the processes and capabilities in place to grapple appropriately with the risk as we currently understand it. My application of the framework has helped to

\footnotetext{
${ }^{602}$ Renn, "Risk Governance-Towards an Integrative Framework," 19.

${ }^{603}$ Renn, "White Paper No. 1: Risk Governance-Towards and Integrative Approach."
} 
identify the landscape of risk-related issues, and it has helped to understand what considerations will be needed as the new information becomes available.

A principal deficiency is the limited evidentiary basis and methodological tools upon which to draw firm conclusions. Models and quantitative analyses performed to this point provide no more value from a policy planning perspective than simply assuming the consequences will be dramatic. A further challenge is that the problem is driven by factors over which NATO has limited ability to influence, i.e. a changing climate, and the human response to it.

The development of an effective approach for climate security risk for NATO is likely to remain a challenge. The associated problems are poorly understood and continuously emerging, and they lack a framework and scientific convention. These encumber and obstruct the identification of options beyond what is required to better understand the environment. However, each also demonstrates that a scenario technique that identified actual impacts would be more useful in understanding potential policy and resource requirements.

While climate change is perhaps one of the most dramatic factors influencing security, its effect cannot be expediently isolated from the other factors with which it interacts. The findings suggest that climate change can have a significant impact on security, although traditional factors nevertheless have more explanatory power. NATO already monitors the traditional factors that lead to conflict or create security concerns generally. Thus, for a climate-centric approach to security to add value, it must account for the additional risk of climate change. It is not clear whether the IRGC Risk Governance Framework succeeds in this.

The author of the IPCC Working Group 2 Report, Chris Field, observed that humanity will face issues (i.e. risks) that result directly from climate change, but the likely consequences probably are not as consequential as those that come from interactions with other outcomes. ${ }^{604}$ This is to say that NATO must understand how the factors and dynamics that create the security environment will interact in new ways as a result of climate change to prepare itself for this environment.

The role that NATO would likely play in this future environment is calibrated by a variety of demands and constraints. Changes in the world are driven by a wide range of factors, only one of which is a changing climate. That said, climate change is likely to impact the world and the human population significantly, which at least suggests that NATO is likely to be called to action more frequently in the future as a result of it.

Indeed, NATO's standing policies, crisis management, and planning capabilities are impressive. However, a posture of 'no further action is needed' is not appropriate for a risk that is anticipated to pose unprecedented challenges. NATO must consider how to adapt to new demands, prepare for new security challenges, as well as manage unforeseen consequences. ${ }^{605}$ Unless NATO can develop options to augment standing procedures and grapple with climate security risk, future crises could be met with ad hoc responses. ${ }^{606}$

\footnotetext{
${ }^{604}$ Christopher B. Field, "Connecting the Dots" (Stanford University Woods Institute, 2014).

${ }^{605}$ Rühle, "NATO and Emerging Security Challenges: Beyond the Deterrence Paradigm," 278-79.

${ }^{606}$ Climate security risk is the potential for climate change to result in a worsening of security.
} 
In going through the exercise of creation and development in the 1950s through the 1980s, NATO coordinated the planning for not only what collective response should be but also what was required of individual member states to enable that response to occur. At least in the ideal, NATO's role is to define what future, climate-related, stressors might be, and to perform a similar function to enable NATO member states and partners to act effectively as a collective in facing these new challenges.

Fortunately for NATO, it operates along the full spectrum of international security affairs. That it has been difficult to identify precise actions related to climate change is perhaps a credit to NATO's ability to establish and maintain a structure capable of addressing an impressively wide variety of security issues. Eventually, however, NATO will need to enhance its policies to ensure its own preparedness, as well as to demonstrate support for wider international community efforts regarding the effects of climate change.

The International Risk Governance Council (IRGC) notes that "[i]t is important to acknowledge that there will never be sufficient capacity to assess all the information relevant to a systemic risk. Thus a crucial skill of the risk assessor, and responsible managers, is deciding what information can be ignored and what simplifications can be made. ${ }^{\circ 67}$ Indeed, what constitutes security for NATO and how it is threatened is dependent on the context-specific judgment of NATO member states in the North Atlantic Council.

The IRGC framework that I have employed in this dissertation has helped to conceive of and articulate initial considerations for NATO in the context of climate security. However, even with wide acknowledgement of the consequences that impact the security environment, what NATO's actual role should be, and how it should adapt to the new environment (beyond minimizing the carbon footprint of NATO military operations), is a much more complex and nuanced discussion.

In mapping the risk governance dimensions of the IRGC Risk Governance Framework to the security and climate nexus from the perspective of NATO, this dissertation provides a foundation for risk-based policy planning for NATO. It has succeeded in identifying near-term actions that can improve NATO's risk governance posture, which provide a basis upon which longer-range considerations can be based. This analysis is, however, only the opening salvo of what is likely to be a complicated process that spans many years, if not decades.

${ }^{607}$ International Risk Governance Council, "Risk Governance Deficits: An Analysis and Illustration of the Most Common Deficits in Risk Governance," 11. 


\section{Bibliography}

ACCES. “Climate Change and Security in Africa.” Manitoba: IISD, 2009.

Ackerman, John T. "Climate Change, National Security, and the Quadrennial Defense Review. Avoiding the Perfect Storm.” Strategic Studies Quarterly, no. Spring (2008): 56-96.

Adano, W. R., T. Dietz, K. Witsenburg, and F. Zaal. "Climate Change, Violent Conflict and Local Institutions in Kenya's Drylands.” Journal of Peace Research 49, no. 1 (January 31, 2012): 65-80.

Adger, W. N., J. M. Pulhin, Jon Barnett, G. D. Dabelko, G. K. Hovelsrud, M. Levy, Ú. Oswald Spring, and C. H. Vogel. "Human Security." In Climate Change 2014: Impacts, Adaptation, and Vulnerability. Part A: Global and Sectoral Aspects. Contribution of Working Group II to the Fifth Assessment Report of the Intergovernmental Panel on Climate Change, edited by C. B. Field, V. R. Barros, D. J. Dokken, K. J. Mach, M. D. Mastrandrea, T. E. Bilir, M. Chatterjee, et al., 755-91. Cambridge, United Kingdom and New York, NY, USA: Cambridge University Press, 2014.

Alexeeva, Olga, and Frédéric Lasserre. "China and the Arctic.” Arctic Yearbook, 2012, 80-90.

Alley, Richard B., Jochem Marotzke, William Nordhaus, Jonathon Overpeck, Dorothy Peteet, Jr. Roger Pielke, Raymond Pierrehumbert, et al. Abrupt Climate Change, Inevitable Surprises. Washington, DC: National Academy Press, 2002.

Almer, Christian, and Stefan Boes. "Climate (Change) and Conflict: Resolving a Puzzle of Association and Causation.” Universitaet Bern, Departement Volkswirtschaft, 2012.

Antilla, Liisa. "Climate of Scepticism: US Newspaper Coverage of the Science of Climate Change." Global Environmental Change 15 (2005): 338-52.

Auffhammer, Maximilian, Christian Huggel, Ulf Molau, Andrew Solow, Maria Assunção Faus da Silva Dias, Dáithí Stone, and Lourdes Tibig. "Detection and Attribution of Observed Impacts." In Climate Change 2014: Impacts, Adaptation, and Vulnerability. Part A: Global and Sectoral Aspects. Contribution of Working Group II to the Fifth Assessment Report of the Intergovernmental Panel on Climate Change, edited by C.B. Field, V. R. Barros, D. J. Dokken, K. J. Mach, M. D. Mastrandrea, T. E. Bilir, M. Chatterjee, et al., 979-1037. Cambridge, United Kingdom and New York, NY, USA: Cambridge University Press, 2014.

Barnett, Jon. "Destabilizing the Environment-Conflict Thesis." Review of International Studies 26.02 (2000): 271-88.

_. "Security and Climate Change." Global Environmental Change 13, no. 1 (2003): 7-17.

Barnett, Jon, and W. Neil Adger. "Climate Change, Human Security and Violent Conflict." Political Geography 26, no. 6 (2007): 639-55.

Barnett, Jon, and Stephen Dovers. "Environmental Security, Sustainability and Policy." Pacifica Review: Peace, Security \& Global Change 13, no. 2 (2001): 157-69.

Barnett, Jon, and Michael Webber. "Accommodating Migration to Promote Adaptation to Climate Change.” Washington, DC: The World Bank, 2010.

Bergholt, Drago, and Päivi Lujala. "Climate-Related Natural Disasters, Economic Growth, and Armed Civil Conflict." Journal of Peace Research 49, no. 1 (2012): 147-62. 
Biggs, Reinette, Ciara Raudsepp-Hearne, Carol Atkinson-Palombo, Erin Bohensky, Emily Boyd, Georgina Cundill, Helen Fox, et al. "Linking Futures across Scales: A Dialog on Multiscale Scenarios." Ecology and Society 12, no. 1 (2007).

Blaikie, Piers, Terry Cannon, Ian Davis, and Ben Wisner. At Risk: Natural Hazards, People's Vulnerability and Disasters. Routledge, 2004.

Blair, Dennis C. "Annual Threat Assessment of the Intelligence Community for the Senate Select Committee on Intelligence." Washington, DC: Office of the Director of National Intelligence, 2009.

Bonneck, Sabine. "Acrylamide Risk Governance in Germany." In Global Risk Governance. Concepts and Practice Using the IRGC Framework, edited by Ortwin Renn and Katherine Walker, 231-67. Heidelberg: Springer Science \& Business Media, 2008.

Borgerson, Scott G. "Arctic Meltdown The Economic and Security Implications of Global Warming." Foreign Affairs 87, no. 2 (2008): 63-77.

- "The Great Game Moves North." Foreign Affairs, March 25, 2009. https://www.foreignaffairs.com/articles/global-commons/2009-03-25/great-game-movesnorth.

Boslough, Mark, James Sprigg, George Backus, Mark Taylor, Laura McNamara, Joy Fujii, Kathryn Murphy, Leonard Malczynski, and Rhonda Reinert. "Climate Change Effects on International Stability: A White Paper." SAND2004-5973. Albuquerque, NM: Sandia National Laboratories, 2004.

Briggs, Chad M. "Arctic Environmental Security and Abrupt Climate Change." Washington, DC: Global Inter-Connections, 2011.

- "Climate Change and Environmental Migration, Briefing for OSCE Workshop on Migration." The Hague, 2009.

- "Climate Security, Risk Assessment and Military Planning." International Affairs 88, no. 5 (2012): 1049-64.

- "Environmental Change, Strategic Foresight, and Impacts on Military Power." Parameters, no. Autumn (2010): 1-15.

- "Environmental Security, Abrupt Climate Change and Strategic Intelligence." Washington, DC: US Department of Energy, 2009.

Briggs, Chad M., Tracy Briggs, Robyn Read, Katie Veazie, and Blair Ellis. "Project Descriptions and Final Status Report (UNCLASSIFIED)." Montgomery: USAF AIR University MINERVA, 2012.

Brown, Ian A. "Assessing Eco-Scarcity as a Cause of the Outbreak of Conflict in Darfur: A Remote Sensing Approach." International Journal of Remote Sensing 31, no. 10 (2010): 2513-20.

Brown, Lester R. "The New Geopolitics of Food: From the Middle East to Madagascar, High Prices Are Spawning Land Grabs and Ousting Dictators. Welcome to the 21st-Century Food Wars." Foreign Policy. Washington, DC, April 2011.

Buckley, Brendan M., Kevin J. Anchukaitis, Daniel Penny, Roland Fletcher, Edward R. Cook, Masaki Sano, Le Canh Nam, Aroonrut Wichienkeeo, Ton That Minh, and Truong Mai 
Hong. "Climate as a Contributing Factor in the Demise of Angkor, Cambodia." Proceedings of the National Academy of Sciences of the United States of America 107, no. 15 (April 13, 2010): 6748-52.

Buhaug, Halvard. "Climate Not to Blame for African Civil Wars." Proceedings of the National Academy of Sciences 107, no. 38 (2010): 16477-82.

Buhaug, Halvard, Nils Petter Gleditsch, and Ole Magnus Theisen. "Implications of Climate Change for Armed Conflict." Washington, DC: World Bank, 2008.

Burke, Sharon, and Christine Parthemore. "Climate Change War Game: Working Paper Major Findings and Background.” Washington, DC: Center for a New American Security, 2009.

Burton, I., O.P. Dube, D. Campbell-Lendrum, I. Davis, R.J.T. Klein, J. Linnerooth-Bayer, A. Sanghi, and F. Toth. "Managing the Risks: International Level and Integration across Scales." In Managing the Risks of Extreme Events and Disasters to Advance Climate Change Adaptation. A Special Report of Working Groups I and II of the Intergovernmental Panel on Climate Change, edited by C. B. Field, V. Barros, T. F. Stocker, D. Qin, D. J. Dokken, K. L. Ebi, M. D. Mastrandrea, et al., 393-435. Cambridge, United Kingdom and New York, NY, USA: Cambridge University Press, 2012.

Busby, Joshua W. "Who Cares about the Weather?: Climate Change and US National Security." Security Studies 17, no. 3 (2008): 468-504.

Busby, Joshua W., Jay Gulledge, Todd G. Smith, and Kaiba L. White. "Of Climate Change and Crystal Balls: The Future Consequences of Climate Change in Africa." In American Political Science Association Annual Conference. Seattle, 2011.

Busby, Joshua W., Todd G. Smith, Kaiba L. White, and Shawn M. Strange. "Climate Change and Insecurity: Mapping Vulnerability in Africa." International Security 37, no. 4 (2013): $132-72$.

Busby, Joshua W., Kaiba L. White, and Todd G. Smith. "Mapping Climate Change and Security in North Africa." Policy Brief. Washington, DC: The German Marshall Fund of the United States, 2010.

Butler, Christopher K., and Scott Gates. "African Range Wars: Climate, Conflict, and Property Rights." Journal of Peace Research 49, no. 1 (2012): 23-34.

Campbell, Kurt M., Jay Gulledge, J.R. McNeill, John Podesta, Peter Ogden, Leon Fuerth, R. James Woolsey, Alexander T. Lennon, Julianne Smith, and Richard Weitz. "The Age of Consequences: The Foreign Policy and National Security Implications of Global Climate Change." Washington, DC: Center for International Strategic Studies, 2007.

Cardona, O. D., M.K. van Aalst, J. Birkmann, M. Fordham, G. McGregor, R. Perez, R. S. Pulwarty, E. L. F. Schipper, and B. T. Sinh. "Determinants of Risk: Exposure and Vulnerability." In Managing the Risks of Extreme Events and Disasters to Advance Climate Change Adaptation. A Special Report of Working Groups I and II of the Intergovernmental Panel on Climate Change, edited by C. B. Field, V. Barros, T. F. Stocker, D. Qin, D. J. Dokken, K. L. Ebi, M. D. Mastrandrea, et al., 65-108. Cambridge, United Kingdom and New York, NY, USA: Cambridge University Press, 2012.

Cederman, Lars-Erik, and Luc Girardin. "Beyond Fractionalization: Mapping Ethnicity onto Nationalist Insurgencies.” Zurich: Swiss Federal Institute of Technology, 2006. 
Cilliers, Jakkie, Barry B. Hughes, and Jonathan Moyer. "African Futures 2050 The Next Forty Years." Pretoria / Denver: Institute for Security Studies and the Frederick S. Pardee Center for International Futures, 2011.

Coffey, Luke. "NATO in the Arctic: Challenges and Opportunities." Washington, DC: The Heritage Foundation, 2012.

Coumou, Dim, Jascha Lehmann, and Johanna Beckmann. "The Weakening Summer Circulation in the Northern Hemisphere Mid-Latitudes." Science 348, no. 6232 (2015): 324-27.

Cubasch, Ulrich, Donald Wuebbles, Deliang Chen, Maria Cristina Facchini, David Frame, Natalie Mahowald, and Jan-Gunnar Winther. "Introduction." In The Physical Science Basis. Contribution of Working Group I to the Fifth Assessment Report of the Intergovernmental Panel on Climate Change, edited by T. F. Stocker, D. Qin, G. -K. Plattner, M. Tignor, S. K. Allen, J. Boschung, A. Nauels, Y. Xia, V. Bex, and P. M. Midgley, 119-58. Cambridge, MA: Cambridge University Press, 2013.

Cuccia, Phillip R. "Implications of a Changing NATO.” Washington, 2010.

Cutter, S., B. Osman-Elasha, J. Campbell, S. -M. Cheong, S. McCormick, R. Pulwarty, S. Supratid, and G. Ziervogel. "Managing the Risks from Climate Extremes at the Local Level." In Managing the Risks of Extreme Events and Disasters to Advance Climate Change Adaptation. A Special Report of Working Groups I and II of the Intergovernmental Panel on Climate Change, edited by C. B. Field, V. Barros, T. F. Stocker, D. Qin, D. J. Dokken, K. L. Ebi, M. D. Mastrandrea, et al., 291-338. Cambridge, United Kingdom and New York, NY, USA: Cambridge University Press, 2012.

Dahl, Ann-Sofie. "NORDEFCO and NATO: 'Smart Defense' in the North?" Rome: NATO Defense College, 2014.

Dalby, Simon. "Security, Intelligence, the National Interest and the Global Environment." Intelligence and National Security 10, no. 4 (1995): 175-97.

- "Security and Environment Linkages Revisited." In Globalisation and Environmental Challenges: Reconceptualising Security in the 21st Century, edited by Hans Günter Brauch, John Grin, Czeslaw Mesjasz, Pal Dunay, Béchir Chourou, Ursula Oswald Spring, P. H. Liotta, and Patricia Kameri-Mbote, 2006.

Davoudi, Simin, Keith Shaw, L. Jamila Haider, Allyson E. Quinlan, Garry D. Peterson, Cathy Wilkinson, Hartmut Fünfgeld, Darryn McEvoy, and Libby Porter. "Resilience: A Bridging Concept or a Dead End? 'Reframing' Resilience: Challenges for Planning Theory and Practice Interacting Traps: Resilience Assessment of a Pasture Management System in Northern Afghanistan Urban Resilience: What Does It Mean in Planni." Planning Theory \& Practice 13, no. 2 (June 2012): 299-333.

Defense Science Board. "Trends and Implications of Climate Change for National and International Security.” Washington, DC, 2011.

DeMenocal, P. B. "Cultural Responses to Climate Change during the Late Holocene." Science 292, no. 5517 (2001): 667-73.

Devitt, Conor, and Richard S. J. Tol. "Civil War, Climate Change, and Development: A Scenario Study for Sub-Saharan Africa." Journal of Peace Research 49, no. 1 (2012): 129-45.

Dodds, Klaus. “A Polar Mediterranean? Accessibility, Resources and Sovereignty in the Arctic 
Ocean." Global Policy 1, no. 3 (2010): 303-11.

Drury, A. Cooper, and Richard Stuart Olson. "Disasters and Political Unrest: An Empirical Investigation." Journal of Contingencies and Crisis Management 6, no. 3 (1998): 153-61.

Dupont, Alan. "The Strategic Implications of Climate Change." Survival 50, no. 3 (2008): 2954.

Enthoven, Alain C., and K. Wayne Smith. How Much Is Enough? RAND Corporation, 2005.

"European Security Round Table," n.d. http://www.security-round-table.eu/esrt/index.php.

Exner-Pirot, Heather, Jay Gulledge, Rob Huebert, and Adam Lajeunesse. "Climate Change \& International Security: The Arctic as a Bellweather." Arlington, Virginia: Center for Climate and Energy Solutions, 2012.

"Expect the Unexpected: The Scenario Creation Workshop on Energy and Environmental Security Risks Facing the Alliance.” Brussels: NATO, 2012.

Fabra-Mata, Javier, and Bo Jensen. "Governance Measurements for Conlict and Fragility." Oslo: United Nations Development Programme, 2012.

Field, Christopher B. "Connecting the Dots." Stanford University Woods Institute, 2014.

Field, Christopher B., V. Barros, T. F. Stocker, Q. Dahe, D. J. Dokken, Kristie L. Ebi, Michael D. Mastrandrea, K. J. Mach, G. K. Plattner, and S. K. Allen. "Managing the Risks of Extreme Events and Disasters to Advance Climate Change Adaptation. A Special Report of Working Groups I and II of the Intergovernmental Panel on Climate Change." Cambridge University Press, 2012.

Fjelde, Hanne, and Nina von Uexkull. "Climate Triggers: Rainfall Anomalies, Vulnerability and Communal Conflict in Sub-Saharan Africa." Political Geography 31 (2012): 444-53.

Fondation pour la Recherche Strategique. "NATO Transformation Seminar Conference Report, 7-9 April 2014." Paris, 2014.

Funk, Cary, Lee Rainie, Aaron Smith, Kenneth Olmstead, Maeve Duggan, and Dana Page. "Public and Scientists' Views on Science and Society." Washington, DC: Pew Research Center, 2015.

Fussel, Hans-Martin. "Vulnerability: A Generally Applicable Conceptual Framework for Climate Change Research." Global Environmental Change 17, no. 2 (2007): 155-67.

Gallis, Paul. "NATO's Decision-Making Procedure." Washington, DC: Congressional Research Service, 2003.

Goodman, Sherri. "National Security and the Accelerating Risks of Climate Change." Washington, DC: Center for Naval Analysis, 2014.

Graham, John D., and Lorenz Rhomberg. "How Risks Are Identified and Assessed." The Annals of the American Academy of Political and Social Science, 1996, 15-24.

Gulledge, Jay. "Scientific Uncertainty and Security Risks of Climate Change." In Proceedings on Climate \& Energy: Imperatives for Future Naval Forces, 47-58, 2010.

Haken, Nate. "The Arab Spring: Where Did That Come From?" Fund For Peace (Failed States Index), 2011. http://library.fundforpeace.org/fsi11-arabspring.

Halverson, Nathan. "We're Running out of Water, and the World's Powers Are Very Worried." 
Reveal, April 2016.

Handmer, J., Y. Honda, Z. W. Kundzewicz, N. Arnell, G. Benito, J. Hatfield, I. F. Mohamed, et al. "Changes in Impacts of Climate Extremes: Human Systems and Ecosystems." In Managing the Risks of Extreme Events and Disasters to Advance Climate Change Adaptation. A Special Report of Working Groups I and II of the Intergovernmental Panel on Climate Change, edited by C. B. Field, V. Barros, T. F. Stocker, D. Qin, D. J. Dokken, K. L. Ebi, M. D. Mastrandrea, et al., 231-90. Cambridge, United Kingdom and New York, NY, USA: Cambridge University Press, 2012.

Harbom, L., and P. Wallensteen. "Armed Conflict, 1989-2006." Journal of Peace Research 44, no. 5 (2007): 623-34.

Hartmann, Betsy. "Lines in the Shifting Sand: The Strategic Politics of Climate Change, Human Security and National Defense." Rethinking Security in a Changing Climate. Oslo: University of Oslo, 2009.

- "Population, Environment and Security: A New Trinity." Environment and Urbanization 10, no. 2 (1998): 113-27.

—. "Rethinking Climate Refugees and Climate Conflict: Rhetoric, Reality and the Politics of Policy Discourse." Journal of International Development 22, no. 1 (2010): 233-46.

Hauge, Wenche, and Tanja Ellingsen. "Beyond Environmental Scarcity: Causal Pathways to Conflict." Journal of Peace Research 35, no. 3 (1998): 299-317.

Hendrix, Cullen S., and Sarah M. Glaser. "Trends and Triggers: Climate, Climate Change and Civil Conflict in Sub-Saharan Africa." Political Geography 26, no. 6 (2007): 695-715.

Hendrix, Cullen S., and Idean Salehyan. "Climate Change, Rainfall, and Social Conflict in Africa." Journal of Peace Research 49, no. 1 (2012): 35-50.

Hidalgo, F. Daniel, Suresh Naidu, Simeon Nichter, and Neal Richardson. "Economic Determinants of Land Invasions." The Review of Economics 92, no. 3 (2010): 505-23.

Holtsmark, Sven G. "Towards Cooperation or Confrontation? Security in the High North." Rome: NATO Defense College, 2009.

Homer-Dixon, Thomas F. "Environmental Scarcities and Violent Conflict: Evience from Cases." International Security 19, no. 1 (2013): 5-40.

Hong, Nong. "The Melting Arctic and Its Impact on China's Maritime Transport." Research in Transportation Economics 35, no. 1 (2012): 50-57.

Hsiang, Solomon M., and Marshall B. Burke. "Climate, Conflict, and Social Stability: What Does the Evidence Say?" Climatic Change 123, no. 1 (October 17, 2013): 39-55.

Hsiang, Solomon M., Marshall B. Burke, and Edward Miguel. "Quantifying the Influence of Climate on Human Conflict." Science 341, no. 6151 (September 13, 2013).

Hsiang, Solomon M., Mark A. Cane, and Kyle C. Meng. "Civil Conflicts Are Associated with the Global Climate." Nature 476 (2011).

Huber, Daniel G., and Jay Gulledge. "Extreme Weather \& Climate Change: Understanding the Link and Managing the Risk." Arlington, Virginia: Center for Climate and Energy Solutions, 2011. 
Intergovernmental Panel on Climate Change. "Climate Change 2007: Impacts, Adaptation and Vulnerability." Generic. Cambridge University Press Cambridge, 2007.

-. "Summary for Policymakers." In Climate Change 2014: Impacts, Adaptation and Vulnerability - Contributions of the Working Group II to the Fifth Assessment Report, edited by C. B. Field, V. R. Barros, D. J. Dokken, K. J. Mach, M. D. Mastrandrea, T. E. Bilir, and M. Chatterje, 1-32. Cambridge, United Kingdom and New York, NY, USA: Cambridge University Press, 2014.

- "Synthesis Report: Summary for Policymakers." In Climate Change 2014. Contribution of Working Groups I, II and III to the Fifth Assessment Report of the Intergovernmental Panel on Climate Change, edited by R. K. Pachauri and L. A. Meyer, 1-31. Cambridge, United Kingdom and New York, NY, USA: Cambridge University Press, 2014.

—. Video on the Working Group II Contribution to the Fifth Assessment Report, 2014.

International Institute for Strategic Studies. "The IISS Transatlantic Dialogue on Climate Change and Security: Report to the European Commission." London, UK: International Institute for Strategic Studies, 2011.

International Risk Governance Council. "Improving the Management of Emerging Risks." Geneva, 2011.

- "Preparing for Future Catastrophes: Governance Principles for Slow-Developing Risks That May Have Potentially Catastrophic Consequences.” Lausanne, 2013.

. "Risk Governance Deficits: An Analysis and Illustration of the Most Common Deficits in Risk Governance.” Lausanne, 2009.

Kevane, Michael, and Leslie Gray. "Darfur: Rainfall and Conflict." Environmental Research Letters 3 (2008).

Knight, Andrew J., Michelle R. Worosz, Ewen C.D. Todd, Leslie D. Bourquin, and Craig K. Harris. "Listeria in Raw Milk Soft Cheese: A Case Study of Risk Governance in the United States Using the IRGC Framework." In Global Risk Governance. Concepts and Practice Using the IRGC Framework, edited by Ortwin Renn and Warren E. Walker, 179-215. Heidelberg: Springer Science \& Business Media, 2008.

Koubi, Vally, Thomas Bernauer, Anna Kalbhenn, and Gabriele Spilker. "Climate Variability, Economic Growth, and Civil Conflict." Journal of Peace Research 49, no. 1 (2012): 11327.

Kovats, R. S., R. Valentini, L. M. Bouwer, E. Georgopoulou, D. Jacob, E. Martin, M. Rounsevell, and J. F. Soussana. "Europe." In Climate Change 2014: Impacts, Adaptation, and Vulnerability. Part B: Regional Aspects. Contribution of Working Group II to the Fifth Assessment Report of the Intergovernmental Panel on Climate Change, edited by V. R. Barros, C. B. Field, D. J. Dokken, M. D. Mastrandrea, K. J. Mach, T. E. Bilir, M. Chatterjee, et al., 1267-1326. Cambridge, United Kingdom and New York, NY, USA: Cambridge University Press, 2014.

Kriendler, John. "NATO Intelligence and Early Warning." Watlington: Conflict Studies Research Centre, 2006.

Kuenzi, Caroline, and Jeff McNeely. "Nature-Based Tourism.” In Global Risk Governance. Concepts and Practice Using the IRGC Framework, edited by Ortwin Renn and Katherine 
Walker, 155-75. Heidelberg: Springer Science \& Business Media, 2008.

Kunreuther, Howard, and Shreekant Gupta. "Integrated Risk and Uncertainty Assessment of Climate Change Response Policies." In Climate Change 2014: Mitigation of Climate Change. Contribution of Working Group III to the Fifth Assessment Report of the Intergovernmental Panel on Climate Change, edited by O. Edenhofer, R. Pichs-Madruga, Y. Sokona, E. Farahani, S. Kadner, K. Seyboth, A. Adler, et al., 151-205. Cambridge, United Kingdom and New York, NY, USA: Cambridge University Press, 2014.

Kunreuther, Howard, Geoffrey Heal, Myles Allen, Ottmar Edenhofer, Christopher B. Field, and Gary Yohe. "Risk Management and Climate Change." Published Articles \& Papers, 2013.

Landis, Steven. "Natural Disasters, State Capacity, and Armed Conflict...? A Closer Look at the Foundations of the Climate Change-to-Conflict Debate." In A Closer Look at the Foundations of the Climate Change-to-Conflict Debate (August 5, 2012). APSA 2012 Annual Meeting Paper, 2012.

Lave, Lester B. "Health and Safety Risk Analyses: Information for Better Decisions." Science 236, no. 4799 (1987): 291-95.

Lavell, A., Michael Oppenheimer, C. Diop, J. Hess, R. Lempert, J. Li, R. Muir-Wood, and S. Myeong. "Climate Change: New Dimensions in Disaster Risk, Exposure, Vulnerability, and Resilience." In Managing the Risks of Extreme Events and Disasters to Advance Climate Change Adaptation. A Special Report of Working Groups I and II of the Intergovernmental Panel on Climate Change, edited by C. B. Field, V. Barros, T. F. Stocker, D. Qin, D. J. Dokken, K. L. Ebi, M. D. Mastrandrea, et al., 25-64. Cambridge, United Kingdom and New York, NY, USA: Cambridge University Press, 2012.

Leichenko, Robin M., and Karen L. O. Brien. "The Dynamics of Rural Vulnerability to Global Change: The Case of Southern Africa." Mitigation and Adaptation Strategies for Global Change 7 (2002): 1-18.

Lempert, Robert J., Steven W. Popper, and Steven C. Bankes. Shaping the next One Hundred Years: New Methods for Quantitative, Long-Term Policy Analysis. RAND Corporation, 2003.

Lenton, Timothy M. “Arctic Climate Tipping Points.” Ambio 41, no. 1 (2012): 10-22.

. "Early Warning of Climate Tipping Points." Nature Climate Change 1, no. 4 (2011): 201-9.

Levy, Marc A., Catherine Thorkelson, Charles Vörösmarty, Ellen Douglas, and Macartan Humphreys. "Freshwater Availability Anomalies and Outbreak of Internal War: Results from a Global Spatial Time Series Analysis." In International Workshop on 'Human Security and Climate Change, Holmen, Norway, 21-23, 2005.

Lorenzoni, Irene, and Nick F. Pidgeon. "Public Views on Climate Change: European and USA Perspectives." Climatic Change 77 (August 2006): 73-95.

Mahmooei, Behrooz Hassani, and Brett Parris. "Why Might Climate Change Not Cause Conflict? An Agent-Based Computational Response," 2013.

McElroy, Michael, and D. James Baker. "Climate Extremes: Recent Trends with Implications for National Security." Boston: Harvard University, 2012. 
Mead, Charles, and Annie Snider. "Why the CIA Is Spying on a Changing Climate." McClatchy DC. 2011.

Mooney, Chris. The Republican War on Science. Basic Books, 2005.

National Intelligence Council. "Global Trends 2030: Alternative Worlds." Washington, DC, 2012.

— . "North Africa: The Impact of Climate Change to 2030." Washington, DC, 2009.

—. "North Africa: The Impact of Climate Change to 2030 - Geopolitical Implications." Washington, DC, 2009.

NATO. “AJP-01(D) Allied Joint Doctrine,” 2010.

—. "Chicago Summit Declaration," 2012.

_. "Civil Emergency Planning," 2014.

—. "Civil Emergency Planning Committee (CEPC)," 2011.

—. "Climate Change (Video Clip)—Copenhagen Spot," 2009.

—. "Commitment to Enhance Resilience." Warsaw: NATO, 2016.

_. "Comprehensive Political Guidance," 2006.

—. "Environment—NATO's Stake," 2014.

— . "Euro-Atlantic Disaster Response Coordination Centre (EADRCC)," 2014.

_. "Implementation of the Comprehensive Approach Action Plan and the Lisbon Summit Decisions on the Comprehensive Approach," 2011.

—. "Lisbon Summit Declaration," 2010.

_. "Meteorology and Oceanography," 2011.

—. "NATO_Topic : Environmental Security," 2011.

—. "NATO's Energy Security Agenda." NATO Review Magazine, 2014. http://www.nato.int/docu/review/2014/NATO-Energy-security-running-on-empty/NATOenergy-security-agenda/EN/index.htm.

- "NATO's Military Committee Visits the CCOMC at SHAPE," 2013. http://www.aco.nato.int/natos-military-committee-visits-the-ccomc-at-shape.aspx.

- "NATO 2020: Assured Security; Dynamic Engagement. Analysis and Recommendations of the Group of Experts on a New Strategic Concept for NATO." Generic, 2010.

— . "NATO Aircraft to Deliver Humanitarian Relief Goods to Pakistan," 2010.

—. "NATO Response Force," 2014.

- "NATO Risk Based Planning Conference (SAS-093)," 2011. https://www.cso.nato.int/Activity_Meta.asp?ACT=1714.

- "NATO Workshop Focuses on Energy and Environmental Risks Facing the Alliance," 2012.

—. "New NATO Division to Deal with Emerging Security Challenges," n.d. 
_. "Political Guidance on Ways to Improve NATO's Involvement in Stabilisation and Reconstruction," 2011.

- "Security Issues of Desertification in the Mediterranean Region Debated at NATO Workshop," 2003. doi:2 Dec. 2003.

—_. "Strategic Concept." Generic, 2010.

- "The NATO Defence Planning Process," 2014. http://www.nato.int/cps/en/natohq/topics_49202.htm.

_ . "The North Atlantic Treaty," 1949.

_ . "The Warsaw Declaration on Transatlantic Security." Warsaw: NATO, 2016.

—. "Wales Summit Declaration," 2014.

—. "Warsaw Summit Communique." Warsaw: NATO, 2016.

NATO ACT. "Framework for Future Alliance Operations," 2015.

—. "Framework for Future Alliance Operations Workshop \#1 Final Report-Leading NATO Military Transformation," 2013.

—. "Framework for Future Alliance Operations Workshop \#1 Read Ahead: Ensuring a Mission Ready Alliance-Forging the Future, Leading NATO Military Transformation," 2013.

—. "Framework for Future Alliance Operations Workshop \#2 Read-Ahead: Military Implications in a Complex Security Environment-Forging the Future Leading; NATO Military Transformation," 2013.

_. "Framework for Future Alliance Operations Workshop \#3 Final Report: Long-Term Military Transformation Broad Strategic Insights Workshop,” 2013.

_. "Framework for Future Alliance Operations Workshop \#4 Final Report-Instability Situations in the Future Security Environment." Budapest, 2014.

—. "Framework for Future Alliance Operations Workshop \#5 Read Ahead-Strategic Military Perspectives," 2014.

—_. "Multiple Futures Project—Final Report," 2009.

_ . "Strategic Foresight Analysis 2013 Report," 2013.

_. "Strategic Foresight Analysis Workshop \#1 Final Report: The World in 2030 and Beyond," 2012.

—. "Strategic Foresight Analysis Workshop \#1 Read Ahead: Global Review," 2012.

_. "Strategic Foresight Analysis Workshop \#2 Read Ahead: The Shared Perspective of the World in 2030 and Beyond Themes and Drivers," 2012.

_. "Strategic Foresight Analysis Workshop \#3 Final Report: The Shared Perspective of the World in 2030 and Beyond Security Implications," 2012.

_ "Strategic Foresight Analysis Workshop \#3 Read Ahead: The Shared Perspective of the World in 2030 and Beyond Security Implications," 2012.

NATO Parliamentary Assembly. "Climate Change, International Security and the Way to Paris 
(2015 Draft Special Report),” 2015.

. "Climate Change: Thinking Beyond Kyoto," 2007.

- "Climate Change and Global Security," 2009.

. "Climate Change in the Arctic: Challenges for the North Atlantic Community," 2005.

—. "Security at the Top of the World: Is There a NATO Role in the High North?," 2010.

NATO Research and Technology Organisation. "Joint Operations 2030-Final Report (Opérations Interarmées 2030-Rapport Final)." Brussels, 2011.

Nel, Philip, and Marjolein Righarts. "Natural Disasters and the Risk of Violent Civil Conflict." International Studies Quarterly 52, no. 1 (2008): 159-85.

Nils Petter Gleditsch, Peter, Mikael Eriksson Wallensteen, Margareta Sollenberg, and Håvard Strand. "Armed Conflict 1946 - 2001: A New Dataset." Journal of Peace Research 39, no. 5 (2002): 615-37.

Noble, Ian, and Saleemul Huq. "Adaptation Needs and Options." In Climate Change 2014: Impacts, Adaptation, and Vulnerability. Part A: Global and Sectoral Aspects. Contribution of Working Group II to the Fifth Assessment Report of the Intergovernmental Panel on Climate Change, edited by C. B. Field, V. R. Barros, D. J. Dokken, K. J. Mach, M. D. Mastrandrea, T. E. Bilir, M. Chatterjee, et al., 833-68. Cambridge, United Kingdom and New York, NY, USA: Cambridge University Press, 2014.

North, D. Warner. "Energy Security for the Baltic Region." In Global Risk Governance. Concepts and Practice Using the IRGC Framework, edited by Ortwin Renn and Katherine Walker, 275-87. Heidelberg: Springer Science \& Business Media, 2008.

O'Brien, Karen, Mark Pelling, and Anand Patwardhan. "Toward a Sustainable and Resilient Future." In Managing the Risks of Extreme Events and Disasters to Advance Climate Change Adaptation. A Special Report of Working Groups I and II of the Intergovernmental Panel on Climate Change, 437-86, 2012.

O’Loughlin, John, Frank D. W. Witmer, Andrew M. Linke, Arlene Laing, Andrew Gettelman, and Jimy Dudhia. "Climate Variability and Conflict Risk in East Africa, 1990-2009." Proceedings of the National Academy of Sciences 109, no. 45 (2012): 18344-49.

Obama, Barack. "National Security Strategy." Washington, DC: The White House, 2010.

_ . "National Security Strategy." Washington, DC: The White House, 2015.

OECD. “Armed Violence Reduction.” Paris: OECD Publishing, 2013.

. "Boosting Resilience through Innovative Risk Governance." Paris: OECD Publishing, 2014.

. "Conflict and Fragility The State's Legitimacy in Fragile Situations. Unpacking Complexity." Paris: OECD Publishing, 2010.

_ . "Do No Harm. International Support for Statebuilding." Paris: OECD Publishing, 2012.

_ . "Emerging Risks in the 21st Century, An Agenda for Action." Paris: OECD Publishing, 2003.

—_. "Future Global Shocks." Paris: OECD Publishing, 2011. 
—_. "Investing in Security." Paris: OECD Publishing, 2011.

. "Linking Security System Reform and Armed Violence Reduction." Paris: OECD Publishing, 2011.

. "Managing Risks in Fragile and Transitional Contexts." Paris: OECD Publishing, 2012.

. "OECD Guidance Document on Risk Communication for Chemical RiskManagement." Paris: Organization for Economic Cooperation and Development, 2002. 2011.

. "Preventing and Reducing Armed Violence in Urban Areas." Paris: OECD Publishing, . "Preventing Violence, War and State Collapse." Paris: OECD Publishing, 2009.

Okada, Norio, Hirokazu Tatano, and Alkiyoshi Takagi. "Nagara River Estuary Barrage Conflict." In Global Risk Governance. Concepts and Practice Using the IRGC Framework, edited by Ortwin Renn and Katherine Walker, 221-28. Heidelberg: Springer Science \& Business Media, 2008.

Oppenheimer, Michael, Maximiliano Campos, and Rachel Warren. "Emergent Risks and Key Vulnerabilities." In Climate Change 2014: Impacts, Adaptation, and Vulnerability. Part A: Global and Sectoral Aspects. Contribution of Working Group II to the Fifth Assessment Report of the Intergovernmental Panel on Climate Change, edited by C. B. Field, V. R. Barros, D. J. Dokken, K. J. Mach, M. D. Mastrandrea, T. E. Bilir, M. Chatterjee, et al., 1039-99. Cambridge, United Kingdom and New York, NY, USA: Cambridge University Press, 2014.

Parker, Geoffrey, John Brooke, Peter Burke, Nicholas Canny, Aidan Clarke, Alice Conklin, Andreas Daum, et al. "Crisis and Catastrophe: The Global Crisis of the Seventeenth Century Reconsidered." American Historical Review Forum, no. October (2008): 1053-79.

Partnership for Peace Consortium of Defense Academies and Security Studies Institutes. "Emerging Security Challenges," n.d. http://www.pfpconsortium.com/\#!emerging-securitychallenges/c1sda.

Politico Brussels. "Playbook Cocktails with Jens Stoltenberg." Brussels, 2016.

Raleigh, Clionadh, and Dominic Kniveton. "Come Rain or Shine: An Analysis of Conflict and Climate Variability in East Africa." Journal of Peace Research 49, no. 1 (2012): 51-64.

Rasmussen, Anders Fogh. “'Hungry for Security: Can NATO Help in a Humanitarian crisis?'Speech by NATO Secretary General at Erasmus University, Rotterdam, the Netherlands." Rotterdam: NATO, 2011.

—. "NATO and Climate Change." Brussels: Huffington Post, 2010.

—. "Speech by NATO Secretary General Rasmussen on Emerging Security Risks Lloyd's of London." Manuscript. London: NATO, 2009.

Read, Mark R. "Embracing Uncertainty: Scenario Planning for Climate Change Security Challenges and Opportunities." Pennsylvania State University, 2014.

Renn, Ortwin. "Acrylamide: Lessons for Risk Management and Communication." Journal of Health Communication 8, no. 5 (2003): 435-41.

_. "Risk Governance-Towards an Integrative Framework." Geneva: International Risk 
Governance Council, 2013.

. "White Paper No. 1: Risk Governance_-Towards and Integrative Approach." Geneva: International Risk Governance Council, 2005.

Renn, Ortwin, and Katherine Walker, eds. Global Risk Governance. Concepts and Practice Using the IRGC Framework. Heidelberg: Springer Science \& Business Media, 2008.

Richardson, Ka, P. Gilliers, and Michael Lissack. "Complexity Science: A 'Gray' Science for the 'Stuff in Between.'" EMERGENCE 3, no. 2 (2001): 6-18.

Risebrobakken, Bjørg, Eystein Jansen, Carin Andersson, Eirik Mjelde, and Kjersti Hevrøy. “A High-Resolution Study of Holocene Paleoclimatic and Paleoceanographic Changes in the Nordic Seas.” Paleoceanography 18, no. 1 (2003).

Roco, Mihail, Ortwin Renn, and Jager Alexander. "Nanotechnology Risk Governance." In Global Risk Governance. Concepts and Practice Using the IRGC Framework, edited by Ortwin Renn and Katherine Walker, 301-25. Heidelberg: Springer Science \& Business Media, 2008.

Rogers, Will, Jay Gulledge, Daniel Saraceno, Will Shields, Elizabeth Threlkeld, Brian Burton, and Eugene Chow. "Lost in Translation: Closing the Gap Between Climate Science and National Security Policy.” Washington, DC: Center for a New American Security, 2010.

"Round Table on Climate Security Risks, March 21, 2012 NATO HQ, Brussels.” Brussels, 2012.

Rühle, Michael. "NATO and Emerging Security Challenges: Beyond the Deterrence Paradigm." American Foreign Policy Interests 33, no. 6 (2011): 278-82.

Salehyan, Idean, and Cullen S. Hendrix. "Climate Shocks \& Political Violence: Is Africa Unique?” In American Political Science Association Annual Meeting, 2011.

Sarkees, Meredith Reid. "The Correlates of War Data on War: An Update to 1997." Conflict Management and Peace Science 18, no. 1 (2000): 123-44.

Scheffer, Jaap De Hoop. "NATO: The Next Decade Speech by NATO Secretary General, Jaap de Hoop Scheffer, at the Security and Defence Agenda." Brussels: NATO, 2008.

—. "Speech by NATO Secretary General Jaap de Hoop Scheffer on Security Prospects in the High North." Brussels: NATO, 2009.

Scheffran, Jürgen, and Antonella Battaglini. "Climate and Conflicts: The Security Risks of Global Warming." Regional Environmental Change 11, no. 1 (2011): 27-39.

Scheffran, Jürgen, Michael Brzoska, Jasmin Kominek, P. Michael Link, and Janpeter Schilling. “Climate Change and Violent Conflict." Science 336, no. 6083 (2012): 869-71.

- "Disentangling the Climate-Conflict Nexus: Empirical and Theoretical Assessment of Vulnerabilities and Pathways." Review of European Studies 4, no. 5 (2012): 1-13.

Schellnhuber, Hans Joachim. World in Transition-Climate Change as a Security Risk. German Advisory Council on Global Change (WGBU), 2007.

Schröter, Regina, Aleksandar S. Jovanovic, and Ortwin Renn. "Social Unrest." Paris: OECD Publishing, 2012.

Schütz, Holger, and Hans Peter Peters. "Risiken Aus Der Perspektive von Wissenschaft, Medien Und Öffentlichkeit." Aus Politik Und Zeitgeschichte 10-11 (2002): 40-45. 
Shea, Jamie. "Q\&A about NATO's New Division for Emerging Security Challenges." Atlantic Community (YouTube), 2011. https://www.youtube.com/watch?v=FziXbYrmAdk.

_. "Why Does NATO's New Strategic Concept Matter." Atlantisch Perspectief 34, no. 8 (2010): 8-13.

Shilling, A. Kaitlin. "Climate Change and Conflict: Identifying the Mechanisms." Thesis, Stanford University, 2011.

Slettebak, Rune T. "Don't Blame the Weather! Climate-Related Natural Disasters and Civil Conflict." Journal of Peace Research 49, no. 1 (2012): 163-76.

Smith-Windsor, Brooke A. "Putting the 'N' Back into NATO: A High North Policy Framework for the Atlantic Alliance?" Rome: NATO Defense College, 2013.

Spiegeleire, Stephan De, Sergei Boeke, U. Mans, and R. Toxopeus. "NATO Future Worlds An Input into the NATO Long-Term Requirements Study." Vol. 212. The Hague, 2005.

Steinbruner, John D. "World Affairs Council Keynote Address: The International Security Implications of Climate Change," 2013.

Stern, N. Nicholas Herbert. The Economics of Climate Change: The Stern Review. Cambridge University Press, 2007.

"Syria Regional Refugee Response Inter-Agency Information Sharing Portal." United Nations High Commissioner for Refugees, n.d. http://data.unhcr.org/syrianrefugees/regional.php.

Tait, Joyce. "Risk Governance of Genetically Modified Crops-European and American Perspectives." In Global Risk Governance. Concepts and Practice Using the IRGC Framework, 133-51. Heidelberg: Springer, 2008.

The Center for Naval Analysis. "National Security and the Threat of Climate Change," 2007.

"The World Bank - Disaster Risk Management." Accessed April 17, 2015. http://www.worldbank.org/en/topic/disasterriskmanagement.

Theisen, Ole Magnus. "Climate Clashes? Weather Variability, Land Pressure, and Organized Violence in Kenya, 1989-2004." Journal of Peace Research 49, no. 1 (2012): 81-96.

Theisen, Ole Magnus, Nils Petter Gleditsch, and Halvard Buhaug. "Is Climate Change a Driver of Armed Conflict?" Climatic Change 117, no. 3 (2013): 613-25.

Theisen, Ole Magnus, and Helge Holtermann. "Climate Wars: Assessing the Claim That Drought Breeds Conflict Climate Wars." International Security 36, no. 3 (2011): 79-106.

UK Ministry of Defence. “Global Strategic Trends-Out to 2045.” London, UK, 2014.

UK Royal Commission on Environmental Pollution. "Adapting Institutions to Climate Change," 2010.

United Nations. The Paris Decision, 2015.

United States House of Representatives. National Defense Authorization Act for Fiscal Year 2008. Washington, DC, 2008.

US Department of Defense. "DOD Directive 4715.21: Climate Change Adaptation and Resilence," 2016.

_. "Quadrennial Defense Review." Washington, DC, 2010. 
—. "Quadrennial Defense Review." Washington, DC, 2014.

US Department of State. "Quadrennial Diplomacy and Development Review (QDDR): Leading through Civilian Power," 2010.

USAID. "Fragile States Indicators: A Supplement to the Country Analytical Template." Washington, DC: USAID, 2006.

—. "Measuring Fragility," 2005.

US National Research Council. Climate and Social Stress: Implications for Security Analysis. Edited by John D. Steinbruner, Paul C. Stern, and Jo L. Husbands. National Academies Press, 2013.

Verhoeven, Harry. "Climate Change, Conflict and Development in Sudan: Global NeoMalthusian Narratives and Local Power Struggles." Development and Change 42, no. 3 (2011): 679-707.

Walker, Brian, Scott Barrett, Stephen Polasky, Victor Galaz, Carl Folke, Gustav Engström, Frank Ackerman, et al. "Looming Global-Scale Failures and Missing Institutions." Science 325 (2009): 7-8.

Wilson, Page. "Between a Rock and a Cold Place? NATO and the Arctic." E-International Relations, 2013.

World Commission on Environment and Development. "Report of the World Commission on Environment and Development: Our Common Future (The Brundtland Report)." Vol. 4, 1987.

"Yale Project on Climate Change Communication." Yale University, 2015. http://environment.yale.edu/poe/v2014/.

Yoffe, Shira, Greg Fiske, Mark Giordano, Meredith Giordano, Kelli Larson, Kerstin Stahl, and Aaron T. Wolf. "Geography of International Water Conflict and Cooperation: Data Sets and Applications." Water Resources Research 40, no. 5 (2004).

Zhang, David D., Harry F. Lee, Cong Wang, Baosheng Li, Qing Pei, Jane Zhang, and Yulun An. "The Causality Analysis of Climate Change and Large-Scale Human Crisis." Proceedings of the National Academy of Sciences 108, no. 42 (2011): 17296-17301.

Zhukov, Yuri M. "NATO's Mediterranean Mission: What the Alliance Is Doing in the Aegean Sea." Foreign Affairs, 2016. https://www.foreignaffairs.com/articles/europe/2016-0221/natos-mediterranean-mission.

\section{End}

